\title{
Cancer Risks from Soil Emissions of Volatile Organic Compounds at the Lawrence Livermore National Laboratory
}

Valerie R. Dibley

February 1998

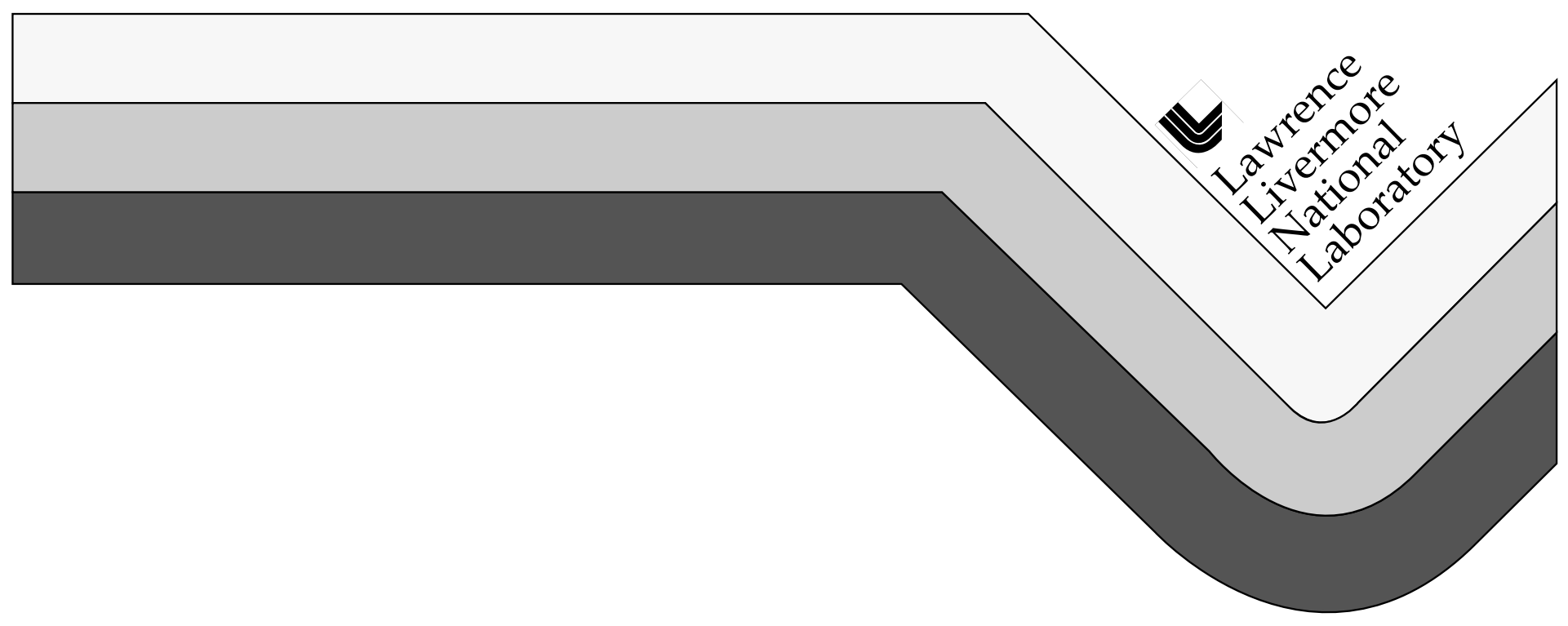




\section{DISCLAIMER}

This document was prepared as an account of work sponsored by an agency of the United States Government. Neither the United States Government nor the University of California nor any of their employees, makes any warranty, express or implied, or assumes any legal liability or responsibility for the accuracy, completeness, or usefulness of any information, apparatus, product, or process disclosed, or represents that its use would not infringe privately owned rights. Reference herein to any specific commercial product, process, or service by trade name, trademark, manufacturer, or otherwise, does not necessarily constitute or imply its endorsement, recommendation, or favoring by the United States Government or the University of California. The views and opinions of authors expressed herein do not necessarily state or reflect those of the United States Government or the University of California, and shall not be used for advertising or product endorsement purposes.

This report has been reproduced directly from the best available copy.

Available to DOE and DOE contractors from the Office of Scientific and Technical Information P.O. Box 62, Oak Ridge, TN 37831

Prices available from (423) 576-8401

Available to the public from the National Technical Information Service

U.S. Department of Commerce

5285 Port Royal Rd.,

Springfield, VA 22161

Work performed under the auspices of the U.S. Department of Energy by Lawrence Livermore National Laboratory under Contract W-7405-ENG-48. 
UCRL-LR-130701

Distribution Category UC-702

\title{
Cancer Risks from Soil Emissions of Volatile Organic Compounds at the Lawrence Livermore National Laboratory
}

\author{
Valerie R. Dibley
}

Master of Science Thesis

Manuscript date: February 1998

LAWRENCE LIVERMORE NATIONAL LABORATORY University of California • Livermore, California • 94551 

CANCER RISKS FROM SOIL EMISSIONS OF VOLATILE ORGANIC COMPOUNDS AT THE LAWRENCE LIVERMORE NATIONAL LABORATORY 


\section{ABSTRACT \\ CANCER RISKS FROM SOIL EMISSIONS OF VOLATILE ORGANIC COMPOUNDS AT THE LAWRENCE LIVERMORE NATIONAL LABORATORY}

The emission isolation flux chamber (EIFC) methodology was applied to Superfund investigations at the Lawrence Livermore National Laboratory Site 300 to determine if on-site workers were exposed to VOCs volatilizing from the subsurface and what, if any, health risks could be attributed to the inhalation of the VOCs volatilizing from the subsurface. During July and August of 1996, twenty, eighteen, and twenty six VOC soil vapor flux samples were collected in the Building 830, 832, and 854 areas, respectively using EIFCs. The VOC concentrations in the vapor samples were used to calculate soil flux rates which were used as input into an air dispersion model to calculate ambient air exposure-point concentrations. The exposure-point concentrations were compared to EPA Region IX Preliminary Remediation Goals (PRGs). Buildings 830 and 832 exposure-point concentrations were less then the PRGs therefore no cancer risks were calculated. The cancer risks for Building 854 ranged from $1.6 \times 10^{-7}$ to $2.1 \times 10^{-6}$. The resultant inhalation cancer risks were all within the acceptable range, implying that onsite workers were not exposed to VOC vapors volatilizing from the subsurface soil that could have significant cancer risks. Therefore remediation in these areas would not be necessary. 


\title{
CANCER RISKS FROM SOIL EMISSIONS OF VOLATILE ORGANIC COMPOUNDS AT THE LAWRENCE LIVERMORE NATIONAL LABORATORY
}

\author{
This Thesis is Written By
}

\author{
Valerie R. Dibley
}

The thesis written under the guidance of the Faculty Advisory Committee, and approved by all its members, has been accepted in partial fulfillment of the requirements for the degree of:

\author{
Master of Science in \\ Environmental Management \\ at the \\ University of San Francisco
}

Thesis Committee:

Peter Flessel, Ph.D. Chairperson

Tina Carlsen, Ph.D

Date

Lawrence Livermore National Laboratory

R. James Brown, Ph.D., Director

Date

Environmental Management Program

Stanley D. Nel, Ph.D., Dean

Date

College of Arts and Sciences 


\section{VITA AUCTORIS}

Name:

Date of Birth:

High School:

Graduated:

Baccalaureate Degree:

Major:

College:

Graduated:
Valerie Rose Dibley

July 15, 1966

Saratoga Springs High School, Saratoga Springs, New York

1984

Bachelor of Arts

Chemistry

Skidmore College, Saratoga Springs, New York

1988 


\section{ACKNOWLEDGEMENTS}

I would like to acknowledge USF alumni Tina Carlsen, who inspired me to continue my education and gave me the opportunity to conduct this research project. I would also like to thank Stan Martins, Pleas McNeel, and Cleo Fry who I had the pleasure of working with in 110 degree heat at Site 300 during the collection of my primary data. In

addition, I'd like to thank Dr. Peter Flessel for his guidance. All these people I thank from the bottom of my heart for all their help and support, but the person that I owe the most thanks for the successful completion of this project is my husband Michael who always kept me going. 


\section{TABLE OF CONTENTS}

ABSTRACT,

\section{CHAPTER I - INTRODUCTION}

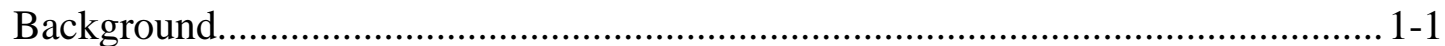

Statement of the Research Problem.................................................................. 1-5

The Subproblems.................................................................................... 1-6

EIFC Sampling and Analysis of VOCs...................................................... 1-6

Estimating Flux rates and Exposure-point Concentrations...............................1-6

Risk Assessment...................................................................................... 1-6

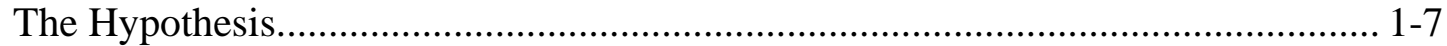

The Subhypotheses.............................................................................................. 1-7

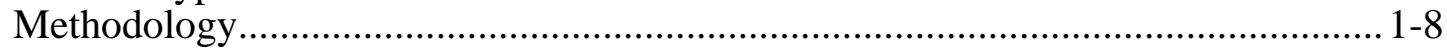

CHAPTER II - LITERATURE REVIEW

Superfund Risk Assessment..............................................................................

Data Collection and Evaluation................................................................. 2-1

Exposure and Toxicity Assessment............................................................. 2-4

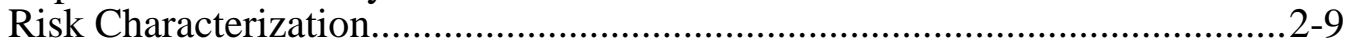

Determining VOCs in Air............................................................................... 2-13

Mathematical Modeling ............................................................................... 2-13

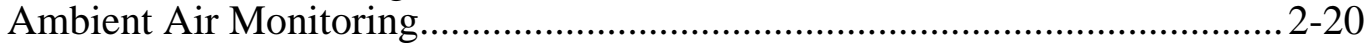

Measuring VOC Emission Rates................................................................. 2-28

VOC Risk Assessments at LLNL....................................................................... 2-43

LLNL Site 300 Site Wide Remedial Investigation (SWRI)............................ 2-43

LLNL Site 300 General Services Area Feasibility Study (GSA FS).................2-55

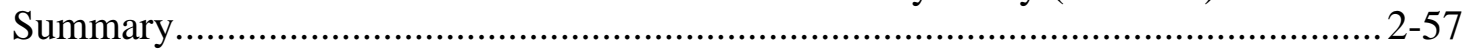

\section{CHAPTER III - RESEARCH DESIGN}

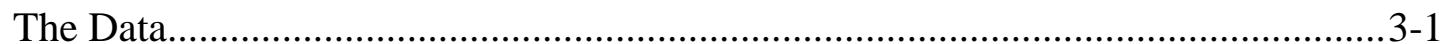

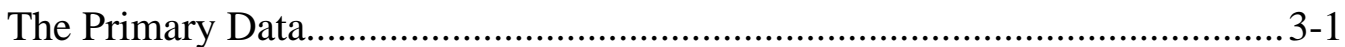

The Secondary Data................................................................................ 3-2

The Criteria for the Admissibility of the Data......................................................... 3-2

The Research Methodology.................................................................................... 3-3

Specific Treatment of the Data for Each Subproblem.............................................. 3-3

EIFC Sampling and Analysis of VOCs........................................................ 3-3

Estimating Flux rates and Exposure-point Concentrations.................................3-5

Risk Assessment....................................................................................... 3-7

CHAPTER IV - RESEARCH DATA AND ANALYSIS

EIFC Sampling and Analysis of VOCs................................................................ 4-1

Building 830, 832, and 854 Sampling Plans................................................... 4-1

EIFC Sampling Methodology .................................................................. 4-12 
Analytical Results from Buildings 830, 832, and 854 Sampling....................4-19

Estimating Flux rates and Exposure-point Concentrations.....................................4-25

VOC Flux Rates................................................................................... 4-26

Exposure-point Concentrations............................................................4-27

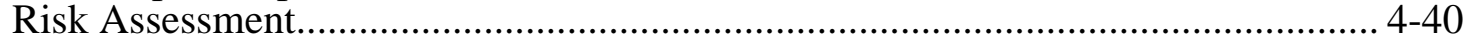

Average Daily Intake of Contaminant Attributable to the Inhalation

of VOCs from Subsurface Soil................................................................... 4-40

Chemical Specific Individual Life-time Cancer Risk.................................... 4-41

\section{CHAPTER V - CONCLUSIONS}

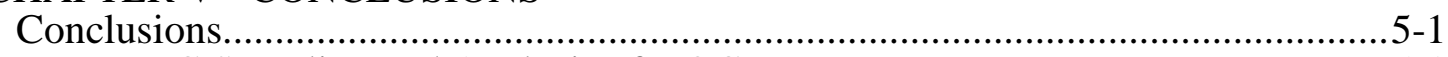

EIFC Sampling and Analysis of VOCs...................................................... 5-1

Estimating Flux rates and Exposure-point Concentrations............................5-2

Risk Assessment............................................................................ 5-3

Comparison of Methods for VOC Measurements.............................................. 5-4

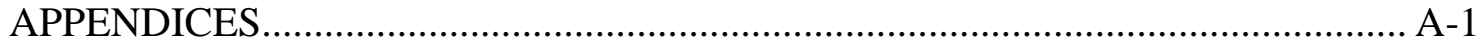

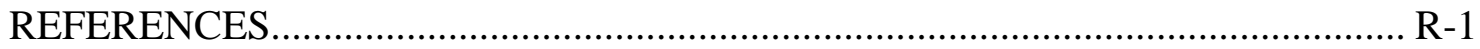




\section{LIST OF TABLES}

Table 2-1. Trifluralin flux from the field and laboratory chambers....................2-34

Table 2-2. Calculation of excess individual lifetime cancer risk attributable to inhalation of VOCs that volatilize from subsurface soil to outdoor ambient air as reported in the LLNL Site 300 Site-Wide Remedial Investigation (Webster-Scholten et al. 1994).

Table 2-3. Calculation of noncancer hazard index attributable to inhalation of VOCs that volatilize from subsurface soil to outdoor ambient air as reported in the LLNL Site 300 Site-Wide Remedial Investigation (Webster-Scholten et al. 1994).

Table 2-4. The 95\% UCL of mean contaminant soil vapor flux and the corresponding estimated potential exposure-point concentration of the contaminant in outdoor air as reported in the General Services Area Feasibility Study (Rueth and Berry 1995).

Table 4-1. Flux chamber control box rotometer calibration results.

Table 4-2. Flux chamber calibration recovery rates.

Table 4-3. Detection limit range for ambient air samples and preliminary remediation goal comparison in $\mathrm{ppb}_{\mathrm{V}} / \mathrm{v}$

Table 4-4. Soil vapor flux rates calculated from the Building 830, 832, and 854 emission isolation flux chamber samples.

Table 4-5. Building 830, 832, and 854 VOC exposure-point concentrations for outdoor air calculated using the maximum soil flux rate.

Table 4-6. Maximum measured VOC concentrations in Building 830, 832, and 854 outdoor ambient air samples compared to the preliminary remediation goal.

Table 4-7. Directly measured VOC concentrations in Building 830, 832, and 854 indoor ambient air samples compared to the PRGs..

Table 4-8. Pathway exposure factor for adult on-site inhalation of VOCs $4-42$

Table 4-9. Adult on-site worker average daily intake of contaminant attributable to the inhalation of VOCs $[\mathrm{mg} /(\mathrm{kg} \bullet \mathrm{d})]$....

Table 4-10. Chemical specific individual life-time cancer risks from the inhalation of VOCs 


\section{LIST OF FIGURES}

Figure 1-1. Schematic of an emission isolation flux chamber (Dibley and Depue 1995).............................................................................. 1-4

Figure 2-1. Risk information activities in the RI/FS process (USEPA 1989b).......2-2

Figure 2-2. Components of the Superfund risk assessment (USEPA 1989b)......... 2-3

Figure 2-3. The exposure assessment process (USEPA 1989b).............................2-6

Figure 2-4. Steps in risk characterization.......................................................... 2-10

Figure 2-5. Cutaway diagram of the emission isolation flux chamber sampling system used by Ritts (1991).....................................................................2-30

Figure 2-6. Locations of LLNL Livermore Site and Site 300................................. 2-45

Figure 2-7. Study areas at LLNL Site 300 at the time of the Site-Wide Remedial Investigation Report (Webster-Scholten et al. 1994)........... 2-46

Figure 4-1. Map of the Building 830 area marked with the ambient air and flux chamber sampling locations.......................................................... 4-5

Figure 4-2. Map of the Building 832 area marked with the ambient air and flux chamber sampling locations............................................................ 4-6

Figure 4-3. Map of the Building 854 area marked with the ambient air and flux chamber sampling locations 


\section{LIST OF APPENDICES}

Appendix A. Wind speed and temperature data collected during the ambient air sampling event at Building 830, 832, and 854.....

Appendix B. Sampling intervals, temperature, and flow rates during emission isolation flux chamber measurement at Buildings 830, 832, and 854

Appendix C. Emission isolation flux chamber effluent concentrations of VOCs in $\mathrm{ppb}_{\mathrm{V} / \mathrm{v}}$ measured at Buildings 830,832 , and $854 \ldots \ldots \ldots \ldots \ldots \ldots \ldots \ldots . . . . . . . .1$

Appendix D. Measured ambient air concentrations of VOCs in $\mathrm{ppb}_{\mathrm{V}} / \mathrm{v}$ at Buildings 830, 832, and 854................................................... D-1

Appendix E. Active soil vapor survey results in $\mathrm{ppm}_{\mathrm{V} / \mathrm{V}}$ collected at Site 300

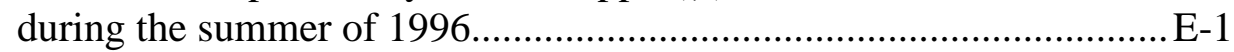




\section{CHAPTER I INTRODUCTION}

\section{Background}

Workers at contaminated sites identified on the National Priorities List are potentially at risk of exposure to hazardous substances that are harmful to their health. To protect the health of such workers, CERCLA (the Comprehensive, Environmental Response, Compensation and Liability Act, also known as Superfund) requires a risk assessment to be performed at these Superfund sites to characterize the potential for adverse health effects to occur. The four steps in a risk assessment are collection and evaluation of exposure data, assessment of exposure, assessment of potential toxicity, and ultimately characterization of cancer risk and noncancer hazard. During the exposure data collection and assessment steps, potential and actual contaminant releases are analyzed, exposed populations and exposure pathways are identified, and exposure concentrations and contaminant intakes are estimated. A primary goal of the exposure assessment is to determine the type and magnitude of potential exposure to contaminants that a worker may come into contact with while working on a Superfund site (USEPA 1988b).

For sites with volatile organic compound (VOC) soil contamination, inhalation of volatiles represents a major potential exposure pathway (Little 1992). VOCs present in the soil vadose zone have the potential to volatilize into the atmosphere, where they are subject to transport, dispersion, and inhalation by individuals downwind of the source (Webster-Scholten et al. 1994). Therefore, the concentration of VOCs in indoor and outdoor air that has volatilized from the subsurface must be determined to assess a workers potential inhalation exposure. The VOC concentration is then used in a general equation for estimating exposure to a site contaminant. Inhalation exposure per event is 
calculated based on the hours per event, the inhalation rate of the exposed individual during the event, and the concentration of the contaminant in the air breathed. The variables in the equation are duration of exposure, average inhalation rate, contaminant air concentration, average adult body weight, and frequency of exposure event. Following the United States Environmental Protection Agency (USEPA) recommended risk assessment procedures, all but one of the variables are replaced with standard default values for an adult site worker (i.e., average adult body weight is $70 \mathrm{~kg}$, duration is based on an 8-hr workday). The variable that drives the exposure is the contaminant air concentration (USEPA 1988b). The credibility of the exposure assessment has it's limitations due to the application of the default assumptions. A more specific review of exposure lengths or body weight for example, may be needed if the assumptions are unrealistic. However, presently default assumptions are used for Superfund site risk assessments.

Three approaches by which the air concentration can be determined are; 1) modeling release rates from the subsurface to air using soil contaminant concentration data, 2) measuring the VOC concentrations in ambient air directly, and 3) using air dispersion models that incorporate measured VOC flux rates. Mathematical models can be used to estimate release rates to air from the volatilization of VOCs from contaminated subsurface soil. The advantage such models have is they use soil VOC concentration data as input that has been gathered by the sampling and analysis of the subsurface soil conducted during the remedial investigation. However, this modeling approach does not take into consideration VOCs from underlying contaminated ground water, which could add to the actual flux. In addition, the model makes assumptions regarding the release rate of VOCs from the soil particles. Because the model is not based on direct measurement, it is by definition not as accurate. The calculated contaminant release rates 
may then be used as an input to air dispersion models that estimate exposure point concentrations (USEPA 1990).

Directly measuring the VOC concentrations in ambient air typically requires sampling and analysis of ambient air. The sampling is commonly done by collecting grab samples of ambient air using sampling media such as sorbent tubes, bags, or canisters. This approach has the advantage of simplicity and direct measurement of VOC concentration in air. However, calculating the potential exposure to VOCs in air that fluxed from the subsurface is difficult using ambient air measurements because other sources may be adding to the VOC concentration, especially in industrial areas (Rueth and Berry 1995).

To better determine VOC emission from the subsurface, a directly measured VOC emission rate from the subsurface is required. This emission rate can be used as input for a dispersion model. In this approach, the VOC exposure being contributed solely by the subsurface (and not other sources) may be determined. Emission rates of VOCs from an isolated surface area may be directly measured using an enclosed device placed on the ground called an emission isolation flux chamber (EIFC). An example of an EIFC is shown in Figure 1-1. The emission isolation flux chamber system consists of three parts: the chamber, the sweep air controller and data logger, and the sampling system. The EIFC shown if Figure 1-1 contains a fan to circulate air and a thermistor to measure the chamber temperature (Rueth and Berry 1995). Gaseous emissions enter the open bottom of the chamber while clean dry sweep air is added at a metered rate. A fan mixes the sweep air with the vapors and once the concentration of the VOC soil flux emissions and the sweep air reach equilibrium, the concentration can be monitored continuously using portable field instruments or discreetly by collecting a sample for analysis. The emission rate is calculated based upon the surface area isolated, the sweep air flow rate, and the gaseous concentration measured. The calculated emission rate is then used in air dispersion models to determine exposure-point concentrations. Exposure-point 

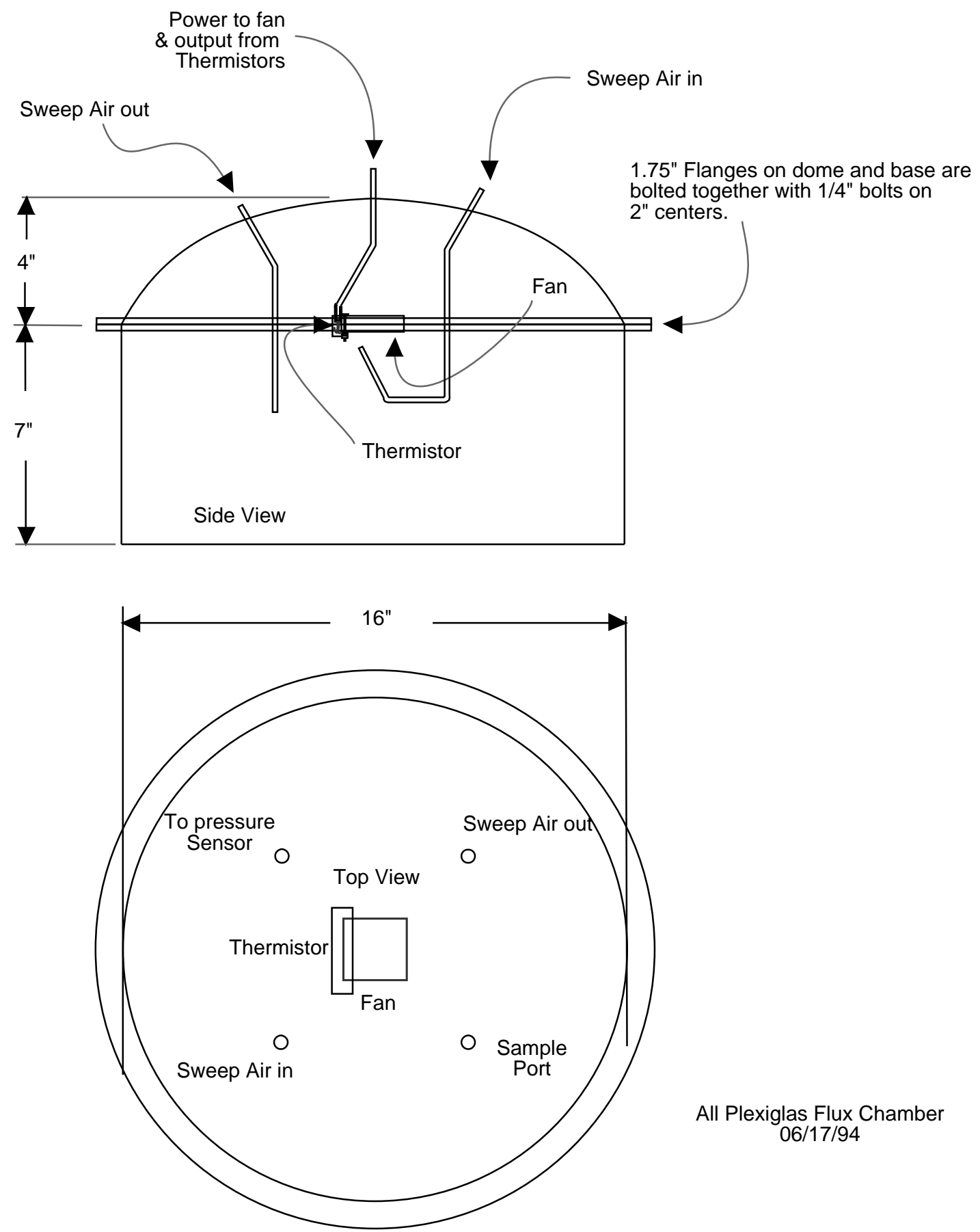

All Plexiglas Flux Chamber $06 / 17 / 94$

Figure 1-1. Schematic of an emission isolation flux chamber (Dibley and Depue 1995). 
concentrations can then be used to model potential health risks to workers from VOCs emitted from the subsurface soil.

\section{$\underline{\text { Statement of the Research Problem }}$}

This research examined the use of EIFC technology to collect soil flux samples, calculate flux rates, and model exposure-point concentrations to determine potential cancer risks for adult on-site workers from the inhalation of VOCs emitting from the subsurface soil at Lawrence Livermore National Laboratory (LLNL).

The purpose of this research was to determine the appropriateness of the application of EIFC technology at a Superfund site to determine adult on-site worker cancer risk from the inhalation of VOC volatilizing from the subsurface soil.

The data consisted of the EIFC sampling and analysis plan, EIFC sampling field data, the resultant analytical data, flux rate calculations, exposure-point model output, and the cancer risk estimates. All the primary data was collected for the Building 830,832 , and 854 exposure assessment conducted at LLNL Site 300 during the summer of 1996. The purpose of this investigation was to determine the inhalation risk of VOCs that volatilize from the subsurface soil. EIFC methodology was used to determine VOC emission rates. The flux rates were used as model inputs to determine VOC inhalation exposure. The exposure assessments were used to calculate cancer risks using standard EPA risk assessment models.

Secondary data gathered from related research regarding exposure assessments, exposure modeling, and emission rate measurement were reviewed. 


\section{The Subproblems}

The problem can be divided into three subproblems.

\section{EIFC Sampling and Analysis of VOCs}

The first subproblem was to identify 1) EIFC sample collection methodology to ensure representative samples; and 2) analytical laboratory analyses to ensure valid results.

\section{Estimating Flux Rates and Exposure-point Concentrations}

The second subproblem was to calculate VOC flux rates from contaminated soil and input the flux rates into an air dispersion model to estimate VOC exposure-point concentrations in ambient air. The flux rates were calculated using the validated analytic results obtained from the EIFC sampling and analysis event performed for the LLNL Site 300 Building 830, 832, and 854 exposure assessment. A simple air dispersion box model was used to calculate VOC exposure-point concentrations.

\section{Risk Assessment}

The third subproblem was to use the VOC exposure-point concentrations in ambient air to determine potential inhalation cancer risk for on-site LLNL workers using standard EPA risk assessment models. 


\section{The Hypothesis}

The main hypothesis was that use of EIFCs to calculate VOC exposure-point concentrations provides plausible exposures for estimating risks to on-site workers at Superfund sites. A major advantage of the EIFC method is that it distinguishes between VOCs from other area sources and VOCs contributed solely from the subsurface. It was hypothesized that VOCs volatilizing from the subsurface at LLNL Buildings 830, 832, and 854 will not result in an adverse health affect for on-site workers.

\section{The Subhypotheses}

\section{Subhypothesis One}

The first subhypothesis was that EIFC can be used with a carefully defined sampling and analysis plan to obtain accurate estimates of soil VOC emissions.

\section{Subhypothesis Two}

The second subhypothesis was that the SUMMA canister concentrations obtained from the EIFC sampling and analysis event as determined by the analytical laboratory could be simply converted into soil vapor flux rates by using the flux rate calculation. These flux rates can then be used as an input into an air dispersion model to derive exposure-point concentrations of VOCs in air contributed solely form the subsurface. 
The third subhypothesis was that the calculated exposure-point concentrations can be used as inputs to estimate plausible inhalation cancer risks for on-site workers at LLNL.

\section{Methodology}

The Building 830, 832, and 854 exposure assessment sampling and analysis plan and EIFC methodology were developed based on USEPA protocol by LLNL. The EIFC samples were collected in SUMMA canisters and submitted to an analytical laboratory under contract with LLNL. The analytical results were validated by LLNL personnel and then entered into LLNL's database. The results were then tabulated and transferred into a spreadsheet. The flux rate calculations were performed on the analytical results to achieve a flux rate. The flux rate was entered into a simple air dispersion box model in a spreadsheet to calculate VOC exposure-point concentrations in air. The exposure-point concentrations were then used in a spreadsheet to calculate potential cancer risk. 


\section{CHAPTER II \\ REVIEW OF THE RELATED LITERATURE}

\section{Superfund Risk Assessment}

Superfund requires a baseline risk assessment of the potential adverse health effects (current or future) caused by hazardous substance releases from a site in the absence of any actions to control or mitigate these releases. The baseline risk assessment is conducted during the remedial investigation/feasibility study (RI/FS) process at Superfund sites. Figure 2-1 shows the risk information activities in the RI/FS process. The RI/FS is the methodology that the Superfund program has established for characterizing the nature and extent of risks posed by uncontrolled hazardous waste sites and for developing and evaluating remedial options. The results of the RI/FS are used to; 1) help determine whether additional response action is necessary at the site, 2) modify preliminary remediation goals, 3) help support selection of "no-action" remedial alternative, and 4) document the magnitude of risk at a site, and the primary causes of that risk. There are four steps in the Superfund risk assessment process. These steps include; 1) data collection and evaluation, 2) exposure assessment, 3) toxicity assessment, and 3) risk characterization. Figure 2-2 depicts the steps of the baseline risk assessment (USEPA 1989b).

\section{Data Collection and Evaluation}

The first step in the risk assessment process is often referred to as the hazard identification step and involves gathering and analyzing the site data relevant to the human health evaluation and identifying the substances present at the site that are the 


\section{RI/FS Stages}

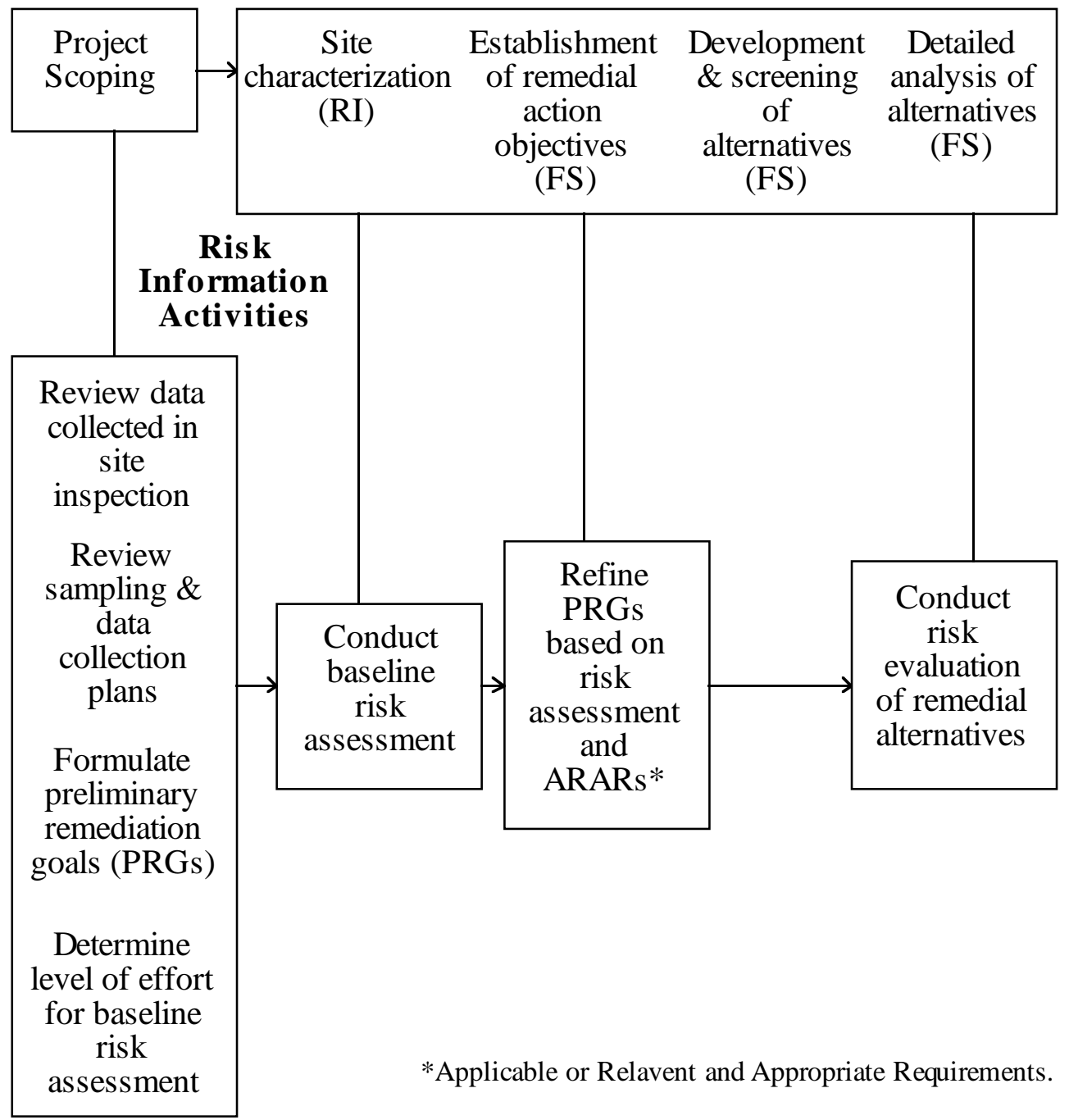

Figure 2-1. Risk information activities in the RI/FS process (USEPA 1989b). 


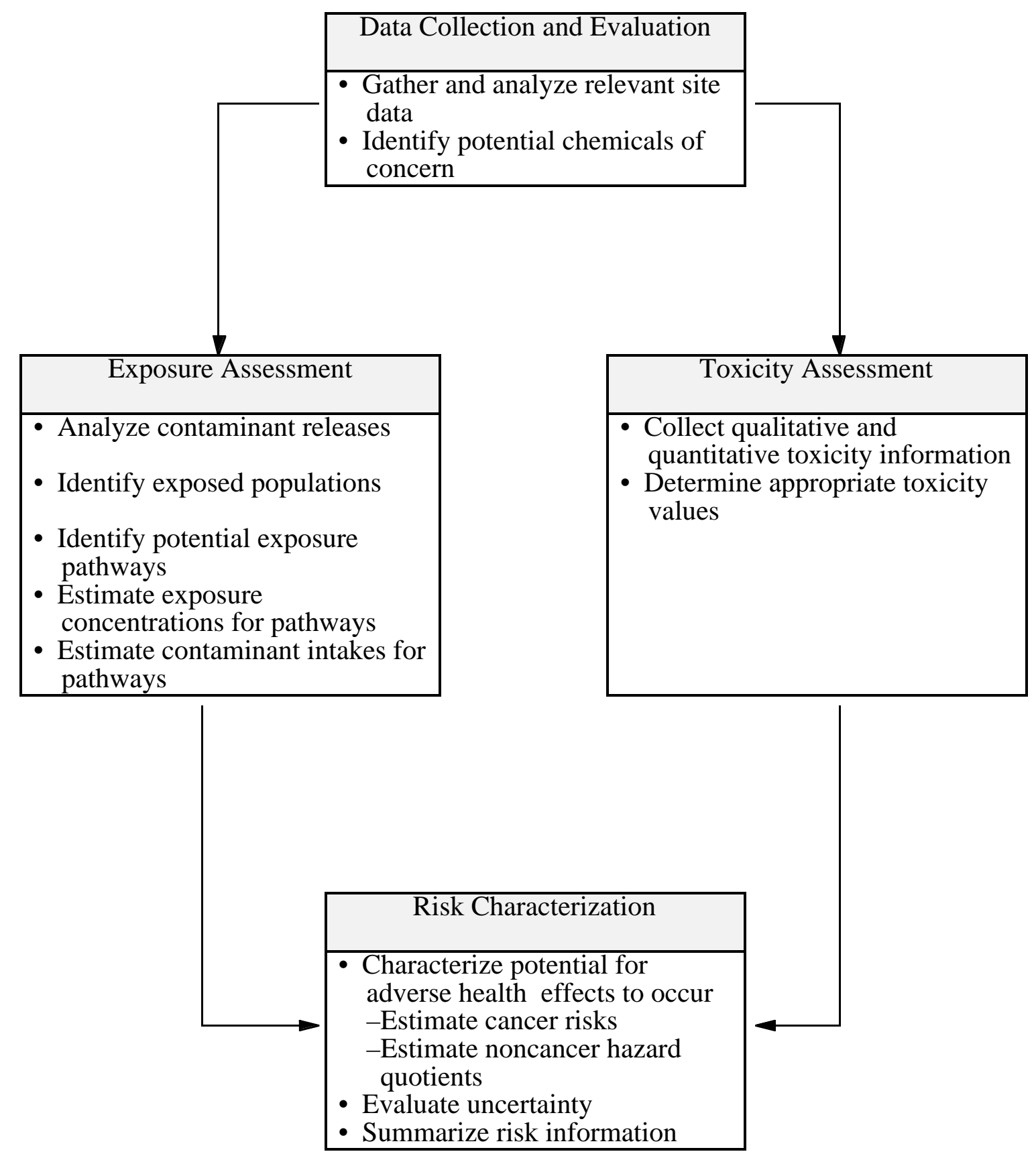

Figure 2-2. Components of the Superfund risk assessment (USEPA 1989b). 
focus of the risk assessment process (USEPA 1989b). Data collection includes; collecting existing data, addressing modeling parameter needs, collecting background data, conducting a preliminary exposure assessment, devising an overall strategy for sample collection, examining quality assurance and quality control (QA/QC) measures, and identifying special analytical needs. Data Evaluation includes; combining data available from site investigations, evaluating analytical methods, quantitation limits, qualified data, laboratory and sampling QA/QC, and tentatively identified compounds, comparing site data with background, and identifying chemicals of potential concern (USDOE 1995).

The types of site data needed for a baseline risk assessment include: contaminant identities, contaminant concentrations in the key sources and media of interest, characteristics of sources, especially information related to release potential, and characteristics of the environmental setting that may affect the fate, transport, and persistence of the contaminants. Most of these data are obtained during the RI/FS(USEPA 1989b).

\section{Exposure and Toxicity Assessment}

Exposure is defined as the contact of an organism (i.e., humans, animals) with a chemical or physical agent. The magnitude of exposure is determined by measuring or estimating the amount of the agent available at the exchange boundaries (i.e., the lungs, gut, skin) during a specified time period. Exposure assessment is the determination or estimation of the magnitude, frequency, duration, and route of exposure. The objective of the exposure assessment is to estimate the type and magnitude of exposures to the chemicals of potential concern that are present at or migrating from the site. The results of the exposure assessment are combined with chemical-specific toxicity information to 
characterize potential risks (USEPA 1989b). The exposure assessment includes; characterizing physical setting, identifying exposed populations, identifying potential exposure pathways, estimating exposure concentrations, and estimating chemical intakes (USDOE 1995). Generally, the detailed exposure assessment process begins after the chemical data have been collected and validated and the chemicals of concern have been selected. The exposure assessment proceeds with the following steps; 1) characterization of exposure setting, 2) identification of exposure pathways, and 3) quantification of exposure (see Figure 2-3).

The first step in an exposure assessment is the contaminant release analysis. Each onsite release point is identified for every target chemical, and the level of release to each environmental medium is determined. The determination of contaminant release may be made either by direct measurement or estimation by modeling release rates based on contaminant concentrations in the relevant environmental medium. The next step is contaminant transport and fate analysis. This analysis describes the extent and magnitude of environmental contamination. Direct measurement of contaminant concentrations is desirable in this step to provide a clear basis for determining exposure potential for some exposure routes. However, since the human health risk assessment also requires projection of potential exposure over a lifetime, this estimate often requires modeling. The third step is the analysis of exposed populations, which delineates the population, frequency, duration, and how populations come into contact with the contaminants. It is in the fourth step that the individual chemical-specific exposure estimates for each exposure route are developed. This analysis is based on the results of all previous analyses. Short-term and long-term exposures are calculated in the same manner with an estimation of exposure per event. Event-based exposure estimates take into account the concentration of contaminant in the environmental medium through which exposure 
STEP 1

STEP 2

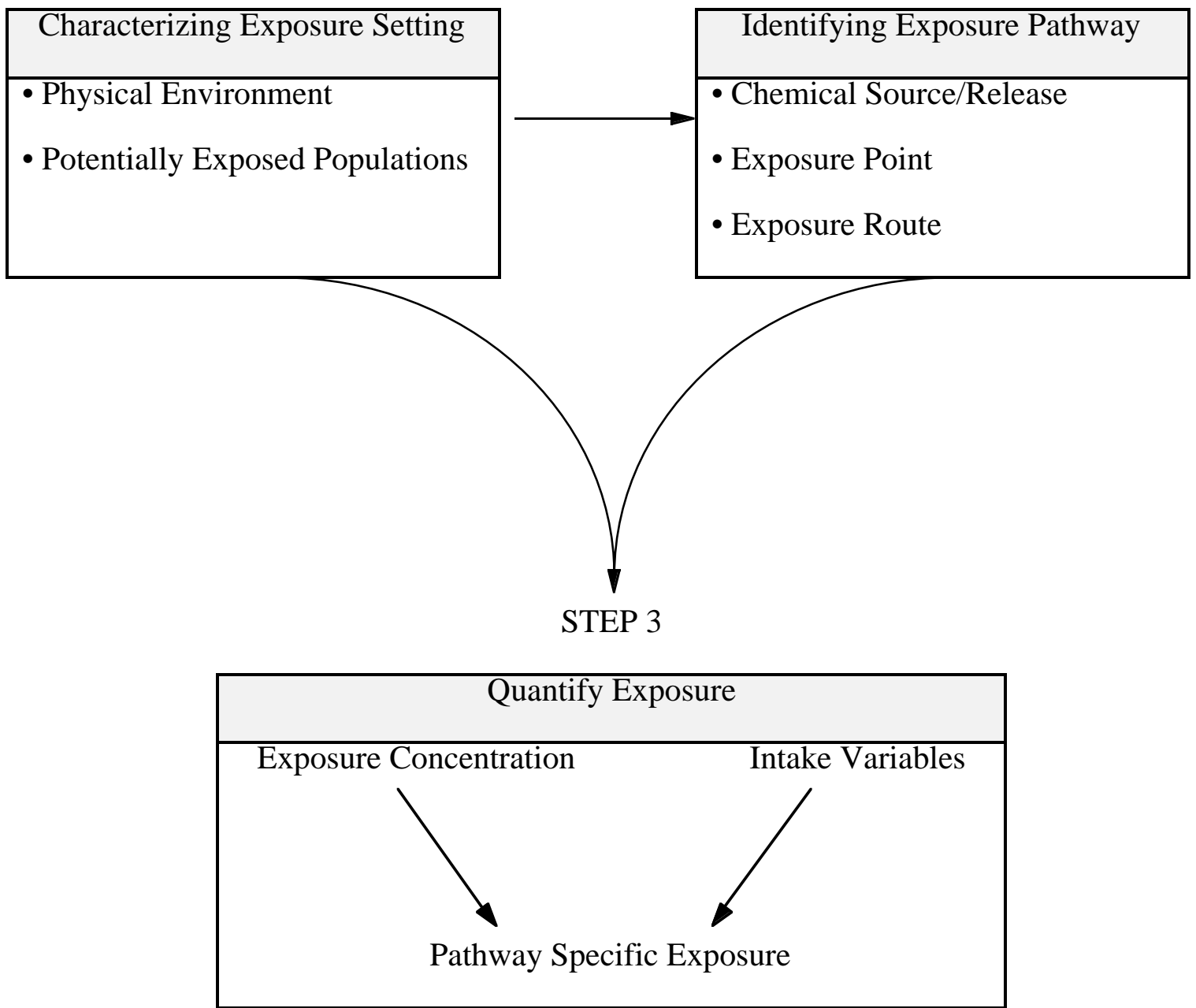

Figure 2-3. The Exposure Assessment Process (USEPA 1989b) 
occurs, the rate of contact with such media , and the duration of each event. The goal of the exposure calculation is to quantify the amount of contaminant contacted within a given time interval. Finally, the exposure assessment concludes with an uncertainty analysis which provides decision makers valuable information for evaluating the results of the exposure assessment (USEPA 1988b). Inhalation exposure per event is calculated based on the hours per event, the inhalation rate of the exposed individual during the event, and the concentration of the contaminant in the air breathed. The formula for calculating event-based exposure is the following:

$$
\mathrm{E}_{\mathrm{e}}=\mathrm{C}_{\mathrm{m}} \times \mathrm{PEF}_{\mathrm{e}}
$$

where:

$E_{e}=$ the average intake of contaminant from pathway e, $[\mathrm{mg} /(\mathrm{kg} \bullet \mathrm{d})]$;

$\mathrm{e}=\quad$ either ingestion (ing), inhalation (inh), or dermal absorption (derm);

$\mathrm{C}_{\mathrm{m}}=$ the concentration of contaminant in exposure medium $\mathrm{m}\left(\mathrm{mg} / \mathrm{m}^{3}\right)$;

$\mathrm{PEF}_{\mathrm{e}}=$ the pathway exposure factor for pathway e $\left[\mathrm{m}^{3} /(\mathrm{kg} \bullet \mathrm{d})\right]$.

The PEF for inhalation of VOCs for adult on-site workers is determined by the following equation:

$$
\operatorname{PEFCm}(\mathrm{d}), \mathrm{e}(\mathrm{t})=\mathrm{R}^{\mathrm{e}(\mathrm{t})} \times[(\mathrm{EF} \times \mathrm{ED}) /(\mathrm{BW} \times \mathrm{AT})]
$$

where:

$\mathrm{PEF}=$ pathway exposure factor for an adult on-site worker, where such exposure may result in health effect, (cancer or noncancer) attributable to contaminant concentration, $\mathrm{C}$, in exposure medium, $\mathrm{m}$ (air), which results directly from the presence of the contaminant in the environmental medium, $\mathrm{d}$ (subsurface soil), and exposure occurs by means of pathway, e (inhalation) via environmental transfer medium, $\mathrm{t}$ (air), units of $\mathrm{m}^{3} /(\mathrm{kg} \bullet \mathrm{d})$

$\mathrm{R}^{\mathrm{e}}(\mathrm{t})=$ rate of intake, EPA breathing rate default value of $20 \mathrm{~m}^{3} / \mathrm{d}$; 
$E F=\quad$ exposure frequency, EPA default value of $250 \mathrm{~d} / \mathrm{y}$

$\mathrm{ED}=$ exposure duration, EPA default value of 25 years;

$\mathrm{BW}=$ body weight, EPA default $70 \mathrm{~kg}$;

$\mathrm{AT}=$ averaging time where exposure may result in health effect, EPA default value of $2.56 \times 10^{4} \mathrm{~d}$.

For an adult site worker, all but one of the variables can be replaced with standard default values (i.e., average adult body weight is $70 \mathrm{~kg}$, duration is based on an 8-hr workday). The variable that drives the calculation of inhalation exposure is the contaminant air concentration (USEPA 1988b).

The toxicity assessment component of the Superfund baseline risk assessment considers: 1) the types of adverse health effects associated with chemical exposures; 2) the relationship between magnitude of exposure and adverse effects; and 3) related uncertainties such as the weight of evidence of a particular chemical's carcinogenicity in humans. The Superfund toxicity assessment can be accomplished in two steps: 1) hazard identification and 2) dose-response evaluation. The first step, hazard identification, is the process of determining whether exposure to an agent can cause an increase in the incidence of an adverse health effect. Hazard identification also involves characterizing the nature and strength of the evidence of causation. The second step, dose-response evaluation, is the process of quantitatively evaluating the toxicity information and characterizing the relationship between the dose of the contaminant administered or received and the incidence of adverse health effects in the exposed population (USEPA 1989b). The toxicity assessment includes gathering qualitative and quantitative toxicity information for substances being evaluated, identifying exposure periods for which toxicity values are necessary, determining toxicity values for noncarcinogenic effects, and determining toxicity values for carcinogenic effects (USDOE 1995). 
A reference dose or RfD, is the toxicity value used most often in evaluating noncarcinogenic effects resulting from exposures at Superfund sites. A chronic RfD is defined as an estimate of a daily exposure level for the human population, including sensitive subpopulations, that is likely to be without an appreciable risk of deleterious effects during a lifetime. Chronic RfDs are specially developed to be protective for longterm exposure to a compound (USEPA 1989b).

Carcinogenesis, unlike many noncarcinogenic health effects, is generally thought to be a phenomenon for which risk evaluation based on presumption of a threshold is inappropriate. The EPA assumes that a small number of molecular events can evoke changes in a single cell that can lead to uncontrolled cellular proliferation and eventually to a clinical state of disease. For carcinogens, no dose is thought to be risk-free. A slope factor and the accompanying weight-of-evidence determination are the toxicity data most commonly used to evaluate potential human carcinogenic risks. The EPA derives these values. For carcinogenic effects, EPA first assigns the substance a weight-of-evidence classification which is the extent to which the available data indicate that an agent is a human carcinogen, and then a slope factor is calculated. The slope factor is the plausible upper-bound estimate of the probability of a response per unit intake of a chemical over a lifetime. It is used to estimate an upper-bound probability of an individual developing cancer as a result of a lifetime of exposure to a particular level of a potential carcinogen (USEPA 1989b).

\section{Risk Characterization}

The final step in the Superfund baseline health risk assessment process is the risk characterization. In this step, the toxicity and exposure assessments are summarized and integrated into quantitative and qualitative expressions of risk (see Figure 2-4). To 


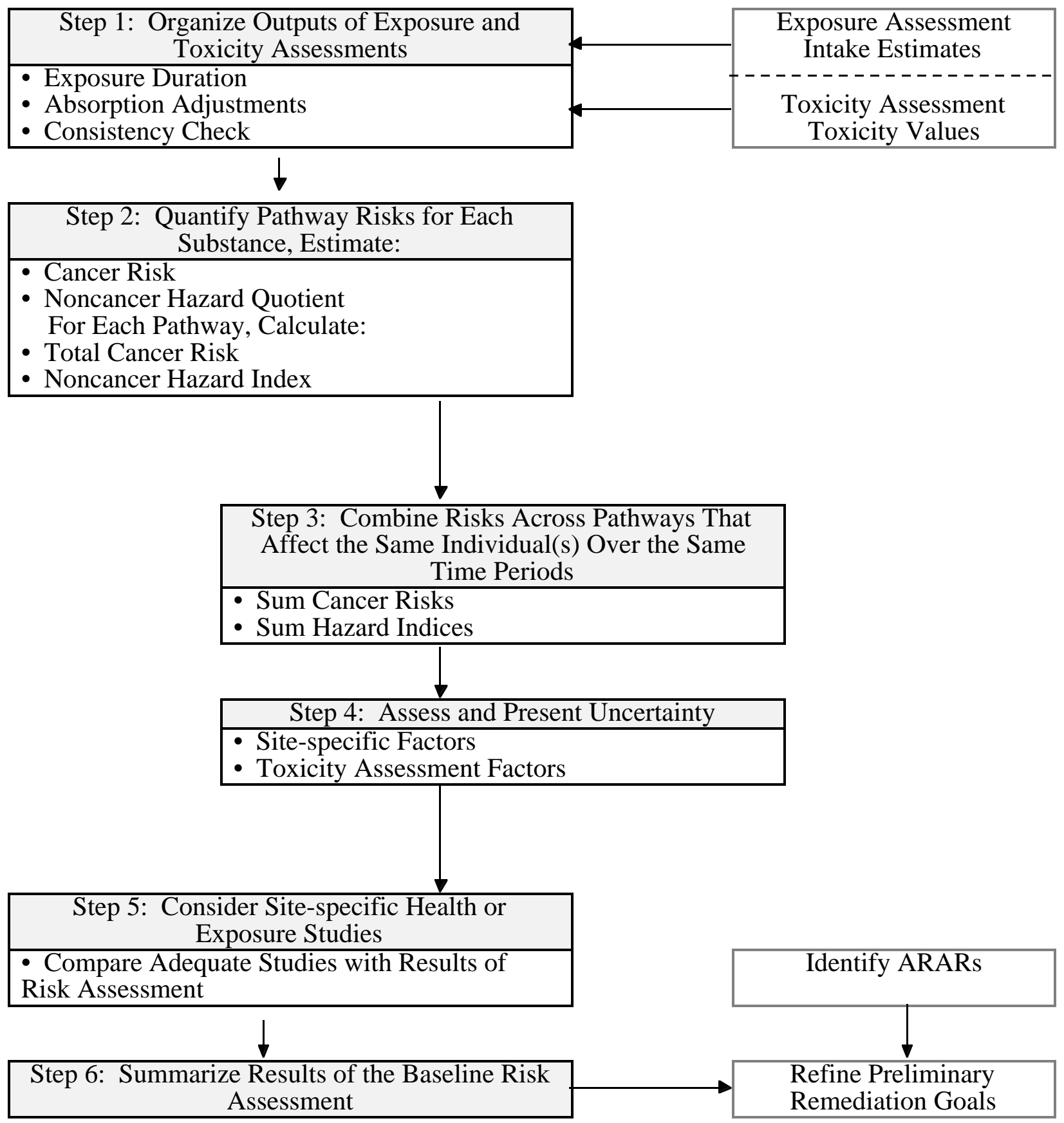

Figure 2-4. Steps in risk characterization (USEPA 1989b). 
characterize potential noncarcinogenic effects, comparisons are made between projected intakes of substances and toxicity values; to characterize potential carcinogenic effects, probabilities that an individual will develop cancer over a lifetime of exposure are estimated from projected intakes and chemical-specific dose-response information (USEPA 1989b). The risk characterization includes; reviewing outputs from toxicity and exposure assessment, quantifying risks from individual chemicals, quantifying risks from multiple chemicals, combining risks across exposure pathways, assessing and presenting uncertainties, and considering site-specific human studies (USDOE 1995).

For carcinogens, risks are estimated as the incremental probability of an individual developing cancer over a lifetime as a result of exposure to the potential carcinogen. The slope factor converts estimated daily intakes averaged over a lifetime of exposure directly to incremental risk of an individual developing cancer. The slope factor is a constant, and risk will be directly related to intake as shown in the following equation used for low risk levels:

$$
\text { Risk }=\text { CDI x SF }
$$

where:

Risk $=$ unitless probability of an individual developing cancer;

$\mathrm{CDI}=$ chronic daily intake averaged over 70 years $(\mathrm{mg} / \mathrm{kg} \bullet$ day $)$; and

$\mathrm{SF}=$ slope factor $(\mathrm{mg} / \mathrm{kg} \bullet \mathrm{day})^{-1}$.

For sites where chemical intakes might be high (i.e., risk above 0.01), the following calculation should be used:

$$
\text { Risk }=1-\exp (-\mathrm{CDI} \mathrm{x} \text { SF })
$$

where:

Risk $=$ unitless probability of an individual developing cancer; $\exp =$ the exponential; 
$\mathrm{CDI}=$ chronic daily intake averaged over 70 years $(\mathrm{mg} / \mathrm{kg} \bullet$ day $)$; and

$\mathrm{SF}=$ slope factor $(\mathrm{mg} / \mathrm{kg} \bullet \mathrm{day})^{-1}$.

The measure used to describe the potential for noncarcinogenic toxicity to occur in an individual is not expressed as the probability. The exposure level over a specified time period is compared with a reference dose. This ratio of exposure to toxicity is called the hazard quotient. The calculation is as follows:

$$
\text { Noncancer Hazard Quotient }(H Q)=\text { E/RfD }
$$

where:

$\mathrm{E}=$ exposure level; and

$\mathrm{RfD}=$ reference dose

E and RfD are expressed in the same units and represent the same exposure period (i.e., chronic, subchronic, or short-term). The HQ assumes that there is a level of exposure below which it is unlikely for even sensitive populations to experience adverse health effects. If the exposure (E) exceeds this threshold (i.e., if E/RfD exceeds unity), there may be concern for potential noncancer effects. As a rule, the greater the HQ value above unity, the greater the concern.

Cancer risks for several carcinogens may be added together to calculate the total cancer risk. This determination for total cancer risk assumes independence of action by the compounds involved (i.e., that there are no synergistic or antagonistic chemical interactions and that all chemicals produce the same effect). To assess overall potential for noncarcinogenic effects posed by more then one chemical, a hazard index (HI) approach has been developed by the EPA. The HI is equal to the sum of HQs. This approach assumes that simultaneous subthreshold exposures to several chemicals could result in an adverse health effect. It also assumes that the magnitude of the adverse effect will be proportional to the sum of the ratios of the subthreshold exposures to acceptable 
exposures. When the HI exceeds unity, there may be concern for potential health effects (USEPA 1989b).

\section{Determining VOCs in Air}

Sampling and analysis of the mediums of interest are required to determine the contaminant concentrations and identities. When the media of interest is the ambient air, there are several ways to determine contaminant concentrations. Three examples of the approaches that can be used to determine the contaminant air concentration are: 1) mathematical modeling of soil and ground water concentrations, 2) direct ambient air monitoring, and 3) the input of directly measured VOC emission rates from the subsurface into an air dispersion model. Each of the approaches have been used in various studies found in the literature.

\section{Mathematical Modeling}

Predictive modeling techniques include calculation of theoretical emission rates. Emission rate models predict emission rates as a function of contaminant concentration and contaminant physical and chemical properties within the surrounding media and through measured or theoretically derived mass transfer coefficients. These models require physical data about the surrounding media as well as physical and chemical properties of the contaminant. Once emission rates have been calculated, atmospheric dispersion models are used to predict ambient air concentrations at the receptor. Dispersion models may include simple hand calculations or special computer models (USEPA 1992a). Monitoring of non-point and fugitive type sources of many hazardous waste landfill emissions imposes technical and economic problems. Thus, it may be 
necessary as a first approach to rely on estimation of emissions (Shen 1981). Although monitoring data is useful, it has limited uses because it can only give a measurement of the existing extent of contamination. Some degree of modeling contaminant movement within and among environmental media is necessary to predict the associated exposure over a 70- year lifetime (USEPA 1988b). Emissions (predictive) modeling can be used if the preliminary site assessment has provided enough detailed information to be used as inputs into a model (USEPA 1990).

\section{Emission Rate Models Found in the Literature}

Volatilization of VOCs from landfills can be treated as a diffusion-controlled process using Fick's Law for steady-state diffusion (Shen 1981). The emission rate of VOCs from landfill waste can be calculated by the following equation:

$$
\mathrm{E}_{\mathrm{i}}=\mathrm{DiC}_{\mathrm{S}} \mathrm{AP}_{\mathrm{t}} 4 / 3\left(\mathrm{~W}_{\mathrm{i}} / \mathrm{L}\right)
$$

Where:

$\mathrm{E}_{\mathrm{i}}=$ emission rate of component $\mathrm{i}(\mathrm{g} / \mathrm{sec})$;

$\mathrm{D}_{\mathrm{i}}=$ diffusion coefficient of component $\mathrm{i}\left(\mathrm{cm}^{2} / \mathrm{sec}\right)$;

$\mathrm{C}_{\mathrm{S}}=$ saturation vapor concentration of component $\mathrm{i}\left(\mathrm{g} / \mathrm{cm}^{3}\right)$;

$A=$ exposed area $\left(\mathrm{cm}^{2}\right)$

$\mathrm{P}_{\mathrm{t}}=$ soil porosity;

$\mathrm{W}_{\mathrm{i}}=$ weight percent of toxic component $\mathrm{i}$ in the waste $(\mathrm{g} / \mathrm{g})$;

$\mathrm{L}=$ effective depth of soil cover $(\mathrm{cm})$.

This equation assumes that the diffusion into the atmosphere comes from a plane surface, at which the concentrations are held constant, biological degradation of the compound is insignificant, and the solubility of the toxic vapor in water is low. It does 
not account for the gas losses in leachate and soil. On the whole, this equation tends to over-estimate emission rates because it ignores the flow resistance of the soil and the decrease in concentration at the surface as volatilization takes place (Shen 1981).

The USEPA (USEPA 1988b) suggests using the following equation to estimate volatile releases from landfills without internal gas generation:

$$
\mathrm{E}_{\mathrm{i}}=\mathrm{D}_{\mathrm{i}} \mathrm{C}_{\mathrm{S}} \mathrm{AP}_{\mathrm{t}}{ }^{4 / 3}\left(\mathrm{M}_{\mathrm{i}} / \mathrm{L}\right)
$$

Where:

$\mathrm{E}_{\mathrm{i}}=$ emission rate of component $\mathrm{i}(\mathrm{g} / \mathrm{sec})$

$\mathrm{D}_{\mathrm{i}}=$ diffusion coefficient of component $\mathrm{i}\left(\mathrm{cm}^{2} / \mathrm{sec}\right)$;

$\mathrm{C}_{\mathrm{S}}=$ saturation vapor concentration of component $\mathrm{i}\left(\mathrm{g} / \mathrm{cm}^{3}\right)$;

$\mathrm{A}=$ exposed area $\left(\mathrm{cm}^{2}\right)$

$\mathrm{P}_{\mathrm{t}}=$ soil porosity;

$\mathrm{M}_{\mathrm{i}}=$ mole fraction (gmole/gmole);

$\mathrm{L}=$ effective depth of soil cover $(\mathrm{cm})$.

This model can be used to estimate volatile releases from covered landfills containing toxic materials alone, or toxic materials segregated from other landfilled nonhazardous wastes. This equation, based on Fick's First Law of steady state diffusion, assumes that diffusion into the atmosphere occurs at a plane surface where concentrations remain constant. It ignores biodegradation, transport in water, adsorption, and production of landfill gas. Diffusion of the toxic vapor through the soil cover is the controlling factor. It also assumes that there is a sufficient mass of toxicant in the landfill so that depletion of the contaminant will not reduce the emission rate. This equation is similar to the model described by Shen (1981). The only difference is $\mathrm{M}_{\mathbf{i}}$, mole fraction of the toxic component $i$ in the waste, replaces $\mathrm{W}_{\mathbf{i}}$, weight percent of toxic component $\mathrm{i}$ in the waste. The USEPA considers multiplying by the mole fraction a more accurate approach. 
Estimating toxic vapor releases from landfills with internal gas generation can be performed using the following equation (USEPA 1988b):

$$
\mathrm{E}_{\mathrm{i}}=\mathrm{C}_{\mathrm{i}} \mathrm{V}_{\mathrm{y}} \mathrm{A}
$$

where:

$\mathrm{E}_{\mathrm{i}}=$ emission rate of chemical $\mathrm{i}(\mathrm{g} / \mathrm{s})$;

$\mathrm{C}_{\mathrm{i}}=$ vapor concentration of chemical $\mathrm{i}$ in the soil pore spaces $\left(\mathrm{g} / \mathrm{cm}^{3}\right)$;

$\mathrm{V}_{\mathrm{y}}=$ mean landfill gas velocity in the soil pore $(\mathrm{cm} / \mathrm{s})$; and

$\mathrm{A}=\operatorname{area}\left(\mathrm{cm}^{2}\right)$.

Co-disposal landfills contain toxic wastes in combination with municipal or sanitary wastes that, because of their considerable organic content, generate landfill gases (i.e., $\mathrm{H}_{2}$, $\mathrm{CH}_{4}, \mathrm{CO}_{2}$ ). In these cases, the gas becomes the significant controlling factor, greatly accelerating the upward migration and subsequent release to the atmosphere. Various site factors such as the presence of saturated soils will tend to reduce the rate of volatile chemical release from landfills. The degree to which this model is able to accurately reflect contaminant release rates for gases, especially soluble gases, generated at sites with moist or wet soils is unknown.

Volatile releases from new spills can be estimated using the following equation (USEPA 1988b):

$$
\mathrm{E}_{\mathrm{i}}=\mathrm{k}_{\mathrm{iG}} \mathrm{C}_{\mathrm{i}} \mathrm{A}
$$

where:

$\mathrm{E}_{\mathrm{i}}=$ emission rate of chemical $\mathrm{i}(\mathrm{g} / \mathrm{s})$;

$\mathrm{kiG}_{\mathrm{iG}}$ gas phase mass transfer coefficient of chemical $\mathrm{i}(\mathrm{cm} / \mathrm{s})$;

$\mathrm{C}_{\mathrm{i}}=$ vapor concentration of chemical $\mathrm{i}\left(\mathrm{g} / \mathrm{cm}^{3}\right)$; and

$$
\mathrm{A}=\quad \operatorname{area}\left(\mathrm{cm}^{2}\right) .
$$


This equation can be applied to estimate volatile releases resulting from spills or leaks where a contaminant pool is visible on the soil surface, or where soil is contaminated (saturated) from the surface down. The equation does not consider soil phase mass transfer resistance, and therefore is not appropriate for use when spilled contaminates have seeped into surface soils. Similarly, because it does not consider liquid phase resistance, it is only useful for estimating releases of pure compounds.

The following equation can be used to estimate volatile releases from old spills, leaks, or landfarming that have resulted in contaminated surface soils with liquids in the pore spaces (USEPA 1988b):

$$
E_{i}=\frac{2 D_{S} A}{d+\sqrt{\frac{2 D C_{s} t}{C_{B}}+d^{2}}}
$$

where:

$\mathrm{E}_{\mathrm{i}}=$ average emission rate of component $\mathrm{i}$ over time $(\mathrm{g} / \mathrm{sec})$;

$\mathrm{D}=\quad$ phase transfer coefficient $\left(\mathrm{cm}^{2} / \mathrm{sec}\right)$

$\mathrm{C}_{\mathrm{S}}=$ the liquid-phase concentration of contaminant $\mathrm{i}$ in the soil $\left(\mathrm{g} / \mathrm{cm}^{3}\right)$;

$\mathrm{C}_{\mathrm{B}}=$ bulk contaminant concentration in soil $\left(\mathrm{g} / \mathrm{cm}^{3}\right)$;

$\mathrm{A}=$ contaminated surface area $\left(\mathrm{cm}^{2}\right)$

$\mathrm{d}=\quad$ depth of dry zone at sampling time $(\mathrm{cm})$; and

$\mathrm{t}=\quad$ time measured from sampling time $(\mathrm{sec})$.

Equation 2-10 assumes that soil pore spaces connect with the soil surface, that soil conditions are isothermal, and that there is no capillary rise of contaminant. It also assumes that there is sufficient liquid contaminant in the pore spaces so that volatilization will not deplete the reservoir of contaminant to the point where it affects the rate of volatilization. Modeling the release from soils with sorbed contaminants and no free 
liquids requires another model. The model described by Equation 2-10 has been determined to be preferable to other approaches for estimating volatile releases of chemicals spilled or incorporated into soils, because it directly takes into account the contaminant loss over time. It describes vapor diffusion as being soil-phase controlled, and essentially assumes that contaminant concentrations in the soil remain constant (until all contaminant is lost to the air) and that contaminant release occurs by the "peeling away" of successive unimolecular layers of contaminant from the surface of the "wet" contaminated zone. Thus, overtime this process results in a "dry" zone of increasing depth at the soil surface, and a wet zone of decreasing depth below the dry zone.

The atmospheric fate of substances released from uncontrolled hazardous waste sites can be estimated by using the following equation to estimate ground-level atmospheric concentrations of pollutants at selected points on a centerline of a plume directly downwind from a ground-level source (USEPA 1988b):

$$
C(X)=\frac{Q}{\pi \sigma_{y} \sigma_{z} \mu}
$$

$\mathrm{C}(\mathrm{X})=$ concentration of substance at distance $\mathrm{x}$ from site (mass/volume);

$\mathrm{Q}=\quad$ release rate of substance from site (mass/time);

$\sigma_{\mathrm{y}}=\quad$ dispersion coefficient in the lateral (crosswind) direction (distance);

$\sigma_{\mathrm{Z}}=$ dispersion coefficient in the vertical direction (distance);

$\mu=\quad$ mean wind speed (distance/time); and

$\pi=\quad$ the value pi (3.14).

This equation assumes that the hazardous substance released from a site is in a form that can remain airborne indefinitely (i.e., either gaseous or consisting of particles less than 20 microns in diameter). In cases where fugitive dust blown from the site includes 
solid hazardous substances (or soil particulates carrying absorbed hazardous substances) of greater diameter than 20 microns, relatively rapid gravitational settling of the larger particles occurs. Consequently, much of the hazardous material reaches the ground before advection and dispersion can transport and dilute the plume. Thus, areas close to the uncontrolled hazardous site may experience significant soil contamination, and human exposure points farther from the site may experience lower atmospheric concentrations than estimated by these equations. In addition, the equation assumes: steady-state conditions (i.e., steady wind direction and speed and continuous release rate); negligible longitudinal dispersion; the substance is refractory (all removal and decay process are disregarded); the substance is distributed normally (vertically and crosswind); and the air environment is homogeneous (USEPA 1988b).

Where estimates of ambient atmospheric concentrations of hazardous substances developed using these simplified procedures indicate that these concentrations pose potential health hazards, more accurate, in-depth analysis of atmospheric fate may be required. Numerous computer models are available for this purpose. Computer models vary in sophistication and in their ability to incorporate expressions describing the effect of various processes on the atmospheric fate of hazardous substances. The most important processes that affect the removal of hazardous substances from the air and their transfer to other environmental media are: dissolution; adsorption; gravitational settling; and precipitation. The importance of each of these processes to the atmospheric fate of the substance must be considered before selecting a computer model (USEPA 1988b).

There is no one single level of uncertainty that is appropriate for exposure modeling. For example, a screening level study has less need for accuracy and defensibility than a study related to a court case that will require a substantial sum of money from a responsible party. Different types of models provide varying accuracy in different 
situations, no one model is best in all cases. Each site-specific situation should be evaluated before a model is selected.

\section{Ambient Air Monitoring}

VOCs enter the atmosphere from a variety of sources. Many of these VOCs are acutely toxic, therefore, their determination in ambient air is necessary to assess human health impacts (USEPA 1988a). Air monitoring techniques that measure the ambient air concentration resulting from area emission sources can be combined with air dispersion modeling to calculate the source emission rate. Air monitoring and air dispersion models are used to determine the emission rate through an iterative process. An emission rate is first estimated for the area source. This estimated emission rate, along with meteorological data collected during air monitoring, is used to calculate a predicted downwind concentration. The predicted concentration is then compared to the measured downwind concentration. Based on this comparison, the estimated emission rate is adjusted, and the process is repeated until acceptable agreement is reached between the measured and predicted downwind air concentrations (USEPA 1990).

There are several techniques to sample and analyze VOCs in the atmosphere. To detect parts per billion levels of a contaminant in air, the trace organic vapors have to be concentrated from large volumes of air and transferred to an analytical system such as a gas chromatograph (Pellizzari et al. 1975). This literature review will not describe the analytical methods used to analyze air samples, but will focus on the various sampling media used to collect ambient air samples. Sampling techniques employed by investigators include trapping organic vapors on sorbent porous polymers, condensing or freezing vapors in cryogenic traps, or confining vapors in evacuated stainless-steel canisters, glass containers, or bags. Gas sampling media should be: 1) safe and easy to 
use and transport, 2) noncontaminating for the substance being measured, 3)

nondegrading or adsorbing for the substance being measured, 4) applicable to a wide variety of gaseous materials, 5) inexpensive, rugged, and easily adapted to the sampling and analytical methods employed, and 6) able to discriminate against water. In addition, the collection devices should have quantifiable collection efficiencies and recoveries of trapped or confined vapors. Sorbent-based collection devices should also have high breakthrough volumes (Harsch 1980, USEPA 1984).

In 1984, a study was performed for the EPA (USEPA 1984) investigating the use of three types of polymeric bags (Teflon, Tedlar, and five-layer polyethylene-aluminized), glass bulbs, stainless steel canisters (electropolished and SUMMA ${ }^{\mathrm{TM}}$-stainless steel canisters with a passivated interior surface), Tenax GC, charcoal and nickel cryogenic traps for air sample collection. The sample storage media was evaluated for: 1) simplicity and convenience, 2) collection and recovery efficiency for GC analysis, 3) accuracy, reproducibility and limits of detection, 4) analyte storage stability, 5) potential interferences from inorganic gases (ozone, $\mathrm{NO}_{\mathrm{X}}, \mathrm{SO}_{2}$ ) and water, and 6) limits of applicability. The results of this study, as well as other investigations are described below.

Various solid adsorbents have long been used to selectively concentrate trace organic chemicals in air to permit successful chemical analysis. Quantitative interpretation of data from such procedures is complicated by the possible existence of at least three factors; exceeding the capacity of the adsorbent, inadequate blank corrections and reactions usually called artifact formation (Walling 1984). The fundamental problem in sampling with adsorbents is to avoid significant adsorbate loss during sampling itself by not exceeding the capacity of the adsorbent (USEPA 1982). The chemical nature of sorbents used for air sampling is important since the process of adsorption may be irreversible and/or thermal desorption may cause decomposition products that could 
interfere with analysis (Pellizzari et al. 1975). The most desired traits of ambient air sampling adsorbents is the ability to trap the most substances, even when sampling large volumes of air, and release higher boiling point compounds when heated at moderate temperatures (Ciccioli et al. 1976). According to Pellizzari et al. (1975), sorbents for a particular air-sampling task should be evaluated using the following criteria: quantitative collection efficiencies and recovery of trapped vapors, high break-through volumes, minimal decomposition or polymerization of sample constituents during collection and recovery, low background contribution from the sorbent, and little or no affinity by the sorbent for water. The most widely used solid sorbent is Tenax. Air samples are drawn through a Tenax-filled cartridge where certain VOCs are trapped on the polymer. The sample cartridge is transferred to a laboratory and analyzed (USEPA 1988a). Other porous polymers have also been employed as adsorbents such as the Chromosorb Century series, Porapak series, and Ambersorb XE-340. Tenax GC, a graphitized carbon black adsorbent, is the most popular due to its high temperature stability and insensitivity to the effects of water vapor (Brown and Purnell 1979). Ciccioli et al. (1976) compared the performances of the porous polymer, Carbopack B and Tenax GC in terms of sample recovery. It was found that Carbopack B behaved as a better trapping and releasing material than Tenax GC. Krost et al. (1982) regarded Tenax GC to be an inadequate material for the collection of highly volatile substances, as well as having low breakthrough volumes for the low molecular amines and alcohols. Three packing materials, Porapak P, Carbon Molecular Sieve (Carbosieve), and Tenax GC, were studied in Zlatkis, Lichtenstein, and Tishbee (1973). Porapak P had a temperature limit that prevented efficient desorption of higher molecular weight volatile organics. Carbon Molecular Sieve had a high temperature stability which required desorptive temperatures that would ultimately destroy the sample. Tenax GC was proved to be superior to the other two as a general adsorbent because it fulfilled the requirements of efficient 
adsorptivity and desorptivity. Sampling of ambient air using Tenax GC is practical, but retention volumes sometimes differ greatly from the literature values. Also, chemical reactions during sampling and thermal desorption frequently occur. Because aromatic and halogenated hydrocarbons display inconsistent behavior, evaluation of data from each sampling situation using distributed air volume sets is necessary to avoid erroneous qualitative conclusions about the atmosphere sampled (Walling et al. 1986).

The EPA studied cartridges filled with charcoal and Tenax GC during their multimedia study (USEPA 1984). The NIOSH charcoal cartridges evaluated were found to be inadequate as applied to sampling of environmental levels (low parts per billion) of test compounds. The Tenax GC sampling cartridges were limited in the breakthrough volume which directly determined the detection limits obtainable for given measurement techniques. In this study, a $30 \mathrm{~L}$ sampling volume was used. Therefore, the breakthrough volumes for chemicals that are less than the sampling volume will severely limit their detection and quantification. Similarly, the collection efficiency was directly related to the breakthrough volume. Short term storage (7 day) did not significantly decrease the recovery of the test compounds. The precision of recoveries was slightly less than those observed for containers, however, with Tenax GC cartridges, the recovery was based upon triplicate sample analysis and not measurement of the same sample. Advantages of the Tenax GC cartridge as reported by the EPA were its ease of preparation, sample transport, and recovery and analysis.

Rothweiler, Wäger, and Schlatter (1991) compared Carbotrap and Tenax TA for sampling and analysis of VOCs in air. Tenax TA is a further development of Tenax GC. It is stable up to $280^{\circ} \mathrm{C}$ and produces less artifacts than Tenax GC. Carbotrap is a very pure graphitized carbon black. It is said to be free of contaminants and not susceptible to sorbent degradation. Both can be used to determine a wide range of VOCs. However, they do not seem to be suitable for many polar compounds. Tenax TA seemed inert 
towards the compounds tested as opposed to Carbotrap which had side reactions. Compounds with higher boiling points up to $270^{\circ} \mathrm{C}$ could be quantitatively desorbed from Tenax TA, but not from Carbotrap. For very volatile organic compounds and various polar VOCs, substantial losses, most probably due to breakthrough, were observed on both adsorbents. Tenax TA showed a decrease in the capacity for volatile compounds when using the same Tenax TA adsorption tubes more then five times, in contrast, Carbotrap does not change its adsorptive properties even after being used 30 times. Due to these adsorbents limitations other methods and adsorbents are necessary for the analysis of a complete VOC-pattern. Hutte et al. (1984) also studied Tenax TA. Hutte took grab samples of automotive exhaust in 1-ml and 5-ml gas-tight syringes fitted with shut-off valves and collected VOCs in the atmosphere using a Tenax-TA. In the air samples that were collected on the Tenax TA, artifacts identified as benzaldehyde and acetophenone were formed when the polymer was exposed to ozone.

Walling (1984) proposed that by simultaneously sampling the same parcel of air with a set of adsorbent beds, each of which samples a very different air volume, data quality issues that arise during the use of tandem beds would be eliminated. The collection of a set of adsorbent beds used to sample a large range of air volumes can provide situationspecific indications of the presence of complicating factors such as artifact formation, blank correction, inadequate retention, and many other kinds of analytical and sampling errors. Constant apparent concentrations over a set indicate the probable lack of importance of such complicating factors. It does not however, guarantee data accuracy or the absence of complications scaling linearly with air volume, but provides presumptive evidence that the data describes the atmosphere sampled.

VOCs can be successfully collected in stainless steel canisters. Collection of ambient air samples in canisters provides: 1) convenient integration of ambient samples over a specified time period, 2) remote sampling, 3) ease of storing and shipping of samples, 4) 
unattended sample collection, and 5) collection of sufficient sample volume to allow assessment of measurement precision and/or analysis of samples by several analytical systems. Because contamination is a critical issue with canister-based sampling, care must be exercised in selecting, cleaning, and handling sample canisters and sampling apparatus to avoid losses or contamination of the samples (USEPA 1988a).

During the EPA's study (USEPA 1984) of various sampling media, canisters were at a disadvantage because they can only collect a limited sample volume (4-6L) compared to the other media. Canisters showed a decrease of some compounds recoveries and an increase in others when inorganic gases were present. The increase may be related to the displacement by water of the test compounds and/or the release of contaminants from the canister. Two advantages of canisters are that they are field rugged and can be thoroughly cleaned by heating while evacuating. The SUMMA ${ }^{\mathrm{TM}}$ polished containers generally showed higher recoveries for high boiling point compounds and a better maintenance of recovery with time than the electropolished containers.

The advantages of SUMMA ${ }^{\mathrm{TM}}$ canisters over other ambient air sampling devices according to Oliver and Pleil (1986) are that stainless steel canisters are not subject to sample permeation or photo-induced chemical effects, and they can be reused after a simple cleaning procedure. Oliver and Pleil (1986) conducted experiments to test storage stability of VOCs. Evacuated new and used canisters were filled at a controlled rate with ambient air spiked with less than $2 \mathrm{ppb}_{\mathrm{V} / \mathrm{v}}$ of each of 15 VOCs (14 chlorinated and 1 brominated). Concentrations of VOCs in each canister were then periodically determined during 7-day and 30-day storage periods. Contaminants were detected in blank new and used canisters but were removed with a repeated cleaning. No initial decreases in concentrations of target compounds were observed. Statistical analysis of data showed that the relative standard deviation of concentrations of most VOCs in each canister set was $10 \%$ or less during the storage periods. For the 7 -day tests, the mean change in 
concentration per day was within $\pm 3 \%$. Therefore, the routine use of canisters appears suitable as an alternative to other sampling techniques, at least for the compounds tested.

Much earlier, Harsch (1980) also evaluated stainless steel sampling containers for stability and cleanliness. Two containers were cleaned and filled to about 45 psi with a gas containing essentially zero concentration of any halocarbon species. The containers were analyzed several times during a month-long period for 10 halocarbons. The containers prevented the intrusion of contaminants even when exposed to exterior contaminants 100 times what was in the container. The stability of various compounds were tested over a four week period. The results indicated that the stainless steel sample containers are acceptable containers for hydrocarbons with the exception of the terpenes and some of the more reactive unsaturated and oxygenated species. However, sulfur compounds and the mercaptans showed instability in the sampling containers.

The EPA has developed a procedure, method TO14, specifically for sampling of VOCs in ambient air using SUMMA ${ }^{\mathrm{TM}}$ canisters and analysis using a gas chromatograph-mass spectrophotometer. This method is applicable to specific VOCs that have been tested and determined to be stable when stored in pressurized and subatmospheric pressure canisters (USEPA 1988a). Ambient 24-hour average levels of VOCs can be determined using stainless steel SUMMA ${ }^{\mathrm{TM}}$ canisters. In this procedure, SUMMA $^{\mathrm{TM}}$ canisters are evacuated, then allowed to fill at a fixed rate through a flow control device. Sample recovery and analytical procedures for this method have been developed to allow measurements down to $0.1 \mathrm{ppb}_{\mathrm{v} / \mathrm{v}}$ for the less reactive chlorinated solvents. However, the procedure has no way of determining emission rates, but only average ambient concentrations (Ritts and Wolbach 1991).

In Millison et al. (1991), sorbent tubes with Tenax and Tedlar bags were used for ambient air sampling at a hazardous waste site in southern California. During the 1987 round of air sampling, hydrogen sulfide $\left(\mathrm{H}_{2} \mathrm{~S}\right)$ was detected in the Tedlar bag samples. 
Additional sampling using zinc acetate impingers did not confirm the $\mathrm{H}_{2} \mathrm{~S}$ detections leading investigators to conclude the $\mathrm{H}_{2} \mathrm{~S}$ results were caused by reaction with the Tedlar bag material. Two rounds of sampling occurred in 1988 using both Tedlar bags and sorbent tubes collected from the breathing zone (4-6 ft). Sorbent tubes were performed in conjunction with Tedlar because of the false $\mathrm{H}_{2} \mathrm{~S}$ detections. Bags were collected using a negative pressure/passive inflation technique. Tube samples were collected by drawing air through a Tenax tube connected with Tygon tubing to a personnel air sampling pump. The Tedlar bag samples were inconclusive due to contamination of field blank samples. Although the Tenax sample results were valid, they still did not conclusively demonstrate the release of vapors into the atmosphere from the wastes because background and upwind samples detected levels of contaminants comparable to those detected on-site. Despite previous cross-contamination of field blanks and false $\mathrm{H}_{2} \mathrm{~S}$ detections, Tedlar bags were chosen over sorbent tubes for the 1989 air sampling. Tedlar bags were chosen over Tenax because Tedlar bags were simpler to use and analyze as well as the potential for breakthrough using Tenax tubes.

The EPA study (USEPA 1984) reported that the bags ability to hold large sample volumes (10-100L) was a clear advantage over the other media. However, the EPA also concluded that bags are easily punctured and clear bags must be protected from the light after sample collection. In addition, thorough cleaning to remove volatile organic background can be complicated since the bags cannot be heated without the seams developing leaks. The background level in five-layer polyethylene-aluminized bags was deemed too high for environmental sampling and was not evaluated further in this study. Recoveries for the 15 test compounds collected from a dynamic-flowing synthetic air/vapor mixture for Teflon and Tedlar bags were generally in the range of 70-100\% with the most volatile substances having the best recoveries. Teflon bags had a larger decrease in recoveries over time compared to Tedlar bags. Tedlar bags showed a 
decrease in recovery of most of the test compounds when inorganic gases were present as well as releases of unknown contaminants from the wall of the bag which appeared as background during analysis. Because both bags lost and gained compounds by permeation through the bag walls, samples should be analyzed within 4 hours after sample collection and stored in a clean environment.

\section{Measuring VOC Emission Rates}

Emission rate or soil-gas data can be useful for: 1) identifying "hot spots", 2) serving as model inputs (source terms) to estimate ambient air concentrations, and 3) estimating emissions during remediation (USEPA 1990). To predict VOC concentrations in the air, existing models, such as the Industrial Source Complex (ISC), require a source strength term. This is the rate of emission of the pollutant from the source. Several factors make generating the source strength term difficult such as: the nature of the source; the concentration levels; and length of exposure for the risk assessment. Because the source is a large, unconfined, soil surface, emission rates will vary greatly, both spatially and temporally and be strongly influenced by both the nature of the surface and the local atmospheric conditions (Ritts and Wolbach 1991).

A variety of methods to determine flux of VOCs from soil have been developed because measuring the volatilization of VOCs into the atmosphere is important in estimating or calculating downwind inhalation exposures (Woodrow and Seiber 1991). Current methods can be classified as direct or indirect emission rate measurement techniques. Indirect emission rates measurements methods involve the measurement of ambient air concentrations under defined meteorological conditions. The ambient air concentration measurements are combined with technique-specific atmospheric dispersion models to determine emission rates. These methods rely on empirical data to 
correlate ambient concentrations to gas emission rates. Direct emission rate measurement techniques include enclosed chamber methods, soil vapor probes, soil vapor monitoring well, and vent sampling (USEPA 1990, Reinhart and Cooper 1992, and Batterman et al. 1992). Due to the extent of material on this topic, this literature review will focus on the enclosed chamber and soil-gas methods.

\section{Flux Chamber Methods}

The flux chamber method has been used to make direct measurements of emission fluxes of sulfur, nitrogen, and VOCs from different sources such as surface impoundments, land farms, landfills and contaminated soils. Emission measurements made with the flux chamber are providing a database for regulatory decision making, validating predictive air emission models, and assessing risk at Superfund cleanup sites (Gholson, Albritton, and Jayanty 1991 and USEPA 1986).

The EPA's User's Guide (USEPA 1986) describes an emission isolation flux chamber (EIFC) methodology for measuring emission rates of VOCs from contaminated soils

and/or ground water. A flux chamber (Figure 2-5) is an enclosure device used to sample gaseous emissions from a defined surface area. Clean dry sweep air is added to the flux chamber at a fixed, controlled rate. The volumetric flow rate of sweep air through the chamber is recorded and the concentration of the substance of interest is measured at the exit of the chamber, or collected for analysis. The emission rate is calculated as:

$$
\mathrm{E}_{\mathrm{i}}=\mathrm{Y}_{\mathrm{i}} \mathrm{Q} / \mathrm{A}
$$

where:

$\mathrm{E}_{\mathrm{i}}=$ emission rate of the component $\mathrm{i}$, (mass/area-time).

$\mathrm{Y}_{\mathrm{i}}=$ concentration of component $\mathrm{i}$ in the air flowing from the chamber, (mass/volume).

$\mathrm{Q}=$ flow rate of air into the chamber, (volume/time). 


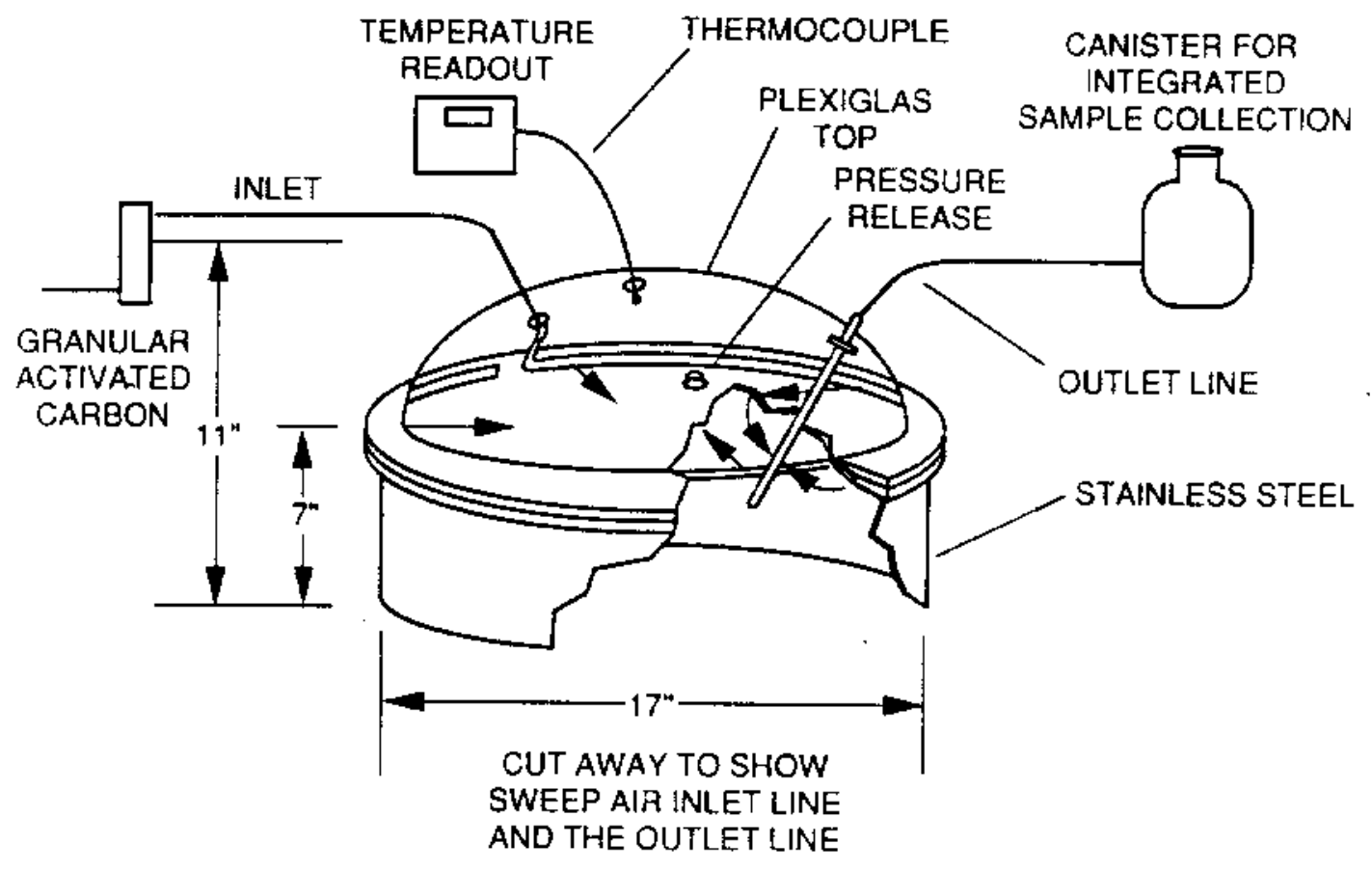

Figure 2-5. Cutaway diagram of the emission isolation flux chamber sampling system used by Ritts and Wolbach (1991). 
$A=$ surface area enclosed by the chamber, (area).

Each of the variables in the equation are measured directly. Because most of the emission rate assessments are of an area source much larger than the enclosed surface area of the flux chamber, an estimated average emission rate for the area source is calculated from multiple measurements based upon random and statistical sampling of a defined total area. The EPA compared three techniques found in literature that were used for determining emission rates from land surfaces, indirect measurements, direct measurements, and laboratory simulation. Indirect techniques usually require measurements of ambient air concentrations at or near a site. These measurements are related to the surface area of the area source and local meteorological conditions using a dispersion model to determine an emission rate. The second approach is to directly measure emission rates using flux chambers. The third approach is to create an emission source in a laboratory and model the emissions by various techniques for application to field sites. The EPA compared these approaches for precision, accuracy, sensitivity, applicability, complexity, manpower requirements, and costs. The advantages the EPA found using emission isolation flux chambers to measure emission rates from land surfaces were: flux chambers had the lowest detection limit (most sensitive); easily obtained accuracy and precision data; simple and economical equipment relative to other techniques; minimal manpower and time requirements; rapid and simple data reduction; and applicable to a wide variety of surfaces (USEPA 1986).

The EPA (USEPA 1989a) was also interested in applying the flux chamber methodology to measuring volatile organic emissions from open liquid bodies of waste during the treatment, storage and disposal of hazardous waste. They conducted another study to estimate the precision and accuracy of the flux chamber method. To do this, a simulated surface impoundment was constructed so that the accuracy and variability of the method could be measured under controlled environmental conditions. Flux chamber 
operational parameters of sweep flow rate, sampling time, sweep flow position, and flux chamber depth were studied to determine their affect on precision and accuracy. Environmental factors such as wind velocity, solar intensity, emission rate, and chemical composition were investigated. Precision of the method in the field was evaluated at two hazardous waste treatment, storage, and disposal facilities. The results of the laboratory and field evaluation of the flux chamber method indicate that liquid surface emission measurements can be made with very good precision, and that operational and environmental parameters have only a minor effect on the precision and accuracy. The laboratory evaluation revealed that the flux chamber precision for a single compound was less than 3 percent relative standard deviation (\%RSD) under the ideal conditions of optimal sweep flow rate, steady solar conditions, and moderate to high emission rates. For the three-component study, precision was between 6 and $13 \%$ RSD. Precision was found to be only slightly influenced by sweep flow rates higher than $2 \mathrm{~L} / \mathrm{min}$, emission rate, and solar radiation. Sweep flow rates of less than $2 \mathrm{~L} / \mathrm{min}$, should not be used for chambers of the design used in this study because of increased variability and poor accuracy. Precision estimated for the field evaluations were higher than those found in the laboratory study. The coefficients of variation (CVs) ranged from 3.5 to $19 \%$ for stable compounds. Variances as great as $30 \%$ were found when questionable values were included. The added $10 \%$ variation caused by technical problems with the chamber illustrate the difficulty of performing flux chamber measurements in the field. Sample collection and storage accounted for 50 to $100 \%$ of the total variability, and instrumental analysis contributed less than $5 \%$ of the total. Variability between flux chambers accounted for the remaining percentage of the total variability. When the variability due to sampling and storage is removed, the precision for the field study matches the laboratory study. A compound-dependent negative bias ranging from 40 to 80 percent was evident during the laboratory studies. This negative bias is believed to be due to 
changes in the liquid turbulence caused by the flux chamber. Little change in the bias was detected over the range of wind velocities and solar intensities studied. Visible changes were noted in the liquid surfaces. This change in turbulence and the magnitude of the change may be due to the large size of the flux chamber in relation to the experimental surface impoundment and the enclosure above it. The bias found for this study may not be valid for real conditions where the impact of the flux chamber would be considerably smaller (USEPA 1989a).

A study performed by Gholson, Albritton, and Jayanty (1991) investigated the flux chamber method for direct measurement of VOC emissions from quiescent liquid surfaces. Precision and accuracy of the method were tested in the field and laboratory under a variety of environmental and operational conditions. The results of this study support the EPA's findings (USEPA 1989a) indicating that liquid surface emission measurements can be made with good precision and that operational and environmental parameters have only a minor effect on precision and accuracy.

The volatilization flux of pesticides in the field has frequently been determined from pesticide air concentration profiles using meteorological techniques. Sanders, McChesney, and Seiber (1985) postulated that these aerodynamic techniques were not applicable to the small surface areas that might exist at waste dumps and spills, which are too small for concentration gradients to be established and measured accurately. Therefore, the flux chamber method was studied to determine the applicability for measuring pesticide flux from sites too small to allow for conventional flux measurements. The flux of trifluralin was determined from a soil evaporation bed used for waste disposal and from a laboratory volatilization chamber. Table 2-1 shows the concentration of trifluran found in the soil from the field investigation and in the laboratory experiment. The flux rate was then calculated and is also shown in Table 2-1. 
Table 2-1. Trifluralin flux from the field and laboratory chambers.

\begin{tabular}{|c|c|c|c|c|}
\hline $\begin{array}{c}\text { Chamber } \\
\text { Samplea }^{\text {Sam }}\end{array}$ & $\begin{array}{c}\text { Soil } \\
\text { Concentration } \\
(\mathbf{p p m})^{\mathbf{b}}\end{array}$ & $\begin{array}{c}\text { Flux in Field } \\
\left(\mu g^{\circ} \mathbf{m}^{-2} \cdot h r^{-1}\right)\end{array}$ & $\begin{array}{c}\text { Flux Adjusted } \\
\text { to } 23^{\circ} \mathrm{C} \\
\left(\mu \mathrm{g}^{\circ} \mathbf{m}^{-2} \cdot \mathbf{h r}^{-1}\right) \\
\end{array}$ & $\begin{array}{c}\text { Concentration } \\
\text { Adjusted Flux } \\
\left(23^{\circ} \mathrm{C}\right) \mathrm{c} \\
\end{array}$ \\
\hline A (field) & $398 \pm 91$ & 434 & 607 & 1.5 \\
\hline B (field) & $486 \pm 12$ & 756 & 1058 & 2.2 \\
\hline A (field) & $86 \pm 9$ & 539 & 328 & 3.8 \\
\hline A (field) & $273 \pm 38$ & 1622 & 441 & 1.6 \\
\hline Laboratory & $398 \pm 91$ & NA & 614 & 1.5 \\
\hline Laboratory & $486 \pm 12$ & NA & 978 & 2.0 \\
\hline Laboratory & $86 \pm 9$ & NA & 345 & 4.0 \\
\hline Laboratory & $273 \pm 38$ & NA & 508 & 1.9 \\
\hline $\begin{array}{ll}\mathrm{a} & \text { Field an } \\
& \text { soil sam } \\
\mathrm{b} & \text { ppm } \pm 1 \\
\mathrm{c} & \mu \mathrm{g} \cdot \mathrm{m}^{-2} \\
\mathrm{NA} & \text { Not app }\end{array}$ & $\begin{array}{l}\text { ooratory chambe } \\
\text { dev., for } 1 \mathrm{~cm} \mathrm{~d} \\
\text { pppm-1. } \\
\text { le. }\end{array}$ & $\begin{array}{l}\text { with identical s } \\
\text { th. }\end{array}$ & concentrations & vere from same \\
\hline
\end{tabular}


After adjusting for temperature differences, a correlation of 0.994 was observed between laboratory chamber and field chamber flux measurements. The surface flux was also calculated from high volume air sample concentration gradients using the aerodynamic method to compare with the chamber-measured flux values. The aerodynamic method yielded a value of $160 \mu \mathrm{g} \bullet \mathrm{m}^{-2} \cdot \mathrm{hr}^{-1}$ at $23^{\circ} \mathrm{C}$. The temperature-corrected field chamber flux values were averaged to give an estimated flux of $600 \pm 300 \mu \mathrm{g} \bullet \mathrm{m}^{-2} \cdot \mathrm{hr}^{-1}$ at $23^{\circ} \mathrm{C}$. It is likely that the small site resulted in systematically low aerodynamic fluxes, thus the chamber-measured values may better reflect the actual flux occurring at the site. The advantages of the flux chamber method for measuring pesticide flux over the aerodynamic method are: 1) the chamber method has a detection limit equal to or better then the aerodynamic method; 2) provides flux values independent of environmental wind conditions (i.e., can be used in gusty conditions without interference), and 3) flux chambers can be sealed to a variety of surfaces. The disadvantages of using the flux chamber method is that: 1) its flux measurement is determined by the surface covered by the chamber, so that several measurements must be taken when working with a surfaces of unhomogeneous concentrations, and 2) the chamber artificially modifies the microclimate at the surface requiring adjustment of the measured flux values to conditions which prevail at the open surface. Two types of glass chambers were studied in Woodrow and Seiber (1991). Field studies were conducted using large, flow through glass chambers, to determine pesticide flux from contaminated soil and water. The dynamic, flow-through chamber worked well for measuring flux for those compounds that have a vapor pressure less than $0.1 \mathrm{~Pa}$, including many common pesticides. However, the chamber was limited by the use of the polymeric adsorbent, XAD-4, used for trapping the volatile organic compounds. Woodrow found the use of static sealed glass "micro-chambers" used in the laboratory with a head-space gas chromatograph to have many advantages over the field chamber. Soil that was enclosed by the large 
chambers in the field was sampled and used in the micro-chambers for comparison. Woodrow and Seiber thought the flow through glass chamber method was labor intensive for essentially one data point, taking 1-2 workers 1 hour for set-up and take down. To obtain statistically reliable data, many chamber measurements would be required. On the other hand, the micro-chamber measurements were fast, requiring a fraction of the time needed for the flow through chambers. The disadvantages of the micro-chamber method are the extrapolation from elevated temperatures to ambient temperatures and the limited use for compounds that are stable enough to withstand elevated temperatures in soil and water.

Ritts and Wolbach (1991), used emission isolation flux chambers and SUMMA ${ }^{\mathrm{TM}}$ canisters to measure VOC flux rates during 8-hour periods from the soil of an area over 20 acres. The system shown in Figure 2-5 consisted of a flux chamber, SUMMATM canister, critical flow orifice, charcoal trap for cleaning the sweep air, and thermocouples for measuring air temperatures at varying heights, the soil-air interface, and the covered soil. Ritts and Wolbach found this sampling system to be advantageous over the USEPA (1986) method because it was easy to set up, does not need power, and collects air samples over an extended period of time. Set-up and breakdown time was short and easily accomplished by a two person sampling crew. The air samples collected in SUMMA $^{\mathrm{TM}}$ canisters were analyzed by EPA Compendium Method TO14 which provides detection levels in the $\mathrm{ppb}_{\mathrm{V} / \mathrm{v}}$ range. The flux emission rate calculations were made as described in USEPA (1986). A laboratory experiment was also conducted to compare the results of the modified sampling system to the sampling system described in USEPA (1986). Batterman et al. (1992) described the use of a passive flux chamber design in comparison to the active sampling flux chamber. The passive flux chamber consists of a passive sampling element mounted in an adsorptive chamber, which is mounted in an insulating housing. Laboratory and field results indicate that the passive 
sampler can accurately measure fluxes over both long and short averaging times under a variety of field conditions. This flux chamber is simpler to use, in comparison with the emission isolation flux chamber because it does not require pumps, gas cylinders, or flow balancing. It is also less costly, therefore a larger number of passive samplers than active flux chambers could be used at a site, which would give better estimates of the extent and spatial variability of the emission rates.

Reinhart and Cooper (1992) describe the use of a hybrid flux chamber-soil gas probe methodology for measuring municipal solid waste (MSW) gas emission rates. The objective of the research described was to optimize design and operational parameters in order to accurately and precisely measure MSW landfill gas emissions. Testing of the flux chamber was accomplished using a simulated subsurface methane emission source used to model a typical landfill surface. In order to accommodate the special needs of MSW landfill gas emission rate measurement (i.e., low concentrations of nonmethane organic compounds), the flux chamber was coupled with a landfill gas sampling probe. This allowed sampling and analysis of methane as well as non-methane organic compounds which might have been diluted below detection levels by the sweep air. Utilizing the measured sweep air flow rate and composition as well as the whole landfill gas composition, and assuming that the chamber behaves as a completely mixed reactor, a mass balance can be developed around the chamber to calculate total gas flow rates. This rate, coupled with concentrations of specific compounds yields mass emission rates as follows:

$$
\mathrm{VdC}_{\mathrm{e}} / \mathrm{dt}=\mathrm{Qi}_{\mathrm{i}}-\mathrm{Qe}_{\mathrm{i}}+\mathrm{QLC}_{\mathrm{L}}
$$

where:

$\mathrm{Q}=\quad$ flow rate (vol/time);

$\mathrm{C}=\quad$ methane concentration $(\mathrm{vol} / \mathrm{vol})$;

i, e, $\mathrm{L}=$ inlet, exit, and landfill, respectively; 
$\mathrm{t}=$ time; and

$\mathrm{V}=\quad$ chamber volume.

Since sweep air is high purity zero air, inlet methane concentration $\left(C_{i}\right)$ is zero. Also, since landfill gas flow rate is much lower than the inlet gas flow rate, it can be assumed that $\mathrm{Q}_{\mathrm{i}}$ is approximately equal to $\mathrm{Q}_{\mathrm{e}}$ and the mass balance simplifies to:

$$
\mathrm{VdC}_{\mathrm{e}} / \mathrm{dt}=-\mathrm{QeC}_{\mathrm{i}}+\mathrm{QLC}_{\mathrm{L}}
$$

Solving the equation for $\mathrm{C}_{\mathrm{e}}$ :

$$
\mathrm{C}_{\mathrm{e}}=\left(\mathrm{QLC}_{\mathrm{L}} / \mathrm{Q}_{\mathrm{i}}\right)[1-\exp (-\mathrm{t} / \mathrm{T})]
$$

where: $\mathrm{T}=\mathrm{V} / \mathrm{Q}$ ( chamber residence time).

The terms $\mathrm{Q}_{\mathrm{i}}$ and $\mathrm{T}$ are fixed for given operating conditions and chamber configurations. The terms $t$ and $\mathrm{C}_{\mathrm{e}}$ are measured during a sampling event. $\mathrm{C}_{\mathrm{L}}$ is determined using samples obtained via the landfill gas probe. Mixing tests conducted to evaluate mixing efficiency indicated that the mixing regime deviated slightly from that of a completely mixed reactor (less than 2.5\%). Duplicate sweep air tests, under identical conditions, were conducted to determine reproducibility of the tests. The results of these tests indicate excellent repeatability. Soil penetration tests were conducted to determine the effect of soil disturbances on emission rates. Positive biasing is encouraged with increasing penetration depth as a result of soil disruption. Insertion depth should be minimized while still maintaining a good seal. Biasing tests were conducted to determine the effects of sweep air flow rate and velocity, chamber insertion depth, wind speed, and chamber pressure on emission rates. Optimal operating parameters were determined to minimize bias for the specific flux chamber design described by Reinhart and Cooper (1992). These parameters are higher than the typical values discussed in literature. This study demonstrates the applicability of the flux chamber which provides accurate and nonintrusive measurement of emission rates from landfill surfaces. However, successful field use of this flux chamber also require measurements which account for the extreme 
variability in surface conditions, cover type, waste composition, waste age, and subsidence which is expected at full size landfills. It is also important to determine the magnitude and distribution of such variability and the impact on gas emissions in order to design an accurate emission monitoring program.

The accuracy and precision of flux chamber measurements will depend on the biases and variability associated with the emission source, the sampling method, and the analytical method. Various sampling and analytical methods have been used with flux chambers. The prevailing method is a combination of portable total hydrocarbon analyzers to monitor for steady-state conditions and evacuated, stainless steel canisters to collect samples for quantification of specific analytes by an analytical laboratory. In general, it has been found that the spatial and temporal variability in emissions at a given site is a greater source of variability than the sampling and analytical methods (Eklund 1992).

\section{$\underline{\text { Soil Vapor Surveys }}$}

Soil-gas surveying is most commonly used as a screening technique during environmental remediation to plan monitoring well locations and define plume boundaries. Static and dynamic grab sampling and passive sampling techniques are used in soil-gas surveying. Static grab samples are collected as quickly as possible to give a snap shot of contaminant concentrations in the soil atmosphere at a particular subsurface location. Dynamic grab sampling involves samples being collected from a moving stream of soil gas that is pumped through a hollow probe. Passive sampling utilizes a sorbent which is buried in shallow soil for as long as one month and then retrieved and analyzed. An advantage of the grab sample is that it may be analyzed in the field using portable instruments giving investigators rapid results. The passive samples, however, 
must be sent to a laboratory where desorption and chemical analysis are performed. One advantage of passive samplers is ease of use. Field operations require minimal training. Also, concentration fluctuations are averaged out over time, unlike the grab sampling technique. Another disadvantage of the passive technique besides the length of time required for results, is the inappropriateness for VOCs with boiling points below approximately $5{ }^{\circ} \mathrm{C}$ or for compounds that are prone to thermal decomposition during pyrolysis (Marrin and Kerfoot 1988). Marrin and Kerfoot (1988) presented case studies that demonstrated how the interpretation of data acquired from soil-gas surveys can be very complex.

LLNL conducted active soil vapor surveys (SVS) at Site 300 as part of the RI. However, emissions of VOCs were modeled rather than using active vacuum soil vapor data for three reasons: 1) the active SVS were deployed as a semiquantitative screening technique during source investigations; 2) at the times the SVS were conducted, the existing soil moisture changes and seasonal variability resulted in variability between the existing data sets; and 3) comparable SVS were not conducted in all study areas (Webster-Scholten 1994). Soil gas sampling provides qualitative results applicable only for determining areas of contamination, not contamination concentration. Data cannot be converted in any meaningful way into a flux rate. In addition, soil gas sampling is not a viable alternative for measuring emissions from landfill surfaces because the technique could severely disrupt the landfill surface (Reinhart and Cooper 1992).

\section{Flux Chamber Sampling Strategy}

For each medium at a site, there are several strategies for collecting samples. The sampling strategies for a site must be appropriate for use in a quantitative risk assessment 
otherwise even the strictest QA/QC procedures will not ensure usability of sample results (USEPA 1989b).

The optimal sampling strategy for determining emission rates will depend on the size and nature of the source and the objective of the measurement program. A statistically based random sampling approach allows one to determine an average emission rate for a zone by making a series of emission flux measurements. The approach calls for dividing the total area at a site into zones where heterogeneous chemical distribution is exhibited i.e., areas expected to exhibit comparable emission rates. Each zone of equivalent emissions is divided into at least 20 grids. The number of grids required varies with the size of the zone and the grid size varies from 25 to a maximum of $200 \mathrm{M}^{2}$. A minimum of six measurements are made at randomly selected gridpoints in each zone. The minimum number of required measurements also varies with the size of the source. The emission measurement data are evaluated and, if the data set exhibits sufficient variability, additional measurements are called for and/or the zone is divided into two or more new zones. In actual practice, time and resources frequently preclude employing the sampling strategy outlined above. The simplest objective to meet is the measurement of maximum or worst-case emission fluxes. Suitable locations for such measurement can be ascertained from field experience, visual observation of the site, and review of any site records, soil borings data, and soil-gas data. In practice, a common sampling strategy is to evaluate both the worst-case and the average emission rate at a site (Eklund 1992).

The following EPA sampling strategy (USEPA 1986) provides an accurate and precise estimate of the emission rate for the total are source through random sampling in which any location within the area source has a theoretically equal chance of being sampled. The sampling strategy described below provides an estimated average emission rate within 20 percent of the true mean with 95 percent confidence. 
Based on the area source records and/or preliminary survey data, subdivide the total area source into zones if nonrandom chemical distribution is exhibited or anticipated. The zones should be arranged to maximize the between-zone variability and minimize the within-zone variability.

Divide each zone by an imaginary grid with unit areas that depend on zone area size (Z) as follows:

If $\mathrm{Z} \leq 500 \mathrm{~m}^{2}$, then divide the zone area in to units with areas equal to $5 \%$ of the total zone area.

If $500 \mathrm{~m}^{2}<\mathrm{Z} \leq 4000 \mathrm{~m}^{2}$, then divide the zone areas into units of $25 \mathrm{~m}^{2}$.

If $4000 \mathrm{~m}^{2}<\mathrm{Z} \leq 32000 \mathrm{~m}^{2}$, then divide the zone area into 160 units.

If $\mathrm{Z}>32000 \mathrm{~m}^{2}$, then divide the zone area into units with area equal to $200 \mathrm{~m}^{2}$.

Assign a series of consecutive numbers to the units in each zone.

Use the following equation to calculate the number of units (grid points) to be sampled for the Kth zone $\mathrm{n}_{\mathrm{K}}$ :

$$
\text { Number of samples }=6+0.15 \cdot\left[\text { sampling zone area }\left(\mathrm{m}^{2}\right)\right]^{0.5} \quad \text { Eq. } 2-16
$$

Using a random numbers table, identify $\mathrm{n}_{\mathrm{K}}$ grid points that will be sampled in zone $\mathrm{K}$.

\section{Flux Chamber and Ambient Air Monitoring Case Study}

Millison et al. (1991) summarized a case study that utilized soil vapor and ambient air sampling. Four techniques were used to measure organic vapor emissions from a hazardous waste site in southern California to characterize potential health risk. The four techniques were soil gas sampling with subsurface probes, ambient air sampling with sorbent tubes, ambient air sampling with Tedlar bags, and vapor emission sampling using an emission isolation flux chamber. In 1987, soil gas samples were collected by driving perforated pipe to a depth of five feet, then retracting the pipe a few inches. Samples 
were then collected in Tedlar bags. This soil vapor survey was unsuccessful in defining the boundaries of the waste site because contaminants were detected in all locations. During 1988, air samples were collected from the breathing zone (4-6 ft) using sorbent tubes and Tedlar bags. Bags were collected using a negative pressure/passive inflation technique. Tube samples were collected by drawing air through a Tenax tube connected with Tygon tubing to a personnel air sampling pump. The air sample results did not conclusively demonstrate the release of vapors into the atmosphere from the wastes because background and upwind samples detected levels of contaminants comparable to those detected on-site. However, in 1989, the RI work plan proposed use of a flux chamber because it measures vapor emissions directly from the ground. Ambient air samples were collected in Tedlar bags concurrently with the flux chambers. The flux chamber and concurrent ambient air sampling provided the data necessary for estimating inhalation exposures at the site. The flux chamber data allowed for calculation of emission rates at the soil-air interface that was used in exposure modeling. Results from the ambient air sampling at the breathing zone near the flux chamber locations provided information about diffusion and dispersion of VOCs from the contaminated soils.

\section{VOC Risk Assessments at LLNL}

The following studies illustrate the steps in the Superfund risk assessment process as they have been implemented by LLNL.

\section{LLNL Site 300 Site-Wide Remedial Investigation (SWRI)}

The Lawrence Livermore National Laboratory's (LLNL) Site 300, a Department of Energy high-explosives test facility, was placed on the Superfund National Priorities List 
in August of 1990. Although investigations had been underway since the early 1980's, work began to summarize what was known about the nature and extent of contamination at Site 300 and to conduct additional investigations and prepare for remediation, where necessary. A Site-Wide Remedial Investigation (SWRI) Report (Webster-Scholten et al. 1994) was prepared to present the findings of these investigations using data collected at the site through December 1991. At the time of the SWRI report preparation, the site was divided into six study areas; 1) Building 833, 2) Building 834, 3) East and West Firing (EWFA) Area, 4) Pit 6 Area, 5) High-Explosives Process Area, and 6) General Service Area (GSA). Figures 2-6 and 2-7 show the Site 300's location and study areas. Subsequent to the SWRI, the Building 833 study area was redefined as the Building 832 Canyon study area, and a new study area, Building 854, was defined from the EWFA study area.

The primary contaminants of concern identified at Site 300 in soil/rock and ground water were VOCs, high-explosive compounds, and tritium. Using the data compiled during the assessment of the nature and extent of contamination at Site 300 , the environmental fate and transport of contaminants at several release sites were evaluated to identify actual or potential routes of migration from the source medium to other environmental media of interest. From that evaluation, exposure points were identified and a set of models were selected to estimate the rate of contaminant exchange between environmental media, transport in those media, and the resulting exposure-point concentrations or activities of the contaminants of concern. The predicted concentrations or activities were then used to estimate the magnitude of human and/or ecological exposure to contaminants identified at Site 300. The release rates and estimated exposure-point concentrations published in the SWRI were calculated using various mathematical models. The average volatilization flux rate of a VOC from soil to the atmosphere was estimated using the model of Hwang, Falco and Nauman (1986). This 


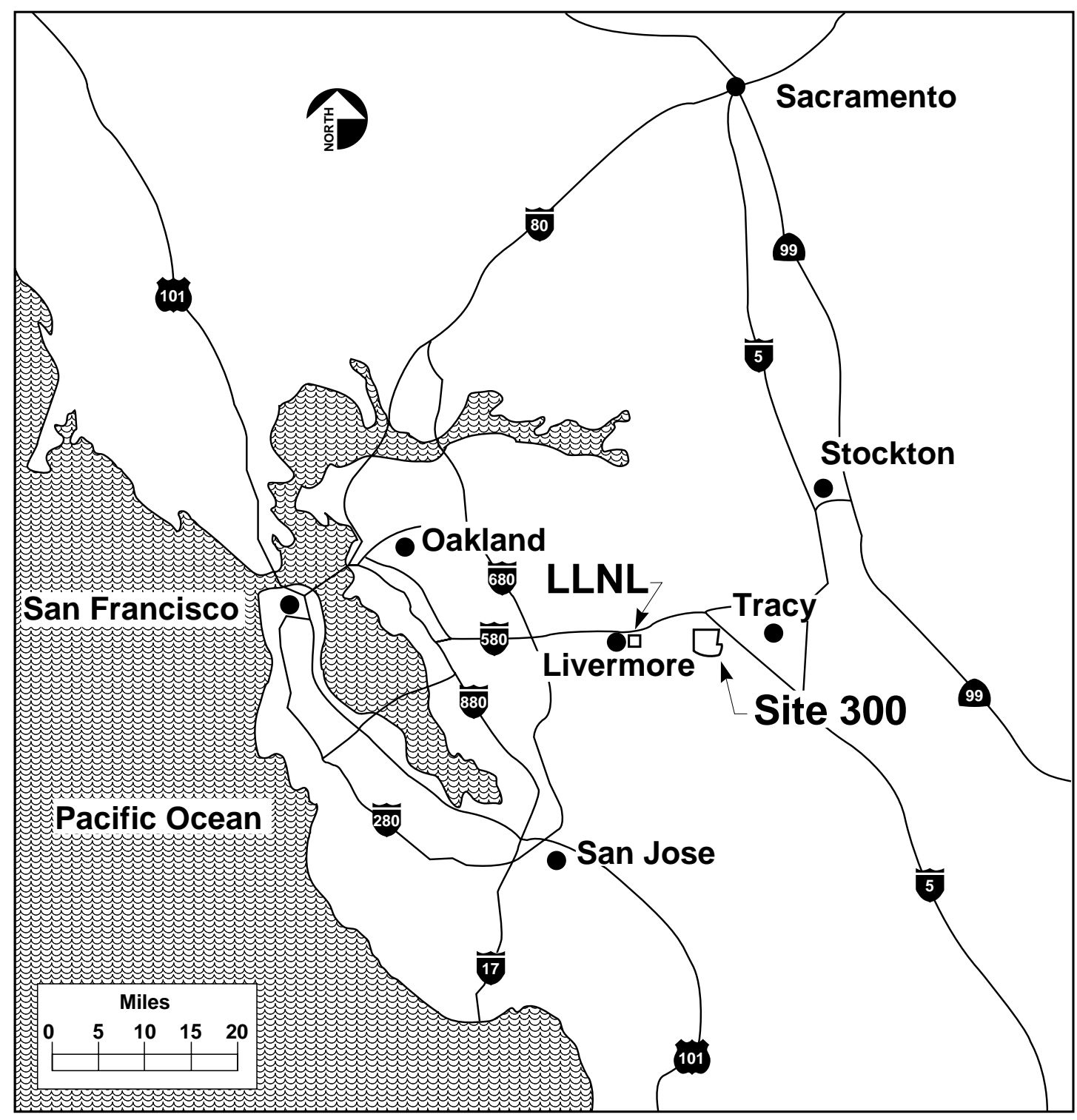

Figure 2-6. Locations of LLNL Livermore Site and Site 300. 


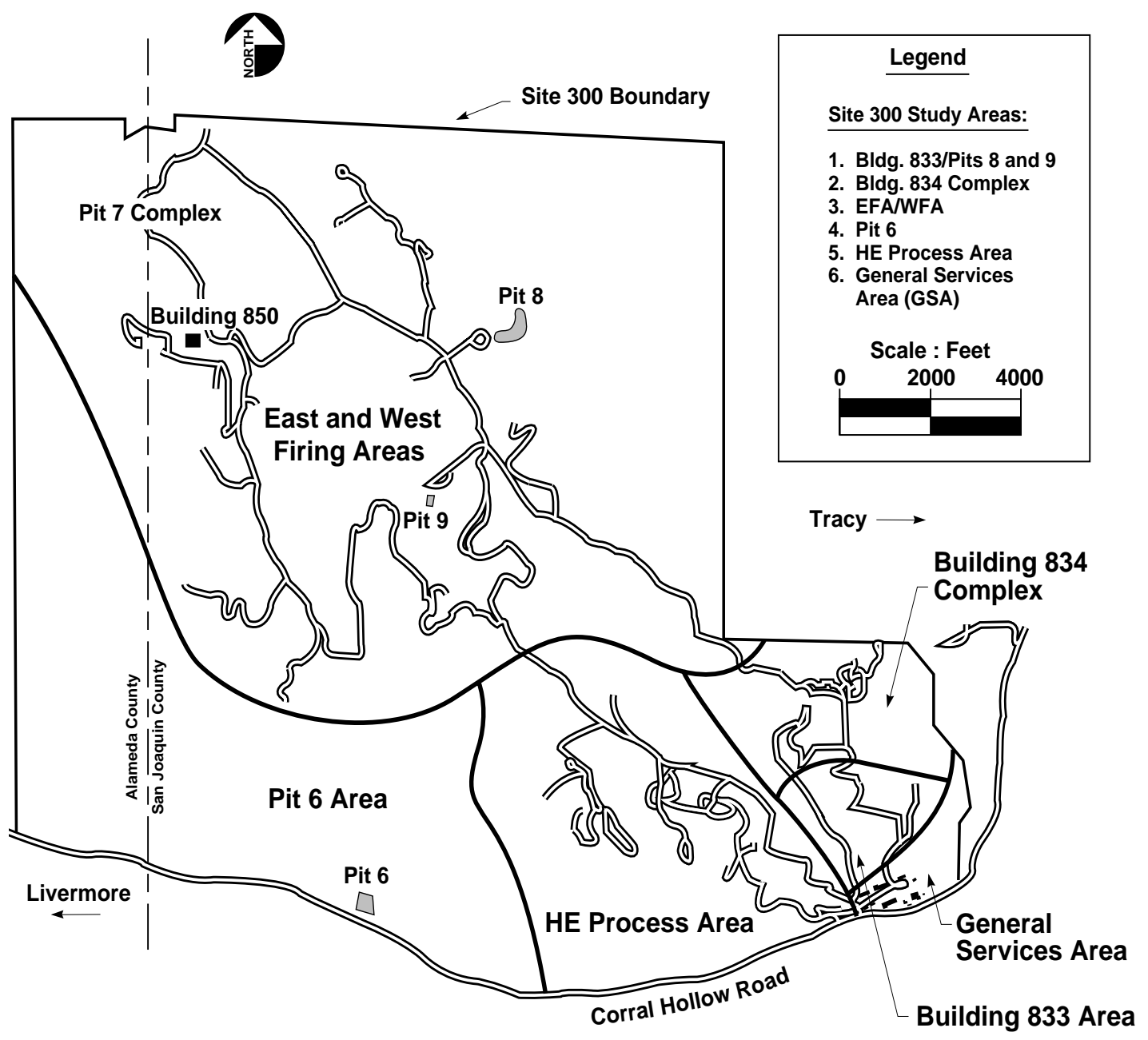

Figure 2-7. Study areas at LLNL Site 300 at the time of the Site-Wide Remedial Investigation Report (Webster-Scholten et al. 1994). 
model was developed to describe volatilization flux of a contaminant through porous soil where the soil surface is exposed to a relatively uncontaminated turbulent atmosphere. Hwang, Falco and Nauman's model is based on the assumptions that: 1) movement of the contaminant through soil occurs only by vapor-phase diffusion; 2) contaminant vapor in the soil is in equilibrium with soil solids and pore water; and 3) contamination exists at the soil surface and extends to an infinite depth. LLNL used the 95\% upper confidence limit (UCL) of the mean VOC concentrations in soil down to a depth of 12 feet as the source term. The average flux rate at the soil surface was defined as:

$$
N_{S}=\left(2 \times P_{S} \times D_{e} \times C_{S} \times H \times 41 \times 10^{-6}\right) \div\left[K_{d} \times(\pi \times C T \times E D)^{0.5}\right]
$$

where:

$$
\begin{aligned}
& \mathrm{N}_{\mathrm{S}}=\text { average volatilization rate of VOC from soil }\left(\mathrm{g} / \mathrm{cm}^{2} \bullet \mathrm{sec}\right) \text { obtained by } \\
& \text { integrating the flux rate at the soil/air interface over an exposure interval; } \\
& \mathrm{P}_{\mathrm{S}}=\text { total soil porosity, dimensionless; } \\
& \mathrm{D}_{\mathrm{e}}=\text { effective diffusivity of VOC in air }\left(\mathrm{cm}^{2} / \mathrm{sec}\right) \text {; } \\
& \mathrm{C}_{\mathrm{S}}=\text { concentration of VOC in soil }(\mathrm{mg} / \mathrm{kg}) \text {; } \\
& \mathrm{H}=\quad \text { Henry's law constant }\left(\mathrm{atm} \cdot \mathrm{m}^{3} / \mathrm{mol}\right) \text {; } \\
& 41=\text { factor for converting Henry's law constant, } \mathrm{H}\left(\mathrm{atm} \cdot \mathrm{m}^{3} / \mathrm{mol}\right) \text { to its dimensionless } \\
& \text { form, } \mathrm{H}^{\prime} \text {, where } \mathrm{H}^{\prime}=\mathrm{H} \times 1 / \mathrm{RT}, \mathrm{R}=8.2 \times 10^{-5} \mathrm{~atm} \bullet \mathrm{m}^{3} / \mathrm{mol}^{\circ} \mathrm{K} \text {, and } \mathrm{T}=298^{\circ} \mathrm{K} \text {; } \\
& 10^{-6}=\text { factor to convert concentration of VOC in soil, } \mathrm{C}_{\mathrm{S}} \text {, from } \mathrm{mg} / \mathrm{kg} \text { to } \mathrm{g} / \mathrm{g} \text {; } \\
& \mathrm{K}_{\mathrm{d}}=\text { adsorption coefficient of contaminant in soil }\left(\mathrm{cm}^{3} / \mathrm{g}\right) \text {; } \\
& \pi=\quad \text { the value pi }(3.14) \\
& \mathrm{ED}=\quad \text { exposure duration }(\mathrm{sec}) ; \text { and } \\
& \mathrm{CT}=\text { a conversion term }\left(\mathrm{cm}^{2} / \mathrm{sec}\right) \text { defined as: }
\end{aligned}
$$




$$
C T=\frac{\mathrm{D}_{\mathrm{e}} \times \mathrm{P}_{\mathrm{s}}}{\mathrm{P}_{\mathrm{s}}+\left[\mathrm{B} \times\left(1-\mathrm{P}_{\mathrm{s}}\right)\right] \times\left[\mathrm{K}_{\mathrm{d}} /(41 \times \mathrm{H})\right]}
$$

Eq. 2-18

where:

$\mathrm{B}=\quad$ soil bulk density $\left(1.39 \mathrm{~g} / \mathrm{cm}^{3}\right)$, the mean site-specific values.

To convert flux rate to an emission rate for input to the point-source air dispersion model described in Turner (1982), the area of contaminated soil was accounted for using:

$$
\mathrm{Q}_{\mathrm{S}}=\mathrm{N}_{\mathrm{S}} \times \mathrm{A}
$$

where:

$\mathrm{Q}_{\mathrm{S}}=$ emission rate of contaminant from soil $(\mathrm{g} / \mathrm{sec})$

$\mathrm{N}_{\mathrm{S}}=$ flux rate of VOC from soil $\left(\mathrm{g} / \mathrm{cm}^{2} \cdot \mathrm{sec}\right)$

$A=\quad$ surface area of the contaminated soil $\left(\mathrm{cm}^{2}\right)$.

The concentration of a contaminant downwind of a point source was estimated using a Gaussian-dispersion model that predicts the ground-level concentration of a contaminant along the centerline of a plume. This model is based on the assumptions that: 1) pointsource emissions of the contaminant are steady and continuous; 2) wind speed is constant and in a single direction; 3) no deposition of the contaminant occurs during transport from the point source to the receptor; and 4) a relatively uniform concentration of the contaminant is present throughout the width of the plume (Webster-Scholten et al. 1994).

From Turner (1982), the annual average ground-level concentration at a distance, $r$, from a point source, $\mathrm{Q}_{\mathrm{X}}$, can be calculated as:

$$
\mathrm{C}_{\mathrm{a}}=\frac{\mathrm{Q}_{\mathrm{x}}}{\mathrm{L} \times \mu \times \mathrm{S}_{\mathrm{y}}(\mathrm{r})}
$$

where: 
$C_{a}=$ annual-average ground-level concentration $\left(\mathrm{mg} / \mathrm{m}^{3}\right)$;

$\mathrm{Q}_{\mathrm{X}}=\quad$ annual-average emission rate from a point source $(\mathrm{mg} / \mathrm{sec}) ;$

$\mathrm{L}=\quad$ annual-average mixing height $(\mathrm{m}) ;$

$\mu=\quad$ annual-average wind speed $(\mathrm{m} / \mathrm{sec})$;

$\mathrm{r}=\quad$ distance from the point source $(\mathrm{m})$ : and

$\mathrm{S}_{\mathrm{y}}(\mathrm{r})=$ annual-average standard deviation across the plume width, $\mathrm{S}_{\mathrm{y}}$, as a function of distance, $r$, in one of 16 downwind sectors in meters can be determined by:

$$
\mathrm{S}_{\mathrm{y}}(\mathrm{r})=(2 \pi \mathrm{r}) \div 16
$$

In the SWRI report, it was assumed that the concentration of an environmental contaminant does not change over time. The average intake attributable to a specific exposure pathway was determined using Equations 2-1 and 2-2.

In the SWRI report, excess individual lifetime risk and noncancer hazard index (HI) for each exposure location were calculated based on the type of associated adverse health affect. For carcinogens, the PEFs were multiplied by the chemical specific exposure point concentrations to obtain pathway-specific intakes for each chemical. Each pathway-specific intake was multiplied by the maximum pathway-specific cancer potency (slope) factor (CPF) to obtain the pathway-specific estimate of risk. The risk associated with inhalation of VOCs was estimated by summing the pathway-specific risk for each chemical. For noncarcinogens and those carcinogens that are known to cause adverse health effects other than cancer, the potential for exposure to result in noncarcinogenic adverse health effects was evaluated by comparing the chronic daily intake (CDI) with a reference dose (RfD). The CDI was calculated using the chemical specific exposure point concentrations multiplied by a PEF. The averaging time used to calculate the PEF differs for carcinogens and noncarcinogens. Therefore separate PEFs were calculated for carcinogens and noncarcinogens. 
To evaluate the potential for noncarcinogenic adverse health effects from simultaneous exposure to multiple chemicals, the HQs for all chemicals were summed, yielding a hazard index (HI). When the HI or HQ exceeds 1, it is indicative of the potential for adverse noncarcinogenic health effects to occur (Webster-Scholten et al. 1994). The estimated exposure point concentrations, pathway exposure factors, pathwayspecific cancer potency (slope) factors, and cancer risk presented in the SWRI report are summarized in Table 2-2. The estimated exposure point concentrations, noncarcinogenic pathway exposure factors, chronic daily intake, reference dose, hazard quotient, and hazard index presented in the SWRI report are summarized in Table 2-3. In the SWRI report, the predicted adult on-site worker individual lifetime cancer risk attributable to inhalation of VOCs that volatilized from the subsurface was $6 \times 10^{-4}$ for the Building 834D in the Building 834 study area, $2 \times 10^{-4}$ for Building $854 \mathrm{~F}$ in the EWFA study area, $1 \times 10^{-4}$ in the vicinity of the debris trenches in the GSA study area, and $3 \times 10^{-6}, 5$ $\times 10^{-6}$, and $2 \times 10^{-7}$ for the vicinity of the Paper Canyon, Rifle Range, and Spring 7 in the Pit 6 Study Area, respectively. The Superfund National Contingency Plan states that, for known or suspected carcinogens, acceptable exposure levels are generally concentration levels that represent an excess, upper bound, lifetime cancer risk to an individual of between $10^{-4}$ and $10^{-6}$ (Rueth and Berry 1995). Based on the National Contingency Plan's acceptable exposure levels for known or suspected carcinogens, Building 834D, Building 854F, and the debris trenches in the GSA study area have concentration levels that represent an unacceptable excess lifetime cancer risk to an individual due to inhalation of VOCs from the subsurface soil. In addition, the HIs calculated for the inhalation of VOCs volatilizing from the subsurface of $2.17 \times 10^{1}$ and 8.75 for Buildings $834 \mathrm{D}$ and $854 \mathrm{~F}$, respectively, represent a potential for adverse noncarcinogenic health effects to occur. TCE drives the cancer and noncancer risks. 
Table 2-2. Calculation of excess individual lifetime cancer risk attributable to inhalation of VOCs that volatilize from subsurface soil to outdoor ambient air as reported in the LLNL Site 300 Site-Wide Remedial Investigation Report (WebsterScholten et al. 1994).

\begin{tabular}{|c|c|c|c|c|c|}
\hline Chemical & $\begin{array}{c}\text { Exposure-pt. } \\
\text { Conc. } \\
\left(\mathbf{m g} / \mathbf{m}^{3}\right)\end{array}$ & $\begin{array}{c}\text { PEF }^{\mathbf{a}} \\
{\left[\mathrm{m}^{3} /\left(\mathrm{kg}^{\prime} \cdot \mathrm{d}\right)\right]}\end{array}$ & $\begin{array}{c}\text { Dose } \\
{[\mathrm{mg} /(\mathrm{kg} \cdot \mathrm{d})]}\end{array}$ & $\begin{array}{c}\text { Slope } \\
\text { Factor for } \\
\text { Risk }\end{array}$ & $\begin{array}{c}70-y r \\
\text { Lifetime } \\
\text { Cancer } \\
\text { Risk }\end{array}$ \\
\hline \multicolumn{6}{|c|}{ Vicinity of Building $834 D$ in the Building 834 Study Area } \\
\hline Benzene & $3.46 \mathrm{E}-06$ & 6.99E-02 & $2.42 \mathrm{E}-07$ & $1.00 \mathrm{E}-01$ & $2.42 \mathrm{E}-08$ \\
\hline Ethylbenzene & 5.38E-06 & $1.96 \mathrm{E}-01$ & $1.05 \mathrm{E}-06$ & $\mathrm{NC}$ & NA \\
\hline Freon 11 & $5.47 \mathrm{E}-03$ & $1.96 \mathrm{E}-01$ & $1.07 \mathrm{E}-03$ & $\mathrm{NC}$ & NA \\
\hline PCE & $2.29 \mathrm{E}-02$ & 6.99E-02 & $1.60 \mathrm{E}-03$ & $5.10 \mathrm{E}-02$ & $8.17 \mathrm{E}-05$ \\
\hline Toluene & $1.49 \mathrm{E}-05$ & $1.96 \mathrm{E}-01$ & $2.92 \mathrm{E}-06$ & $\mathrm{NC}$ & NA \\
\hline TCE & $7.98 \mathrm{E}-01$ & 6.99E-02 & $5.58 \mathrm{E}-02$ & $1.00 \mathrm{E}-02$ & $5.58 \mathrm{E}-04$ \\
\hline Xylenes & $1.21 \mathrm{E}-04$ & $1.96 \mathrm{E}-01$ & 2.38E-05 & ${ }^{\mathrm{NC}}{ }_{\sum \mathrm{Ri}}$ & $\begin{array}{c}\text { NA } \\
=6.40 \mathrm{E}-04\end{array}$ \\
\hline \multicolumn{6}{|c|}{ Study Area } \\
\hline Benzene & $4.21 \mathrm{E}-04$ & 6.99E-02 & $2.94 \mathrm{E}-05$ & $1.00 \mathrm{E}-01$ & 2.94E-06 \\
\hline Chloroform & $5.32 \mathrm{E}-05$ & 6.99E-02 & $3.72 \mathrm{E}-06$ & 8.10E-02 & $3.01 \mathrm{E}-07$ \\
\hline 1,2-DCE & $5.08 \mathrm{E}-05$ & $1.96 \mathrm{E}-01$ & 9.95E-06 & NA & NA \\
\hline Ethylbenzene & $5.39 \mathrm{E}-05$ & $1.96 \mathrm{E}-01$ & $1.06 \mathrm{E}-05$ & NA & NA \\
\hline PCE & $3.94 \mathrm{E}-05$ & 6.99E-02 & $2.75 \mathrm{E}-06$ & $5.10 \mathrm{E}-02$ & $1.40 \mathrm{E}-07$ \\
\hline Toluene & 4.33E-04 & $1.96 \mathrm{E}-01$ & 8.48E-05 & NA & NA \\
\hline TCE & $1.17 \mathrm{E}-05$ & 6.99E-02 & $8.15 \mathrm{E}-07$ & $1.00 \mathrm{E}-02$ & $8.15 \mathrm{E}-09$ \\
\hline Xylenes & $5.63 \mathrm{E}-05$ & $1.96 \mathrm{E}-01$ & $1.10 \mathrm{E}-05$ & ${ }^{\mathrm{NA}}{ }_{\sum \mathrm{Ri}}$ & $\begin{array}{c}\text { NA } \\
=3.39 \mathrm{E}-06\end{array}$ \\
\hline \multicolumn{6}{|c|}{ Vicinity of the Rifle Range in the Pit 6 Study Area } \\
\hline 1,2-DCE & 7.58E-06 & 1.96E-01 & $1.49 \mathrm{E}-06$ & NA & NA \\
\hline Chloroform & 1.99E-04 & 6.99E-02 & 1.39E-05 & 8.10E-02 & $1.13 \mathrm{E}-06$ \\
\hline Freon 113 & $4.58 \mathrm{E}-04$ & $1.96 \mathrm{E}-01$ & 8.98E-05 & NA & NA \\
\hline $\mathrm{MeCl} 2$ & $1.62 \mathrm{E}-05$ & 6.99E-02 & $1.13 \mathrm{E}-06$ & $3.50 \mathrm{E}-03$ & $3.96 \mathrm{E}-09$ \\
\hline PCE & $6.56 \mathrm{E}-04$ & 6.99E-02 & 4.59E-05 & $5.10 \mathrm{E}-02$ & 2.34E-06 \\
\hline $1,1,1-\mathrm{TCA}$ & $4.25 \mathrm{E}-06$ & $1.96 \mathrm{E}-01$ & 8.34E-07 & NA & NA \\
\hline TCE & $1.96 \mathrm{E}-03$ & $6.99 \mathrm{E}-02$ & 1.37E-04 & $1.00 \mathrm{E}-02$ & $1.37 \mathrm{E}-06$ \\
\hline Freon 11 & $5.27 \mathrm{E}-05$ & $1.96 \mathrm{E}-01$ & $1.03 \mathrm{E}-05$ & ${ }^{\mathrm{NA}}{ }_{\sum \mathrm{Ri}}$ & $\begin{array}{c}\text { NA } \\
=4.84 \mathrm{E}-06\end{array}$ \\
\hline \multicolumn{6}{|c|}{ Vicinity of spring 7 in the Pit 6 Study Area } \\
\hline Ethylbenzene & 4.61E-06 & $1.96 \mathrm{E}-01$ & $9.04 \mathrm{E}-07$ & NA & NA \\
\hline PCE & $1.01 \mathrm{E}-05$ & 6.99E-02 & 7.03E-07 & $5.10 \mathrm{E}-02$ & $3.58 \mathrm{E}-08$ \\
\hline Toluene & $6.19 \mathrm{E}-05$ & $1.96 \mathrm{E}-01$ & $1.21 \mathrm{E}-05$ & NA & NA \\
\hline TCE & $2.44 \mathrm{E}-04$ & 6.99E-02 & $1.71 \mathrm{E}-05$ & $1.00 \mathrm{E}-02$ & $1.71 \mathrm{E}-07$ \\
\hline Xylenes & $3.16 \mathrm{E}-05$ & $1.96 \mathrm{E}-01$ & $6.19 \mathrm{E}-06$ & ${ }^{\mathrm{NA}}{ }_{\sum \mathrm{Ri}}$ & $\begin{array}{c}\text { NA } \\
=2.07 \mathrm{E}-07\end{array}$ \\
\hline \multicolumn{6}{|c|}{ Vicinity of Building 815 (outside) in the HE Study Area } \\
\hline $\mathrm{MeCl} 2$ & $1.35 \mathrm{E}-04$ & 6.99E-02 & $9.41 \mathrm{E}-06$ & $3.50 \mathrm{E}-03$ & 3.29E-08 \\
\hline PCE & 3.89E-04 & 6.99E-02 & 2.72E-05 & $5.10 \mathrm{E}-02$ & 1.39E-06 \\
\hline Toluene & $3.27 \mathrm{E}-05$ & $1.96 \mathrm{E}-01$ & $6.40 \mathrm{E}-06$ & NA & NA \\
\hline TCE & $5.27 \mathrm{E}-03$ & 6.99E-02 & 3.68E-04 & $1.00 \mathrm{E}-02$ & $3.68 \mathrm{E}-06$ \\
\hline Freon 11 & $1.55 \mathrm{E}-03$ & $1.96 \mathrm{E}-01$ & 3.04E-04 & NA & NA \\
\hline Xylenes & $6.64 \mathrm{E}-05$ & $1.96 \mathrm{E}-01$ & $1.30 \mathrm{E}-05$ & ${ }_{2}^{\mathrm{NA}}$ & $\begin{array}{c}\text { NA } \\
=5.10 \mathrm{E}-06\end{array}$ \\
\hline
\end{tabular}


Table 2-2. Continued.

\begin{tabular}{|c|c|c|c|c|c|}
\hline Chemical & $\begin{array}{c}\text { Exposure-pt. } \\
\text { Conc. } \\
\left(\mathbf{m g} / \mathrm{m}^{3}\right)\end{array}$ & $\begin{array}{c}\text { PEF }^{\mathbf{a}} \\
{\left[\mathrm{m}^{3} /\left(\mathrm{kg}^{\prime} \cdot \mathrm{d}\right)\right]}\end{array}$ & $\begin{array}{c}\text { Dose } \\
{[\mathrm{mg} /(\mathbf{k g} \bullet \mathrm{d})]}\end{array}$ & $\begin{array}{c}\text { Slope } \\
\text { Factor for } \\
\text { Risk }\end{array}$ & $\begin{array}{c}\text { 70-yr } \\
\text { Lifetime } \\
\text { Cancer } \\
\text { Risk }\end{array}$ \\
\hline \multicolumn{6}{|c|}{ Vicinity of Building $854 F$ in the EWFA Study Area } \\
\hline TCE & $3.28 \mathrm{E}-01$ & 6.99E-02 & $2.29 \mathrm{E}-02$ & \multicolumn{2}{|c|}{$\sum$ Risk $=2.29 \mathrm{E}-04$} \\
\hline \multicolumn{6}{|c|}{ Vicinity of the debris burial trench in the GSA Study Area } \\
\hline Chloroform & $1.35 \mathrm{E}-02$ & $6.99 \mathrm{E}-02$ & $9.41 \mathrm{E}-04$ & $8.10 \mathrm{E}-02$ & 7.62E-05 \\
\hline Freon 113 & $5.53 \mathrm{E}-03$ & $1.96 \mathrm{E}-01$ & $1.08 \mathrm{E}-03$ & $\mathrm{NC}$ & NA \\
\hline $\mathrm{MeCl} 2$ & $6.23 \mathrm{E}-03$ & $6.99 \mathrm{E}-02$ & $4.36 \mathrm{E}-04$ & $3.50 \mathrm{E}-03$ & $1.52 \mathrm{E}-06$ \\
\hline PCE & $1.18 \mathrm{E}-02$ & $6.99 \mathrm{E}-02$ & $8.28 \mathrm{E}-04$ & $5.10 \mathrm{E}-02$ & $4.22 \mathrm{E}-05$ \\
\hline Toluene & $6.68 \mathrm{E}-03$ & $1.96 \mathrm{E}-01$ & $1.31 \mathrm{E}-03$ & $\mathrm{NC}$ & NA \\
\hline TCE & $1.24 \mathrm{E}-02$ & $6.99 \mathrm{E}-02$ & $8.65 \mathrm{E}-04$ & $1.00 \mathrm{E}-02$ & 8.65E-06 \\
\hline Freon 11 & $7.01 \mathrm{E}-03$ & $1.96 \mathrm{E}-01$ & $1.37 \mathrm{E}-03$ & \multicolumn{2}{|c|}{$\begin{array}{l}\mathrm{C} \text { NA } \\
\sum \text { Risk }=1.29 \mathrm{E}-04\end{array}$} \\
\hline
\end{tabular}

a Pathway Exposure Factor.

$\mathrm{NC}$ Indicates not carcinogenic.

NA Indicates the parameter is not applicable. 
Table 2-3. Calculation of noncancer hazard index attributable to inhalation of VOCs that volatilize from subsurface soil to outdoor ambient air as reported in the LLNL Site 300 Site-Wide Remedial Investigation (Webster-Scholten et al. 1994).

\begin{tabular}{|c|c|c|c|c|c|}
\hline$\overline{\text { Chemical }}$ & $\begin{array}{c}\text { Exposure-pt. } \\
\text { Conc. } \\
\left(\mathrm{mg} / \mathrm{m}^{3}\right)\end{array}$ & $\begin{array}{c}\text { PEF }^{\mathbf{a}} \\
{\left[\mathrm{m}^{3} /\left(\mathrm{kg}^{\prime} \cdot \mathrm{d}\right)\right]}\end{array}$ & $\begin{array}{c}\text { Dose } \\
{[\mathrm{mg} /(\mathrm{kg} \cdot \mathrm{d})]}\end{array}$ & $\begin{array}{c}\text { Chronic } \\
\text { Reference } \\
\text { Dose (RfD) } \\
{[\text { mg/(kg•d)] }}\end{array}$ & $\begin{array}{c}\text { Hazard } \\
\text { Quotient } \\
\text { (Dose/RfD) }\end{array}$ \\
\hline \multicolumn{6}{|c|}{ Vicinity of Building $834 D$ in the Building 834 Study Area } \\
\hline Benzene & $3.46 \mathrm{E}-06$ & $1.96 \mathrm{E}-01$ & $6.78 \mathrm{E}-07$ & NA & NA \\
\hline Ethylbenzene & $5.38 \mathrm{E}-06$ & $1.96 \mathrm{E}-01$ & $1.05 \mathrm{E}-06$ & $1.00 \mathrm{E}-01$ & $1.05 \mathrm{E}-05$ \\
\hline Freon 11 & $5.47 \mathrm{E}-03$ & $1.96 \mathrm{E}-01$ & $1.07 \mathrm{E}-03$ & $2.00 \mathrm{E}-01$ & $5.36 \mathrm{E}-03$ \\
\hline PCE & $2.29 \mathrm{E}-02$ & $1.96 \mathrm{E}-01$ & 4.49E-03 & $1.00 \mathrm{E}-02$ & 4.49E-01 \\
\hline Toluene & $1.49 \mathrm{E}-05$ & $1.96 \mathrm{E}-01$ & $2.92 \mathrm{E}-06$ & $2.00 \mathrm{E}-01$ & $1.46 \mathrm{E}-05$ \\
\hline $\mathrm{TCE}$ & $7.98 \mathrm{E}-01$ & $1.96 \mathrm{E}-01$ & $1.56 \mathrm{E}-01$ & 7.35E-03 & $2.13 \mathrm{E}+01$ \\
\hline Xylenes & $1.21 \mathrm{E}-04$ & $1.96 \mathrm{E}-01$ & $2.38 \mathrm{E}-05$ & \multicolumn{2}{|c|}{ Hazard Index $=2.17 \mathrm{E}+01$} \\
\hline \multicolumn{6}{|c|}{ Vicinity of Paper Canyon in the Pit 6 Study Area } \\
\hline Benzene & $4.21 \mathrm{E}-04$ & $1.96 \mathrm{E}-01$ & 8.25E-05 & NA & NA \\
\hline Chloroform & $5.32 \mathrm{E}-05$ & $1.96 \mathrm{E}-01$ & $1.04 \mathrm{E}-05$ & $1.00 \mathrm{E}-02$ & $1.04 \mathrm{E}-03$ \\
\hline $1,2-\mathrm{DCE}$ & $5.08 \mathrm{E}-05$ & $1.96 \mathrm{E}-01$ & 9.95E-06 & $1.00 \mathrm{E}-02$ & $9.95 \mathrm{E}-04$ \\
\hline Ethylbenzene & $5.39 \mathrm{E}-05$ & $1.96 \mathrm{E}-01$ & $1.06 \mathrm{E}-05$ & $1.00 \mathrm{E}-01$ & $1.06 \mathrm{E}-04$ \\
\hline PCE & $3.94 \mathrm{E}-05$ & $1.96 \mathrm{E}-01$ & 7.72E-06 & $1.00 \mathrm{E}-02$ & 7.72E-04 \\
\hline Toluene & $4.33 \mathrm{E}-04$ & $1.96 \mathrm{E}-01$ & 8.48E-05 & 2.00E-01 & 4.24E-04 \\
\hline TCE & $1.17 \mathrm{E}-05$ & $1.96 \mathrm{E}-01$ & 2.28E-06 & 7.35E-03 & $3.11 \mathrm{E}-04$ \\
\hline Xylenes & $5.63 \mathrm{E}-05$ & $1.96 \mathrm{E}-01$ & $1.10 \mathrm{E}-05$ & $2.00 \mathrm{E}+00$ & $5.52 \mathrm{E}-06$ \\
\hline \multicolumn{6}{|c|}{ Vicinity of the Rifle Range in the Pit 6 Study Area } \\
\hline $1,1,1-\mathrm{TCA}$ & $4.25 \mathrm{E}-06$ & $1.96 \mathrm{E}-01$ & $8.34 \mathrm{E}-7$ & $3.00 \mathrm{E}-01$ & $2.78 \mathrm{E}-06$ \\
\hline \multicolumn{6}{|c|}{ Vicinity of the Rifle Range in the Pit 6 Study Area Continued } \\
\hline 1,2-DCE & $7.58 \mathrm{E}-06$ & 1.96E-01 & 1.49E-06 & $1.00 \mathrm{E}-02$ & 1.49E-04 \\
\hline Chloroform & $1.99 \mathrm{E}-04$ & $1.96 \mathrm{E}-01$ & 3.90E-05 & $1.00 \mathrm{E}-02$ & $3.90 \mathrm{E}-03$ \\
\hline Freon 113 & $4.58 \mathrm{E}-04$ & $1.96 \mathrm{E}-01$ & 8.98E-05 & $3.00 \mathrm{E}+01$ & 2.99E-06 \\
\hline $\mathrm{MeCl} 2$ & $1.62 \mathrm{E}-05$ & $1.96 \mathrm{E}-01$ & $3.17 \mathrm{E}-06$ & $6.00 \mathrm{E}-02$ & $5.28 \mathrm{E}-05$ \\
\hline PCE & $6.56 \mathrm{E}-04$ & $1.96 \mathrm{E}-01$ & 1.29E-04 & $1.00 \mathrm{E}-02$ & 1.29E-02 \\
\hline TCE & $1.96 \mathrm{E}-03$ & $1.96 \mathrm{E}-01$ & $3.85 \mathrm{E}-04$ & 7.35E-03 & $5.23 \mathrm{E}-02$ \\
\hline Freon 11 & $5.27 \mathrm{E}-05$ & $1.96 \mathrm{E}-01$ & $1.03 \mathrm{E}-05$ & $\begin{array}{l}2.00 \mathrm{E}-01 \\
\text { Hazard Ind }\end{array}$ & $\begin{array}{l}5.17 \mathrm{E}-05 \\
\times=6.94 \mathrm{E}-02\end{array}$ \\
\hline \multicolumn{6}{|c|}{ Vicinity of spring 7 in the Pit 6 Study Area } \\
\hline Ethylbenzene & $4.61 \mathrm{E}-06$ & $1.96 \mathrm{E}-01$ & 9.04E-07 & $1.00 \mathrm{E}-01$ & 9.04E-06 \\
\hline PCE & $1.01 \mathrm{E}-05$ & $1.96 \mathrm{E}-01$ & $1.97 \mathrm{E}-06$ & $1.00 \mathrm{E}-02$ & $1.97 \mathrm{E}-04$ \\
\hline Toluene & $6.19 \mathrm{E}-05$ & $1.96 \mathrm{E}-01$ & $1.21 \mathrm{E}-05$ & $2.00 \mathrm{E}-01$ & $6.06 \mathrm{E}-05$ \\
\hline TCE & $2.44 \mathrm{E}-04$ & $1.96 \mathrm{E}-01$ & 4.79E-05 & 7.35E-03 & $6.51 \mathrm{E}-03$ \\
\hline Xylenes & $3.16 \mathrm{E}-05$ & $1.96 \mathrm{E}-01$ & $6.19 \mathrm{E}-06$ & $\begin{array}{l}2.00 \mathrm{E}+00 \\
\text { Hazard Ind }\end{array}$ & $\begin{array}{c}3.10 \mathrm{E}-06 \\
\times=6.78 \mathrm{E}-03\end{array}$ \\
\hline \multicolumn{6}{|c|}{ Vicinity of Building 815 (outside) in the HE Study Area } \\
\hline Freon 11 & $1.55 \mathrm{E}-03$ & $1.96 \mathrm{E}-01$ & $3.04 \mathrm{E}-04$ & $2.00 \mathrm{E}-01$ & $1.52 \mathrm{E}-03$ \\
\hline $\mathrm{MeCl} 2$ & $1.35 \mathrm{E}-04$ & $1.96 \mathrm{E}-01$ & $2.64 \mathrm{E}-05$ & $6.00 \mathrm{E}-02$ & 4.40E-04 \\
\hline PCE & $3.89 \mathrm{E}-04$ & $1.96 \mathrm{E}-01$ & 7.63E-05 & $1.00 \mathrm{E}-02$ & 7.63E-03 \\
\hline Toluene & $3.27 \mathrm{E}-05$ & $1.96 \mathrm{E}-01$ & $6.40 \mathrm{E}-06$ & 2.00E-01 & $3.20 \mathrm{E}-05$ \\
\hline TCE & $5.27 \mathrm{E}-03$ & $1.96 \mathrm{E}-01$ & $1.03 \mathrm{E}-03$ & 7.35E-03 & $1.40 \mathrm{E}-01$ \\
\hline Xylenes & $6.64 \mathrm{E}-05$ & $1.96 \mathrm{E}-01$ & $1.30 \mathrm{E}-05$ & \multicolumn{2}{|c|}{ Hazard Index $=1.50 \mathrm{E}-01$} \\
\hline
\end{tabular}


Table 2-3. Continued.

\begin{tabular}{|c|c|c|c|c|c|}
\hline Chemical & $\begin{array}{c}\text { Exposure-pt. } \\
\text { Conc. } \\
\left(\mathrm{mg} / \mathrm{m}^{3}\right)\end{array}$ & $\begin{array}{c}\text { PEF }^{\mathbf{a}} \\
{\left[\mathrm{m}^{3} /(\mathrm{kg} \cdot \mathrm{d})\right]}\end{array}$ & $\begin{array}{c}\text { Dose } \\
{[\mathrm{mg} /(\mathbf{k g} \cdot \mathbf{d})]}\end{array}$ & $\begin{array}{c}\text { Chronic } \\
\text { Reference } \\
\text { Dose }(\text { RfD) } \\
{[\mathrm{mg} /(\mathbf{k g} \bullet \mathbf{d})]}\end{array}$ & $\begin{array}{c}\text { Hazard } \\
\text { Quotient } \\
\text { (Dose/RfD) }\end{array}$ \\
\hline \multicolumn{6}{|c|}{ Vicinity of Building $854 F$ in the EWFA Study Area } \\
\hline TCE & $3.28 \mathrm{E}-01$ & $1.96 \mathrm{E}-01$ & $6.43 \mathrm{E}-02$ & \multicolumn{2}{|c|}{ Hazard Index $=8.75 \mathrm{E}+00$} \\
\hline \multicolumn{6}{|c|}{ Vicinity of the debris burial trench in the GSA Study Area } \\
\hline Chloroform & $1.35 \mathrm{E}-02$ & $1.96 \mathrm{E}-01$ & $2.64 \mathrm{E}-03$ & $1.00 \mathrm{E}-02$ & 2.64E-01 \\
\hline Freon 113 & $5.53 \mathrm{E}-03$ & $1.96 \mathrm{E}-01$ & $1.08 \mathrm{E}-03$ & $3.00 \mathrm{E}+01$ & $3.61 \mathrm{E}-05$ \\
\hline $\mathrm{MeCl} 2$ & $6.23 \mathrm{E}-03$ & $1.96 \mathrm{E}-01$ & $1.22 \mathrm{E}-03$ & $6.00 \mathrm{E}-02$ & 2.04E-02 \\
\hline PCE & $1.18 \mathrm{E}-02$ & $1.96 \mathrm{E}-01$ & 2.32E-03 & $1.00 \mathrm{E}-02$ & 2.32E-01 \\
\hline Toluene & $6.68 \mathrm{E}-03$ & $1.96 \mathrm{E}-01$ & $1.31 \mathrm{E}-03$ & $2.00 \mathrm{E}-01$ & $6.55 \mathrm{E}-03$ \\
\hline TCE & $1.24 \mathrm{E}-02$ & $1.96 \mathrm{E}-01$ & 2.43E-03 & 7.35E-03 & 3.30E-01 \\
\hline Freon 11 & $7.01 \mathrm{E}-03$ & $1.96 \mathrm{E}-01$ & $1.37 \mathrm{E}-03$ & \multicolumn{2}{|c|}{ Hazard Index $=8.60 \mathrm{E}-01$} \\
\hline
\end{tabular}

Pathway Exposure Factor.

NA Indicates the parameter is not available. 
The estimates of risk for adult on-site workers was based on very conservative exposure scenarios and model parameters. The true risk may have been over estimated (WebsterScholten et al. 1994). Some of the sources of error in the SWRI modeling approach as identified by Carlsen, Martins, and McNeel (1996) include: 1) contribution of shallow contaminated ground water or soil contaminants at depths greater than 12 feet was not accounted for, 2) the assumption that contaminant vapor is in equilibrium with soil solids and pore water, 3) the assumption that there was an unlimited contaminant reservoir, and 4) a point-source air dispersion model was used for an area source. Further investigations were conducted in these areas to determine more realistic risk estimates.

\section{LLNL Site 300 General Services Area Feasibility Study (GSA FS)}

In 1995, the Final Feasibility Study for the General Services Area Operable Unit Lawrence Livermore National Laboratory Site 300 was prepared using SWRI data as well as additional data obtained during field work conducted in early- to mid-1994. This study was conducted after the completion of the SWRI to better characterize VOC vapor flux from the soil and better define the release rates of VOC vapor from soil. The ultimate purpose of the GSA Feasibility Study (FS) was to develop and evaluate alternatives for remedial action at the GSA.

In September 1994, VOC soil flux measurements were made in the GSA using EIFC methodology. Flux chamber effluent samples collected in SUMMA ${ }^{\mathrm{TM}}$ canisters were analyzed at an analytical laboratory using EPA method TO14. The flux rates were calculated using Equation 2-12. The measured soil flux rates were used as inputs into an air dispersion model to calculate VOC exposure-point concentrations in ambient air. The exposure-point concentrations were used to calculate VOC inhalation risk. SVS were also conducted to measure soil gas directly. These measurements 1) identified chemicals 
of potential concern that may be emitted to ambient air, 2) were used to calculate a statistically significant 95\% UCL of the mean soil flux emission rates, and 3) were used to conduct a human health exposure assessment (Rueth and Berry 1995).

The SWRI used purely modeled emission rates, while the GSA FS used models that used measured soil flux rates to estimate exposure-point concentrations of VOCs in outdoor air. The GSA FS approach was taken because of the difficulties in accurately estimating VOC vapor flux from soil to air using contaminant data from the subsurface soil, and the modeling uncertainties introduced into the estimates of risk. In addition, there were difficulties directly measuring VOC concentrations in ambient outdoor air due to the continued industrial use of VOC solvents and fuels in the area.

A simple box model from the American Society for Testing and Materials (ASTM), Emergency Standard Guide for Risked-Based Corrective Action Applied at Petroleum Release Sites (ASTM 1994) was used to estimate exposure-point concentrations of VOCs in ambient air. The box model was chosen because it estimates exposure-point concentrations in outdoor air for receptors in the immediate vicinity and directly over the GSA. Other standard air dispersion models would not be applicable because these models are intended to estimate exposure concentrations at larger distances from the source. The box model is simple to apply, but the ASTM default assumptions are very conservative. The measured VOC soil vapor flux rates were determined using emission isolation flux chamber methodology. The $95 \%$ UCL of the mean measured VOC soil vapor flux from each sampling zone were used as model inputs. This simply applied box model resulted in very conservative exposure estimates. The actual air concentrations corresponding to the measured VOC soil flux emissions were expected to be lower than those estimated by the application of this model (Rueth and Berry 1995).

The model, taken from ASTM (1994) is as follows:

$$
\mathrm{C}_{\text {outdoor }}=\left(\mathrm{E}_{\mathrm{i}} \bullet \mathrm{L}\right) /\left(\mathrm{U}_{\mathrm{W}} \bullet \mathrm{H}_{\mathrm{m}}\right)
$$


where:

$\mathrm{C}_{\text {outdoor }}=$ VOC concentration resulting from the area vapor source $\left(\mu \mathrm{g} / \mathrm{m}^{3}\right)$;

$E_{i}=\quad$ emission rate of VOC soil flux from the area source $\left(\mu \mathrm{g} / \mathrm{m}^{2} \bullet \mathrm{sec}\right)$;

$\mathrm{L}=\quad$ downwind length of the emission source (site specific);

$\mathrm{U}_{\mathrm{W}}=\quad$ average wind speed within the mixing zone (ASTM default value); and

$\mathrm{H}_{\mathrm{m}}=\quad$ ambient air mixing zone height (ASTM default value).

The flux rates, exposure-point concentrations, risk, and hazard values calculated in the GSA FS (Rueth and Berry 1995) using measured flux rates for the volatilization of VOCs from the soil to the atmosphere are summarized in Table 2-4. Flux measurements were obtained in three locations in the GSA, the Building 875 dry well area, the central GSA, and the eastern GSA. Adult employees of LLNL who work outdoors in the GSA could be exposed to contaminants in outdoor air in the vicinity of the Building 875 dry well area resulting in a total cancer risk of $2 \times 10^{-7}$ and a $\mathrm{HI}$ of $6.2 \times 10^{-3}$. The excess lifetime cancer risks attributable to exposure to VOCs that flux from the soil to ambient air in the vicinity of the central and eastern GSA are $7 \times 10^{-7}$ and $2 \times 10^{-7}$, respectively. The corresponding HIs are $1.2 \times 10^{-3}$ and $1.3 \times 10^{-3}$. These risk estimates are within acceptable limits.

\section{Summary}

The steps of a Superfund risk assessment are: data evaluation and collection, exposure and toxicity assessment, and risk characterization. During the data collection and evaluation step, the concentration of contaminants in the media of interest are determined for use in the exposure and toxicity assessments. When the media of interest is air, the contaminant concentration can be determined by mathematically modeling soil or ground 
Table 2-4. The $95 \%$ UCL of mean contaminant soil vapor flux and the corresponding estimated potential exposure-point concentration of the contaminant in outdoor air as reported in the General Services Area Feasibility Study (Rueth and Berry 1995).

\begin{tabular}{|c|c|c|c|c|}
\hline$\overline{\text { Chemical }}$ & $\begin{array}{c}95 \% \text { UCL of } \\
\text { Emission } \\
\text { Rate } \\
\left(\mathrm{mg}^{2} \mathbf{m}^{2} \cdot \mathbf{s}\right)\end{array}$ & $\begin{array}{c}\text { Exposure- } \\
\text { point Conc. } \\
\left(\mathrm{mg} / \mathrm{m}^{3}\right)\end{array}$ & $\begin{array}{c}\text { Excess } \\
\text { Individual } \\
70-y r \\
\text { Lifetime } \\
\text { Cancer Risk }\end{array}$ & $\begin{array}{c}\text { Noncancer } \\
\text { Hazard } \\
\text { Quotient } \\
\text { (Dose/RfD) }\end{array}$ \\
\hline \multicolumn{5}{|l|}{ Central GSA } \\
\hline $\begin{array}{l}\text { 1,2,4- } \\
\text { Trimethylbenzene }\end{array}$ & 2.00E-06 & 4.89E-05 & NA & NA \\
\hline $\begin{array}{l}\text { 1,3,5- } \\
\text { Trimethylbenzene }\end{array}$ & 2.10E-06 & $5.13 \mathrm{E}-05$ & NA & NA \\
\hline Benzene & $3.64 \mathrm{E}-06$ & $8.90 \mathrm{E}-05$ & $6.22 \mathrm{E}-07$ & NA \\
\hline Methylene chloride & $1.69 \mathrm{E}-05$ & $4.13 \mathrm{E}-04$ & $1.01 \mathrm{E}-07$ & $9.41 \mathrm{E}-05$ \\
\hline Toluene & $1.37 \mathrm{E}-06$ & $3.35 \mathrm{E}-05$ & NA & $5.97 \mathrm{E}-05$ \\
\hline Trichloroethene & $1.11 \mathrm{E}-06$ & $2.71 \mathrm{E}-05$ & $1.89 \mathrm{E}-08$ & $8.85 \mathrm{E}-04$ \\
\hline Freon 113 & $2.22 \mathrm{E}-04$ & $5.43 \mathrm{E}-03$ & NA & $1.24 \mathrm{E}-04$ \\
\hline $\mathrm{m}$ - and $\mathrm{p}$-Xylenes & $1.97 \mathrm{E}-06$ & $4.82 \mathrm{E}-05$ & NA & 4.72E-05 \\
\hline o-Xylenes & $9.35 \mathrm{E}-07$ & $2.29 \mathrm{E}-05$ & $\begin{array}{c}\text { NA } \\
\sum \text { Risk }=7 \mathrm{E}-07\end{array}$ & $\begin{array}{c}2.24 \mathrm{E}-05 \\
\sum \mathrm{HI}=1.2 \mathrm{E}-03\end{array}$ \\
\hline \multicolumn{5}{|l|}{ Eastern GSA } \\
\hline 1,1,1-Trichloroethane & $1.32 \mathrm{E}-03$ & 2.64E-05 & NA & $1.78 \mathrm{E}-05$ \\
\hline $\begin{array}{l}1,2,4- \\
\text { Trichlorobenzene }\end{array}$ & $1.36 \mathrm{E}-06$ & $2.72 \mathrm{E}-05$ & $\mathrm{NA}$ & NA \\
\hline Freon 12 & $1.12 \mathrm{E}-06$ & $2.24 \mathrm{E}-05$ & NA & $7.70 \mathrm{E}-05$ \\
\hline Methylene chloride & $3.52 \mathrm{E}-05$ & 7.04E-04 & $1.72 \mathrm{E}-07$ & $1.60 \mathrm{E}-04$ \\
\hline Styrene & $1.01 \mathrm{E}-06$ & $2.02 \mathrm{E}-05$ & NA & $1.98 \mathrm{E}-05$ \\
\hline Toluene & $1.27 \mathrm{E}-06$ & $2.54 \mathrm{E}-05$ & NA & $4.53 \mathrm{E}-05$ \\
\hline Trichloroethene & $1.35 \mathrm{E}-06$ & $2.70 \mathrm{E}-05$ & $1.89 \mathrm{E}-08$ & $8.82 \mathrm{E}-04$ \\
\hline Freon 113 & $4.06 \mathrm{E}-05$ & $8.12 \mathrm{E}-04$ & NA & $1.85 \mathrm{E}-05$ \\
\hline $\mathrm{m}$ - and p-Xylenes & $1.63 \mathrm{E}-06$ & $3.26 \mathrm{E}-05$ & $\mathrm{NA}$ & $3.19 \mathrm{E}-05$ \\
\hline o-Xylenes & $1.16 \mathrm{E}-06$ & $2.32 \mathrm{E}-05$ & NA & $2.27 \mathrm{E}-05$ \\
\hline & & & $\sum$ Risk $=2 \mathrm{E}-07$ & $\sum \mathrm{HI}=1.3 \mathrm{E}-03$ \\
\hline \multicolumn{5}{|c|}{ Building 875 dry well area } \\
\hline $\begin{array}{l}\text { 1,2,4- } \\
\text { Trimethylbenzene }\end{array}$ & $1.98 \mathrm{E}-06$ & $2.86 \mathrm{E}-05$ & NA & NA \\
\hline Chloromethane & 4.38E-07 & $6.33 \mathrm{E}-06$ & 2.79E-09 & NA \\
\hline Freon 12 & $1.10 \mathrm{E}-06$ & $1.59 \mathrm{E}-05$ & NA & $5.47 \mathrm{E}-05$ \\
\hline Ethylbenzene & $1.41 \mathrm{E}-06$ & $2.04 \mathrm{E}-05$ & NA & $1.38 \mathrm{E}-05$ \\
\hline Methylene chloride & $1.14 \mathrm{E}-05$ & $1.65 \mathrm{E}-04$ & $4.04 \mathrm{E}-08$ & $3.76 \mathrm{E}-05$ \\
\hline Tetrachloroethene & $1.83 \mathrm{E}-06$ & $2.64 \mathrm{E}-05$ & $3.88 \mathrm{E}-08$ & $5.17 \mathrm{E}-04$ \\
\hline Toluene & $2.97 \mathrm{E}-06$ & $4.29 \mathrm{E}-05$ & NA & 7.64E-05 \\
\hline Trichloroethene & $1.13 \mathrm{E}-05$ & 1.63E-04 & $1.14 \mathrm{E}-07$ & $5.32 \mathrm{E}-03$ \\
\hline Freon 113 & $3.96 \mathrm{E}-05$ & $5.72 \mathrm{E}-04$ & NA & $1.30 \mathrm{E}-05$ \\
\hline m- and p-Xylenes & $1.30 \mathrm{E}-05$ & $1.88 \mathrm{E}-04$ & NA & $1.84 \mathrm{E}-04$ \\
\hline o-Xylenes & $1.39 \mathrm{E}-06$ & $2.01 \mathrm{E}-05$ & NA & $1.97 \mathrm{E}-05$ \\
\hline & & & $\sum$ Risk $=2 \mathrm{E}-07$ & $\sum \mathrm{HI}=6.2 \mathrm{E}-03$ \\
\hline
\end{tabular}

NA Not available or applicable. 
water concentrations, directly monitoring the ambient air, or by measuring the soil emissions to determine flux rates used as inputs into an air dispersion model.

Different mathematical emission models provide varying accuracy in different situations, no one model is best in all cases. Each site-specific situation should be evaluated before a model is selected (USEPA 1988b). This is also true for the various methods for sampling VOCs in air. Because each technique possesses inherent problems including irreversible adsorption, artifact formation, sample contamination and limitations on the type of compounds that can be sampled and recovered (Hutte et al. 1984), some planning and research should be conducted before sampling to determine the most appropriate solid adsorbent or gas container for the conditions and contaminants to be sampled. The two best air sample collection techniques identified during the EPA's study of various sampling media were the SUMMA ${ }^{\mathrm{TM}}$ stainless steel canister and the Tenax GC sampling cartridge. SUMMA ${ }^{\mathrm{TM}}$ canisters gave the highest recoveries for the volatile chemicals in the test group, while Tenax GC performed better for those chemicals with breakthrough volumes larger than the sampling volumes. The EPA also concluded that those two sample collection techniques can compliment each other when sampling a broad spectrum of vapor-phase organics in air (USEPA 1984).

A promising method for monitoring VOC emissions is the emission isolation flux chamber. The EPA has endorsed its use for RCRA (Resource Conservation and Recovery Act) and CERCLA facilities because it is simple, easily available and inexpensive (USEPA 1986 and 1989a).

Once the contaminant concentration, frequently called the exposure-point concentration is determined, the exposure and toxicity assessments can be performed. The exposure-point concentration is used to calculate an average daily intake of the contaminant of concern. The daily intake is then used in the final step of the risk 
assessment to calculate the probability of an individual developing cancer as a result of the exposure to the concentration of the contaminant of concern.

The risk assessment performed by LLNL and documented in the Site 300 SWRI report (Webster-Scholten et al. 1994) used mathematical models to determine the adult on-site worker predicted individual lifetime cancer risk attributable to inhalation of VOCs that volatilized from the subsurface. The three areas that had concentration levels greater then the $10^{-4}$ to $10^{-6}$ acceptable risk range were Building $834 \mathrm{D}$, Building $854 \mathrm{~F}$, and the debris trenches in the GSA study area. The calculated excess lifetime cancer risks attributable to inhalation of VOCs from the subsurface soil for these areas were $6 \times 10^{-4}$ for the Building $834 \mathrm{D}, 2 \times 10^{-4}$ for Building $854 \mathrm{~F}$, and $1 \times 10^{-4}$ in the vicinity of the debris trenches in the GSA study area. In addition to the cancer risk, Buildings 834D and 854F had HIs greater then 1 which indicates a potential for adverse noncarcinogenic health effects to occur. The calculated HIs for the inhalation of VOCs volatilizing from the subsurface were $2.17 \times 10^{1}$ for Building $834 \mathrm{D}$ and 8.75 Building $854 \mathrm{~F}$. The chemical TCE was the main driver for the cancer and noncancer risks.

Because the estimates of risk for adult on-site workers in the SWRI report were believed to be over estimated due to very conservative exposure scenarios and model parameters, a different approach was taken for the GSA FS (Rueth and Berry 1995). The GSA FS approach incorporated measured VOC flux rates with an air dispersion model. The flux rates were measured using a flux chamber. Flux measurements were obtained in three locations in the GSA, the Building 875 dry well area, the central GSA, and the eastern GSA. The GSA FS exposure assessment resulted in much lower cancer and noncancer estimates compared to the SWRI GSA estimates. The GSA FS adult on-site worker VOC inhalation cancer risks were $2 \times 10^{-7}$ for the vicinity of the Building 875 dry well area, $7 \times 10^{-7}$ for central GSA, and $2 \times 10^{-7}$ for the eastern GSA. The GSA FS 
adult on-site worker noncancer risks (HIs) for the inhalation of VOCs were $6.2 \times 10^{-3}$ for the vicinity of the Building 875 dry well area, $1.2 \times 10^{-3}$ for the central GSA, and $1.3 \mathrm{x}$ $10^{-3}$ for the eastern GSA. These risk estimates are within acceptable limits.

Further investigation was required at Site 300 in those areas that had unacceptable risk estimates using SWRI models or insufficient data at the time the SWRI report was being performed. Three such areas were the Building 830, 832, and 854 areas. The flux chamber approach was selected for the new study based on the GSA FS results which eliminated an exposure pathway (inhalation of VOCs) from consideration. The Building 830, 832, and 854 exposure assessment results are described in Chapters 4 and 5. 



\title{
CHAPTER III
}

\section{RESEARCH DESIGN}

\author{
The Data
}

The VOC data used in this research is both primary and secondary.

\author{
The Primary Data
}

The primary VOC data was collected by LLNL personnel during the summer of 1996 as part of CERCLA investigations at the Building 832 Canyon and Building 854 study areas at Site 300. SUMMA ${ }^{\mathrm{TM}}$ canisters were used to collect both the emission isolation flux chamber effluent samples and 8-hr. integrated ambient air samples at Buildings 830, 832, and 854. The purpose of this investigation was to determine VOC exposure-point concentrations for use in calculations of inhalation cancer risks. The SUMMA ${ }^{\mathrm{TM}}$ canister samples were collected using the LLNL Livermore Site and Site 300 Environmental Project Standard Operating Procedures (Dibley and Depue 1995). The primary analytical data consists of results from the analysis of the integrated ambient air samples and emission isolation flux chamber effluent samples. The flux chamber samples were analyzed by gas chromatography using EPA method TO14. A modified EPA TO14 employing Selective Ion Monitoring was performed on the ambient air samples to achieve lower detection limits. A California state certified analytical laboratory was used for the analyses of the SUMMA ${ }^{\mathrm{TM}}$ canister samples. The analytical results were validated and qualified as necessary by a chemist as they were received from the analytical laboratory. The results from the analysis of the flux chamber effluent samples were used to calculate soil vapor flux rates. The flux rates were then used in an air dispersion box 
model to calculate exposure-point concentrations. The exposure-point concentrations were compared to the EPA Region IX Preliminary Remediation Goals (PRGs). Cancer risk for the inhalation of VOCs was calculated when the exposure-point concentrations were greater then the PRGs. The ambient air sample results were also compared to the PRGs. VOC inhalation cancer risk was calculated when the VOC concentrations detected in air were greater then the PRGs.

The Secondary Data

The secondary data was drawn from published studies and EPA documents reviewed in Chapter II and two LLNL Site 300 technical documents, the Site 300 SWRI Report (Webster-Scholten et al. 1994) and the Site 300 GSA FS (Rueth and Berry 1995). This data consists of published results of studies using modeling techniques, measured ambient air concentrations, and flux chamber measurements to estimate exposure-point concentrations and ultimately cancer risk for inhalation of VOCs.

\section{The Criteria for the Admissibility of the Data}

A sampling and analysis plan was developed to ensure that the nature and extent of the emission source was correctly characterized at Buildings 830, 832 and 854 . The sampling and analysis plan was based on EPA methodology and approved by LLNL Site 300 Remedial Program Managers (RPMs). The analytical data is of a known, high quality. Samples were analyzed by California state certified analytical laboratories. These laboratories followed standard EPA protocol for the analysis of samples. The gas chromatography technique (EPA method T014) includes quality assurance/ quality control (QA/QC) measures including the analysis of method blanks, laboratory control 
standards, and sample duplicates. The LLNL sampling protocol also includes appropriate QA/QC measures including equipment blanks, trip blanks, and collection of collocated samples.

The published studies data come from peer reviewed scientific journals. Other documents used were published by the EPA and LLNL. The LLNL documents were prepared by LLNL scientists and were peer reviewed. Proper QA/QC measures were performed on these data.

\section{$\underline{\text { The Research Methodology }}$}

The research methodology used in this study is a combination of historical and analytical survey methods (Leedy 1993).

\section{$\underline{\text { Specific Treatment of the Data for Each Subproblem }}$}

The specific treatment of the data, including the data needed, location of the data, and the means of obtaining the data is described below.

\section{EIFC Sampling and Analysis of VOCs}

The first subproblem identified 1) the EIFC sample collection methodology to ensure representative samples; and 2) the analytical laboratory analyses to ensure valid results. 


\section{The Data Needed}

To solve the first subproblem, data was needed that described, 1) proper sampling plan preparation, 2) selection of appropriate sampling locations, and 3) EIFC sampling methodology to ensure representative samples were collected that thoroughly characterized the area source. Data was also needed that described the sampling and laboratory QA/QC protocols that should be followed to ensure that the end results are traceable, defensible and of sufficient quality to be used in the exposure assessment.

\section{The Location of the Data}

The data was located in the LLNL Site 300 GSA FS (Rueth and Berry 1995) and in various literature reviewed for Chapter II.

The Means of Obtaining the Data

All LLNL published documents are obtainable through LLNL's Technical Information Department. The published studies and EPA documents were obtained through the LLNL Library. All information is available to the general public.

\section{The Treatment of the Data}

The data on EIFC sampling and analysis of VOCs is found in the LLNL Site 300 GSA FS (Rueth and Berry 1995) and in the literature review (Chapter II) and was used to develop the Building 830, 832, and 854 exposure assessment sampling and analysis plan, EIFC sampling methodology, QA/QC sampling, and analytical data review procedures. 


\section{Estimating Flux Rates and Exposure-point Concentrations}

The second subproblem calculated VOC flux rates from contaminated soil and input the flux rates into an air dispersion model to estimate VOC exposure-point concentrations in ambient air. The flux rates are calculated using the validated analytic results obtained from the EIFC sampling and analysis event performed for the LLNL Site 300 Building 830, 832, and 854 exposure assessment. A simple air dispersion box model was used to calculate VOC exposure-point concentrations.

\section{The Data Needed}

Using a two step process, the VOC flux rates and exposure-point concentrations were calculated. The first step was to calculate the VOC soil flux rate from the area source. For this calculation the following data were needed; 1) validated analytical data from the analyses of the SUMMA ${ }^{\mathrm{TM}}$ canisters which were used to collect the air flowing from the EIFC, 2) flow rate of air into the chambers, and 3) surface area enclosed by the chamber. The second step was to calculate the VOC exposure-point concentrations. For this calculation the following data were needed; 1) calculated VOC soil flux rate from the source area, 2) downwind length of the emission source, 3) average wind speed within the mixing zone, and 4) ambient air mixing zone height.

\section{The Location of the Data}

The data consists of primary and secondary data. The primary data was collected during the summer of 1996 for the Site 300 Building 830, 832, and 854 exposure assessment and resides in the LLNL Environmental Restoration Division (ERD) 
relational database. The secondary data consists of default variables recommended by the American Society for Testing and Materials (ASTM 1994).

\section{The Means of Obtaining the Data}

The primary data was collected as described in the Building 830,832 , and 854 exposure assessment sampling plan. The secondary data was obtained from LLNL published documents which are obtainable through LLNL's Technical Information Department.

\section{The Treatment of the Data}

Flux rates were estimated using the soil vapor flux rate calculation and exposure-point concentrations calculated with the air dispersion box model that were used in the Site 300 GSA FS (Rueth and Berry 1995) described in Chapter II. The validated analytical data, flow rate of air into the chambers, and surface area enclosed by the chamber were entered into a spreadsheet that calculated the flux rates. The calculated VOC soil flux rates, downwind length of the emission source, ASTM default average wind speed within the mixing zone, and ASTM default ambient air mixing zone height were entered into a spreadsheet that calculated the exposure-point concentrations for VOCs in ambient air. All data were tabulated. 


\section{Risk Assessment}

The third subproblem was to use the VOC exposure-point concentrations in ambient air to determine potential inhalation cancer risk for on-site LLNL workers in the Building 830, 832, and 854 areas using standard EPA risk assessment models.

\section{The Data Needed}

To estimate cancer risk, the average daily intake of contaminant attributable to the inhalation of VOCs from subsurface soil and the chemical specific individual life-time risk above background of developing cancer were calculated. To calculate the average daily intake the following data were needed; 1) the mathematically modeled ambient air exposure-point concentrations from the Building 830, 832, and 854 exposure assessment, rate of contaminant intake, exposure frequency, exposure duration, body weight, and averaging time for an individual where exposure may result in an adverse health effect. To calculate cancer risk, the average daily intakes and pathway-specific cancer potency slope factors were necessary.

\section{The Location of the Data}

The data consists of primary and secondary data. The primary data was collected during the summer of 1996 for the Site 300 Building 830, 832, and 854 exposure assessment. The secondary data consists of default variables recommended by the EPA (EPA 1991). 
The Means of Obtaining the Data

The primary data was collected as described in the Building 830, 832, and 854 exposure assessment sampling plan. The secondary data was obtained from published studies and EPA documents acquired through the LLNL Library.

The Treatment of the Data

The average daily intake of contaminant attributable to the inhalation of VOCs from subsurface soil and the chemical specific individual life-time cancer risk calculations were obtained from the Site 300 SWRI Report (Webster-Scholten et al. 1994) described in Chapter II. The average daily intake and cancer risks were calculated using spreadsheets. All data were tabulated. 


\title{
CHAPTER IV \\ RESEARCH DATA AND ANALYSIS
}

\author{
EIFC Sampling and Analysis of VOCs
}

The first subproblem was to identify 1) EIFC sample collection methodology to ensure representative samples; and 2) analytical laboratory analyses to ensure valid results. The corresponding subhypothesis was that EIFC can be used with a carefully defined sampling and analysis plan to obtain accurate estimates of soil VOC emissions.

To accurately estimate VOC emissions using EIFC sampling, data was needed that described, 1) proper sampling plan preparation, 2) selection of appropriate sampling locations, and 3) EIFC sampling methodology to ensure representative samples were collected that thoroughly characterized the area source. Data was also needed that described the sampling and laboratory QA/QC protocols that should be followed to ensure that the end results are traceable, defensible and of sufficient quality to be used in the exposure assessment.

\section{Building 830, 832, and 854 Sampling Plans}

EIFCs were used to make VOC soil flux measurements during July and August of 1996 using the LLNL EIFC methodology (Dibley and Depue 1995) in the Building 830, 832, and 854 areas. The primary goal of the flux chamber sampling was to collect adequate data to determine the VOC soil vapor flux rates for use in subsequent risk assessments for the Building 832 Canyon and EWFA study areas.

Because VOC contamination under investigation may be the result of direct surface spills or diffuse releases, exposure-point concentrations in the vicinity of the Building 830, 
832 and 854 complexes may result from both hot-spots in the vicinity of past spill areas and from diffuse source areas. The Building 830, 832, and 854 sampling plans incorporated source area hot-spot sampling and diffuse source area sampling to address the potential VOC sources. In addition to the EIFC sampling, ambient air samples were also collected. The sampling approaches used for each study area are described below.

\section{Source Area Hot-spot and Diffuse Source Area Sampling}

The hot-spot sampling was used to detect emissions from the leveled areas surrounding Buildings 830, 832, and 854 from which shallow VOCs may be volatilizing from past spills or from volatilization of VOCs present in deeper soils. The leveled areas are for the most part paved, and it is expected that in those areas not directly impacted by a surface spill, the highest emissions would be along the unpaved strip and bermed areas surrounding the leveled area. EIFC samples were therefore planned at regular intervals along unpaved areas surrounding the leveled areas. Additionally, EIFC sample points were collected at or near PETREX soil vapor survey points and soil borings which indicated known hot-spots (when these data were available), and at other suspected hot-spots. At least one EIFC sample in each area were collected over an area of pavement away and down gradient from known surface spills and assumed to be representative of soil vapor flux through the pavement resulting from volatilization of VOCs present in deeper soils.

Diffuse source area sampling was used to detect emissions from those areas where there were releases to septic systems, contaminated storm water runoff from paved areas, or to subsurface ground water or vadose zone transport of contaminants.

A gridded source area sampling approach was applied at suspected diffuse source areas in which sampling zones were determined based upon existing data. Diffuse source area 
sampling zones were outlined based upon prevailing winds, existing characterization data and geology, and treated as area sources of VOC emissions.

The minimum total number of soil vapor flux samples collected from each potential source area was determined based upon the area of the sampling zone using Equation 2-16. The equation determines the number of samples necessary to provide an estimated average surface soil flux emission rate within $20 \%$ of the true mean with $95 \%$ confidence as recommended in the Air/Superfund Technical Guidance Series, Volume II (USEPA 1990). The specific samples collected in each area are described below.

\section{Building 830 Sampling Plan}

For Building 830, the source of the contamination is thought to be caused by 1) leaks from the TCE brine distribution system which was removed in the 1980s; 2) transfer and handling related spills in the vicinity of Building 830; and 3) releases to the septic system and the HE drain trench which drained to the former disposal lagoon. Boring logs indicate that trichloroethene (TCE) is present primarily in shallow soils but is found at over $30 \mathrm{ft}$ below ground surface (bgs) in the vicinity of Building 830 .

The sampling zone area for the unpaved area at Building 830 was $2600 \mathrm{~m}^{2}$. The paved area including the building footprint was $905 \mathrm{~m}^{2}$. Based on the sampling zones, 14 and 11 samples were required in the unpaved and paved areas, respectively. A total of twenty samples were collected. Only 3 of the 11 pavement area samples were collected (3SFB830-006, 010, and 013). No flux samples were collected inside the building. The pavement samples were collected over cracks in the asphalt. A total of seventeen samples were collected in the unpaved area. Seven of these samples were collected from the leveled area surrounding Building 830 (locations 3SF-B830-001 through 005, 012, and 014) and ten additional samples were collected in the wash below Building 830 (locations 3SF- 
B830-007 through 009, 011, and 015-020). Figure 4-1 shows the Building 830 EIFC sampling locations.

\section{Building 832 Sampling Plan}

The source of the contamination at Building 832 is thought to be caused by 1) leaks from the TCE brine distribution system which was removed in 1987, 2) transfer and handling related spills in the vicinity of Building 832, and 3) releases to the septic system. Boring logs indicate that TCE is present in both shallow and deep soils in the vicinity of Building 832 .

The sampling zone area for the paved area of Building 832 was $2600 \mathrm{~m}^{2}$ including the building footprint. An unpaved area was not used to calculate sample locations. Based on this sampling zone, 14 samples were required. Eighteen EIFC samples were collected on and around the paved area. EIFC samples were collected at or near PETREX survey points and soil borings indicating known hot-spots (locations 3SF-832-011, 012, and 013), placed at regular interval along the unpaved strip surrounding the leveled area (locations 3SF-832-001 through 003, 009, 010, 016, \& 017), between the test cell area and the control room where historic spills were documented (locations 3SF-832-014 and 015), and in the area of the septic tank leach field (location 3SF-832-004). One soil vapor flux sample was collected over an area of pavement away from known surface spills and assumed to be representative of soil vapor flux through the pavement resulting from volatilization of VOCs present in deeper soils (location 3SF-832-018). Four other samples were taken in a sampling zone from the edge of the pavement at Building 832 down the valley to the leveled area in the vicinity of monitoring wells W-832-01 and W-832-09 (locations 3SF-832-005 through 008). Figure 4-2 shows the Building 832 EIFC sampling locations. 


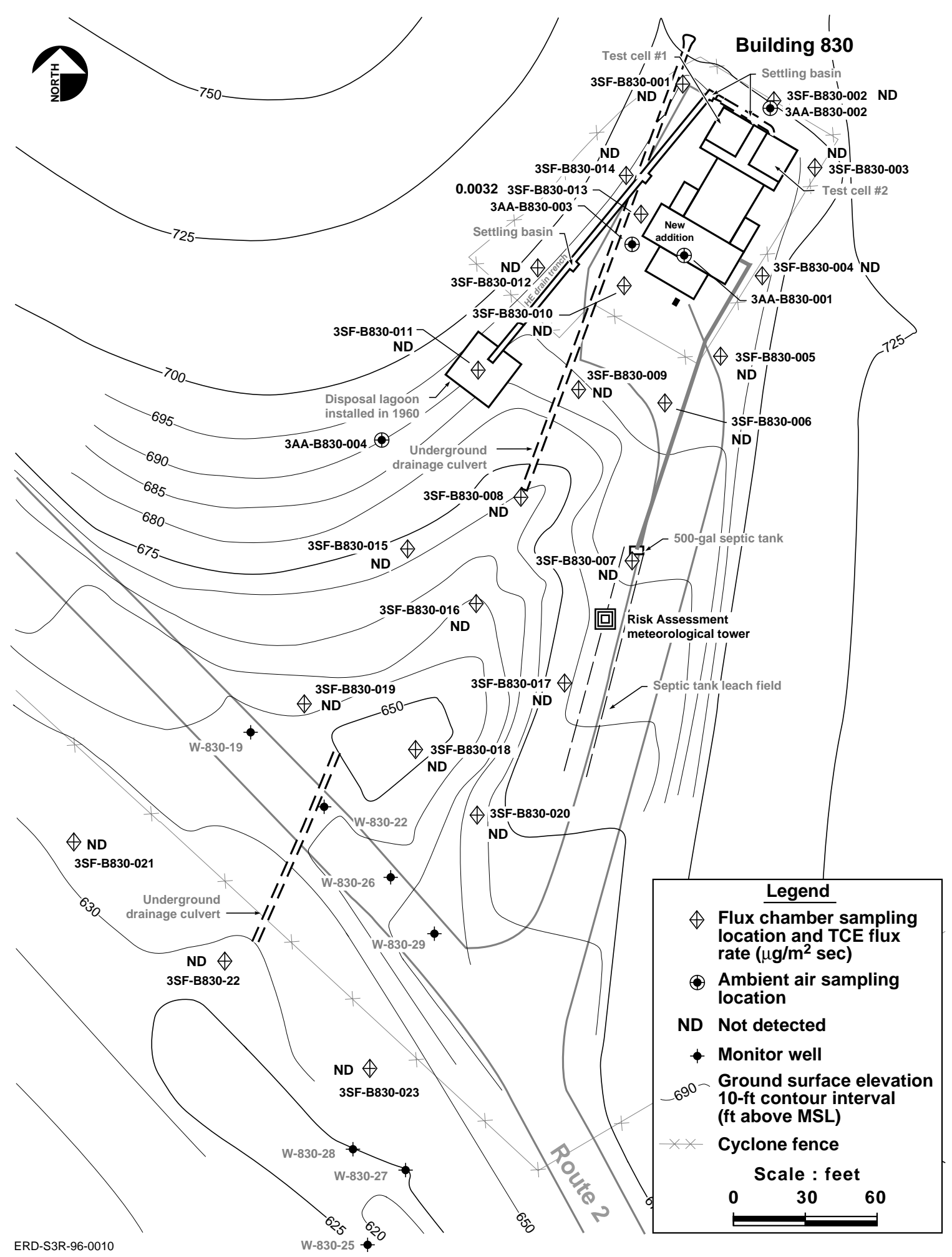

Figure 4-1. Map of the Building 830 area marked with the ambient air and flux chamber sampling locations. 


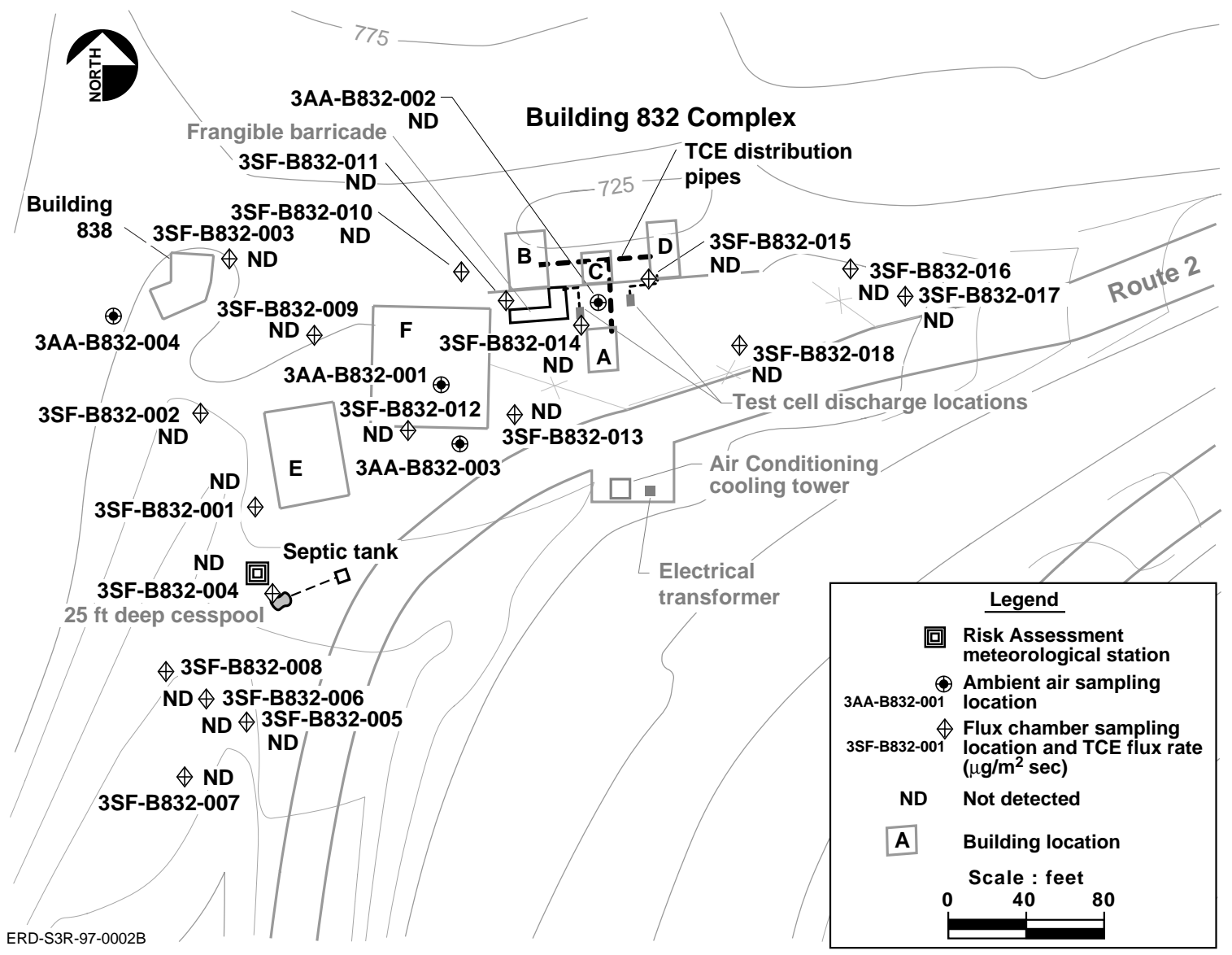

Figure 4-2. Map of the Building 832 area marked with the ambient air and flux chamber sampling locations. 
Building 854 Sampling Plan

For Building 854, the source of the contamination is thought to be a spill at the TCE brine distribution system, which was removed in 1989. Soil boring logs indicate that TCE may be present both in shallow and deep soils.

The leveled area surrounding the Building $854 \mathrm{~F}$ area is estimated to be $630 \mathrm{~m}^{2}$. Based on the sampling zone, 10 samples were required. However, a total of twenty-six flux chamber samples were collected throughout the Building 854 complex area. Several additional samples were collected from suspected hot-spots and the areas surrounding Building 854F. Nine EIFC samples were collected to characterize emissions from this area (3SF-B854-001 through 007, 011, and 012). Three of the EIFC samples were collocated with the PETREX survey points SVX-854-060 (3SF-B854-003), SVX-854-061 (3SFB854-004), and SVX-854-062 (3SF-B854-005), which have indicated potential hot-spots. Several of these EIFC samples were placed at regular intervals along the unpaved strip surrounding the leveled area (3SF-B854-001 through 007), and two were located within the paved area where significant cracking is observed (3SF-B854-011 and 012). Based upon PETREX data, the hillside immediately west of the Building 854 complex may be a source of soil vapor flux. The reasons for this are currently not well understood, but may be due to preferential vadose zone transport from the Building 854 area. Soil vapor flux sampling on the hillsides and berm in the vicinity of Building 854F were limited to six EIFC sampling points. One EIFC sample was collocated with the PETREX survey point SVX-854-011 (3SF-B854-015), which indicated a potential hot-spot. Three EIFC sampling points were located at regular intervals along the berms surrounding the leveled area (3SF-B854-008 through 010). One sample was collected on top of the berm above the former brine system piping conduit (3SF-B854-013), and another was collected on the fire road along the hillside to the west of Building 854F (3SF-B854-014). Additional EIFC 
samples were collected in the vicinity of the TCE brine system valve stations, piping and storage tanks near Building 854D area (3SF-B854-017 and 018), the former Building 854G drum storage rack (3SF-B854-023 and 024), and the Building 854H drain outfall (3SF-B854-025). EIFC samples were also collected in areas of potential brine system contamination. These include samples collected near Building 854E (3SF-B854-019 and 020), samples collected near Building 854C (3SF-B854-022 and 026), and the sample collected behind Building 854B (3SF-B854-021). One additional sample was collected with the PETREX survey point SVX-854-006, located on the fire road to the west of Building 854J, because of the PETREX survey point's relatively high VOC values (3SFB854-016). Figure 4-3 shows the Building 854 EIFC sampling locations.

\section{$\underline{\text { Ambient Air Sampling }}$}

Indoor and outdoor ambient air samples were collected in the vicinity of each suspected source area concurrent with the EIFC sampling efforts to provide additional exposure-point information. Ambient air samples were collected using SUMMA ${ }^{\mathrm{TM}}$ canisters over an approximately $8 \mathrm{hr}$ time period ( $8 \mathrm{hr}$ integrated air sample).

A meteorological tower was erected during sampling activities to record temperature, wind speed and direction data. Site specific meteorological data was correlated with data from the LLNL Site 300 meteorological tower to address seasonal meteorological variations and assure that final exposure-point calculations are representative of average conditions. The ambient air field data including wind speed, temperatures, and sampling times are presented in Appendix A.

At each suspected source area, one ambient air sample was collected at a location representative of the most likely outdoor exposure-point (location representative of most frequent outdoor activity). A second sample was collected upwind from all source areas to 


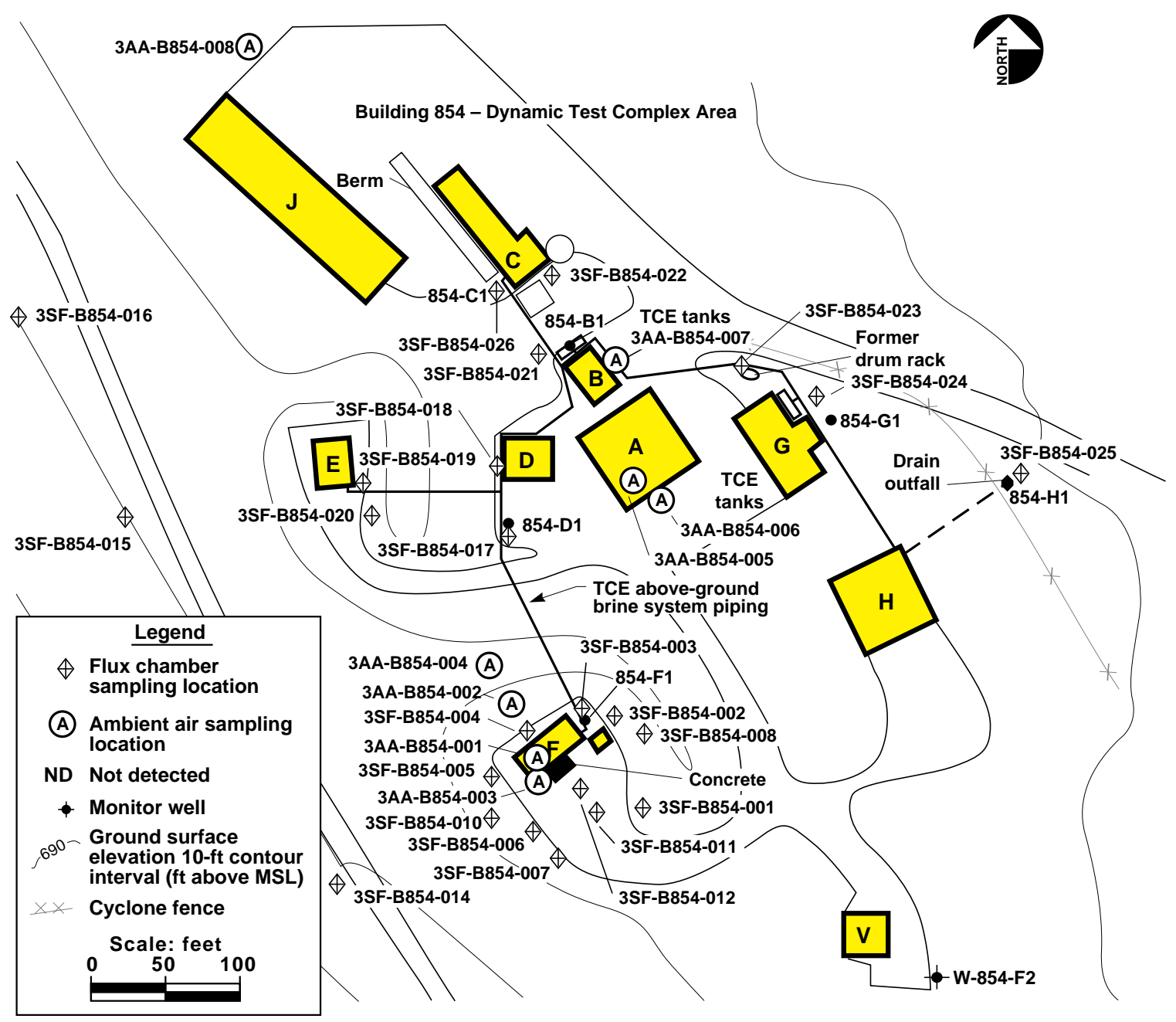

ERD-S3R-98-0024

Figure 4-3. Map of the Building 854 area marked with the ambient air and flux chamber sampling locations. 
provide a measure of the contribution of background VOC concentrations. A third sample was also collected where ambient air concentrations might be expected to be elevated as a result of the proximity to known hot-spots or where air mixing is expected to be minimized due to building configuration, berms, etc. Indoor air samples were collected inside potentially impacted buildings to determine whether indoor inhalation exposure-point concentrations of VOCs warrants further investigation. One indoor air sample was collected from each building complex each day EIFC sampling was conducted. The specific outdoor and indoor ambient air samples collected in each area are described below.

\section{Building 830 Ambient Air Sampling}

Four approximately $8 \mathrm{hr}$ integrated air samples were collected on each day of EIFC sampling (8/13/96 and 8/14/96) in the vicinity of Building 830. One sample location was behind Building 830 near the doorway to test cells \#1 and 2 (at the building outfall to the HE drain trench) where ambient air concentrations would be expected to be highest as a result of the proximity to known hot-spots and where air mixing is expected to be minimized in a covered area between Building 830 and the berm to the immediate north (location 3AA-B830-002). A second sample location was west-southwest of the building which represented the most likely outdoor exposure point (location 3AA-B830-003). This sample also provided validation of VOC exposure-point contributions from the disposal lagoon and septic tank leach field. The third sample location was upwind from all Building 830 sources to provide a measure of the contribution of other source areas (location 3AAB830-004). The fourth sample location was located inside of Building 830 which is used as a storage area (location 3AA-B830-001). Figure 4-1 shows the Building 830 ambient air sampling locations. 
Building 832 Ambient Air Sampling

Four approximately $8 \mathrm{hr}$ integrated air samples were collected on each day of EIFC sampling (8/6/96 and 8/7/96) in the vicinity of Building 832. One sample location was between the test cell area and the control room where ambient air concentrations were expected to be highest as a result of the proximity to known hot-spots and where air mixing is expected to be minimized between the two buildings (location 3AA-832-002). A second sample location was south of the building currently used most regularly as office space to represent the most common outdoor exposure point (location 3AA-832-003). This sample provided validation of VOC exposure-point contributions from the septic tank leach field and valley to the south. The third sample location was on the berm above Building 838 upwind from all Building 832 to provide a measure of the contribution of other source areas (location 3AA-832-004). The fourth sample location was located inside Building $832 \mathrm{~F}$ which is used regularly as offices (sample 3AA-832-001). Figure 4-2 shows the Building 832 ambient air sampling locations.

\section{Building 854 Ambient Air Sampling}

A total of eight integrated ambient air samples were collected during EIFC sampling (7/31/96 and 8/1/96) in the vicinity of Building 854F area and other potential B854 area hot-spots. One sample location was near the doorway to Building 854F to represent the most likely outdoor exposure-point (3AA-B854-003). Another sample location was at the base of the berm directly north of Building 854F (3AA-B854-002). A third sample location was on top of the berm directly northwest of Building 854F (3AA-B854-004) to provide a measure of background concentrations in the vicinity of Building 854F. A fourth sample location was north of the Building 854 complex (3AA-B854-008) and provided a 
background sample up-wind of the B854 area. A fifth sample location was out front of Building 854A by the dock (3AA-B854-006) representing a common outdoor exposure location. The sixth sample location was near the phone located outside Building 854B (3AA-B854-007) which is also used frequently by field personnel. Eight-hour integrated indoor air samples were also collected from Building 854F and Building 854B (3AAB854-001 and 3AA-B854-005, respectively). Figure 4-3 shows the Building 854 ambient air sampling locations.

\section{EIFC Sampling Methodology}

The emission isolation flux chamber methodology used by LLNL is based on U.S. EPA guidance (USEPA 1986) and follows the Environmental Restoration Division (ERD) Standard Operating Procedure, SOP1-11, "Soil Surface Flux Monitoring of Gaseous Emissions" (Dibley and Depue 1995). The emission isolation flux chamber is placed on the ground surface, and VOC soil emissions enter the open bottom of the chamber. Clean dry sweep air is added into the chamber at a metered rate. Within the chamber a fan mixes the sweep air with emitted VOC vapors. When the concentration of the VOC soil flux emissions and the sweep air reaches equilibrium, a sample is collected in a SUMMA ${ }^{\mathrm{TM}}$ canister for analysis. VOC flux (emission/area-time) from the soil surface is then calculated from the VOC vapor concentration.

The emission isolation flux chamber system is composed of three parts: the chamber, the sweep air controller and data logger, and the sampling system. The flux chamber contains a fan to circulate air and a thermistor to measure the chamber temperature. Three emission isolation flux chambers have been constructed by LLNL (Martins 1993). Each chamber encloses a surface area of approximately $0.122 \mathrm{~m}^{2}$ and a total volume of about $27 \mathrm{~L}\left(0.027 \mathrm{~m}^{3}\right)$. 
The sweep air controller and data logger contains a metering pump, two rotometers used to measure air flow in and out of the chamber, a battery, and the associated electronics required for chamber control and data acquisition. The metering pump and two rotometers are used to control air flow in and out of the chamber to maintain a negligible pressure differential across the chamber. The chamber controller is connected to an external data logger that acquires temperature and pressure data.

When the flux chamber is in operation, ultra-pure "zero air" is metered into the chamber using a pressure regulator and the first rotometer. At approximately the same rate, air is pulled from the chamber through the second rotometer using the pump in the chamber controller. Both rotometers are adjusted to achieve a net pressure drop of zero $( \pm 0.1 \mathrm{in}$. $\mathrm{H}_{2} \mathrm{O}$ ) between the inside and the outside of the chamber. An air flow rate of about $3 \mathrm{~L} / \mathrm{min}$ is used to achieve a chamber air residence time of approximately $10 \mathrm{~min}$. A minimum of $30 \mathrm{~min}$. is required for the sweep air to reach a steady state concentration with the VOC soil flux emissions. At that time, the effluent sweep air pump is turned off and an evacuated SUMMA ${ }^{\mathrm{TM}}$ canister is used to withdraw a vapor sample at approximately the same air flow rate $(3 \mathrm{~L} / \mathrm{min})$.

\section{Equipment Calibration}

All flux chambers and associated equipment were calibrated between November 19, 1996 and December 9, 1996. These calibrations include all Dwyer rotometers on each flux-chamber control-box (FCCB) as well as the measurement of flux chamber recovery rates.

All rotometers were calibrated under field conditions. Zero-air was used to calibrate units that control zero-air flow. Units used to control return-air flow were calibrated with air from the FCCB's internal air pump. 
The displacement method was used for these calibrations. A 1-liter graduated cylinder was filled with water, covered and inverted in a water bath. Once under water, the cover was removed from the cylinder. The desired flow rate for the test was set on the rotometer undergoing the test and flow was started. A 1/4" plastic tube connected to the rotometer was placed in the cylinder at the same time a timer was started. After about 15 to 20 seconds, the tube was removed from the cylinder and the elapse time was noted. The volume of displaced water was then recorded and the observed flow rate was calculated by dividing this volume by the elapsed time. At least 5 observations were made for each rotometer. When all data were collected, linear regression analysis was performed with data pairs composed of the observed flow-rate and the flow-rate set point. These results may be seen in Table 4-1. The constant (b) and the X Coefficient (m) listed in Table 4-1 were used to corrected flow-rates listed on the field log-sheets using the formula:

$$
\mathrm{y}=\mathrm{mx}+\mathrm{b}
$$

where:

$$
\begin{aligned}
& \mathrm{x}=\text { recorded flow-rate } \\
& \mathrm{m}=\mathrm{X} \text { Coefficient } \\
& \mathrm{b}=\text { constant }, \text { and } \\
& \mathrm{y}=\text { corrected flow-rate }
\end{aligned}
$$

Each flux chamber was set up on the chamber-blank stainless steel sheet. In order to eliminate rotometer flow-rate calibration as a variable, only FCCB 3 was used in these tests. A tank of stock gas containing $48 \mathrm{ppm}_{\mathrm{V} / \mathrm{v}}$ of 1, 1, 1-trichloroethane (1, 1, 1-TCA) was obtained for this test. This gas was metered into each flux chamber with a mass-flow meter rated at 0 to $10 \mathrm{SCCM}\left(\mathrm{cm}^{3} /\right.$ minute at standard temperature and pressure). The mass-flow meter was controlled by an Octagon SBS2300 single board computer.

The mass-flow meter was calibrated during the course of these studies using the displacement method. The observed flow rate was calculated by dividing the volume of 
Table 4-1: Flux chamber control box rotometer calibration results.

\begin{tabular}{|c|c|c|}
\hline \multirow[b]{2}{*}{ Parameter } & \multicolumn{2}{|c|}{$\overline{\text { Rotometer }}$} \\
\hline & Zero Air & Return Air \\
\hline \multicolumn{3}{|l|}{ Control box 3} \\
\hline Constant (b) & 0.143529 & -0.86 \\
\hline X Coefficient (m) & 1.039216 & 1.233333 \\
\hline $\mathrm{R}^{2}$ & 0.861075 & 0.975071 \\
\hline $\mathrm{N}$ & 5 & 5 \\
\hline \multicolumn{3}{|l|}{ Control box 2} \\
\hline Constant (b) & -0.9 & -0.3875 \\
\hline X Coefficient (m) & 1.366667 & 1.0625 \\
\hline $\mathrm{R}^{2}$ & 0.915577 & 0.982993 \\
\hline $\mathrm{N}$ & 5 & 5 \\
\hline \multicolumn{3}{|l|}{ Control box 1} \\
\hline$\overline{\text { Constant (b) }}$ & 0.5475 & -1 \\
\hline X Coefficient (m) & 0.904167 & 1.266667 \\
\hline $\mathrm{R}^{2}$ & 0.787257 & 0.996549 \\
\hline $\mathrm{N}$ & 5 & 5 \\
\hline
\end{tabular}


water displaced from a $100 \mathrm{~mL}$ graduated cylinder by the elapsed time. Linear regression analysis was performed with data pairs composed of the observed flow-rate and the flowrate set point in D/A (digital to analog) units. The D/A units represent the voltage of a signal that is used by the mass flow controller to control gas flow rates.

Flux measurements were made using methods detailed in ERD SOP1-11 (Dibley and Depue 1995). A theoretical flux rate was calculated under each condition by multiplying the standard-gas flow rate-in $\mathrm{m}^{3} / \mathrm{min}$ by the concentration of the standard gas in $\mathrm{mg} / \mathrm{m}^{3}$ and dividing by the base area of the flux chamber. The observed flux-rate was calculated using the method detailed in SOP1-11. The percent recovery was then calculated by dividing the observed flux-rate by the theoretical flux-rate. These data are listed in Table 4-2. At one point in these tests, the return-air pump was inadvertently left on during sampling. In this case, the sweep-air rate was adjusted with a time-weighted average of the initial sweep-rate and the final sweep-rate plus the sample flow-rate.

\section{Field QA/QC}

The VOC soil flux measurement protocol developed for the Building 830, 832, and 854 surveys meets or exceeds all the data quality objectives recommended by the U.S. EPA (1986).

Field blank samples (chamber blanks) were collected at a frequency of one per chamber per day whenever possible to measure possible contamination being contributed by the equipment. Field blanks were not always collected for all chambers on each day of sampling due to time constraints. In the Building 830 area, field blanks were not collected from Chamber 2 on 8/14/96, or Chambers 1 and 3 on 8/15/96. No field blanks were collected on 8/7/96 in the Building 832 area. Field blanks were not collected from Chambers 2 and 3 on 7/29/96 in the Building 854 area. When field blank data does not 
Table 4-2: Flux chamber calibration recovery rates.

\begin{tabular}{cccccc}
\hline \hline Chamber & Date & $\begin{array}{c}\text { Analysis } \\
\text { Method }\end{array}$ & $\begin{array}{c}\text { Observed } \\
\text { Flux } \\
\left(\mu \mathbf{g} / \mathbf{m}^{2} / \mathbf{m i n}\right)\end{array}$ & $\begin{array}{c}\text { Theoretical } \\
\text { Flux } \\
\left(\mu \mathbf{g} / \mathbf{m}^{2} / \mathbf{m i n}\right)\end{array}$ & $\begin{array}{c}\text { Percent } \\
\text { Recovery }\end{array}$ \\
\hline 1 & $12 / 09 / 96$ & TO-14 & 13.72 & 13.66 & $100 \%$ \\
& $12 / 09 / 96$ & TO-14 & 5.58 & 6.49 & $86 \%$ \\
& & & & Average & $93 \%$ \\
2 & $12 / 09 / 96^{\mathrm{a}}$ & TO-14 & 13.70 & 13.66 & $100 \%$ \\
& $12 / 09 / 96^{\mathrm{b}}$ & TO-14 & 5.61 & 6.49 & $86 \%$ \\
& & & & Average & $93 \%$ \\
3 & $12 / 09 / 96$ & TO-14 & 13.09 & 13.66 & $96 \%$ \\
& $11 / 19 / 96$ & TO-14 & 6.85 & 6.50 & $105 \%$ \\
& & & & Average & $101 \%$ \\
\hline \hline
\end{tabular}

a 30 minutes of purge time instead of the 40 minutes called for in SOP1-11.

b Return pump left on, flow rate adjusted. 
exist for a chamber on a particular day of sampling, the data is qualified using the previous days chamber blank results. Collection of field blank samples for emission isolation flux chambers consisted of placing the chamber over a clean surface and running a test using ultra-pure sweep air under routine operating conditions.

Collocated samples (field duplicates) were collected at a frequency of one per day. The collocated samples were collected one right after the other in two separate SUMMA ${ }^{\mathrm{TM}}$ canisters using the same flux chamber to measure analytical and sampling precision. Collocated samples were not collected on 8/7/96 in the Building 832 area or on 7/29/96 in the Building 854 area. The locations for duplicate samples were selected in the field.

One control point location was sampled at two different times during the diurnal cycle to measure the effects of temperature variations. These times were chosen near the maximum and minimum diurnal temperatures. The control point samples were also collected from those locations where the highest VOC soil vapor flux was expected to be measured.

A SUMMA' ${ }^{\mathrm{TM}}$ canister of the zero air was collected and analyzed with the introduction of each new gas cylinder. An unused SUMMA ${ }^{\mathrm{TM}}$ canister was used as trip blanks and sent to the laboratory for analysis.

A field sample log sheet was completed for each sample collected. All relevant parameters were recorded on the sample log sheet: sample location and number, chamber number, sweep flow rate, ambient and chamber air temperature, and sample start and stop time. A daily field log was also completed, noting field conditions of interest. EIFC field data from sample log sheets are summarized in Appendix B.

For each sample collected, proper sample labeling was completed using indelible ink. Sample ID, sampler initials, and date were recorded on the sample label. Formal chain-ofcustody procedures, as described in LLNL standard operating procedures (Dibley and Depue 1995), were followed by all field personnel. SUMMA ${ }^{\mathrm{TM}}$ canister samples were 
delivered to a certified analytical laboratory within 48 hours of the time collected, and were analyzed for VOCs using EPA method TO-14.

Analytical Results from Buildings 830, 832, and 854 Sampling

Contaminants of concern were identified for each site based on past investigation data and historic accounts. The analytical laboratory analyzed the SUMMA тм canisters by EPA method TO14 for the contaminants of concern only: vinyl chloride; 1, 1-dichloroethene (1,1-DCE); Freon 113; methylene chloride (MeCl2); cis-1, 2-dichloroethene (cis-1,1DCE); chloroform (CHCl3); 1, 2-dichloroethane (1,2-DCA); TCE; 1, 2-dichloropropane (1,2-DCPa); 1, 1, 2-trichloroethane (1,1,2-TCA); PCE; and trans-1, 2-dichloroethene (trans-1,2-DCE).

Analytical Result from the Analyses of the EIFC Effluent Samples

The analytical results of the EIFC samples are presented in Appendix C. Almost all the EIFC samples consistently contained $\mathrm{MeCl} 2$. Such a distribution of $\mathrm{MeCl} 2$ results would not be expected if the $\mathrm{MeCl} 2$ was a result of volatilizing from the subsurface. However, no $\mathrm{MeCl} 2$ was detected in the analytical laboratory method blanks analyzed with the EIFC samples, this $\mathrm{MeCl} 2$ was not contributed by the laboratory even though $\mathrm{MeCl} 2$ is a common analytical laboratory contaminant (EPA 1989b). Based on the chamber blank results, the $\mathrm{MeCl} 2$ is believed to be volatilizing from the materials used to construct the EIFC. The $\mathrm{MeCl} 2$ concentrations detected in the samples and chamber blanks increased with higher ambient temperatures during sampling. This indicates that the summer heat was driving $\mathrm{MeCl} 2$ out of the EIFC system. Field blank samples (chamber blanks) were collected to provided a measure of such contamination. U.S. EPA Guidance (1989b) states 
that if blanks contain detectable levels of common contaminants ( $\mathrm{MeCl}$, acetone, 2butanone, toluene, and phthalate esters), then the sample results should be considered as positive results only if the concentrations in the sample exceed ten times the maximum concentration detected in any blank. If the concentration of a common contaminant is less than ten times the blank concentration, then it is concluded that the chemical was not detected in the associated samples. Such guidance prevents the inclusion of non-site-related contaminants in a risk assessment. All soil vapor flux samples had a $\mathrm{MeCl} 2$ concentration less than ten times the maximum concentration detected in the chamber blanks. The U.S. EPA guidance recommends that these data be treated as nondetections in the calculations of cancer risks. However, the $\mathrm{MeCl} 2$ results were carried through the flux rate and exposure-point calculations for information purposes.

Other then the $\mathrm{MeCl} 2$ detections, TCE and PCE were detected in EIFC samples at locations that would be expected based on the previous investigation data and historic accounts. The analytical results for the specific areas are described below.

\section{Building 830 EIFC Results}

At the Building 830 area, only TCE and $\mathrm{MeCl} 2$ were detected in the EIFC samples. TCE was observed in one sample (3SF-B830-013) collected west-southwest of the building where TCE spills were thought to have occurred, and where staining in a low spot in the pavement was evident. The active soil vapor survey (SVS) that occurred following the flux chamber study (see Appendix E for SVS results) detected only TCE at Building 830. The SVS did not detect any other compounds. The soil vapor sample collected in the vicinity of sample 3SF-B830-013 had the highest shallow (5ft) soil vapor sample TCE concentration in the Building 830 area, with concentrations increasing with depth, indicating TCE may have resulted from a surface spill. Other SVS samples collected at $5 \mathrm{ft}$ 
bgs were lower but of the same magnitude indicating that it is not unreasonable to suspect that TCE emissions may be present in the vicinity of Building 830 just below the detection limit.

\section{Building 832 EIFC Results}

In the Building 832 flux chamber samples, with the exception of $\mathrm{MeCl} 2$ all compounds on the analyte list were below the detection limit. However, the SVS did detect measurable levels of TCE and 1, 1-DCE at Building 832 at depths of $10 \mathrm{ft}$ bgs or greater. No other compounds were detected by the SVS at Building 832. The EIFC sample 3SF-B832-015 was collected near the highest SVS TCE detection. TCE emissions may be present below the detection limit.

\section{Building 854 EIFC Results}

TCE was detected in several Building 854 EIFC samples and PCE was detected once. The EIFC sample 3SF-B854-015 had the highest TCE detection (7.9 $\mathrm{ppb} / \mathrm{v})$ in the area. This sample was collected at a potential hot-spot. All other analytes (with the exception of $\mathrm{MeCl} 2)$ were below the detection limits. The SVS detected measurable levels of TCE at Building 854. The SVS did not detect any other compounds.

\section{Analytical Result from the Analyses of the Ambient Air Samples}

The ambient air samples were analyzed for the same constituents as the EIFC samples using a modified EPA TO-14 with Selective Ion Monitoring (SIMs) to achieve lower detection limits. SIMs was requested in an attempt to obtain ambient air detection limits 
lower then the EPA Region IX PRGs. Unfortunately, the $8 \mathrm{hr}$ integrated air sample methodology requires a vacuum to be left on the canister, requiring the analytical laboratory to dilute the sample to bring it to ambient pressure for analysis. This caused the detection limit to be increased above the PRG for vinyl chloride; 1,1-DCE; CHCl3; 1,2-DCA; 1,2DCPa; and 1,1,2-TCA. However, for the two primary analytes of concern, TCE and PCE, the PRG exceeded the detection limit. A comparison of the ambient air sample detection limits versus the EPA Region IX PRGs are presented in Table 4-3.

The analytical results of the ambient air samples are presented in Appendix D. All the ambient air samples had $\mathrm{MeCl} 2$ detections. The source of the $\mathrm{MeCl} 2$ is presumed to be the analytical laboratory since it was also detected in the analytical laboratory method blanks analyzed with the ambient air samples. All ambient air samples, with the exception of one location at Building 854 (3AA-B854-005), had a MeCl2 concentration less than ten times the maximum concentration detected in the laboratory method blanks. Normally, these data would be excluded from the risk assessment based on the EPA guidance. However, the $\mathrm{MeCl} 2$ results were compared to the PRG for information purposes. Freon 113 was another analyte that was detected in all the ambient air samples. Freon 113 has been widely used in industry.

Based on the EIFC sample results we would only expect to see TCE and PCE in the ambient air. However, the ambient air sample analysis detected several other analytes. The ambient air samples may be detecting VOCs introduced by sources other then the subsurface. For example, PCE is commonly used in the dry cleaning industry, therefore, distinguishing between what was contributed from the subsurface or other sources is difficult using ambient air samples. Nevertheless, the ambient air samples results that are greater then the PRGs will be carried through the cancer risk calculations. The analytical results for the specific areas are described below. 
Table 4-3. Detection limit range for ambient air samples and preliminary remediation goal (PRG) comparison in $\mathrm{ppb}_{\mathrm{v}} / \mathrm{v}$.

\begin{tabular}{lcc}
\hline \hline \multicolumn{1}{c}{ Analyte } & $\begin{array}{c}\text { Detection Limit } \\
\text { Range }\end{array}$ & $\begin{array}{c}\text { EPA } \\
\text { Region IX } \\
\text { PRG }\end{array}$ \\
\hline Vinyl chloride & $0.033-0.055^{\mathrm{a}}$ & 0.009 \\
1, 1-Dichloroethene (1,1-DCE) & $0.033-0.055^{\mathrm{a}}$ & 0.010 \\
Freon 113 & $0.033-0.055$ & 4036 \\
Methylene chloride (MeCl2) & $0.033-0.055$ & 1.178 \\
cis-1, 2-Dichloroethene (cis-1,2-DCE) & $0.033-0.055$ & 9.312 \\
Chloroform (CHCl3) & $0.033-0.055^{\mathrm{a}}$ & 0.017 \\
1, 2-Dichloroethane (1,2-DCA) & $0.082-0.14^{\mathrm{a}}$ & 0.018 \\
Trichloroethene (TCE) & $0.033-0.055$ & 0.204 \\
1, 2-Dichloropropane (1,2-DCPa) & $0.082-0.14^{\mathrm{a}}$ & 0.021 \\
1, 1, 2-Trichloroethane (1,1,2-TCA) & $0.033-0.055^{\mathrm{a}}$ & 0.022 \\
Tetrachloroethene (PCE) & $0.033-0.055$ & 0.485 \\
trans-1, 2-Dichloroethene (trans-1,2-DCE) & $0.033-0.055$ & 18.372 \\
\hline \hline
\end{tabular}

a Detection limit is greater then the PRG. 
Building 830 Ambient Air Results

Vinyl chloride, Freon 113, MeCl2 (laboratory contamination), CHCl3, 1,2-DCA, TCE, and PCE were detected in Building 830 outdoor air samples. The vinyl chloride, $\mathrm{CHCl} 3$, 1,2-DCA, and PCE were detected only once all on the same day (8/13/96) at location 3AAB830-004. TCE was detected on both days of sampling at several locations as expected. Vinyl chloride, Freon 113, MeCl2 (laboratory contamination), and TCE were detected in the Building 830 indoor air samples.

Building 832 Ambient Air Results

Only Freon 113 and MeCl2 (laboratory contamination) were detected in Building 832 outdoor air samples. Freon 113, MeCl2 (laboratory contamination), CHCl3, TCE, 1,2DCPa, and PCE were detected in Building 832 indoor air samples.

Building 854 Ambient Air Results

Freon 113, $\mathrm{MeCl} 2$ (laboratory contamination), $\mathrm{CHCl} 3$, and PCE were detected in Building 854 outdoor air. Freon 113, MeCl2 (laboratory contamination), $\mathrm{CHCl} 3, \mathrm{TCE}$, and PCE were detected in Building 854F indoor air samples. Freon 113, MeCl2 (greater then 10 times the method blank concentration), and PCE were detected in Building 854A indoor air samples. The elevated concentrations of $\mathrm{MeCl} 2$ may be from an indoor source. 


\section{Laboratory QA/QC and Validation}

The laboratory reported full QA/QC results, including results from method blanks, method spikes, and duplicate analyses with each analytical batch. The results were validated according to the ERD SOP4.6 (Dibley and Depue 1995). The analytical laboratory and field QA/QC samples were reviewed against acceptance criteria and the sample results were flagged with data qualifier flags when necessary. Based on the review

of laboratory QA/QC, the data is believed valid and of a known quality. EIFC effluent and ambient air SUMMA' ${ }^{\text {TM }}$ canister analytical results were flagged with an 'F' when the VOC was detected in a chamber blank sample. When a specific VOC was detected in the laboratory method blank, the affected ambient air samples were flagged with a 'B'. Those analytes flagged with an 'F' or 'B' should not be used in the risk assessment if the results are less then ten times the blank result as described above. The qualifier flags applied to the EIFC and ambient air analytical results are shown in Appendices C and D, respectively. Sample results were not blank subtracted.

\section{Estimating Flux Rates and Exposure-point Concentrations}

The second subproblem was to calculate VOC flux rates from contaminated soil and input the flux rates into an air dispersion model to estimate VOC exposure-point concentrations in ambient air. The flux rates were calculated using the validated analytic results obtained from the EIFC sampling and analysis event performed for the LLNL Site 300 Building 830, 832, and 854 exposure assessment. A simple air dispersion box model was used to calculate VOC exposure-point concentrations. The corresponding subhypothesis was that the SUMMA ${ }^{\mathrm{TM}}$ canister concentrations obtained from the EIFC sampling and analysis event as determined by the analytical laboratory could be simply 
converted into soil vapor flux rates by using the flux rate calculation. These flux rates can then be used as input into an air dispersion model to derive exposure-point concentrations of VOCs in air contributed solely form the subsurface.

The first step was to calculate the VOC soil flux rate from the area source. For this calculation the following data were needed; 1) validated analytical data from the analyses of the SUMMA'T canisters which were used to collect the air flowing from the EIFC, 2) flow rate of air into the chambers, and 3) surface area enclosed by the chamber. The second step was to calculate the VOC exposure-point concentrations. For this calculation the following data were needed; 1) calculated VOC soil flux rate from the source area, 2) downwind length of the emission source, 3) average wind speed within the mixing zone, and 4) ambient air mixing zone height.

\section{VOC Flux Rates}

Once the field data and analytical laboratory results for the EIFC samples were tabulated, these data were input into a spreadsheet that calculated the VOC soil vapor flux rate. VOC soil vapor flux was calculated using Equation 2-12. The VOC soil flux was calculated using the sweep flow rates from Appendix B, VOC SUMMA ${ }^{\text {тм }}$ canister concentration measured by the analytical laboratory from Appendix C (converted to units of $\left.\mu \mathrm{g} / \mathrm{m}^{3}\right)$, and the surface area enclosed by the chamber $\left(0.122 \mathrm{~m}^{2}\right)$.

The flux rates were calculated using the maximum VOC concentration detected in the EIFC samples. When an analyte was not detected in the EIFC samples, the maximum detection limit was used to calculate the flux rate. This is indicated by a less then sign $(<)$ in front of the flux rate. The only exception was Freon 113, which was detected in the Building 854 area. Freon 113 had detection limits greater then the single detection, 
therefore, the highest detection limit was used to determine the flux rate. The VOC soil vapor flux rates that were calculated for each sample location are presented in Table 4-4.

\section{Exposure-point Concentrations}

To estimate outdoor exposure-point concentrations of VOCs in air, an exposure model was applied that utilizes the measured VOC soil flux. To estimate maximum plausible ambient outdoor air concentrations in the vicinity of the Buildings 830,832 , and 854 , a calculated maximum measured VOC soil vapor flux from each sampling zone was used as model inputs (to be conservative, where there were no detections, the emission rate was assumed at the detection limit).

A simple box model was applied to estimate local exposure-point concentrations. This approach is applicable to the prediction of local short- and long-term exposure-point concentrations resulting from any area source. Because estimated exposure-point concentrations in outdoor air are intended only for receptors in the immediate vicinity of Building 830, 832, and 854, standard air dispersion modeling methods cannot be used because these methods are intended to estimate exposure concentrations at larger distances from the source.

The ASTM box model used to estimate VOC exposure point concentrations in outdoor air was used previously by LLNL for the GSA FS (Equation 2-22). Although the ASTM box model is simple to apply, it is also very conservative. As a result, it is used as a screening method only. Actual air concentrations corresponding to measured VOC soil vapor flux emissions are expected to be lower than those estimated by application of this model. The maximum plausible downwind length of the vapor emission source was estimated based upon the estimated source area boundaries. The downwind length of the vapor emission sources was estimated to be $40 \mathrm{~m}$ and $80 \mathrm{~m}$, for Buildings 830 and 832 , 
Table 4-4. Soil vapor flux rates calculated from the Building 830, 832, and 854 emission isolation flux chamber samples.

\begin{tabular}{|c|c|c|c|c|c|c|c|c|c|c|c|c|c|}
\hline Location & $\underset{\text { Date }}{\text { Sample }}$ & $\begin{array}{c}\text { Vinyl } \\
\text { chloride }\end{array}$ & $1,1-\mathrm{DCE}$ & Freon 113 & MeCl2 & $\underset{\text { DCE }}{\text { cis-1, }}$ & $\begin{array}{c}\text { Flux Rate } \\
\text { CCI3 }\end{array}$ & $\begin{array}{c}\overline{\text { in } \mu \mathrm{g} /\left(\mathrm{m}^{2} \cdot \mathrm{sec}\right)} \\
1,2-\mathrm{DCA}\end{array}$ & TCE & 1, 2-DCPa & $\begin{array}{c}1,1,2- \\
\text { TCA }\end{array}$ & PCE & $\underset{\text { DCE }}{\operatorname{trans-1,}}$ \\
\hline $\begin{array}{l}\text { Building } 830 \\
\text { 3SF-B830-001 }\end{array}$ & $8 / 14 / 96$ & $<0.0008$ & $<0.0013$ & $<0.0025$ & $0.0015 \mathrm{~F}$ & $<0.0013$ & $<0.0016$ & $<0.0013$ & $<0.0018$ & $<0.0015$ & $<0.0018$ & $<0.0022$ & $<0.0053$ \\
\hline 3SF-B830-001 a & $8 / 14 / 96$ & $<0.0007$ & $<0.001$ & $<0.002$ & $0.0023 \mathrm{~F}$ & $<0.001$ & $<0.0013$ & $<0.0011$ & $<0.0014$ & $<0.0012$ & $<0.0014$ & $<0.0018$ & $<0.0042$ \\
\hline 3SF-B $830-001^{b}$ & $8 / 14 / 96$ & $<0.0008$ & $<0.0013$ & $<0.0025$ & $0.0029 \mathrm{~F}$ & $<0.0013$ & $<0.0016$ & $<0.0013$ & $<0.0017$ & $<0.0015$ & $<0.0017$ & $<0.0022$ & $<0.0052$ \\
\hline 3SF-B830-002 & $8 / 14 / 96$ & $<0.0008$ & $<0.0013$ & $<0.0025$ & $0.0066^{\mathrm{F}}$ & $<0.0013$ & $<0.0016$ & $<0.0013$ & $<0.0018$ & $<0.0015$ & $<0.0018$ & $<0.0022$ & $<0.0053$ \\
\hline 3SF-B830-003 & $8 / 14 / 96$ & $<0.0008$ & $<0.0013$ & $<0.0025$ & $0.002 \mathrm{~F}$ & $<0.0013$ & $<0.0016$ & $<0.0013$ & $<0.0017$ & $<0.0015$ & $<0.0018$ & $<0.0022$ & $<0.0051$ \\
\hline 3SF-B830-004 & $8 / 14 / 96$ & $<0.0008$ & $<0.0013$ & $<0.0025$ & $0.0025 \mathrm{~F}$ & $<0.0013$ & $<0.0016$ & $<0.0013$ & $<0.0018$ & $<0.0015$ & $<0.0018$ & $<0.0022$ & $<0.0053$ \\
\hline 3 SF-B $830-004 \mathrm{~b}$ & $8 / 14 / 96$ & $<0.001$ & $<0.0015$ & $<0.003$ & $0.0028^{\mathrm{F}}$ & $<0.0015$ & $<0.0019$ & $<0.0016$ & $<0.0021$ & $<0.0018$ & $<0.0021$ & $<0.0026$ & $<0.0062$ \\
\hline 3SF-B830-005 & $8 / 14 / 96$ & $<0.0008$ & $<0.0013$ & $<0.0025$ & $0.0055^{\mathrm{F}}$ & $<0.0013$ & $<0.0016$ & $<0.0013$ & $<0.0018$ & $<0.0015$ & $<0.0018$ & $<0.0022$ & $<0.0053$ \\
\hline 3SF-B830-006 & $8 / 14 / 96$ & $<0.0008$ & $<0.0013$ & $<0.0025$ & $0.0028^{\mathrm{F}}$ & $<0.0013$ & $<0.0016$ & $<0.0013$ & $<0.0017$ & $<0.0015$ & $<0.0017$ & $<0.0022$ & $<0.0052$ \\
\hline 3SF-B830-007 & $8 / 14 / 96$ & $<0.0008$ & $<0.0013$ & $<0.0025$ & $0.0093^{2} \mathrm{~F}$ & $<0.0013$ & $<0.0016$ & $<0.0013$ & $<0.0017$ & $<0.0015$ & $<0.0017$ & $<0.0022$ & $<0.0052$ \\
\hline 3SF-B830-008 & $8 / 15 / 96$ & $<0.0008$ & $<0.0013$ & $<0.0025$ & $0.0023 \mathrm{~F}$ & $<0.0013$ & $<0.0016$ & $<0.0013$ & $<0.0018$ & $<0.0015$ & $<0.0018$ & $<0.0022$ & $<0.0052$ \\
\hline 3SF-B830-008c & $8 / 15 / 96$ & $<0.0008$ & $<0.0012$ & $<0.0024$ & $0.0028^{\mathrm{F}}$ & $<0.0012$ & $<0.0015$ & $<0.0013$ & $<0.0017$ & $<0.0014$ & $<0.0017$ & $<0.0021$ & $<0.005$ \\
\hline 3 SF-B $830-008^{b}$ & $8 / 15 / 96$ & $<0.0009$ & $<0.0014$ & $<0.0028$ & $0.0023 \mathrm{~F}$ & $<0.0014$ & $<0.0018$ & $<0.0015$ & $<0.002$ & $<0.0017$ & $<0.002$ & $<0.0025$ & $<0.0059$ \\
\hline 3SF-B830-009 & $8 / 14 / 96$ & $<0.0008$ & $<0.0013$ & $<0.0024$ & $0.0075^{\mathrm{F}}$ & $<0.0013$ & $<0.0015$ & $<0.0013$ & $<0.0017$ & $<0.0015$ & $<0.0017$ & $<0.0022$ & $<0.0051$ \\
\hline 3SF-B830-010 & $8 / 14 / 96$ & $<0.0008$ & $<0.0013$ & $<0.0025$ & $0.002{ }^{2} \mathrm{~F}$ & $<0.0013$ & $<0.0016$ & $<0.0013$ & $<0.0017$ & $<0.0015$ & $<0.0018$ & $<0.0022$ & $<0.0052$ \\
\hline 3SF-B830-011 & $8 / 14 / 96$ & $<0.0008$ & $<0.0013$ & $<0.0025$ & $0.0157 \mathrm{~F}$ & $<0.0013$ & $<0.0016$ & $<0.0013$ & $<0.0018$ & $<0.0015$ & $<0.0018$ & $<0.0022$ & $<0.0053$ \\
\hline 3SF-B830-012 & $8 / 14 / 96$ & $<0.0008$ & $<0.0013$ & $<0.0025$ & $0.0022 \mathrm{~F}$ & $<0.0013$ & $<0.0016$ & $<0.0013$ & $<0.0017$ & $<0.0015$ & $<0.0017$ & $<0.0022$ & $<0.0052$ \\
\hline $\begin{array}{l}\text { 3SF-B830-013 } \\
\text { 3SF-B830-014 }\end{array}$ & $\begin{array}{l}8 / 14 / 96 \\
8 / 14 / 96\end{array}$ & $\begin{array}{l}<0.0008 \\
<0.0008\end{array}$ & $\begin{array}{l}<0.0013 \\
<0.0013\end{array}$ & $\begin{array}{l}<0.0025 \\
<0.0024\end{array}$ & $\begin{array}{l}<0.0011 \\
0.0014 \mathrm{~F}\end{array}$ & $\begin{array}{l}<0.0013 \\
<0.0013\end{array}$ & $\begin{array}{l}<0.0016 \\
<0.0015\end{array}$ & $\begin{array}{l}<0.0013 \\
<0.0013\end{array}$ & $\begin{array}{l}0.0032 \\
<0.0017\end{array}$ & $\begin{array}{l}<0.0015 \\
<0.0015\end{array}$ & $\begin{array}{l}<0.0018 \\
<0.0017\end{array}$ & $\begin{array}{l}<0.0022 \\
<0.0021\end{array}$ & $\begin{array}{l}<0.0053 \\
<0.005\end{array}$ \\
\hline 3 SF-B830-014c & $8 / 14 / 96$ & $<0.0008$ & $<0.0013$ & $<0.0025$ & $0.0015^{F}$ & $<0.0013$ & $<0.0016$ & $<0.0013$ & $<0.0017$ & $<0.0015$ & $<0.0017$ & $<0.0022$ & $<0.0052$ \\
\hline 3SF-B830-015 & $8 / 15 / 96$ & $<0.0008$ & $<0.0013$ & $<0.0025$ & $0.0048^{\mathrm{F}}$ & $<0.0013$ & $<0.0016$ & $<0.0013$ & $<0.0017$ & $<0.0015$ & $<0.0017$ & $<0.0022$ & $<0.0052$ \\
\hline 3SF-B830-016 & $8 / 15 / 96$ & $<0.0008$ & $<0.0013$ & $<0.0025$ & $0.0025^{\mathrm{F}}$ & $<0.0013$ & $<0.0016$ & $<0.0013$ & $<0.0018$ & $<0.0015$ & $<0.0018$ & $<0.0022$ & $<0.0053$ \\
\hline 3SF-B830-017 & $8 / 15 / 96$ & $<0.0008$ & $<0.0013$ & $<0.0025$ & $0.0019 \mathrm{~F}$ & $<0.0013$ & $<0.0016$ & $<0.0013$ & $<0.0018$ & $<0.0015$ & $<0.0018$ & $<0.0022$ & $<0.0053$ \\
\hline 3 SF-B830-018 & $8 / 15 / 96$ & $<0.0008$ & $<0.0013$ & $<0.0025$ & $0.0019^{F}$ & $<0.0013$ & $<0.0016$ & $<0.0013$ & $<0.0018$ & $<0.0015$ & $<0.0018$ & $<0.0022$ & $<0.0053$ \\
\hline 3SF-B830-019 & $8 / 15 / 96$ & $<0.0009$ & $<0.0013$ & $<0.0026$ & $0.0041^{\mathrm{F}}$ & $<0.0013$ & $<0.0017$ & $<0.0014$ & $<0.0018$ & $<0.0016$ & $<0.0019$ & $<0.0023$ & $<0.0055$ \\
\hline 3SF-B830-019a & $8 / 16 / 96$ & $<0.0008$ & $<0.0012$ & $<0.0023$ & $0.003^{F}$ & $<0.0012$ & $<0.0014$ & $<0.0012$ & $<0.0016$ & $<0.0014$ & $<0.0016$ & $<0.002$ & $<0.0048$ \\
\hline 3SF-B830-020 & $8 / 15 / 96$ & $<0.0008$ & $<0.0013$ & $<0.0025$ & $0.0011^{\mathrm{F}}$ & $<0.0013$ & $<0.0016$ & $<0.0013$ & $<0.0018$ & $<0.0015$ & $<0.0018$ & $<0.0022$ & $<0.0053$ \\
\hline 3SF-B830-021 & $8 / 16 / 96$ & $<0.0009$ & $<0.0014$ & $<0.0026$ & $<0.0012$ & $<0.0014$ & $<0.0017$ & $<0.0014$ & $<0.0019$ & $<0.0016$ & $<0.0019$ & $<0.0023$ & $<0.0056$ \\
\hline 3SF-B830-021 c & $8 / 16 / 96$ & $<0.0009$ & $<0.0014$ & $<0.0026$ & $<0.0012$ & $<0.0014$ & $<0.0017$ & $<0.0014$ & $<0.0019$ & $<0.0016$ & $<0.0019$ & $<0.0023$ & $<0.0056$ \\
\hline 3SF-B830-022 & $8 / 16 / 96$ & $<0.0008$ & $<0.0013$ & $<0.0025$ & $<0.0011$ & $<0.0013$ & $<0.0016$ & $<0.0013$ & $<0.0018$ & $<0.0015$ & $<0.0018$ & $<0.0022$ & $<0.0053$ \\
\hline 3SF-B830-023 & $8 / 16 / 96$ & $<0.0008$ & $<0.0012$ & $<0.0024$ & $0.0014 \mathrm{~F}$ & $<0.0012$ & $<0.0015$ & $<0.0012$ & $<0.0017$ & $<0.0014$ & $<0.0017$ & $<0.0021$ & $<0.005$ \\
\hline $\begin{array}{l}\text { Building } 832 \\
\text { 3SF-B832-001 }\end{array}$ & $8 / 6 / 96$ & $<0.0008$ & $<0.0013$ & $<0.0024$ & & $<0.0013$ & $<0.0015$ & $<0.0013$ & $<0.0017$ & $<0.0015$ & $<0.0017$ & $<0.0022$ & $<0.0051$ \\
\hline 3 SF-B832-001 & $8 / 6 / 96$ & $<0.0008$ & $<0.0013$ & $<0.0025$ & $0.0053^{\mathrm{F}}$ & $<0.0013$ & $<0.0016$ & $<0.0013$ & $<0.0017$ & $<0.0015$ & $<0.0018$ & $<0.0022$ & $<0.0052$ \\
\hline $\begin{array}{l}\text { 3SF-B832-002 } \\
\text { 3SF-B832-003 }\end{array}$ & $\begin{array}{l}8 / 6 / 96 \\
8 / 6 / 96\end{array}$ & $\begin{array}{l}<0.0008 \\
<0.0009\end{array}$ & $\begin{array}{l}<0.0013 \\
<0.0015\end{array}$ & $\begin{array}{l}<0.0025 \\
<0.0028\end{array}$ & $\begin{array}{l}<0.0011 \\
0.0073 \mathrm{~F}\end{array}$ & $\begin{array}{l}<0.0013 \\
<0.0015\end{array}$ & $\begin{array}{l}<0.0016 \\
<0.0018\end{array}$ & $\begin{array}{l}<0.0013 \\
<0.0015\end{array}$ & $\begin{array}{l}<0.0018 \\
<0.002\end{array}$ & $\begin{array}{l}<0.0015 \\
<0.0017\end{array}$ & $\begin{array}{l}<0.0018 \\
<0.002\end{array}$ & $\begin{array}{l}<0.0022 \\
<0.0025\end{array}$ & $\begin{array}{l}<0.0053 \\
<0.0059\end{array}$ \\
\hline $\begin{array}{l}\text { 3SF-B832-004 } \\
\text { 3SF-B832-005 }\end{array}$ & $\begin{array}{l}8 / 6 / 96 \\
8 / 6 / 96\end{array}$ & $\begin{array}{l}<0.0008 \\
<0.0008\end{array}$ & $\begin{array}{l}<0.0013 \\
<0.0013\end{array}$ & $\begin{array}{l}<0.0025 \\
<0.0025\end{array}$ & $\begin{array}{l}<0.0011 \\
<0.0011\end{array}$ & $\begin{array}{l}<0.0013 \\
<0.0013\end{array}$ & $\begin{array}{l}<0.0016 \\
<0.0016\end{array}$ & $\begin{array}{l}<0.0013 \\
<0.0013\end{array}$ & $\begin{array}{l}<0.0018 \\
<0.0017\end{array}$ & $\begin{array}{l}<0.0015 \\
<0.0015\end{array}$ & $\begin{array}{l}<0.0018 \\
<0.0018\end{array}$ & $\begin{array}{l}<0.0022 \\
<0.0022\end{array}$ & $\begin{array}{l}<0.0053 \\
<0.0051\end{array}$ \\
\hline
\end{tabular}


Table 4-4. Continued.

\begin{tabular}{|c|c|c|c|c|c|c|c|c|c|c|c|c|c|}
\hline Location & $\begin{array}{c}\text { Sample } \\
\text { Date }\end{array}$ & $\begin{array}{c}\text { Vinyl } \\
\text { chloride }\end{array}$ & 1, 1-DCE & Freon 113 & $\mathrm{MeCl} 2$ & $\begin{array}{c}\text { cis-1, } \\
\text { DCE }\end{array}$ & $\begin{array}{c}\text { Flux Rate } \\
\text { CCl3 }\end{array}$ & $\begin{array}{l}\mu \mathrm{gg} /\left(\mathrm{m}^{2} \cdot \mathrm{sec}\right) \\
1,2-\mathrm{DCA}\end{array}$ & TCE & 1, 2-DCPa & $1,1,2-$ & PCE & $\begin{array}{c}\text { trans-1, } \\
\text { DCE }\end{array}$ \\
\hline 3 SF-B832-006 & $8 / 6 / 96$ & $<0.0009$ & $<0.0014$ & $<0.0027$ & $0.003 \mathrm{~F}$ & $<0.0014$ & $<0.0017$ & $<0.0014$ & $<0.0019$ & $<0.0016$ & $<0.0019$ & $<0.0024$ & $<0.0057$ \\
\hline 3SF-B832-007 & $8 / 6 / 96$ & $<0.0008$ & $<0.0012$ & $<0.0023$ & $0.0052^{\mathrm{F}}$ & $<0.0012$ & $<0.0014$ & $<0.0012$ & $<0.0016$ & $<0.0014$ & $<0.0016$ & $<0.002$ & $<0.0048$ \\
\hline 3SF-B832-008 & $8 / 6 / 96$ & $<0.0008$ & $<0.0013$ & $<0.0025$ & $0.0014 \mathrm{~F}$ & $<0.0013$ & $<0.0016$ & $<0.0013$ & $<0.0018$ & $<0.0015$ & $<0.0018$ & $<0.0022$ & $<0.0053$ \\
\hline 3SF-B832-009 & $8 / 6 / 96$ & $<0.0009$ & $<0.0013$ & $<0.0026$ & $0.0068^{\mathrm{F}}$ & $<0.0013$ & $<0.0017$ & $<0.0014$ & $<0.0018$ & $<0.0016$ & $<0.0019$ & $<0.0023$ & $<0.0055$ \\
\hline 3SF-B832-010 & $8 / 6 / 96$ & $<0.0008$ & $<0.0013$ & $<0.0025$ & $0.005^{\mathrm{F}}$ & $<0.0013$ & $<0.0016$ & $<0.0013$ & $<0.0018$ & $<0.0015$ & $<0.0018$ & $<0.0022$ & $<0.0053$ \\
\hline $3 \mathrm{SF}-\mathrm{B} 832-010^{\mathrm{C}}$ & $8 / 6 / 96$ & $<0.0008$ & $<0.0013$ & $<0.0025$ & $0.0054 \mathrm{~F}$ & $<0.0013$ & $<0.0016$ & $<0.0013$ & $<0.0017$ & $<0.0015$ & $<0.0018$ & $<0.0022$ & $<0.0051$ \\
\hline 3SF-B832-011 & $8 / 7 / 96$ & $<0.0008$ & $<0.0013$ & $<0.0024$ & $0.0071^{\mathrm{F}}$ & $<0.0013$ & $<0.0015$ & $<0.0013$ & $<0.0017$ & $<0.0015$ & $<0.0017$ & $<0.0021$ & $<0.005$ \\
\hline 3SF-B832-012 & $8 / 13 / 96$ & $<0.0008$ & $<0.0013$ & $<0.0025$ & $0.0022 \mathrm{~F}$ & $<0.0013$ & $<0.0016$ & $<0.0013$ & $<0.0017$ & $<0.0015$ & $<0.0018$ & $<0.0022$ & $<0.0052$ \\
\hline $\begin{array}{l}\text { 3SF-B832-013 } \\
\text { 3SF-B832-014 }\end{array}$ & $\begin{array}{l}8 / 13 / 96 \\
8 / 13 / 96\end{array}$ & $\begin{array}{l}<0.001 \\
<0.0009\end{array}$ & $\begin{array}{l}<0.0015 \\
<0.0014\end{array}$ & $\begin{array}{l}<0.003 \\
<0.0027\end{array}$ & $\begin{array}{l}<0.0013 \\
0.003 \mathrm{~F}\end{array}$ & $\begin{array}{l}<0.0015 \\
<0.0014\end{array}$ & $\begin{array}{l}<0.0019 \\
<0.0017\end{array}$ & $\begin{array}{l}<0.0016 \\
<0.0014\end{array}$ & $\begin{array}{l}<0.0021 \\
<0.0019\end{array}$ & $\begin{array}{l}<0.0018 \\
<0.0016\end{array}$ & $\begin{array}{l}<0.0021 \\
<0.0019\end{array}$ & $\begin{array}{l}<0.0026 \\
<0.0024\end{array}$ & $\begin{array}{l}<0.0062 \\
<0.0057\end{array}$ \\
\hline 3 SF-B832-014c & $8 / 13 / 96$ & $<0.0009$ & $<0.0014$ & $<0.0027$ & $0.0034 \mathrm{~F}$ & $<0.0014$ & $<0.0017$ & $<0.0014$ & $<0.0019$ & $<0.0016$ & $<0.0019$ & $<0.0024$ & $<0.0057$ \\
\hline 3SF-B832-015 & $8 / 7 / 96$ & $<0.0008$ & $<0.0013$ & $<0.0025$ & $0.0014 \mathrm{~F}$ & $<0.0013$ & $<0.0016$ & $<0.0013$ & $<0.0018$ & $<0.0015$ & $<0.0018$ & $<0.0022$ & $<0.0053$ \\
\hline 3SF-B832-016 & $8 / 7 / 96$ & $<0.0008$ & $<0.0013$ & $<0.0025$ & $0.002^{\mathrm{F}}$ & $<0.0013$ & $<0.0016$ & $<0.0013$ & $<0.0017$ & $<0.0015$ & $<0.0018$ & $<0.0022$ & $<0.0051$ \\
\hline 3SF-B832-016a & $8 / 13 / 96$ & $<0.0009$ & $<0.0013$ & $<0.0026$ & $0.0054 \mathrm{~F}$ & $<0.0013$ & $<0.0017$ & $<0.0014$ & $<0.0018$ & $<0.0016$ & $<0.0019$ & $<0.0023$ & $<0.0055$ \\
\hline 3SF-B832-017 & $8 / 13 / 96$ & $<0.0008$ & $<0.0013$ & $<0.0025$ & $0.0033^{\mathrm{F}}$ & $<0.0013$ & $<0.0016$ & $<0.0013$ & $<0.0018$ & $<0.0015$ & $<0.0018$ & $<0.0022$ & $<0.0053$ \\
\hline $\begin{array}{r}\text { 3SF-B832-018 } \\
\text { Building } \mathbf{8 5 4}\end{array}$ & $8 / 7 / 96$ & $<0.0009$ & $<0.0014$ & $<0.0027$ & $<0.0012$ & $<0.0014$ & $<0.0017$ & $<0.0014$ & $<0.0019$ & $<0.0016$ & $<0.0019$ & $<0.0024$ & $<0.0057$ \\
\hline 3SF-B854-001 & 7/29/96 & $<0.0008$ & $<0.0013$ & $<0.0025$ & $0.0252^{\mathrm{F}}$ & $<0.0013$ & $<0.0016$ & $<0.0013$ & 0.0088 & $<0.0015$ & $<0.0018$ & 0.0034 & $<0.0053$ \\
\hline 3SF-B854-002 & 7/29/96 & $<0.0008$ & $<0.0013$ & $<0.0025$ & $0.0105 \mathrm{~F}$ & $<0.0013$ & $<0.0016$ & $<0.0013$ & 0.0032 & $<0.0015$ & $<0.0018$ & $<0.0022$ & $<0.0053$ \\
\hline 3 SF-B854-002b & 7/29/96 & $<0.001$ & $<0.0015$ & 0.0029 & $0.0114 \mathrm{~F}$ & $<0.0015$ & $<0.0018$ & $<0.0015$ & 0.0017 & $<0.0017$ & $<0.0021$ & $<0.0026$ & $<0.0061$ \\
\hline 3SF-B854-003 & $7 / 29 / 96$ & $<0.0009$ & $<0.0014$ & $<0.0026$ & $0.0083 \mathrm{~F}$ & $<0.0014$ & $<0.0017$ & $<0.0014$ & $<0.0019$ & $<0.0016$ & $<0.0019$ & $<0.0023$ & $<0.0055$ \\
\hline 3 SF-B854-003c & 7/29/96 & $<0.0008$ & $<0.0013$ & $<0.0025$ & $0.0082^{F}$ & $<0.0013$ & $<0.0016$ & $<0.0013$ & $<0.0018$ & $<0.0015$ & $<0.0018$ & $<0.0022$ & $<0.0053$ \\
\hline 3SF-B854-003a & 7/30/96 & $<0.0009$ & $<0.0013$ & $<0.0026$ & $0.0068^{\mathrm{F}}$ & $<0.0013$ & $<0.0017$ & $<0.0014$ & $<0.0018$ & $<0.0016$ & $<0.0019$ & $<0.0023$ & $<0.0055$ \\
\hline 3SF-B854-003a & 7/31/96 & $<0.0009$ & $<0.0013$ & $<0.0026$ & $0.0068^{\mathrm{F}}$ & $<0.0013$ & $<0.0017$ & $<0.0014$ & $<0.0018$ & $<0.0016$ & $<0.0019$ & $<0.0023$ & $<0.0055$ \\
\hline 3SF-B854-004 & $7 / 30 / 96$ & $<0.0009$ & $<0.0014$ & $<0.0026$ & $0.0013^{\mathrm{F}}$ & $<0.0014$ & $<0.0017$ & $<0.0014$ & 0.0026 & $<0.0016$ & $<0.0019$ & $<0.0023$ & $<0.0055$ \\
\hline 3SF-B854-004c & 7/30/96 & $<0.0009$ & $<0.0014$ & $<0.0027$ & $<0.0012$ & $<0.0014$ & $<0.0017$ & $<0.0014$ & 0.004 & $<0.0016$ & $<0.0019$ & $<0.0024$ & $<0.0057$ \\
\hline 3SF-B854-005 & 7/30/96 & $<0.0009$ & $<0.0013$ & $<0.0026$ & $0.0014 \mathrm{~F}$ & $<0.0013$ & $<0.0017$ & $<0.0014$ & $<0.0018$ & $<0.0016$ & $<0.0019$ & $<0.0023$ & $<0.0055$ \\
\hline 3SF-B854-006 & 7/30/96 & $<0.0008$ & $<0.0013$ & $<0.0025$ & $0.0019^{\mathrm{F}}$ & $<0.0013$ & $<0.0016$ & $<0.0013$ & $<0.0018$ & $<0.0015$ & $<0.0018$ & $<0.0022$ & $<0.0053$ \\
\hline 3SF-B854-006b & 7/30/96 & $<0.001$ & $<0.0016$ & $<0.0031$ & $0.0019^{\mathrm{F}}$ & $<0.0016$ & $<0.002$ & $<0.0016$ & $<0.0022$ & $<0.0019$ & $<0.0022$ & $<0.0027$ & $<0.0065$ \\
\hline 3SF-B854-007 & 7/30/96 & $<0.0008$ & $<0.0013$ & $<0.0025$ & $0.0016 \mathrm{~F}$ & $<0.0013$ & $<0.0016$ & $<0.0013$ & $<0.0018$ & $<0.0015$ & $<0.0018$ & $<0.0022$ & $<0.0053$ \\
\hline 3SF-B854-008 & 7/30/96 & $<0.0009$ & $<0.0014$ & $<0.0027$ & $0.0032^{\mathrm{F}}$ & $<0.0014$ & $<0.0017$ & $<0.0014$ & $<0.0019$ & $<0.0016$ & $<0.0019$ & $<0.0024$ & $<0.0056$ \\
\hline 3SF-B854-009 & $7 / 30 / 96$ & $<0.0009$ & $<0.0014$ & $<0.0028$ & $0.0015^{\mathrm{F}}$ & $<0.0014$ & $<0.0018$ & $<0.0015$ & $<0.0019$ & $<0.0017$ & $<0.002$ & $<0.0024$ & $<0.0058$ \\
\hline 3SF-B854-009b & $7 / 30 / 96$ & $<0.0011$ & $<0.0017$ & $<0.0032$ & $0.0013 \mathrm{FJ}$ & $<0.0017$ & $<0.002$ & $<0.0017$ & $<0.0022$ & $<0.0019$ & $<0.0023$ & $<0.0028$ & $<0.0068$ \\
\hline 3SF-B854-010 & 7/30/96 & $<0.0009$ & $<0.0013$ & $<0.0026$ & $0.0205^{\mathrm{F}}$ & $<0.0013$ & $<0.0017$ & $<0.0014$ & $<0.0018$ & $<0.0016$ & $<0.0019$ & $<0.0023$ & $<0.0055$ \\
\hline $\begin{array}{l}\text { 3SF-B854-011 } \\
\text { 3SF-B854-012 }\end{array}$ & $\begin{array}{l}7 / 30 / 96 \\
7 / 30 / 96\end{array}$ & $\begin{array}{l}<0.0009 \\
<0.0008\end{array}$ & $\begin{array}{l}<0.0014 \\
<0.0013\end{array}$ & $\begin{array}{l}<0.0027 \\
<0.0025\end{array}$ & $\begin{array}{l}<0.0012 \\
0.0019^{\mathrm{F}}\end{array}$ & $\begin{array}{l}<0.0014 \\
<0.0013\end{array}$ & $\begin{array}{l}<0.0017 \\
<0.0016\end{array}$ & $\begin{array}{l}<0.0014 \\
<0.0013\end{array}$ & $\begin{array}{l}<0.0019 \\
<0.0018\end{array}$ & $\begin{array}{l}<0.0016 \\
<0.0015\end{array}$ & $\begin{array}{l}<0.0019 \\
<0.0018\end{array}$ & $\begin{array}{l}<0.0024 \\
<0.0022\end{array}$ & $\begin{array}{l}<0.0057 \\
<0.0053\end{array}$ \\
\hline 3SF-B854-013 & $7 / 31 / 96$ & $<0.0008$ & $<0.0013$ & $<0.0025$ & $0.0036^{\mathrm{F}}$ & $<0.0013$ & $<0.0016$ & $<0.0013$ & $<0.0018$ & $<0.0015$ & $<0.0018$ & $<0.0022$ & $<0.0053$ \\
\hline 3SF-B854-014 & 7/31/96 & $<0.0007$ & $<0.0012$ & $<0.0022$ & $0.0127 \mathrm{~F}$ & $<0.0012$ & $<0.0014$ & $<0.0012$ & 0.002 & $<0.0013$ & $<0.0016$ & $<0.002$ & $<0.0047$ \\
\hline
\end{tabular}




\begin{tabular}{|c|c|c|c|c|c|c|c|c|c|c|c|c|c|}
\hline Location & $\begin{array}{c}\text { Sample } \\
\text { Date }\end{array}$ & $\begin{array}{c}\text { Vinyl } \\
\text { chloride }\end{array}$ & 1, 1-DCE & Freon 113 & MeCl2 & $\begin{array}{c}\text { cis-1, } \\
\text { DCE }\end{array}$ & $\begin{array}{c}\text { Flux Rate } \\
\text { CCI3 }\end{array}$ & $\begin{array}{c}\text { in } \mu \mathrm{g} /\left(\mathrm{m}^{2} \cdot \mathrm{sec}\right) \\
1,2-\mathrm{DCA}\end{array}$ & TCE & 1, 2-DCPa & $\begin{array}{c}1,1,2- \\
\text { TCA }\end{array}$ & PCE & $\begin{array}{c}\operatorname{trans-1,} \\
\text { DCE }\end{array}$ \\
\hline 3SF-B854-015 & $7 / 31 / 96$ & $<0.0007$ & $<0.0011$ & $<0.0021$ & $0.0092^{\mathrm{F}}$ & $<0.0011$ & $<0.0014$ & $<0.0011$ & 0.0157 & $<0.0013$ & $<0.0015$ & $<0.0019$ & $<0.0045$ \\
\hline 3SF-B854-016 & $7 / 31 / 96$ & $<0.0008$ & $<0.0012$ & $<0.0023$ & $0.0033^{F}$ & $<0.0012$ & $<0.0015$ & $<0.0012$ & $<0.0016$ & $<0.0014$ & $<0.0016$ & $<0.002$ & $<0.0048$ \\
\hline 3SF-B854-017 & $7 / 31 / 96$ & $<0.0009$ & $<0.0014$ & $<0.0026$ & $0.002^{\mathrm{F}}$ & $<0.0014$ & $<0.0017$ & $<0.0014$ & $<0.0019$ & $<0.0016$ & $<0.0019$ & $<0.0023$ & $<0.0055$ \\
\hline 3SF-B $854-017 \mathrm{C}$ & $7 / 31 / 96$ & $<0.0009$ & $<0.0014$ & $<0.0026$ & $0.0024 \mathrm{~F}$ & $<0.0014$ & $<0.0017$ & $<0.0014$ & $<0.0019$ & $<0.0016$ & $<0.0019$ & $<0.0023$ & $<0.0055$ \\
\hline 3SF-B854-018 & $7 / 31 / 96$ & $<0.0009$ & $<0.0014$ & $<0.0027$ & $0.0134 \mathrm{~F}$ & $<0.0014$ & $<0.0017$ & $<0.0014$ & $<0.0019$ & $<0.0017$ & $<0.002$ & $<0.0024$ & $<0.0059$ \\
\hline 3SF-B854-019 & $7 / 31 / 96$ & $<0.0009$ & $<0.0014$ & $<0.0027$ & $0.002^{\mathrm{F}}$ & $<0.0014$ & $<0.0017$ & $<0.0014$ & $<0.0019$ & $<0.0016$ & $<0.0019$ & $<0.0024$ & $<0.0057$ \\
\hline 3SF-B854-019b & $7 / 31 / 96$ & $<0.0011$ & $<0.0017$ & $<0.0032$ & $0.0025^{\mathrm{F}}$ & $<0.0017$ & $<0.002$ & $<0.0017$ & $<0.0022$ & $<0.0019$ & $<0.0023$ & $<0.0028$ & $<0.0068$ \\
\hline 3SF-B854-020 & $7 / 31 / 96$ & $<0.0009$ & $<0.0014$ & $<0.0027$ & $0.0041^{\mathrm{F}}$ & $<0.0014$ & $<0.0017$ & $<0.0014$ & $<0.0019$ & $<0.0017$ & $<0.002$ & $<0.0024$ & $<0.0059$ \\
\hline 3SF-B854-021 & $8 / 1 / 96$ & $<0.0008$ & $<0.0013$ & $<0.0025$ & $0.0035^{\mathrm{F}}$ & $<0.0013$ & $<0.0016$ & $<0.0013$ & $<0.0018$ & $<0.0015$ & $<0.0018$ & $<0.0022$ & $<0.0053$ \\
\hline 3 SF-B854-021 $\mathrm{c}$ & $8 / 1 / 96$ & $<0.0009$ & $<0.0013$ & $<0.0026$ & $0.0031^{\mathrm{F}}$ & $<0.0013$ & $<0.0017$ & $<0.0014$ & $<0.0018$ & $<0.0016$ & $<0.0019$ & $<0.0023$ & $<0.0055$ \\
\hline 3SF-B854-021a & $8 / 1 / 96$ & $<0.0009$ & $<0.0013$ & $<0.0026$ & $0.0031^{F}$ & $<0.0013$ & $<0.0017$ & $<0.0014$ & $<0.0018$ & $<0.0016$ & $<0.0019$ & $<0.0023$ & $<0.0055$ \\
\hline 3SF-B854-022 & $8 / 1 / 96$ & $<0.001$ & $<0.0015$ & $<0.0029$ & $0.0072^{\mathrm{F}}$ & $<0.0015$ & $<0.0018$ & $<0.0015$ & $<0.002$ & $<0.0017$ & $<0.002$ & $<0.0025$ & $<0.0061$ \\
\hline $\begin{array}{l}\text { 3SF-B854-023 } \\
\text { 3SF-B854-024 }\end{array}$ & $\begin{array}{l}8 / 1 / 96 \\
8 / 1 / 96\end{array}$ & $\begin{array}{l}<0.0009 \\
<0.0009\end{array}$ & $\begin{array}{l}<0.0014 \\
<0.0013\end{array}$ & $\begin{array}{l}<0.0027 \\
<0.0026\end{array}$ & $\begin{array}{l}<0.0012 \\
0.0036^{\mathrm{F}}\end{array}$ & $\begin{array}{l}<0.0014 \\
<0.0013\end{array}$ & $\begin{array}{l}<0.0017 \\
<0.0017\end{array}$ & $\begin{array}{l}<0.0014 \\
<0.0014\end{array}$ & $\begin{array}{l}<0.0019 \\
<0.0018\end{array}$ & $\begin{array}{l}<0.0016 \\
<0.0016\end{array}$ & $\begin{array}{l}<0.0019 \\
<0.0019\end{array}$ & $\begin{array}{l}<0.0024 \\
<0.0023\end{array}$ & $\begin{array}{l}<0.0056 \\
<0.0055\end{array}$ \\
\hline 3SF-B854-025 & $8 / 1 / 96$ & $<0.0009$ & $<0.0013$ & $<0.0026$ & $0.0019 \mathrm{~F}$ & $<0.0013$ & $<0.0017$ & $<0.0014$ & $<0.0018$ & $<0.0016$ & $<0.0019$ & $<0.0023$ & $<0.0055$ \\
\hline 3SF-B854-026 & $8 / 1 / 96$ & $<0.0008$ & $<0.0013$ & $<0.0025$ & $0.0046^{\mathrm{F}}$ & $<0.0013$ & $<0.0016$ & $<0.0013$ & $<0.0017$ & $<0.0015$ & $<0.0018$ & $<0.0022$ & $<0.0052$ \\
\hline
\end{tabular}

a Control point sample.

c Collocated sample.

F Analyte found in the equipment blank. Sample results were not blank subtracted.

J Analyte concentration estimated because it was detected below the detection limit.

Note: The $<$ sign indicates that the flux rate was calculated based on the analyte detection limit. 
respectively. Building 854 can be broken down into individual lengths of $40 \mathrm{~m}$ for Building 854F, $25 \mathrm{~m}$ for Building 854E, $45 \mathrm{~m}$ for Building 854A, $45 \mathrm{~m}$ for Building 854B, and $45 \mathrm{~m}$ for Building 854D. To be conservative, a downwind length of $200 \mathrm{~m}$ was used for Building 854 complex. In addition, the conservative ASTM default parameters for wind speed $(2.25 \mathrm{~m} / \mathrm{sec})$ and mixing height $(2 \mathrm{~m})$ were used in the model. The annual average wind speed reported for Site 300 in the LLNL Environmental Report for 1995, is approximately $5.5 \mathrm{~m} / \mathrm{sec}$ (Lentzner et. al. 1996). This wind speed would result in even lower ambient air concentrations.

The maximum measured flux rates from Table 4-4, modeled exposure-point concentrations, and the U.S. EPA Region IX PRGs are presented in Table 4-5.

The VOC concentrations detected in the canisters from the ambient air sampling are directly measured inhalation exposure-point concentrations. Table 4-6 presents the maximum outdoor ambient air sample VOC concentrations compared to the applicable PRGs. Table 4-7 presents the building indoor ambient air VOCs concentrations compared to the applicable PRGs. In instances where the analyte was not detected, the maximum detection limit was compared to the PRG. When an exposure-point concentration in air is below the PRG, the analyte does not represent a potential health risk, therefore the calculation of cancer risk is not necessary. However, when an analyte is detected at a concentration greater then the PRG, the associated cancer risk was calculated. To provide additional information, the cancer risk associated with analyte detection limits greater than their respective PRGs was also calculated. 
Table 4-5. Building 830, 832, and 854 VOC exposure-point concentrations for outdoor air calculated using the maximum soil flux rate.

\begin{tabular}{|c|c|c|c|}
\hline Analyte & $\begin{array}{l}\text { Maximum } \\
\text { Measured Flux } \\
{\left[\mu \mathrm{g} /\left(\mathrm{m}^{2} \cdot \sec \right)\right]^{\mathrm{a}}}\end{array}$ & $\begin{array}{c}\text { Calculated } \\
\text { Outdoor Air } \\
\text { Concentration } \\
(\mathrm{ppb} / \mathrm{v})\end{array}$ & $\begin{array}{l}\text { EPA Region } \\
\text { IX PRGs } \\
\left(p p b_{v / v}\right)\end{array}$ \\
\hline \multicolumn{4}{|l|}{ Building 830} \\
\hline Vinyl chloride & $<0.0010$ & 0.00346 & 0.009 \\
\hline 1,1-Dichloroethene & $<0.0015$ & 0.00346 & 0.010 \\
\hline Freon 113 & $<0.0030$ & 0.00346 & 4036 \\
\hline Methylene Chloride & $0.0157 \mathrm{~b}$ & 0.0402 & 1.178 \\
\hline cis-1,2-Dichloroethene & $<0.0015$ & 0.00346 & 9.312 \\
\hline Chloroform & $<0.0015$ & 0.00281 & 0.017 \\
\hline 1,2-Dichloroethane & $<0.0016$ & 0.00346 & 0.018 \\
\hline Trichloroethene & 0.0032 & 0.00523 & 0.204 \\
\hline 1,2-Dichloropropane & $<0.0018$ & 0.00346 & 0.021 \\
\hline $1,1,2$-Trichloroethane & $<0.0021$ & 0.00346 & 0.022 \\
\hline Tetrachloroethene & $<0.0026$ & 0.00346 & 0.485 \\
\hline trans-1,2-Dichloroethane & $<0.0062$ & 0.0137 & 18.372 \\
\hline \multicolumn{4}{|l|}{ Building 832} \\
\hline Vinyl chloride & $<0.0010$ & 0.00687 & 0.009 \\
\hline 1,1-Dichloroethene & $<0.0015$ & 0.00687 & 0.010 \\
\hline Freon 113 & $<0.0030$ & 0.00687 & 4036 \\
\hline Methylene Chloride & $0.0073^{b}$ & 0.0371 & 1.178 \\
\hline cis-1,2-Dichloroethene & $<0.0015$ & 0.00655 & 9.312 \\
\hline Chloroform & $<0.0019$ & 0.00687 & 0.017 \\
\hline 1,2-Dichloroethane & $<0.0016$ & 0.00687 & 0.018 \\
\hline Trichloroethene & $<0.0021$ & 0.00687 & 0.204 \\
\hline 1,2-Dichloropropane & $<0.0018$ & 0.00687 & 0.021 \\
\hline $1,1,2$-Trichloroethane & $<0.0021$ & 0.00687 & 0.022 \\
\hline Tetrachloroethene & $<0.0026$ & 0.00687 & 0.485 \\
\hline trans-1,2-Dichloroethane & $<0.0062$ & 0.0271 & 18.372 \\
\hline \multicolumn{4}{|l|}{ Building 854} \\
\hline Vinyl chloride & $<0.0011$ & $0.0123^{c}$ & 0.009 \\
\hline 1,1-Dichloroethene & $<0.0017$ & $0.0190^{c}$ & 0.010 \\
\hline Freon 113 & $<0.0032$ & 0.0185 & 4036 \\
\hline Methylene Chloride & $0.0252^{b}$ & 0.322 & 1.178 \\
\hline cis-1,2-Dichloroethene & $<0.0017$ & 0.0190 & 9.312 \\
\hline Chloroform & $<0.0020$ & $0.0182^{c}$ & 0.017 \\
\hline 1,2-Dichloroethane & $<0.0017$ & $0.0186^{\mathrm{c}}$ & 0.018 \\
\hline Trichloroethene & 0.0157 & 0.130 & 0.204 \\
\hline 1,2-Dichloropropane & $<0.0019$ & 0.0182 & 0.021 \\
\hline 1,1,2-Trichloroethane & $<0.0023$ & 0.0187 & 0.022 \\
\hline Tetrachloroethene & 0.0034 & 0.0222 & 0.485 \\
\hline trans-1,2-Dichloroethane & $<0.0068$ & 0.0745 & 18.372 \\
\hline
\end{tabular}

\footnotetext{
a Maximum calculated VOC flux rate or detection limit (indicated by $<$ ), whichever was greater.

b Compound detected in chamber blanks.

c Concentration greater then PRG.
} 
Table 4-6. Maximum measured VOC concentrations in Building 830, 832, and 854 outdoor ambient air samples compared to the PRGs.

\begin{tabular}{|c|c|c|}
\hline Analyte & $\begin{array}{c}\text { Maximum Measured } \\
\text { Outdoor Air } \\
\text { Concentration }\left(\mathrm{ppb}_{\mathrm{v} / \mathrm{v}}\right)^{\mathrm{a}}\end{array}$ & $\begin{array}{c}\text { EPA Region IX PRGS } \\
\left(\mathrm{ppb}_{\mathrm{v} / \mathrm{v})}\right.\end{array}$ \\
\hline \multicolumn{3}{|l|}{$\begin{array}{l}\text { Building } 830 \\
\end{array}$} \\
\hline Vinyl chloride & $0.091^{\mathrm{c}}$ & 0.009 \\
\hline 1,1-Dichloroethene & $<0.051^{\mathrm{c}}$ & 0.010 \\
\hline Freon 113 & 0.11 & 4036 \\
\hline Methylene Chloride & $0.62^{b}$ & 1.178 \\
\hline cis-1,2-Dichloroethene & $<0.051$ & 9.312 \\
\hline Chloroform & $0.49 \mathrm{c}$ & 0.017 \\
\hline 1,2-Dichloroethane & $0.41^{\mathrm{c}}$ & 0.018 \\
\hline Trichloroethene & $0.26^{\mathrm{c}}$ & 0.204 \\
\hline 1,2-Dichloropropane & $<0.13^{\mathrm{c}}$ & 0.021 \\
\hline 1,1,2-Trichloroethane & $<0.051^{\mathrm{c}}$ & 0.022 \\
\hline Tetrachloroethene & 0.072 & 0.485 \\
\hline trans-1,2-Dichloroethane & $<0.051$ & 18.372 \\
\hline \multicolumn{3}{|l|}{ Building 832} \\
\hline Vinyl chloride & $<0.045^{\mathrm{c}}$ & 0.009 \\
\hline 1,1-Dichloroethene & $<0.045^{\mathrm{c}}$ & 0.010 \\
\hline Freon 113 & 0.1 & 4036 \\
\hline Methylene Chloride & $0.74 \mathrm{~b}$ & 1.178 \\
\hline cis-1,2-Dichloroethene & $<0.045$ & 9.312 \\
\hline Chloroform & $<0.045^{\mathrm{c}}$ & 0.017 \\
\hline 1,2-Dichloroethane & $<0.11^{\mathrm{c}}$ & 0.018 \\
\hline Trichloroethene & $<0.045$ & 0.204 \\
\hline 1,2-Dichloropropane & $<0.11^{\mathrm{c}}$ & 0.021 \\
\hline 1,1,2-Trichloroethane & $<0.045^{\mathrm{c}}$ & 0.022 \\
\hline Tetrachloroethene & $<0.045$ & 0.485 \\
\hline trans-1,2-Dichloroethane & $<0.045$ & 18.372 \\
\hline \multicolumn{3}{|l|}{ Building 854} \\
\hline Vinyl chloride & $<0.050^{\mathrm{c}}$ & 0.009 \\
\hline 1,1-Dichloroethene & $<0.050^{\mathrm{c}}$ & 0.010 \\
\hline Freon 113 & 0.13 & 4036 \\
\hline Methylene Chloride & $0.32^{b}$ & 1.178 \\
\hline cis-1,2-Dichloroethene & $<0.050$ & 9.312 \\
\hline Chloroform & $1^{\mathrm{c}}$ & 0.017 \\
\hline 1,2-Dichloroethane & $<0.13^{\mathrm{c}}$ & 0.018 \\
\hline Trichloroethene & $<0.050$ & 0.204 \\
\hline 1,2-Dichloropropane & $<0.13^{\mathrm{c}}$ & 0.021 \\
\hline 1,1,2-Trichloroethane & $<0.050^{\mathrm{c}}$ & 0.022 \\
\hline Tetrachloroethene & 0.4 & 0.485 \\
\hline trans-1,2-Dichloroethane & $<0.050$ & 18.372 \\
\hline
\end{tabular}


a Maximum measured VOC concentration or detection limit (indicated by $<$ ), whichever was greater.

b Compound detected in the analytical laboratory method blank.

c Concentration or detection limit greater then PRG. 
Table 4-7. Directly measured VOC concentrations in Building 830, 832, and 854 indoor ambient air samples compared to the PRGs.

\begin{tabular}{|c|c|c|}
\hline Analyte & $\begin{array}{c}\text { Maximum Measured } \\
\text { Indoor Air } \\
\text { Concentration }\left(\mathrm{ppb}_{\mathrm{v} / \mathrm{v}}\right)^{\mathrm{a}}\end{array}$ & $\begin{array}{c}\text { EPA Region IX PRGs } \\
\left(\mathrm{ppb}_{\mathrm{v} / \mathrm{v})}\right.\end{array}$ \\
\hline \multicolumn{3}{|l|}{ Building 830} \\
\hline Vinyl chloride & $0.14^{\mathrm{c}}$ & 0.009 \\
\hline 1,1-Dichloroethene & $<0.043^{\mathrm{c}}$ & 0.010 \\
\hline Freon 113 & 0.15 & 4036 \\
\hline Methylene Chloride & $0.5^{\mathrm{b}}$ & 1.178 \\
\hline cis-1,2-Dichloroethene & $<0.043$ & 9.312 \\
\hline Chloroform & $<0.043^{c}$ & 0.017 \\
\hline 1,2-Dichloroethane & $<0.11^{\mathrm{c}}$ & 0.018 \\
\hline Trichloroethene & $0.21^{\mathrm{c}}$ & 0.204 \\
\hline 1,2-Dichloropropane & $<0.11^{\mathrm{c}}$ & 0.021 \\
\hline 1,1,2-Trichloroethane & $<0.043^{c}$ & 0.022 \\
\hline Tetrachloroethene & $<0.043$ & 0.485 \\
\hline trans-1,2-Dichloroethane & $<0.043$ & 18.372 \\
\hline \multicolumn{3}{|l|}{ Building 832} \\
\hline Vinyl chloride & $<0.050^{\mathrm{c}}$ & 0.009 \\
\hline 1,1-Dichloroethene & $<0.050^{\mathrm{c}}$ & 0.010 \\
\hline Freon 113 & 0.16 & 4036 \\
\hline Methylene Chloride & $0.32^{b}$ & 1.178 \\
\hline cis-1,2-Dichloroethene & $<0.050$ & 9.312 \\
\hline Chloroform & $0.064^{\mathrm{c}}$ & 0.017 \\
\hline 1,2-Dichloroethane & $<0.12^{\mathrm{c}}$ & 0.018 \\
\hline Trichloroethene & $<0.050$ & 0.204 \\
\hline 1,2-Dichloropropane & $0.43^{\mathrm{c}}$ & 0.021 \\
\hline 1,1,2-Trichloroethane & $<0.050^{\mathrm{c}}$ & 0.022 \\
\hline Tetrachloroethene & $<0.050$ & 0.485 \\
\hline trans-1,2-Dichloroethane & $<0.050$ & 18.372 \\
\hline \multicolumn{3}{|l|}{ Building $854 F$} \\
\hline Vinyl chloride & $<0.045^{\mathrm{c}}$ & 0.009 \\
\hline 1,1-Dichloroethene & $<0.045^{c}$ & 0.010 \\
\hline Freon 113 & 0.15 & 4036 \\
\hline Methylene Chloride & $0.24^{\mathrm{b}}$ & 1.178 \\
\hline cis-1,2-Dichloroethene & $<0.045$ & 9.312 \\
\hline Chloroform & $0.51^{\mathrm{c}}$ & 0.017 \\
\hline 1,2-Dichloroethane & $<0.11^{\mathrm{c}}$ & 0.018 \\
\hline Trichloroethene & $0.45^{\mathrm{c}}$ & 0.204 \\
\hline 1,2-Dichloropropane & $<0.11^{\mathrm{c}}$ & 0.021 \\
\hline 1,1,2-Trichloroethane & $<0.045^{\mathrm{c}}$ & 0.022 \\
\hline Tetrachloroethene & 0.05 & 0.485 \\
\hline trans-1,2-Dichloroethane & $<0.045$ & 18.372 \\
\hline
\end{tabular}


Table 4-7. Continued.

\begin{tabular}{|c|c|c|}
\hline Analyte & $\begin{array}{c}\text { Maximum Measured } \\
\text { Indoor Air } \\
\text { Concentration }\left(p p b_{v} / v\right)^{a}\end{array}$ & $\begin{array}{c}\text { EPA Region IX PRGs } \\
\left(\mathrm{ppb}_{\mathrm{v} / \mathrm{v})}\right.\end{array}$ \\
\hline Building 854A & & \\
\hline Vinyl chloride & $<0.055^{c}$ & 0.009 \\
\hline 1,1-Dichloroethene & $<0.055^{\mathrm{c}}$ & 0.010 \\
\hline Freon 113 & 2 & 4036 \\
\hline Methylene Chloride & $7.7 \mathrm{bc}$ & 1.178 \\
\hline cis-1,2-Dichloroethene & $<0.055$ & 9.312 \\
\hline Chloroform & $<0.055^{\mathrm{c}}$ & 0.017 \\
\hline 1,2-Dichloroethane & $<0.14^{\mathrm{c}}$ & 0.018 \\
\hline Trichloroethene & $<0.055$ & 0.204 \\
\hline 1,2-Dichloropropane & $<0.14^{\mathrm{c}}$ & 0.021 \\
\hline 1,1,2-Trichloroethane & $<0.055^{\mathrm{c}}$ & 0.022 \\
\hline Tetrachloroethene & 0.046 & 0.485 \\
\hline trans-1,2-Dichloroethane & $<0.055$ & 18.372 \\
\hline
\end{tabular}

a Maximum measured VOC concentration or detection limit (indicated by $<$ ), whichever was greater.

b Compound detected in the analytical laboratory method blank.

c Concentration or detection limit greater then PRG. 


\section{Building 830 Exposure-point Concentration Results}

Building 830 Exposure-point Concentrations Calculated From EIFC Sample Results

The calculated outdoor air concentrations for Building 830 presented in Table 4-5 are all below the PRGs and do not represent a potential for adverse health effects, therefore, no calculation of health risk was performed on the EIFC sample results.

Building 830 Directly Measured Exposure-point concentrations

Based upon the single detection of TCE in the flux chamber effluent and the assumption that the resulting flux is prevalent in the vicinity of Building 830, the maximum estimated exposure-point concentration would be approximately five parts per trillion $\left(5 \mathrm{ppt}_{\mathrm{V}} / \mathrm{v}\right)$. The concentration would be too small to measure even using the EPAT014 with SIMs.

Therefore, based upon the soil vapor flux measurements, and the fact that only TCE was detected in subsurface soil vapor samples, we would not expect to see measurable concentrations of any of the compounds from the analyte list in the ambient air samples. However, as presented in Tables 4-6 and 4-7, several VOCs were detected in the indoor and outdoor ambient air samples at Building 830. The detected concentrations were compared to the PRGs. For indoor air, only vinyl chloride and TCE were above the PRGs. For outdoor air, vinyl chloride, $\mathrm{CHCl} 3,1,2-\mathrm{DCA}$, and TCE were detected at concentrations greater then the PRGs. When there were no detections of an analyte, the maximum detection limit was compared to the PRGs. Several analytes including 1,1-DCE, CHCl3 (indoor only), 1,2-DCA (indoor only), 1,2-DCPa, and 1,1,2-TCA had detection limits greater then the PRGs. The VOC inhalation risk was calculated for those analytes that had a maximum detection or detection limit greater then the PRGs. 


\section{Building 832 Exposure-point Concentration Results}

Building 832 Exposure-point Concentrations Calculated From EIFC Sample Results

Of the calculated outdoor air concentrations for Building 832 presented in Table 4-5, only $\mathrm{MeCl} 2$ was detected. All exposure-point concentrations are below the PRGs and do not represent a potential for adverse health effects, therefore, no calculation of health risk was performed.

Building 832 Directly Measured Exposure-point concentrations

Based upon the soil vapor flux measurements, and the fact that only TCE and 1, 1-DCE were detected in subsurface soil vapor samples, we would not expect to see measurable concentrations of any of the compounds from the analyte list in the ambient air samples. However, as presented in Tables 4-6 and 4-7, several VOCs were detected in the indoor and outdoor ambient air samples at Building 832. The detected concentrations were compared to the PRGs. For indoor air, only 1,2-DCPa and $\mathrm{CHCl} 3$ were above the PRGs. No analytes were detected greater then the PRGs in outdoor air. When there were no detections of an analyte, the maximum detection limit was compared to the PRGs. Several analytes including vinyl chloride, 1,1-DCE, 1,2-DCA, CHCl3 (outdoor only), 1,2-DCPa (outdoor only), and 1,1,2-TCA had detection limits greater then the PRGs. The VOC inhalation risk was calculated for those analytes that had a maximum detection or detection limit greater then the PRGs. 


\section{Building 854 Exposure-point Concentration Results}

Building 854 Exposure-point Concentrations Calculated From EIFC Sample Results

Of the calculated outdoor air concentrations for Building 854 presented in Table 4-5, only MeCl2, TCE (3SF-854-001, 002, 004, 014, 015), and PCE (3SF-854-001) were detected in flux chamber effluent samples. The resultant exposure-point concentrations are all below the PRGs. When there were no detections of an analyte, the maximum detection limit was used to calculate a flux and an exposure-point concentration, which was subsequently compared to the PRG. Several analytes, including vinyl chloride, 1,1-DCE, $\mathrm{CHCl} 3$, and 1,2-DCA had exposure-point concentrations based on the detection limit just above the PRGs. However, these analytes were not detected in the flux chamber effluent samples or during the SVS. The health risk was calculated for the VOCs with exposurepoint concentrations above the PRGs.

Building 854 Directly Measured Exposure-point concentrations

Based upon the soil vapor flux measurements, and the fact that only TCE was detected in subsurface soil vapor samples, we would not expect to see measurable concentrations of any of the compounds on the analyte list in the ambient air samples. However, as presented in Tables 4-6 and 4-7, several VOCs were detected in the indoor and outdoor ambient air samples at the Building 854 complex. The detected concentrations were compared to the PRGs. Only MeCl2 (indoor 854A), TCE (indoor 854F) and $\mathrm{CHCl} 3$ (indoor $854 \mathrm{~F}$ and outdoor) were above the PRGs. When there were no detections of an analyte, the maximum detection limit was compared to the PRGs. Several analytes including vinyl chloride, 1,1-DCE, CHCl3 (indoor 854A), 1,2-DCA, 1,2-DCPa, and 
1,1,2-TCA had detection limits greater then the PRGs. The VOC inhalation risk was calculated for those analytes that had a maximum detection or detection limit greater then the PRGs.

\section{$\underline{\text { Risk Assessment }}$}

The third subproblem was to use the VOC exposure-point concentrations in air as determined by the analysis of the EIFC and ambient air samples to determine potential inhalation cancer risk for on-site LLNL workers using standard EPA risk assessment models. The corresponding subhypothesis was that the calculated exposure-point concentrations can be used as inputs to estimate inhalation cancer risks for on-site workers at LLNL resulting in cancer risks that are well below levels of regulatory concern.

The average daily intake of a contaminant attributable to the inhalation of VOCs from subsurface soil and the total chemical specific individual life-time risk above background of developing cancer were calculated. To calculate the average daily intake the following data were needed; 1) the mathematically modeled ambient air exposure-point concentrations from the Building 830, 832, and 854 exposure assessment, rate of contaminant intake, exposure frequency, exposure duration, body weight, and averaging time for an individual where exposure may result in health effect. To calculate cancer risk, the average daily intake and pathway-specific cancer potency slope factor were necessary.

Average Daily Intake of Contaminant Attributable to the Inhalation of VOCs from Subsurface Soil

The adult on-site worker average daily intake of contaminant attributable to the inhalation of VOCs from the subsurface soil was calculated using Equations 2-1 and 2-2. 
For the Building 830, 832, and 854 exposure assessment, an exposure frequency of 83.33 $\mathrm{d} / \mathrm{y}$ was used since a worker is exposed only $8 \mathrm{hr}$. of a $24 \mathrm{hr}$. day, 5 days a week for 50 weeks (assuming 2 weeks vacation). This differs from the Site 300 SWRI report (Webster-Scholten et al. 1994) which conservatively used the exposure frequency of 250 $\mathrm{d} / \mathrm{y}$ for (50 weeks/year, 5 days/week). The Table 4-8 shows the variables used for the PEF calculation. Once the PEF is calculated, the average daily intake can then be calculated by multiplying the modeled or measured contaminant concentration in air with the PEF. The PEF was multiplied by the measured or calculated exposure-point concentrations or detection limits that were above the PRGs. Table 4-9 presents the exposure-point concentrations, PEFs and the resultant daily intakes. The daily intakes range from $6.2 \mathrm{x}$ $10^{-4}$ to $7.3 \times 10^{-7} \mathrm{mg} /(\mathrm{kg} \bullet \mathrm{d})$. The calculated daily intake results were then used to determine inhalation cancer risk.

\section{Chemical Specific Individual Life-time Cancer Risk}

To calculate chemical specific individual life-time risk above background of developing cancer, the following equation is used:

Cancer Risk $=$ Daily Intake $\mathrm{x}$ Pathway-specific Cancer Potency (slope) Factor (CPF)

The VOC inhalation cancer risks calculated for indoor and outdoor air that had either VOC detections or detection limits greater then the PRGs are shown in Table 4-10. When there were multiple detections, the maximum concentration was used to calculate risk. The cancer risk calculation results are described below. 
Table 4-8. Pathway exposure factor for adult on-site inhalation of VOCs.

\begin{tabular}{cccccc}
\hline \hline $\begin{array}{c}\text { Rate of } \\
\text { Intake } \\
\left(\mathbf{m}^{\mathbf{3}} / \mathbf{d}\right)\end{array}$ & $\begin{array}{c}\text { Exposure } \\
\text { Frequency } \\
(\mathbf{d} / \mathbf{y})\end{array}$ & $\begin{array}{c}\text { Exposure } \\
\text { Duration } \\
(\mathbf{y})\end{array}$ & $\begin{array}{c}\text { Body } \\
\text { Weight } \\
(\mathbf{k g})\end{array}$ & $\begin{array}{c}\text { Averaging } \\
\text { Time }(\mathbf{d})\end{array}$ & $\begin{array}{c}\text { Pathway } \\
\text { Exposure } \\
\text { Factor } \\
\mathbf{3} / \mathbf{( k g} \cdot \mathbf{d})]\end{array}$ \\
\hline 20 & 83.33 & 25 & 70 & $2.56 \times 10^{4}$ & $2.33 \times 10^{-2}$ \\
\hline \hline
\end{tabular}


Table 4-9. Adult on-site worker average daily intake of contaminant attributable to the inhalation of VOCs $[\mathrm{mg} /(\mathrm{kg} \bullet \mathrm{d})]$.

\begin{tabular}{|c|c|c|c|c|}
\hline Compounda $^{a}$ & $\begin{array}{c}\text { Concentration } \\
\left(\mathbf{p p}_{\mathrm{v} / \mathrm{v})}\right.\end{array}$ & $\begin{array}{c}\text { Concentration } \\
\left(\mathbf{m g} / \mathrm{m}^{3}\right)\end{array}$ & $\begin{array}{c}\text { PEFb } \\
\left(\mathrm{m}^{3} / \mathrm{kg}^{\circ} \mathrm{d}\right)\end{array}$ & $\begin{array}{c}\text { Daily } \\
\text { Intakec } \\
{\left[\mathrm{mg} /\left(\mathrm{kg}^{\bullet} \mathrm{d}\right]\right.}\end{array}$ \\
\hline \multicolumn{5}{|c|}{ Building 830 Daily Intake Based on Outdoor Ambient Air Samples } \\
\hline Vinyl chloride & 9.10E-02 & 2.331E-04 & $2.330 \mathrm{E}-02$ & 5.431E-06 \\
\hline 1,1-Dichloroethene & $<5.10 \mathrm{E}-02$ & 2.027E-04 & 2.330E-02 & 4.724E-06 \\
\hline Chloroform & 4.90E-01 & $2.398 \mathrm{E}-03$ & $2.330 \mathrm{E}-02$ & $5.587 \mathrm{E}-05$ \\
\hline 1,2-Dichloroethane & 4.10E-01 & $1.664 \mathrm{E}-03$ & $2.330 \mathrm{E}-02$ & 3.876E-05 \\
\hline Trichloroethene & $2.60 \mathrm{E}-01$ & $1.400 \mathrm{E}-03$ & $2.330 \mathrm{E}-02$ & $3.262 \mathrm{E}-05$ \\
\hline 1,2-Dichloropropane & $<1.30 \mathrm{E}-01$ & $6.020 \mathrm{E}-04$ & 2.330E-02 & $1.403 \mathrm{E}-05$ \\
\hline 1,1,2-Trichloroethane & $<5.10 \mathrm{E}-02$ & $2.788 \mathrm{E}-04$ & 2.330E-02 & $6.497 \mathrm{E}-06$ \\
\hline \multicolumn{5}{|c|}{ Building 830 Daily Intake Based on Indoor Ambient Air Samples } \\
\hline Vinyl chloride & 1.40E-01 & 3.586E-04 & $2.330 \mathrm{E}-02$ & $8.356 \mathrm{E}-06$ \\
\hline 1,1-Dichloroethene & $<4.30 \mathrm{E}-02$ & $1.709 \mathrm{E}-04$ & $2.330 \mathrm{E}-02$ & $3.983 \mathrm{E}-06$ \\
\hline Chloroform & $<4.30 \mathrm{E}-02$ & 2.104E-04 & $2.330 \mathrm{E}-02$ & 4.903E-06 \\
\hline 1,2-Dichloroethane & $<1.10 \mathrm{E}-01$ & 4.463E-04 & $2.330 \mathrm{E}-02$ & $1.040 \mathrm{E}-05$ \\
\hline Trichloroethene & $2.10 \mathrm{E}-01$ & $1.131 \mathrm{E}-03$ & $2.330 \mathrm{E}-02$ & $2.635 \mathrm{E}-05$ \\
\hline 1,2-Dichloropropane & $<1.10 \mathrm{E}-01$ & 5.094E-04 & $2.330 \mathrm{E}-02$ & $1.187 \mathrm{E}-05$ \\
\hline 1,1,2-Trichloroethane & $<4.30 \mathrm{E}-02$ & $2.351 \mathrm{E}-04$ & $2.330 \mathrm{E}-02$ & 5.478E-06 \\
\hline \multicolumn{5}{|c|}{ Building 832 Daily Intake Based on Outdoor Ambient Air Samples } \\
\hline Vinyl chloride & $<4.50 \mathrm{E}-02$ & $1.153 \mathrm{E}-04$ & $2.330 \mathrm{E}-02$ & $2.686 \mathrm{E}-06$ \\
\hline 1,1-Dichloroethene & $<4.50 \mathrm{E}-02$ & $1.789 \mathrm{E}-04$ & $2.330 \mathrm{E}-02$ & 4.168E-06 \\
\hline Chloroform & $<4.50 \mathrm{E}-02$ & $2.202 \mathrm{E}-04$ & $2.330 \mathrm{E}-02$ & $5.131 \mathrm{E}-06$ \\
\hline 1,2-Dichloroethane & $<1.10 \mathrm{E}-01$ & 4.463E-04 & $2.330 \mathrm{E}-02$ & $1.040 \mathrm{E}-05$ \\
\hline 1,2-Dichloropropane & $<1.10 \mathrm{E}-01$ & 5.094E-04 & $2.330 \mathrm{E}-02$ & $1.187 \mathrm{E}-05$ \\
\hline 1,1,2-Trichloroethane & $<4.50 \mathrm{E}-02$ & $2.460 \mathrm{E}-04$ & $2.330 \mathrm{E}-02$ & $5.732 \mathrm{E}-06$ \\
\hline \multicolumn{5}{|c|}{ Building 832 Daily Intake Based on Indoor Ambient Air Samples } \\
\hline Vinyl chloride & $<5.00 \mathrm{E}-02$ & 1.281E-04 & $2.330 \mathrm{E}-02$ & $2.984 \mathrm{E}-06$ \\
\hline 1,1-Dichloroethene & $<5.00 \mathrm{E}-02$ & $1.988 \mathrm{E}-04$ & $2.330 \mathrm{E}-02$ & 4.631E-06 \\
\hline Chloroform & $6.40 \mathrm{E}-02$ & $3.132 \mathrm{E}-04$ & $2.330 \mathrm{E}-02$ & 7.297E-06 \\
\hline 1,2-Dichloroethane & $<1.20 \mathrm{E}-01$ & 4.869E-04 & $2.330 \mathrm{E}-02$ & $1.134 \mathrm{E}-05$ \\
\hline 1,2-Dichloropropane & 4.30E-01 & $1.991 \mathrm{E}-03$ & $2.330 \mathrm{E}-02$ & 4.640E-05 \\
\hline 1,1,2-Trichloroethane & $<5.00 \mathrm{E}-02$ & 2.734E-04 & $2.330 \mathrm{E}-02$ & $6.369 \mathrm{E}-06$ \\
\hline \multicolumn{5}{|c|}{ Building 854 Daily Intake Based on the EIFC Samples } \\
\hline Vinyl chloride & $<1.23 \mathrm{E}-02$ & 3.151E-05 & 2.330E-02 & $7.341 \mathrm{E}-07$ \\
\hline 1,1-Dichloroethene & $<1.90 \mathrm{E}-02$ & 7.553E-05 & $2.330 \mathrm{E}-02$ & $1.760 \mathrm{E}-06$ \\
\hline Chloroform & $<1.82 \mathrm{E}-02$ & $8.906 \mathrm{E}-05$ & $2.330 \mathrm{E}-02$ & $2.075 \mathrm{E}-06$ \\
\hline 1,2-Dichloroethane & $<1.86 \mathrm{E}-02$ & 7.547E-05 & 2.330E-02 & $1.758 \mathrm{E}-06$ \\
\hline \multicolumn{5}{|c|}{ Building 854 Daily Intake Based on Outdoor Ambient Air Samples } \\
\hline Vinyl chloride & $<5.00 \mathrm{E}-02$ & 1.281E-04 & $2.330 \mathrm{E}-02$ & 2.984E-06 \\
\hline 1,1-Dichloroethene & $<5.00 \mathrm{E}-02$ & $1.988 \mathrm{E}-04$ & 2.330E-02 & 4.631E-06 \\
\hline Chloroform & $1.00 \mathrm{E}+00$ & 4.893E-03 & $2.330 \mathrm{E}-02$ & $1.140 \mathrm{E}-04$ \\
\hline 1,2-Dichloroethane & $<1.30 \mathrm{E}-01$ & $5.275 \mathrm{E}-04$ & 2.330E-02 & $1.229 \mathrm{E}-05$ \\
\hline 1,2-Dichloropropane & $<1.30 \mathrm{E}-01$ & $6.020 \mathrm{E}-04$ & 2.330E-02 & $1.403 \mathrm{E}-05$ \\
\hline 1,1,2-Trichloroethane & $<5.00 \mathrm{E}-02$ & $2.734 \mathrm{E}-04$ & $2.330 \mathrm{E}-02$ & $6.369 \mathrm{E}-06$ \\
\hline \multicolumn{5}{|c|}{ Building 854F Daily Intake Based on Indoor Ambient Air Samples } \\
\hline Vinyl chloride & $<4.50 \mathrm{E}-02$ & 1.153E-04 & 2.330E-02 & $2.686 \mathrm{E}-06$ \\
\hline hloroethene & $<4.50 \mathrm{E}-02$ & $1.789 \mathrm{E}-04$ & $2.330 \mathrm{E}-02$ & $4.168 \mathrm{E}-06$ \\
\hline Chloroform & $5.10 \mathrm{E}-01$ & $2.496 \mathrm{E}-03$ & $2.330 \mathrm{E}-02$ & $5.815 \mathrm{E}-05$ \\
\hline
\end{tabular}


Table 4-9. Continued.

\begin{tabular}{|c|c|c|c|c|}
\hline Compound $^{a}$ & $\begin{array}{c}\text { Concentration } \\
\left(\mathrm{ppb}_{\mathrm{v} / \mathrm{v})}\right.\end{array}$ & $\begin{array}{c}\text { Concentration } \\
\left(\mathbf{m g} / \mathrm{m}^{\mathbf{3}}\right)\end{array}$ & $\begin{array}{c}\text { PEFb } \\
\left(\mathrm{m}^{3} / \mathrm{kg}^{\circ} \mathrm{d}\right)\end{array}$ & $\begin{array}{c}\text { Daily } \\
\text { Intakec }^{c} \\
{[\mathrm{mg} /(\mathrm{kg} \bullet \mathrm{d}]}\end{array}$ \\
\hline 1,2-Dichloroethane & $<1.10 \mathrm{E}-01$ & $4.463 \mathrm{E}-04$ & $2.330 \mathrm{E}-02$ & $1.040 \mathrm{E}-05$ \\
\hline Trichloroethene & $4.50 \mathrm{E}-01$ & 2.423E-03 & 2.330E-02 & $5.646 \mathrm{E}-05$ \\
\hline 1,2-Dichloropropane & $<1.10 \mathrm{E}-01$ & 5.094E-04 & 2.330E-02 & $1.187 \mathrm{E}-05$ \\
\hline 1,1,2-Trichloroethane & $<4.50 \mathrm{E}-02$ & 2.460E-04 & $2.330 \mathrm{E}-02$ & $5.732 \mathrm{E}-06$ \\
\hline \multicolumn{5}{|c|}{ Building 854A Daily Intake Based on Indoor Ambient Air Samples } \\
\hline Vinyl chloride & $<5.50 \mathrm{E}-02$ & 1.409E-04 & $2.330 \mathrm{E}-02$ & $3.283 \mathrm{E}-06$ \\
\hline 1,1-Dichloroethene & $<5.50 \mathrm{E}-02$ & $2.186 \mathrm{E}-04$ & 2.330E-02 & $5.094 \mathrm{E}-06$ \\
\hline Methylene Chloride & $7.70 \mathrm{E}+00$ & 2.679E-02 & 2.330E-02 & $6.243 \mathrm{E}-04$ \\
\hline Chloroform & $<5.50 \mathrm{E}-02$ & 2.691E-04 & 2.330E-02 & $6.271 \mathrm{E}-06$ \\
\hline 1,2-Dichloroethane & $<1.40 \mathrm{E}-01$ & 5.680E-04 & $2.330 \mathrm{E}-02$ & $1.324 \mathrm{E}-05$ \\
\hline 1,2-Dichloropropane & $<1.40 \mathrm{E}-01$ & $6.484 \mathrm{E}-04$ & $2.330 \mathrm{E}-02$ & $1.511 \mathrm{E}-05$ \\
\hline 1,1,2-Trichloroethane & $<5.50 \mathrm{E}-02$ & 3.007E-04 & $2.330 \mathrm{E}-02$ & 7.006E-06 \\
\hline
\end{tabular}

a Daily intake was calculated for those compounds with detections or detection limits greater then the EPA Region IX Preliminary Remediation Goal.

b Pathway Exposure Factor.

c Daily intake was calculated using the maximum VOC concentration when detected or the detection limit (as indicated by < sign). 
Table 4-10. Chemical specific individual life-time cancer risks from the inhalation of VOCs.

\begin{tabular}{|c|c|c|c|}
\hline Compounda & $\begin{array}{c}\text { Daily Intake } \\
{[\mathrm{mg} /(\mathrm{kg} \cdot \mathrm{d}]}\end{array}$ & $\begin{array}{c}\text { EPA CPFb } \\
{[\mathrm{mg} /(\mathrm{kg} \cdot \mathrm{d})]^{-1}}\end{array}$ & Riskc \\
\hline \multicolumn{4}{|c|}{ Building 830 Cancer Risk Based on Outdoor Ambient Air Samples } \\
\hline Vinyl chloride & 5.431E-06 & 3.000E-01 & $1.629 \mathrm{E}-06$ \\
\hline 1,1-Dichloroethene & $<4.724 \mathrm{E}-06$ & $1.800 \mathrm{E}-01$ & 8.503E-07 \\
\hline Chloroform & 5.587E-05 & $8.100 \mathrm{E}-02$ & 4.525E-06 \\
\hline 1,2-Dichloroethane & 3.876E-05 & $9.100 \mathrm{E}-02$ & $3.527 \mathrm{E}-06$ \\
\hline Trichloroethene & $3.262 \mathrm{E}-05$ & $6.030 \mathrm{E}-03$ & 1.967E-07 \\
\hline 1,2-Dichloropropane & $<1.403 \mathrm{E}-05$ & $6.800 \mathrm{E}-02$ & 9.539E-07 \\
\hline 1,1,2-Trichloroethane & $<6.497 \mathrm{E}-06$ & $5.600 \mathrm{E}-02$ & 3.638E-07 \\
\hline \multicolumn{4}{|c|}{ Building 830 Cancer Risk Based on Indoor Ambient Air Samples } \\
\hline Vinyl chloride & $8.356 \mathrm{E}-06$ & $3.000 \mathrm{E}-01$ & $2.507 \mathrm{E}-06$ \\
\hline 1,1-Dichloroethene & $<3.983 \mathrm{E}-06$ & $1.800 \mathrm{E}-01$ & 7.169E-07 \\
\hline Chloroform & $<4.903 \mathrm{E}-06$ & 8.100E-02 & 3.971E-07 \\
\hline 1,2-Dichloroethane & $<1.040 \mathrm{E}-05$ & $9.100 \mathrm{E}-02$ & 9.463E-07 \\
\hline Trichloroethene & $2.635 \mathrm{E}-05$ & $6.030 \mathrm{E}-03$ & $1.589 \mathrm{E}-07$ \\
\hline 1,2-Dichloropropane & $<1.187 \mathrm{E}-05$ & $6.800 \mathrm{E}-02$ & 8.071E-07 \\
\hline 1,1,2-Trichloroethane & $<5.478 \mathrm{E}-06$ & $5.600 \mathrm{E}-02$ & 3.067E-07 \\
\hline \multicolumn{4}{|c|}{ Building 832 Cancer Risk Based on Outdoor Ambient Air Samples } \\
\hline Vinyl chloride & $<2.686 \mathrm{E}-06$ & $3.000 \mathrm{E}-01$ & 8.057E-07 \\
\hline 1,1-Dichloroethene & $<4.168 \mathrm{E}-06$ & $1.800 \mathrm{E}-01$ & 7.503E-07 \\
\hline Chloroform & $<5.131 \mathrm{E}-06$ & 8.100E-02 & 4.156E-07 \\
\hline 1,2-Dichloroethane & $<1.040 \mathrm{E}-05$ & $9.100 \mathrm{E}-02$ & 9.463E-07 \\
\hline 1,2-Dichloropropane & $<1.187 \mathrm{E}-05$ & $6.800 \mathrm{E}-02$ & 8.071E-07 \\
\hline 1,1,2-Trichloroethane & $<5.732 \mathrm{E}-06$ & $5.600 \mathrm{E}-02$ & $3.210 \mathrm{E}-07$ \\
\hline \multicolumn{4}{|c|}{ Building 832 Cancer Risk Based on Indoor Ambient Air Samples } \\
\hline Vinyl chloride & $<2.984 \mathrm{E}-06$ & 3.000E-01 & 8.952E-07 \\
\hline 1,1-Dichloroethene & $<4.631 \mathrm{E}-06$ & $1.800 \mathrm{E}-01$ & 8.336E-07 \\
\hline Chloroform & 7.297E-06 & $8.100 \mathrm{E}-02$ & 5.911E-07 \\
\hline 1,2-Dichloroethane & $<1.134 \mathrm{E}-05$ & $9.100 \mathrm{E}-02$ & $1.032 \mathrm{E}-06$ \\
\hline 1,2-Dichloropropane & 4.640E-05 & $6.800 \mathrm{E}-02$ & $3.155 \mathrm{E}-06$ \\
\hline 1,1,2-Trichloroethane & $<6.369 \mathrm{E}-06$ & $5.600 \mathrm{E}-02$ & 3.567E-07 \\
\hline \multicolumn{4}{|c|}{ Building 854 Cancer Risk Based on the EIFC Samples } \\
\hline Vinyl chloride & $<7.341 \mathrm{E}-07$ & $3.000 \mathrm{E}-01$ & 2.202E-07 \\
\hline 1,1-Dichloroethene & $<1.760 \mathrm{E}-06$ & $1.200 \mathrm{E}+00$ & $2.112 \mathrm{E}-06$ \\
\hline Chloroform & $<2.075 \mathrm{E}-06$ & $8.100 \mathrm{E}-02$ & $1.681 \mathrm{E}-07$ \\
\hline 1,2-Dichloroethane & $<1.758 \mathrm{E}-06$ & $9.100 \mathrm{E}-02$ & $1.600 \mathrm{E}-07$ \\
\hline \multicolumn{4}{|c|}{ Building 854 Cancer Risk Based on Outdoor Ambient Air Samples } \\
\hline Vinyl chloride & $<2.984 \mathrm{E}-06$ & $3.000 \mathrm{E}-01$ & $8.952 \mathrm{E}-07$ \\
\hline 1,1-Dichloroethene & $<4.631 \mathrm{E}-06$ & $1.800 \mathrm{E}-01$ & 8.336E-07 \\
\hline Chloroform & $1.140 \mathrm{E}-04$ & $8.100 \mathrm{E}-02$ & $9.235 \mathrm{E}-06$ \\
\hline 1,2-Dichloroethane & $<1.229 \mathrm{E}-05$ & $9.100 \mathrm{E}-02$ & $1.118 \mathrm{E}-06$ \\
\hline 1,2-Dichloropropane & $<1.403 \mathrm{E}-05$ & $6.800 \mathrm{E}-02$ & 9.539E-07 \\
\hline 1,1,2-Trichloroethane & $<6.369 \mathrm{E}-06$ & $5.600 \mathrm{E}-02$ & 3.567E-07 \\
\hline \multicolumn{4}{|c|}{ Building 854F Cancer Risk Based on Indoor Ambient Air Samples } \\
\hline Vinyl chloride & $<2.686 \mathrm{E}-06$ & $3.000 \mathrm{E}-01$ & 8.057E-07 \\
\hline 1,1-Dichloroethene & $<4.168 \mathrm{E}-06$ & $1.800 \mathrm{E}-01$ & 7.503E-07 \\
\hline Chloroform & $5.815 \mathrm{E}-05$ & $8.100 \mathrm{E}-02$ & 4.710E-06 \\
\hline 1,2-Dichloroethane & $<1.040 \mathrm{E}-05$ & $9.100 \mathrm{E}-02$ & 9.463E-07 \\
\hline
\end{tabular}


Table 4-10. Continued.

\begin{tabular}{|c|c|c|c|}
\hline Compound $^{\mathbf{a}}$ & $\begin{array}{c}\text { Daily Intake } \\
{[\mathrm{mg} /(\mathrm{kg} \cdot \mathrm{d}]}\end{array}$ & $\begin{array}{c}\text { EPA CPFb } \\
{[\mathrm{mg} /(\mathrm{kg} \cdot \mathrm{d})]^{-1}}\end{array}$ & Riskc \\
\hline Trichloroethene & $5.646 \mathrm{E}-05$ & $6.030 \mathrm{E}-03$ & $3.405 \mathrm{E}-07$ \\
\hline 1,2-Dichloropropane & $<1.187 \mathrm{E}-05$ & $6.800 \mathrm{E}-02$ & 8.071E-07 \\
\hline 1,1,2-Trichloroethane & $<5.732 \mathrm{E}-06$ & $5.600 \mathrm{E}-02$ & $3.210 \mathrm{E}-07$ \\
\hline \multicolumn{4}{|c|}{ Building 854A Cancer Risk Based on } \\
\hline Vinyl chloride & $<3.283 \mathrm{E}-06$ & $3.000 \mathrm{E}-01$ & 9.848E-07 \\
\hline 1,1-Dichloroethene & $<5.094 \mathrm{E}-06$ & $1.800 \mathrm{E}-01$ & $9.170 \mathrm{E}-07$ \\
\hline Methylene Chloride & $6.243 \mathrm{E}-04$ & $1.600 \mathrm{E}-03$ & 9.988E-07 \\
\hline Chloroform & $<6.271 \mathrm{E}-06$ & $8.100 \mathrm{E}-02$ & 5.079E-07 \\
\hline 1,2-Dichloroethane & $<1.324 \mathrm{E}-05$ & $9.100 \mathrm{E}-02$ & $1.204 \mathrm{E}-06$ \\
\hline 1,2-Dichloropropane & $<1.511 \mathrm{E}-05$ & $6.800 \mathrm{E}-02$ & $1.027 \mathrm{E}-06$ \\
\hline 1,1,2-Trichloroethane & $<7.006 \mathrm{E}-06$ & $5.600 \mathrm{E}-02$ & 3.923E-07 \\
\hline
\end{tabular}

a Cancer risk was calculated for those compounds with detections or detection limits greater then the EPA Region IX Preliminary Remediation Goal.

b USEPA Cancer Potency Factor.

c Cancer risk was calculated using the maximum VOC concentration when detected or the detection limit (as indicated by $<$ sign). 


\section{Building 830 Cancer Risk Results}

Building 830 Cancer Risk Based on the EIFC Sample Results

The EIFC samples resulted in exposure-point concentrations less then the PRGs, no cancer risks were calculated.

Building 830 Cancer Risk Based on Outdoor Ambient Air Sample Results

Vinyl chloride, $\mathrm{CHCl} 3, \mathrm{TCE}$, and 1,2-DCA and were detected above the PRG in

Building 830 outdoor air. The cancer risks were $1.6 \times 10^{-6}, 4.5 \times 10^{-6}, 2.0 \times 10^{-7}$, and $3.5 \times 10^{-6}$ for vinyl chloride, $\mathrm{CHCl} 3$, TCE, and 1,2-DCA, respectively. 1,1-DCE, 1,2DCPa, and 1,1,2-TCA had detection limits greater then the PRGs. The cancer risks that were calculated based on the detection limits ranged from $3.6 \times 10^{-7}$ to $9.5 \times 10^{-7}$. Cancer risks for all analytes are within the Superfund National Contingency Plan acceptable exposure level range of $10^{-4}$ and $10^{-6}$.

Building 830 Cancer Risk Based on Indoor Ambient Air Sample Results

Vinyl chloride and TCE were detected above the PRGs in Building 830 indoor air. The cancer risks for vinyl chloride and TCE were $2.5 \times 10^{-6}$ and $1.6 \times 10^{-7}$, respectively. The analytes 1,1-DCE, $\mathrm{CHCl} 3,1,2-\mathrm{DCA}, 1,2-\mathrm{DCPa}$, and 1,12-TCA had detection limits greater then the PRGs. The cancer risks ranged from $3.1 \times 10^{-7}$ to $9.5 \times 10^{-7}$. All analytes are within the Superfund National Contingency Plan acceptable exposure level range of $10^{-4}$ and $10^{-6}$. 


\section{Building 832 Cancer Risk Results}

Building 832 Cancer Risk Based on the EIFC Sample Results

The EIFC samples resulted in exposure-point concentrations less then the PRGs, no cancer risks were calculated.

Building 832 Cancer Risk Based on Outdoor Ambient Air Sample Results

There were no VOCs detected above the PRGs in the outdoor air in the Building 832 area. The detection limit for vinyl chloride, 1,1-DCE, CHCl3, 1,2-DCA, 1,2-DCPa, and 1,1,2-TCA were greater then the PRGs. The cancer risks that were calculated based on the detection limits were all less then $1 \times 10^{-6}\left(3.2 \times 10^{-7}\right.$ to $\left.9.5 \times 10^{-7}\right)$ and do not represent a health risk.

Building 832 Cancer Risk Based on Indoor Ambient Air Sample Results

$\mathrm{CHCl} 3$ and 1,2-DCPa were detected inside Building 832 above the PRGs. The cancer risks were $5.9 \times 10^{-7}$ and $3.2 \times 10^{-6}$ for $\mathrm{CHCl} 3$ and $1,2-\mathrm{DCPa}$, respectively. The detection limits were greater then the PRGs for vinyl chloride, 1,1-DCE, 1,2-DCA, and 1,12-TCA. The cancer risks that were calculated based on the detection limits were determined to be in the $3.6 \times 10^{-7}$ to $1.0 \times 10^{-6}$ range. The results of the indoor air sampling for Building 832 indicate that the VOCs present do not present a potential for adverse health effects. 


\section{Building 854 Cancer Risk Results}

Building 854 Cancer Risk based on the EIFC Sample Results

The exposure-point concentrations for vinyl chloride, 1,1-DCE, $\mathrm{CHCl} 3$, and 1,2-DCA as determined by EIFC sampling were above the PRGs. These constituents were not detected in the EIFC effluent but are based on the maximum detection limit. The calculated cancer risk are $1.6 \times 10^{-7}$ to $2.1 \times 10^{-6}$ and do not represent potential for adverse health affects.

Building 854 Cancer Risk based on Outdoor Ambient Air Sample Results

$\mathrm{CHCl} 3$ was detected in the Building 854 complex outdoor air. The calculated cancer risk was $9.2 \times 10^{-6}$. The detection limit for vinyl chloride, 1,1-DCE, 1,2-DCA, 1,2DCPa, and 1,1,2-TCA were greater then the PRGs. The cancer risks that were calculated based on the detection limits were at or below $1 \times 10^{-6}$. The $\mathrm{CHCl} 3$ cancer risk represents the highest cancer risk found during the exposure assessment. The source of the $\mathrm{CHCl} 3$ is unknown. It does not appear to be volatilizing from the subsurface. $\mathrm{CHCl} 3$ is widely distributed in the atmosphere and water including municipal drinking water primarily as a consequence of chlorination (Sittig 1991). Water supplies used at Site 300 are chlorinated. The cancer risk for $\mathrm{CHCl} 3$ is within the Superfund National Contingency Plan acceptable exposure level range of $10^{-4}$ and $10^{-6}$. 
Building 854 Cancer Risk based on Indoor Ambient Air Sample Results

$\mathrm{CHCl} 3$ and TCE were detected above the PRGs inside Building 854F, while MeCl2 was detected above the PRGs inside Building 854A. The cancer risks were 4.7 x 10-6, $3.4 \times 10^{-7}$, and $1.0 \times 10^{-6}$, for $\mathrm{CHCl} 3$, TCE, and $\mathrm{MeCl} 2$, respectively. The detection limit for vinyl chloride, 1,1-DCE, CHCl3 (854A only), 1,2-DCA, 1,2-DCPa, and 1,1,2TCA were greater then the PRGs. The cancer risks that were calculated based on the detection limits were all at or below $1 \times 10^{-6}$. All analytes are within the Superfund National Contingency Plan acceptable exposure level range of $10^{-4}$ and $10^{-6}$. 


\section{CHAPTER V CONCLUSIONS}

The research described above investigated the LLNL Site 300 Buildings 830, 832, and 854 to determine if site workers might be exposed to VOCs volatilizing from the subsurface and what, if any, health risks could be attributed to the inhalation of the VOCs volatilizing from the subsurface. The EIFC methodology for measuring soil flux was employed to better characterize the site. This research also afforded an opportunity to apply EIFC methodology to CERCLA investigations at LLNL.

\section{Conclusions}

\section{EIFC Sampling and Analysis of VOCs}

The first subproblem was to identify 1) the EIFC sample collection methodology to ensure representative samples; and 2) the analytical laboratory analyses to ensure valid results.

By using a combination of EPA approved sampling strategies, the necessary samples were collected to adequately characterize the potential source area. In addition, the EIFC sampling methodology employed, which was slightly modified from the EPA EIFC methodology, ensured that the samples collected were representative of the contamination present. The EIFC and field QC samples were analyzed by a certified analytical laboratory using standard EPA methodology to ensure that the analytical results were valid, accurate, traceable, defensible, and of an adequate quality to be used in an exposure assessment. 


\section{Estimating Flux Rates and Exposure-point Concentrations}

VOC flux rates were calculated from contaminated soil and the flux rates were input into an air dispersion model to estimate VOC exposure-point concentrations in ambient air.

The flux rates were calculated using the validated analytic results obtained from the EIFC sampling and analysis event performed for the LLNL Site 300 Building 830, 832, and 854 exposure assessment. To be conservative, when no analyte concentrations were detected in the canisters, the analyte detection limit was used to calculate flux. The maximum flux rates were then used as input into a simple air dispersion box model to calculate VOC exposure-point concentrations. The ambient air concentrations calculated using the EIFC-modeling combination were compared to the PRGs. All the VOC EIFCbased exposure-point concentrations in the Building 830 and 832 areas were below the PRGs. In the Building 854 area, there were several compounds with EIFC-based exposure-point concentrations greater then the PRGs. However, the chemicals were not detected in the EIFC samples. The exposure-point concentrations were calculated based on the detection limit. Results below the PRG were taken to mean that there was no potential for adverse health effects from the inhalation of the analyte at that concentration.

Based on the results of the EIFC sampling, measurable quantities of VOCs in the ambient air were not expected. However, VOCs were detected in the ambient air samples. Since there were VOCs detected in the ambient air samples placed upgradient from the suspected contamination, it can be concluded that the presence of VOCs in the ambient air are not from VOCs volatilizing from the local subsurface, but are being contributed from another source. The directly measured VOC concentrations detected in the indoor and outdoor ambient air samples were also compared to the PRGs. When an 
analyte concentration or detection limit was greater then the PRG, the cancer risk was calculated.

\section{Risk Assessment}

The VOC exposure-point concentrations in ambient air were used to determine potential inhalation cancer risk for on-site LLNL workers using standard EPA risk assessment model.

Average daily intake of contaminant attributable to the inhalation of VOCs from the subsurface soil was calculated. This was performed for the chemicals that were either detected or had detection limits above the PRGs. The ambient air concentrations that were either measured or calculated were then multiplied by the pathway exposure factor. The chemical specific individual life-time cancer risks from the inhalation of VOCs volatilizing from the subsurface were calculated using the previously calculated daily intakes. The resultant inhalation cancer risks for Building 830 based on the ambient air samples ranged from $1.6 \times 10^{-7}$ to $4.5 \times 10^{-6}$. Building 832 cancer risks based on the ambient air samples ranged from $3.2 \times 10^{-7}$ to $3.2 \times 10^{-6}$. Building 854 was the only area to have cancer risks calculated based on the EIFC. Those cancer risks ranged from $1.6 \times 10^{-7}$ to $2.1 \times 10^{-6}$. The Building 854 cancer risks based on the ambient air samples ranged from $3.2 \times 10^{-7}$ to $9.2 \times 10^{-6}$.

All the cancer risks calculated for the Buildings 830, 832, and 854 were within the acceptable risk range of $10^{-4}$ to $10^{-6}$. However, the $9.2 \times 10^{-6}$ cancer risk for chloroform in the Building 854 outdoor ambient air is approaching the midrange of this acceptable range used to guide remediation activities, and thus is borderline acceptable. Since the chloroform is not being emitted from the subsurface based on the EIFC results, it must be from another source, possibly industrial. 


\section{Comparison of Methods for VOC Measurement}

Historically, LLNL has used three approaches for determining exposure-point concentrations: 1) mathematically modeling ground water and soil VOC concentrations; 2) combining EIFC results with an air dispersion model; and 3) directly measuring the ambient air.

A comparison of the ambient air VOC exposure-point concentrations calculated using an air dispersion model that incorporated measured flux rates to the ambient air VOC exposure-point concentrations mathematically modeled from soil concentrations for the same areas at Site 300 indicates that the flux-modeling combination results in substantially lower cancer risk estimates. The mathematical models use conservative assumptions that can inflate risk estimates. By incorporating the EIFC flux rates, the number of assumptions is reduced resulting in more plausible risk estimates. A comparison of the VOC exposure-point concentrations determined by measuring ambient air VOC concentrations directly versus the exposure-point concentrations that were mathematically modeled using soil concentrations for the same areas at Site 300 indicates that the measuring VOCs directly also results in lower cancer risk estimates. Cancer risks based on directly measured ambient concentrations may be lower since no conservative assumptions are used as in the mathematical calculations. However, the cancer risks calculated using an air dispersion model that utilizes EIFC measured flux rates were much smaller then the cancer risks that were calculated using directly measured ambient air VOC concentrations for the same areas at Site 300. EIFC results in lower risk estimates because it is very specific, while ambient air measurements cannot distinguish between VOCs volatilizing from the subsurface or other sources.

Modeling VOC air concentrations using measured VOCs soil concentrations may be necessary if no ambient air data is available and there is no time or resources to perform 
air or flux chamber sampling. Modeling VOC air concentrations could save time and money, but the resultant exposure-point concentrations may be over estimated. Contaminants detected in the ambient air by directly measuring the VOC concentration can be misleading when trying to determine the VOC inhalation cancer risk from VOCs volatilizing from the subsurface since it can not distinguish VOCs contributed from other sources. The emission isolation flux chamber method stands out as the most promising method for monitoring VOC emissions. This method has been endorsed by the for use by Resource Conservation and Recovery Act and Comprehensive Environmental Response, Compensation, and Liability Act facilities because it is simple, easily available and inexpensive. The flux chamber methodology enables the measurement of contaminants volatilizing from the subsurface. Therefore, the concentrations in ambient air contributed solely from the subsurface can be calculated. This is particularly helpful in industrial areas where VOCs are continually used. By directly measuring VOC emission rates using emission isolation flux chambers for the GSA FS, LLNL was able to completely eliminate one exposure pathway from consideration for remediation alternatives that was identified in the SWRI using a purely modeling approach. In addition, the flux chamber work performed for the Building 830, 832, and 854 exposure assessment indicated that the VOCs in ambient air are not being contributed from the subsurface and the VOC concentrations fluxing from the subsurface are much lower than have been previously modeled.

Because the three techniques for determining exposure-point concentrations have not been performed in unison at LLNL, it is difficult to draw conclusions from the concurrent comparisons. Additional studies comparing the three techniques using collocated sampling and modeling is highly desirable. 

APPENDIX A

Wind Speed and Temperature Data Collected During the Ambient Air Sampling Event at Buildings 830, 832, and 854 


\begin{tabular}{|c|c|c|c|c|}
\hline$\overline{\text { Location }}$ & $\begin{array}{c}\text { Date } \\
\text { Sampled }\end{array}$ & $\begin{array}{c}\text { Sample } \\
\text { Time (hr) }\end{array}$ & $\begin{array}{l}\text { Average } \\
\text { Wind } \\
\text { Speed } \\
(\mathrm{m} / \mathrm{s}) \\
\end{array}$ & $\begin{array}{c}\text { Average } \\
\text { Ambient } \\
\text { Temperatureb } \\
(\text { deg C }) \\
\end{array}$ \\
\hline \multicolumn{5}{|l|}{ Building 830} \\
\hline 3AA-B830-001 & $8 / 13 / 96$ & 6.78 & 1.9 & 35.0 \\
\hline 3AA-B830-002 & $8 / 13 / 96$ & 6.72 & 1.9 & 37.2 \\
\hline $3 \mathrm{AA}-\mathrm{B} 830-002^{\mathrm{C}}$ & $8 / 13 / 96$ & 6.72 & 1.9 & 37.2 \\
\hline 3AA-B830-003 & $8 / 13 / 96$ & 6.68 & 1.9 & 37.2 \\
\hline 3AA-B830-004 & $8 / 13 / 96$ & 5.65 & 1.9 & 37.2 \\
\hline 3AA-B830-001 & $8 / 14 / 96$ & 7.33 & 2.8 & 36.9 \\
\hline 3AA-B830-002 & $8 / 14 / 96$ & 7.27 & 2.8 & 38.6 \\
\hline 3AA-B830-003 & $8 / 14 / 96$ & 7.27 & 2.8 & 38.6 \\
\hline 3AA-B830-004 & $8 / 14 / 96$ & 6.92 & 2.8 & 38.6 \\
\hline \multicolumn{5}{|l|}{ Building 832} \\
\hline 3AA-B832-001 & $8 / 6 / 96$ & 6.78 & 2.4 & 22.8 \\
\hline 3AA-B832-001C & $8 / 6 / 96$ & 6.78 & 2.4 & 22.8 \\
\hline 3AA-B832-001 & $8 / 7 / 96$ & 6.41 & 2.7 & 22.9 \\
\hline 3AA-B832-002 & $8 / 6 / 96$ & 6.72 & 2.4 & 26.3 \\
\hline 3AA-B832-002 & $8 / 7 / 96$ & 6.50 & 2.7 & 30.3 \\
\hline 3AA-B832-003 & $8 / 6 / 96$ & 6.67 & 2.4 & 26.3 \\
\hline 3AA-B832-003 & $8 / 7 / 96$ & 6.30 & 2.7 & 30.3 \\
\hline 3AA-B832-004 & $8 / 6 / 96$ & 6.30 & 2.4 & 26.3 \\
\hline 3AA-B832-004 & $8 / 7 / 96$ & 6.20 & 2.7 & 30.3 \\
\hline \multicolumn{5}{|l|}{ Building 854} \\
\hline 3AA-B854-001 & $7 / 31 / 96$ & 6.47 & 2.9 & 22.0 \\
\hline 3AA-B854-001 & 8/1/96 & 6.66 & 4.4 & 25.2 \\
\hline 3AA-B854-002 & $7 / 31 / 96$ & 6.90 & 2.9 & 36.3 \\
\hline 3AA-B854-002 & 8/1/96 & 6.65 & 4.4 & 29.5 \\
\hline 3AA-B854-003 & 7/31/96 & 7.02 & 2.9 & 36.3 \\
\hline 3AA-B854-003 & 8/1/96 & 6.61 & 4.4 & 29.5 \\
\hline 3AA-B854-004 & 7/31/96 & 6.58 & 2.9 & 36.3 \\
\hline 3AA-B854-004 & 8/1/96 & 6.64 & 4.4 & 29.5 \\
\hline 3AA-B854-005 & $8 / 1 / 96$ & 6.59 & 4.4 & 29.5 \\
\hline $3 \mathrm{AA}-\mathrm{B} 854-005^{\mathrm{C}}$ & $8 / 1 / 96$ & 6.59 & 4.4 & 29.5 \\
\hline 3AA-B854-006 & $8 / 1 / 96$ & 6.01 & 4.4 & 29.5 \\
\hline 3AA-B854-007 & $8 / 1 / 96$ & 5.83 & 4.4 & 29.5 \\
\hline 3AA-B854-008 & $8 / 1 / 96$ & 5.72 & 4.4 & 29.5 \\
\hline
\end{tabular}

a Wind speed data and averages from onsite meteorological station data.

b Temperature data from field data sheets where available, or from onsite meteorological station data.

c Laboratory duplicate. 


\section{APPENDIX B}

Sampling Intervals, Temperature, and Flow Rates During Emission

Isolation Flux Chamber Measurement at Buildings 830, 832, and 854 


\begin{tabular}{|c|c|c|c|c|c|c|c|c|c|c|c|c|c|c|}
\hline \multirow[b]{2}{*}{$\begin{array}{r}\text { Location } \\
\end{array}$} & \multirow[b]{2}{*}{$\begin{array}{l}\text { Chamber } \\
\text { Number }\end{array}$} & \multirow[b]{2}{*}{$\begin{array}{c}\text { Sample } \\
\text { Date }\end{array}$} & \multirow[b]{2}{*}{$\underset{\text { Purge Time }}{\text { (min) }}$} & \multirow[b]{2}{*}{$\begin{array}{c}\text { Sample } \\
\text { Start Time }\end{array}$} & \multirow[b]{2}{*}{$\begin{array}{c}\text { Sample } \\
\text { Stop Time }\end{array}$} & \multirow[b]{2}{*}{$\begin{array}{c}\text { Sample } \\
\text { Time (min) }\end{array}$} & \multicolumn{3}{|c|}{ Temperatures (deg C) } & \multirow[b]{2}{*}{$\begin{array}{l}\text { Rotometer } \\
\text { Number }\end{array}$} & \multicolumn{2}{|c|}{ Rotometer Setting } & \multicolumn{2}{|c|}{ Corrected Flow Rates } \\
\hline & & & & & & & Ambient & $\begin{array}{c}\text { Start } \\
\text { Chamber }\end{array}$ & $\begin{array}{c}\text { End } \\
\text { chamber }\end{array}$ & & $\begin{array}{c}\text { Sweep In } \\
(\mathrm{L} / \mathrm{min})\end{array}$ & $\begin{array}{c}\text { Sweep Out } \\
\text { (L/min) }\end{array}$ & $\begin{array}{c}\text { Sweep In } \\
(\mathrm{L} / \mathrm{min})\end{array}$ & $\begin{array}{c}\text { Sweep Out } \\
\text { (L/min) }\end{array}$ \\
\hline Building 830 & & & & & & & & & & & & & & \\
\hline 3SF-B830-001 & 1 & $8 / 14 / 96$ & 53.00 & 9:43:00 & 9:46:13 & 3.22 & 36.2 & 32.7 & 35.7 & 1 & 3.00 & 2.40 & 3.26 & 2.04 \\
\hline 3SF-B830-001 & 2 & $8 / 14 / 96$ & 60.50 & $14: 45: 30$ & $14: 48: 40$ & 3.17 & 42.9 & 43.2 & 43.1 & 2 & 2.56 & 2.40 & 2.60 & 2.16 \\
\hline 3SF-B830-001b & 2 & $8 / 14 / 96$ & 60.50 & $14: 45: 30$ & $14: 48: 40$ & 3.17 & 42.9 & 43.2 & 43.1 & 2 & 3.00 & 2.40 & 3.20 & 2.16 \\
\hline 3SF-B830-002 & 3 & $8 / 14 / 96$ & 42.00 & 10:19:00 & 10:22:08 & 3.13 & 36.2 & 34.6 & 36.2 & 3 & 3.00 & 2.40 & 3.26 & 2.10 \\
\hline 3SF-B830-003 & 3 & $8 / 14 / 96$ & 45.08 & $9: 31: 45$ & $9: 35: 09$ & 3.40 & 34.5 & 32.9 & 34.5 & 3 & 3.00 & 2.40 & 3.26 & 2.10 \\
\hline 3SF-B830-004 & 3 & $8 / 14 / 96$ & 41.68 & $11: 10: 41$ & $11: 13: 30$ & 2.82 & 36.5 & 42.8 & 42.6 & 3 & 3.00 & 2.40 & 3.26 & 2.10 \\
\hline 3SF-B830-004b & 3 & $8 / 14 / 96$ & 41.68 & $11: 10: 41$ & $11: 13: 30$ & 2.82 & 36.5 & 42.8 & 42.6 & 3 & 3.00 & 2.40 & 3.26 & 2.10 \\
\hline 3SF-B830-005 & 3 & $8 / 14 / 96$ & 45.00 & $12: 12: 00$ & $12: 15: 35$ & 3.58 & 41 & 50.4 & 48.3 & 3 & 3.00 & 1.80 & 3.26 & 1.36 \\
\hline 3SF-B830-006 & 2 & $8 / 14 / 96$ & 46.25 & $11: 48: 15$ & $11: 51: 44$ & 3.48 & 40.7 & 44.4 & 42.2 & 2 & 3.00 & 2.40 & 3.20 & 2.16 \\
\hline 3SF-B830-007 & 2 & $8 / 14 / 96$ & 41.00 & 13:04:00 & $13: 07: 20$ & 3.33 & 35.3 & 46.4 & 45.7 & 2 & 3.00 & 2.40 & 3.20 & 2.16 \\
\hline 3SF-B830-008 & 2 & $8 / 15 / 96$ & 45.58 & $9: 20: 35$ & $9: 23: 58$ & 3.38 & 35.3 & 22.8 & 27.5 & 2 & 3.00 & 2.40 & 3.20 & 2.16 \\
\hline 3 SF-B830-008c & 2 & $8 / 15 / 96$ & 50.42 & $9: 25: 25$ & 9:28:43 & 3.30 & 22.8 & 22.8 & 27.5 & 2 & 3.00 & 2.40 & 3.20 & 2.16 \\
\hline 3SF-B830-008b & 2 & $8 / 15 / 96$ & 50.42 & $9: 25: 25$ & $9: 28: 43$ & 3.30 & 22.8 & 27.5 & -f & 2 & 3.00 & 2.40 & 3.20 & 2.16 \\
\hline 3SF-B830-009 & 1 & $8 / 14 / 96$ & 45.00 & $11: 25: 00$ & $11: 28: 18$ & 3.30 & 39.3 & 40.7 & 43 & 1 & 2.85 & 2.20 & 3.12 & 1.79 \\
\hline 3SF-B830-010 & 2 & $8 / 14 / 96$ & 41.00 & $10: 53: 00$ & $10: 56: 15$ & 3.25 & 36.5 & 43 & 40.5 & 2 & 3.00 & 2.40 & 3.20 & 2.16 \\
\hline 3SF-B830-011 & 1 & $8 / 14 / 96$ & 46.50 & $12: 16: 30$ & $12: 19: 45$ & 3.25 & 41 & 48.8 & 50.6 & 1 & 3.00 & 2.40 & 3.26 & 2.04 \\
\hline 3SF-B830-012 & 2 & $8 / 14 / 96$ & 42.50 & 10:07:30 & $10: 10: 39$ & 3.15 & 35.9 & 40 & 39.9 & 2 & 3.00 & 2.40 & 3.20 & 2.16 \\
\hline 3SF-B830-013 & 1 & $8 / 14 / 96$ & 47.23 & $10: 35: 14$ & $10: 38: 31$ & 3.28 & 36.6 & 35.6 & 36.3 & 1 & 3.00 & 2.40 & 3.26 & 2.04 \\
\hline 3SF-B830-014 & 2 & $8 / 14 / 96$ & 40.50 & $9: 14: 30$ & $9: 17: 50$ & 3.33 & 35 & 33.3 & 37.4 & 2 & 3.00 & 2.40 & 3.20 & 2.16 \\
\hline 3SF-B830-014c & 2 & $8 / 14 / 96$ & 45.00 & $9: 19: 00$ & $9: 22: 10$ & 3.17 & 35 & 33.3 & 36.8 & 2 & 3.00 & 2.40 & 3.20 & 2.16 \\
\hline 3SF-B830-015 & 2 & $8 / 15 / 96$ & 43.50 & $10: 19: 30$ & $10: 23: 44$ & 4.23 & 34.5 & 37.5 & 39.7 & 2 & 3.00 & 2.40 & 3.20 & 2.16 \\
\hline 3SF-B830-016 & 3 & $8 / 15 / 96$ & 40.50 & $10: 07: 30$ & $10: 10: 45$ & 3.25 & 34.2 & 30.8 & 31.8 & 3 & 3.00 & 2.40 & 3.26 & 2.10 \\
\hline 3SF-B830-017 & 3 & $8 / 15 / 96$ & 44.00 & 9:18:00 & $9: 21: 05$ & 3.08 & 39.8 & 24.7 & 26.4 & 3 & 3.00 & 2.40 & 3.26 & 2.10 \\
\hline 3SF-B830-018 & 1 & $8 / 15 / 96$ & 42.50 & $10: 37: 30$ & 10:40:40 & 3.17 & 38.7 & 37.2 & 37.3 & 1 & 3.00 & 2.40 & 3.26 & 2.04 \\
\hline 3SF-B830-019 & 1 & $8 / 15 / 96$ & 56.50 & $9: 48: 30$ & $9: 51: 38$ & 3.13 & 38.7 & 32.6 & 36.3 & 1 & 3.00 & 2.40 & 3.26 & 2.04 \\
\hline 3SF-B830-019a & 2 & $8 / 16 / 96$ & 41.00 & $9: 14$ & $9: 17: 15$ & 3.25 & 37 & 27.3 & 32.9 & 2 & 2.80 & 2.40 & 2.93 & 2.16 \\
\hline 3SF-B830-020 & 3 & $8 / 15 / 96$ & 39.17 & 11:09:10 & $11: 12: 40$ & 3.50 & 36.2 & 33.4 & 34.7 & 3 & 3.00 & 2.40 & 3.26 & 2.10 \\
\hline 3SF-B830-021 & 1 & $8 / 16 / 96$ & 39.25 & $10: 15: 15$ & $10: 18: 42$ & 3.45 & 33.6 & 35.2 & 34.3 & 1 & 3.20 & 2.40 & 3.44 & 2.04 \\
\hline 3 SF-B830-021 c & 1 & $8 / 16 / 96$ & 44.33 & $10: 20: 20$ & $10: 23: 35$ & 3.25 & 33.6 & 35.2 & 34.3 & 1 & 3.20 & 2.40 & 3.44 & 2.04 \\
\hline 3SF-B830-022 & 3 & $8 / 16 / 96$ & 41.50 & $9: 29: 30$ & $9: 32: 35$ & 3.08 & 32 & 27.9 & 29.1 & 3 & 3.00 & 2.40 & 3.26 & 2.10 \\
\hline 3SF-B830-023 & 1 & $8 / 16 / 96$ & 45.00 & $9: 29: 00$ & $9: 32: 15$ & 3.25 & 32 & 25.9 & 36.8 & 1 & 2.80 & 2.40 & 3.08 & 2.04 \\
\hline 3 SF-B830-CB-01d & 1 & $8 / 14 / 96$ & 49.00 & $14: 36: 00$ & $14: 38: 50$ & 2.83 & 42.2 & 44.4 & 40.8 & 3 & 3.00 & 2.40 & 3.26 & 2.10 \\
\hline 3SF-B830-CB-02d & 2 & $8 / 15 / 96$ & 38.00 & $11: 14: 00$ & $11: 17: 00$ & 3.00 & 36.6 & 39.3 & 33.8 & 2 & 3.00 & 2.40 & 3.20 & 2.16 \\
\hline 3 SF-B830-CB-03d & 3 & $8 / 14 / 96$ & 43.00 & $15: 28: 00$ & $15: 31: 20$ & 3.33 & 40.5 & 40.7 & 41.4 & 3 & 2.80 & 2.40 & 3.05 & 2.10 \\
\hline 3 SF-B $830-C B-01^{d}$ & 1 & $8 / 16 / 96$ & 69.37 & $12: 04: 22$ & $12: 07: 37$ & 3.25 & 38 & 33.9 & 37.1 & 1 & 3.00 & 2.20 & 3.26 & 1.79 \\
\hline 3 SF-B830-CB-02d & 2 & $8 / 16 / 96$ & 40.63 & $10: 02: 38$ & - & 3.00 & 32.3 & 34.8 & 33.8 & 2 & 3.00 & 2.40 & 3.20 & 2.16 \\
\hline 3SF-B830-CB-03d & 3 & $8 / 16 / 96$ & 41.75 & $10: 48: 40$ & $10: 52: 05$ & 3.42 & 34.4 & 35.1 & 34 & 3 & 3.00 & 2.40 & 3.26 & 2.10 \\
\hline 3SF-B830-CB-03 db & 3 & $8 / 16 / 96$ & 41.75 & $10: 48: 40$ & $10: 52: 05$ & 3.42 & 34.4 & 35.1 & 34 & 3 & 3.00 & 2.40 & 3.26 & 2.10 \\
\hline Building 832 & & & & & & & & & & & & & & \\
\hline 3SF-B832-001 & 1 & $8 / 6 / 96$ & 45.72 & $9: 34: 43$ & $9: 37: 57$ & 3.23 & 24.2 & 24.75 & 23.25 & 1 & 3.00 & 2.40 & 3.26 & 2.04 \\
\hline 3SF-B832-001 & 2 & $8 / 6 / 96$ & 68.18 & $13: 46: 11$ & $13: 49: 25$ & 3.23 & 52.5 & 40.25 & 35.75 & 2 & 3.00 & 2.40 & 3.20 & 2.16 \\
\hline 3SF-B832-002 & 3 & $8 / 6 / 96$ & 48.23 & $9: 58: 14$ & 10:01:00 & 2.77 & 25.7 & 22.75 & $21: 25$ & 3 & 3.00 & 2.40 & 3.26 & 2.10 \\
\hline 3SF-B832-003 & 2 & $8 / 6 / 96$ & 50.28 & $10: 14: 17$ & $10: 17: 17$ & 3.00 & 26.2 & 25.5 & 28.25 & 2 & 3.00 & 2.50 & 3.20 & 2.27 \\
\hline
\end{tabular}




\begin{tabular}{|c|c|c|c|c|c|c|c|c|c|c|c|c|c|c|}
\hline \multirow[b]{2}{*}{ Location } & \multirow[b]{2}{*}{$\begin{array}{l}\text { Chamber } \\
\text { Numbere }\end{array}$} & \multirow[b]{2}{*}{$\begin{array}{c}\text { Sample } \\
\text { Date }\end{array}$} & \multirow[b]{2}{*}{$\underset{\text { (min) }}{\text { Purge Time }}$} & \multirow[b]{2}{*}{$\begin{array}{c}\text { Sample } \\
\text { Start Time }\end{array}$} & \multirow[b]{2}{*}{$\begin{array}{c}\text { Sample } \\
\text { Stop Time }\end{array}$} & \multirow[b]{2}{*}{$\begin{array}{c}\text { Sample } \\
\text { Time (min) }\end{array}$} & \multicolumn{3}{|c|}{ Temperatures (deg C) } & \multirow[b]{2}{*}{$\begin{array}{l}\text { Rotometer } \\
\text { Number }\end{array}$} & \multicolumn{2}{|c|}{ Rotometer Setting } & \multicolumn{2}{|c|}{ Corrected Flow Rates } \\
\hline & & & & & & & Ambient & $\begin{array}{c}\text { Start } \\
\text { Chamber }\end{array}$ & $\begin{array}{c}\text { End } \\
\text { chamber }\end{array}$ & & $\begin{array}{c}\text { Sweep In } \\
\text { (L/min) }\end{array}$ & $\begin{array}{c}\text { Sweep Out } \\
\text { (L/min) }\end{array}$ & $\begin{array}{c}\text { Sweep In } \\
(\mathrm{L} / \mathrm{min})\end{array}$ & $\begin{array}{c}\text { Sweep Out } \\
\text { (L/min) }\end{array}$ \\
\hline 3 SF-B832-004 & 1 & $8 / 6 / 96$ & 49.67 & $10: 47: 40$ & $10: 50: 47$ & 3.12 & 35.5 & 26.75 & 42.25 & 1 & 3.00 & 2.40 & 3.26 & 2.04 \\
\hline 3SF-B832-005 & 3 & $8 / 6 / 96$ & 41.75 & $11: 19: 45$ & $11: 22: 50$ & 3.08 & 25.8 & 34 & 31.75 & 3 & 3.00 & 2.40 & 3.26 & 2.10 \\
\hline 3SF-B832-006 & 2 & $8 / 6 / 96$ & 44.00 & $11: 26: 00$ & $11: 28: 50$ & 2.83 & 28.2 & 32.75 & 21.25 & 2 & 3.20 & 2.40 & 3.47 & 2.16 \\
\hline 3SF-B832-007 & 2 & $8 / 6 / 96$ & 47.80 & $12: 16: 48$ & $12: 19: 20$ & 2.53 & 34.7 & 34.75 & 36 & 2 & 2.80 & 2.40 & 2.93 & 2.16 \\
\hline 3SF-B832-008 & 1 & $8 / 6 / 96$ & 50.50 & $11: 45: 30$ & $11: 48: 25$ & 2.92 & 34.1 & 36.5 & 35.5 & 1 & 3.00 & 2.40 & 3.26 & 2.04 \\
\hline 3SF-B832-009 & 1 & $8 / 6 / 96$ & 49.03 & $12: 54: 02$ & $12: 57: 10$ & 3.13 & 28 & 39.5 & 39.5 & 1 & 3.00 & 2.80 & 3.26 & 2.55 \\
\hline 3SF-B832-010 & 1 & $8 / 6 / 96$ & 55.67 & $13: 57: 40$ & $14: 01: 02$ & 3.37 & 30.4 & 44 & 41.25 & 1 & 3.00 & 2.20 & 3.26 & 1.79 \\
\hline 3 SF-B $832-010^{\mathrm{C}}$ & 1 & $8 / 6 / 96$ & 60.73 & $14: 02: 44$ & $14: 06: 10$ & 3.43 & 30.4 & 44 & 41.25 & 1 & 3.00 & 2.20 & 3.26 & 1.79 \\
\hline 3SF-B832-011 & 2 & $8 / 7 / 96$ & 68.33 & $9: 45: 20$ & 9:48:38 & 3.30 & 25.2 & 20 & 25.75 & 2 & 3.00 & 2.40 & 3.20 & 2.16 \\
\hline 3SF-B832-012 & 2 & $8 / 13 / 96$ & 42.00 & $9: 34: 00$ & $9: 37: 20$ & 3.33 & 36.6 & 37.25 & 39 & 2 & 3.00 & 2.40 & 3.20 & 2.16 \\
\hline 3SF-B832-013 & 1 & $8 / 13 / 96$ & 58.00 & $9: 53: 00$ & $9: 56: 20$ & 3.33 & 36 & 36 & 36 & 1 & 3.20 & 2.40 & 3.44 & 2.04 \\
\hline 3SF-B832-014 & 2 & $8 / 13 / 96$ & 50.50 & $10: 55: 30$ & $10: 59: 10$ & 3.67 & 36.7 & 41.75 & 40.5 & 2 & 3.20 & 2.40 & 3.47 & 2.16 \\
\hline 3 SF-B832-014C & 2 & $8 / 13 / 96$ & 55.50 & $11: 00: 30$ & $11: 04: 15$ & 3.75 & 36.7 & 41.75 & 40.5 & 2 & 3.20 & 2.40 & 3.47 & 2.16 \\
\hline 3SF-B832-015 & 3 & $8 / 7 / 96$ & 63.00 & $9: 28: 00$ & $9: 31: 20$ & 3.33 & 24 & 24.75 & 28.25 & 3 & 3.00 & 2.40 & 3.26 & 2.10 \\
\hline 3SF-B832-016 & 1 & $8 / 7 / 96$ & 48.12 & $10: 12: 25$ & $10: 15: 40$ & 3.25 & 25 & 40 & 29.25 & 1 & 3.00 & 2.40 & 3.26 & 2.04 \\
\hline 3SF-B832-016a & 3 & $8 / 13 / 96$ & 55.50 & $10: 40: 30$ & $10: 43: 20$ & 2.83 & 36 & 42.6 & 42.5 & 3 & 3.00 & 2.40 & 3.26 & 2.10 \\
\hline 3SF-B832-017 & 3 & $8 / 13 / 96$ & 47.20 & $9: 21: 12$ & $9: 24: 12$ & 3.00 & 36.3 & 34.5 & 38 & 3 & 3.00 & 2.40 & 3.26 & 2.10 \\
\hline 3SF-B832-018 & 1 & $8 / 7 / 96$ & 53.50 & $9: 16: 30$ & $9: 19: 40$ & 3.17 & 24 & 25.25 & 26.25 & 1 & 3.00 & 2.40 & 3.26 & 2.04 \\
\hline 3SF-B832-CB-01d & 3 & $8 / 6 / 96$ & 60.17 & $13: 37: 10$ & $13: 40: 24$ & 3.23 & 29.2 & 33.1 & 27.8 & 3 & 3.00 & 2.40 & 3.26 & 2.10 \\
\hline 3SF-B832-CB-02d & 2 & $8 / 6 / 96$ & 41.33 & $14: 32: 20$ & $14: 35: 26$ & 3.10 & 33.8 & 33.4 & 33.3 & 2 & 3.00 & 2.40 & 3.20 & 2.16 \\
\hline 3SF-B832-CB-02db & 2 & $8 / 6 / 96$ & 41.33 & $14: 32: 20$ & $14: 35: 26$ & 3.10 & 33.8 & 33.4 & 33.3 & 2 & 3.00 & 2.40 & 3.20 & 2.16 \\
\hline 3SF-B832-CB-03d & 1 & $8 / 6 / 96$ & 19.43 & $15: 17: 26$ & $15: 20: 27$ & 3.02 & 31 & 34.4 & 33.9 & 1 & 3.10 & 2.30 & 3.35 & 1.91 \\
\hline 3SF-B832-CB-01d & 1 & $8 / 13 / 96$ & 41.42 & $10: 38: 25$ & $10: 41: 45$ & 3.33 & 36 & 37.6 & 38 & 1 & 3.00 & 2.40 & 3.26 & 2.04 \\
\hline 3 SF-B832-CB-02d & 2 & $8 / 13 / 96$ & 46.58 & $12: 26: 35$ & $12: 29: 57$ & 3.37 & 39.9 & 51 & 53 & 2 & 2.60 & 2.40 & 2.65 & 2.16 \\
\hline 3SF-B832-CB-03d & 3 & $8 / 13 / 96$ & 42.50 & $11: 31: 30$ & $11: 34: 25$ & 2.92 & 40.8 & 43.5 & 41 & 3 & 2.90 & 2.20 & 3.16 & 1.85 \\
\hline \multicolumn{15}{|l|}{ Building 854} \\
\hline 3SF-B854-001 & 2 & $7 / 29 / 96$ & 43.25 & $11: 57: 15$ & $12: 00: 15$ & 3.00 & 50 & 51 & 45 & 1 & 3.00 & 2.90 & 3.26 & 2.67 \\
\hline 3SF-B854-002 & 2 & $7 / 29 / 96$ & 33.48 & $13: 41: 29$ & $13: 43: 00$ & 1.52 & 36 & 40 & 39 & 1 & 3.00 & 2.40 & 3.26 & 2.04 \\
\hline 3 SF-B854-002b & 2 & $7 / 29 / 96$ & 33.48 & $13: 41: 29$ & $13: 43: 00$ & 1.52 & 36 & 40 & 39 & 2 & 3.00 & 2.40 & 3.20 & 2.16 \\
\hline 3SF-B854-003 & 3 & $7 / 29 / 96$ & 30.00 & $13: 36: 00$ & $13: 38: 00$ & 2.00 & 38 & 40 & 40 & 3 & 3.00 & 2.40 & 3.26 & 2.10 \\
\hline 3SF-B854-003C & 3 & $7 / 29 / 96$ & 43.10 & 13:49:06 & $13: 52: 40$ & 3.57 & 38 & 40 & 40 & 3 & 3.00 & 2.40 & 3.26 & 2.10 \\
\hline 3SF-B854-003a & 3 & $7 / 30 / 96$ & 48.00 & $10: 12: 00$ & $10: 15: 30$ & 3.50 & 35 & 32 & 31.8 & 3 & 3.00 & 2.40 & 3.26 & 2.10 \\
\hline 3 SF-B854-003a & 3 & 7/31/96 & 44.67 & $9: 19: 40$ & $9: 23: 00$ & 3.33 & 35.6 & 35 & 35 & 3 & 3.00 & 2.40 & 3.26 & 2.10 \\
\hline 3SF-B854-004 & 3 & $7 / 30 / 96$ & 54.25 & $11: 58: 15$ & $12: 01: 05$ & 2.83 & 36.9 & 43 & 36 & 3 & 2.90 & 2.30 & 3.16 & 1.98 \\
\hline 3SF-B854-004c & 3 & 7/30/96 & 59.00 & $12: 03: 00$ & $12: 06: 40$ & 3.67 & 36.9 & 43 & 36 & 3 & 2.90 & 2.30 & 3.16 & 1.98 \\
\hline 3SF-B854-005 & 3 & $7 / 30 / 96$ & 41.75 & $13: 02: 45$ & $13: 05: 45$ & 3.00 & 34 & 40 & 35 & 3 & 3.00 & 2.20 & 3.26 & 1.85 \\
\hline 3SF-B854-006 & 2 & $7 / 30 / 96$ & 47.33 & $13: 22: 20$ & $13: 25: 15$ & 2.92 & 37 & 42 & 40 & 1 & 3.00 & 2.40 & 3.26 & 2.04 \\
\hline 3 SF-B854-006 & 2 & $7 / 30 / 96$ & 47.33 & $13: 22: 20$ & $13: 25: 15$ & 2.92 & 34 & 42 & 40 & 2 & 3.00 & 2.40 & 3.20 & 2.16 \\
\hline 3SF-B854-007 & 3 & 7/30/96 & 40.00 & $14: 00: 00$ & $14: 02: 45$ & 2.75 & 33 & 37 & 40 & 3 & 3.00 & 2.40 & 3.26 & 2.10 \\
\hline 3SF-B854-008 & 2 & 7/30/96 & 54.00 & $10: 37: 00$ & $10: 39: 40$ & 2.67 & 38 & 34 & 29.3 & 2 & 3.10 & 2.40 & 3.34 & 2.16 \\
\hline 3SF-B854-009 & 3 & $7 / 30 / 96$ & 41.00 & $11: 00: 00$ & $11: 02: 25$ & 2.42 & 40 & 41 & 40 & 1 & 3.06 & 2.60 & 3.31 & 2.29 \\
\hline 3SF-B854-009b & 3 & $7 / 30 / 96$ & 41.00 & 11:00:00 & $11: 02: 25$ & 2.42 & 41 & 41 & 40 & 3 & 3.00 & 2.40 & 3.26 & 2.10 \\
\hline 3SF-B854-010 & 2 & $7 / 30 / 96$ & 44.00 & $12: 30: 00$ & $12: 33: 00$ & 3.00 & 37 & 44.7 & 34 & 1 & 3.00 & 2.40 & 3.26 & 2.04 \\
\hline 3SF-B854-011 & 2 & $7 / 30 / 96$ & 53.50 & $11: 36: 30$ & $11: 40: 30$ & 4.00 & 35.1 & 37 & 36 & 1 & 3.00 & 2.40 & 3.26 & 2.04 \\
\hline
\end{tabular}




\begin{tabular}{|c|c|c|c|c|c|c|c|c|c|c|c|c|c|c|}
\hline \multirow[b]{2}{*}{ Location } & \multirow[b]{2}{*}{$\begin{array}{l}\text { Chamber } \\
\text { Numbere }\end{array}$} & \multirow[b]{2}{*}{$\begin{array}{c}\text { Sample } \\
\text { Date }\end{array}$} & \multirow[b]{2}{*}{$\underset{\text { (min) }}{\text { Purge Time }}$} & \multirow[b]{2}{*}{$\begin{array}{c}\text { Sample } \\
\text { Start Time }\end{array}$} & \multirow[b]{2}{*}{$\begin{array}{c}\text { Sample } \\
\text { Stop Time }\end{array}$} & \multirow[b]{2}{*}{$\begin{array}{c}\text { Sample } \\
\text { Time (min) }\end{array}$} & \multicolumn{3}{|c|}{ Temperatures $(\operatorname{deg} \mathrm{C})$} & \multirow[b]{2}{*}{$\begin{array}{c}\text { Rotometer } \\
\text { Number }\end{array}$} & \multicolumn{2}{|c|}{ Rotometer Setting } & \multicolumn{2}{|c|}{ Corrected Flow Rates } \\
\hline & & & & & & & Ambient & $\begin{array}{c}\text { Start } \\
\text { Chamber }\end{array}$ & $\begin{array}{c}\text { End } \\
\text { chamber }\end{array}$ & & $\begin{array}{c}\text { Sweep In } \\
\text { (L/min) }\end{array}$ & $\begin{array}{c}\text { Sweep Out } \\
(\mathrm{L} / \mathrm{min})\end{array}$ & $\begin{array}{c}\text { Sweep In } \\
\text { (L/min) }\end{array}$ & $\begin{array}{c}\text { Sweep Out } \\
\text { (L/min) }\end{array}$ \\
\hline 3SF-B854-012 & 2 & $7 / 30 / 96$ & 44.50 & $14: 14: 30$ & $14: 17: 30$ & 3.00 & 34 & 41 & 38 & 1 & 3.00 & 2.40 & 3.26 & 2.04 \\
\hline 3SF-B854-013 & 2 & $7 / 31 / 96$ & 46.00 & 10:00:00 & 10:03:00 & 3.00 & -3 & 39.5 & 38 & 1 & 3.00 & 2.40 & 3.26 & 2.04 \\
\hline 3SF-B854-014 & 1 & $7 / 31 / 96$ & 42.00 & 11:19:00 & $11: 22: 00$ & 3.00 & - & - & - & 2 & 2.70 & 2.40 & 2.79 & 2.16 \\
\hline 3SF-B854-015 & 1 & $7 / 31 / 96$ & 114.00 & 13:43:00 & $13: 46: 00$ & 3.00 & 41 & - & - & 2 & 2.60 & 2.40 & 2.65 & 2.16 \\
\hline 3SF-B854-016 & 3 & $7 / 31 / 96$ & 62.00 & 15:27:00 & $15: 30: 00$ & 3.00 & 38 & - & - & 3 & 2.60 & 2.40 & 2.85 & 2.10 \\
\hline 3SF-B854-017 & 3 & $7 / 31 / 96$ & 42.00 & $11: 45: 00$ & $11: 48: 20$ & 3.33 & 39.8 & 43 & 42 & 3 & 3.00 & 2.40 & 3.26 & 2.10 \\
\hline 3SF-B854-017c & 3 & $7 / 31 / 96$ & 48.00 & 11:51:00 & $11: 54: 35$ & 3.58 & 39.8 & 43 & 42 & 3 & 3.00 & 2.40 & 3.26 & 2.10 \\
\hline 3SF-B854-018 & 2 & $7 / 31 / 96$ & 51.00 & 12:02:00 & 12:05:00 & 3.00 & 41 & 39 & 51 & 1 & 3.00 & 2.40 & 3.26 & 2.04 \\
\hline 3SF-B854-019 & 3 & $7 / 31 / 96$ & 47.17 & $13: 17: 10$ & $13: 19: 30$ & 2.33 & 40.7 & 49 & - & 3 & 3.00 & 2.40 & 3.26 & 2.10 \\
\hline 3 SF-B854-019b & 3 & $7 / 31 / 96$ & 47.17 & $13: 17: 10$ & $13: 19: 30$ & 2.33 & 40.7 & 49 & - & 3 & 3.00 & 2.40 & 3.26 & 2.10 \\
\hline 3SF-B854-020 & 2 & $7 / 31 / 96$ & 45.00 & $13: 55: 00$ & 13:57:15 & 2.25 & 45.7 & 45 & 45 & 1 & 3.00 & 2.40 & 3.26 & 2.04 \\
\hline 3SF-B854-021 & 3 & $8 / 1 / 96$ & 43.08 & $9: 28: 05$ & $9: 30: 55$ & 2.83 & 40.7 & 32 & 37 & 3 & 3.00 & 2.40 & 3.26 & 2.10 \\
\hline 3SF-B854-021C & 3 & $8 / 1 / 96$ & 48.50 & $9: 33: 30$ & $9: 36: 00$ & 2.50 & 40.7 & 32 & 37 & 3 & 3.00 & 2.40 & 3.26 & 2.10 \\
\hline 3SF-B854-021 a & 1 & $8 / 1 / 96$ & 50.50 & 13:15:30 & $13: 18: 15$ & 2.75 & 33 & 37 & 33 & 1 & 3.00 & 2.40 & 3.26 & 2.04 \\
\hline 3SF-B854-022 & 2 & $8 / 1 / 96$ & 45.17 & $9: 47: 10$ & 9:51:40 & 4.50 & 27 & 25 & 32 & 2 & 3.40 & $2.40^{\circ}$ & 3.75 & 2.16 \\
\hline 3SF-B854-023 & 2 & $8 / 1 / 96$ & 51.50 & 11:07:30 & $11: 10: 25$ & 2.92 & 30.7 & 35 & 35 & 2 & 3.10 & 2.20 & 3.34 & 1.95 \\
\hline 3SF-B854-024 & 3 & $8 / 1 / 96$ & 58.00 & 11:22:00 & $11: 25: 20$ & 3.33 & 32.5 & 37 & 37 & 3 & 3.00 & 2.40 & 3.26 & 2.10 \\
\hline 3SF-B854-025 & 1 & $8 / 1 / 96$ & 61.00 & 12:07:00 & $12: 10: 00$ & 3.00 & 31.3 & - & 39 & 1 & 3.00 & 2.40 & 3.26 & 2.04 \\
\hline 3SF-B854-026 & 1 & $8 / 1 / 96$ & 41.50 & $10: 36: 30$ & $10: 39: 20$ & 2.83 & 27 & 26 & 36.5 & 1 & 2.90 & 2.40 & 3.17 & 2.04 \\
\hline 3SF-B854-CB-01 & 2 & $7 / 30 / 96$ & 40.00 & $9: 36: 00$ & $9: 39: 20$ & 3.33 & 32 & 37 & 34 & 1 & 3.00 & 2.40 & 3.26 & 2.04 \\
\hline 3SF-B854-CB-02d & 3 & $7 / 30 / 96$ & 40.83 & 14:45:50 & $14: 48: 29$ & 2.65 & 34 & 40 & 40 & 3 & 3.00 & 2.40 & 3.26 & 2.10 \\
\hline 3SF-B854-CB-03 d & 3 & $7 / 31 / 96$ & 42.00 & 10:32:00 & 10:35:00 & 3.00 & 36.3 & 37 & 37 & 3 & 3.00 & 2.40 & 3.26 & 2.10 \\
\hline 3SF-B854-CB-04d & 2 & $7 / 30 / 96$ & 96.50 & $12: 51: 30$ & 12:54:17 & 2.78 & 37.8 & 42 & 42 & 1 & 3.00 & 2.40 & 3.26 & 2.04 \\
\hline 3 SF-B854-CB-05d & 1 & $7 / 31 / 96$ & 46.00 & $14: 38: 00$ & $14: 40: 30$ & 2.50 & 39.9 & 42 & 40 & 2 & 3.00 & 2.20 & 3.20 & 1.95 \\
\hline 3SF-B854-CB-06d & 3 & $8 / 1 / 96$ & 54.25 & $12: 34: 15$ & $12: 37: 15$ & 3.00 & 28.7 & 29 & 25 & 3 & 3.00 & 2.40 & 3.26 & 2.10 \\
\hline 3SF-B854-CB-07d & 2 & $8 / 1 / 96$ & 44.75 & $13: 24: 45$ & $13: 27: 50$ & 3.08 & 320.2 & 25 & 25 & 2 & 3.00 & 2.40 & 3.20 & 2.16 \\
\hline 3SF-B854-CB-07bd & 2 & $8 / 1 / 96$ & 44.75 & $13: 24: 45$ & $13: 27: 50$ & 3.08 & 320.2 & 25 & 25 & 2 & 3.00 & 2.40 & 3.20 & 2.16 \\
\hline 3 SF-B854-CB-08d & 1 & $8 / 1 / 96$ & 48.25 & $14: 17: 15$ & $14: 20: 00$ & 2.75 & 31.9 & 26 & 28 & 1 & 3.00 & 2.40 & 3.26 & 2.04 \\
\hline
\end{tabular}

a Control point sample.

b Laboratory duplicate.

c Collocated sample.

d Chamber blank.

e Chamber number (one through three) signifies the chamber with which the individual sample was collected.

f Measurement not recorded. 


\section{APPENDIX $\mathrm{C}$}

Emission Isolation Flux Chamber Effluent Concentrations of VOCs in $p p b_{v} / v$ Measured at Buildings 830, 832, and 854 


\begin{tabular}{|c|c|c|c|c|c|c|c|c|c|c|c|c|c|c|}
\hline Location & $\begin{array}{c}\text { Sample } \\
\text { Date }\end{array}$ & $\begin{array}{c}\text { Vinyl } \\
\text { chloride }\end{array}$ & 1,1-DCE & Freon 113 & $\begin{array}{c}\text { Analy } \\
\text { MeCl2 }\end{array}$ & $\begin{array}{c}\text { Concentrat } \\
\text { cis- } \\
\text { 1,2-DCE }\end{array}$ & $\begin{array}{l}\text { Detected } \\
\text { CHC13 }\end{array}$ & $\begin{array}{l}\text { the SUMM } \\
\text { 1,2-DCA }\end{array}$ & $\begin{array}{l}{ }^{4} \text { Caniste } \\
\text { TCE }\end{array}$ & $\begin{array}{l}\left.2 p b_{v / v}\right) \\
1,2-D C P a\end{array}$ & $1,1,2-\mathrm{TCA}$ & PCE & $\begin{array}{c}\text { trans- } \\
\text { 1,2-DCE }\end{array}$ & $\begin{array}{l}\text { Chamber } \\
\text { Number }\end{array}$ \\
\hline \multicolumn{15}{|l|}{$\begin{array}{l}\text { Building 830 } \\
\text { 3SF-B830-001 }\end{array}$} \\
\hline 3 SF-B830-001a & $8 / 14 / 96$ & $\begin{array}{l}<0.72 \mathrm{U} \\
<0.72 \mathrm{U}\end{array}$ & $<0.72 \mathrm{U}$ & $\begin{array}{l}<0.72 \mathrm{U} \\
<0.72 \mathrm{U}\end{array}$ & $\begin{array}{l}0.96^{\mathrm{F}} \\
1.8^{\mathrm{F}}\end{array}$ & $\begin{array}{l}<0.72 \mathrm{U} \\
<0.72 \mathrm{U}\end{array}$ & $\begin{array}{l}<0.72 \mathrm{U} \\
<0.72 \mathrm{U}\end{array}$ & $\begin{array}{l}<0.720 \\
<0.72 \mathrm{U}\end{array}$ & $<0.72 \mathrm{U}$ & $<0.72 \mathrm{U}$ & $<0.72 \mathrm{U}$ & $<0.72 \mathrm{U}$ & $\begin{array}{l}<2.9 \mathrm{U} \\
<2.9 \mathrm{U}\end{array}$ & 2 \\
\hline 3SF-B830-001b & $8 / 14 / 96$ & $<0.72 \mathrm{U}$ & $<0.72 \mathrm{U}$ & $<0.72 \mathrm{U}$ & $1.9 \mathrm{~F}$ & $<0.72 \mathrm{U}$ & $<0.72 \mathrm{U}$ & $<0.72 \mathrm{U}$ & $<0.72 \mathrm{U}$ & $<0.72 \mathrm{U}$ & $<0.72 \mathrm{U}$ & $<0.72 \mathrm{U}$ & $<2.9 \mathrm{U}$ & 2 \\
\hline 3SF-B830-002 & $8 / 14 / 96$ & $<0.72 \mathrm{U}$ & $<0.72 \mathrm{U}$ & $<0.72 \mathrm{U}$ & $4.2^{\mathrm{F}}$ & $<0.72 \mathrm{U}$ & $<0.72 \mathrm{U}$ & $<0.72 \mathrm{U}$ & $<0.72 \mathrm{U}$ & $<0.72 \mathrm{U}$ & $<0.72 \mathrm{U}$ & $<0.72 \mathrm{U}$ & $<2.9 \mathrm{U}$ & 3 \\
\hline 3SF-B830-003 & $8 / 14 / 96$ & $<0.71^{U}$ & $<0.71^{U}$ & $<0.71 \mathrm{U}$ & $1.3^{\mathrm{F}}$ & $<0.71 \mathrm{U}$ & $<0.71 \mathrm{U}$ & $<0.71 \mathrm{U}$ & $<0.71 \mathrm{U}$ & $<0.71 \mathrm{U}$ & $<0.71 \mathrm{U}$ & $<0.71 \mathrm{U}$ & $<2.8^{U}$ & 3 \\
\hline 3SF-B830-004 & $8 / 14 / 96$ & $<0.73 \mathrm{U}$ & $<0.73 \mathrm{U}$ & $<0.73 \mathrm{U}$ & $1.6^{\mathrm{F}}$ & $<0.73 \mathrm{U}$ & $<0.73 \mathrm{U}$ & $<0.73 \mathrm{U}$ & $<0.73^{\mathrm{U}}$ & $<0.73 \mathrm{U}$ & $<0.73 \mathrm{U}$ & $<0.73 \mathrm{U}$ & $<2.9 \mathrm{U}$ & 3 \\
\hline $3 \mathrm{SF}-\mathrm{B} 830-004^{\mathrm{b}}$ & $8 / 14 / 96$ & $<0.86 \mathrm{U}$ & $<0.86^{\mathrm{U}}$ & $<0.86^{\mathrm{U}}$ & $1.8^{\mathrm{F}}$ & $<0.86^{\mathrm{U}}$ & $<0.86^{\mathrm{U}}$ & $<0.86^{\mathrm{U}}$ & $<0.86^{\mathrm{U}}$ & $<0.86 \mathrm{U}$ & $<0.86^{\mathrm{U}}$ & $<0.86^{\mathrm{U}}$ & $<3.4 \mathrm{U}$ & 3 \\
\hline 3SF-B830-005 & $8 / 14 / 96$ & $<0.73 \mathrm{U}$ & $<0.73 \mathrm{U}$ & $<0.73 \mathrm{U}$ & $3.5^{\mathrm{F}}$ & $<0.73 \mathrm{U}$ & $<0.73^{U}$ & $<0.73 \mathrm{U}$ & $<0.73 \mathrm{U}$ & $<0.73 \mathrm{U}$ & $<0.73 \mathrm{U}$ & $<0.73 \mathrm{U}$ & $<2.9 \mathrm{U}$ & 3 \\
\hline 3SF-B830-006 & $8 / 14 / 96$ & $<0.72 \mathrm{U}$ & $<0.72 \mathrm{U}$ & $<0.72 \mathrm{U}$ & $1.8^{\mathrm{F}}$ & $<0.72 \mathrm{U}$ & $<0.72 \mathrm{U}$ & $<0.72 \mathrm{U}$ & $<0.72 \mathrm{U}$ & $<0.72 \mathrm{U}$ & $<0.72 \mathrm{U}$ & $<0.72 \mathrm{U}$ & $<2.9 \mathrm{U}$ & 2 \\
\hline 3SF-B830-007 & $8 / 14 / 96$ & $<0.72 \mathrm{U}$ & $<0.72 \mathrm{U}$ & $<0.72 \mathrm{U}$ & ${ }_{6} \mathrm{~F}$ & $<0.72 \mathrm{U}$ & $<0.72^{\mathrm{U}}$ & $<0.72^{U}$ & $<0.72 \mathrm{U}$ & $<0.72 \mathrm{U}$ & $<0.72 \mathrm{U}$ & $<0.72 \mathrm{U}$ & $<2.9 \mathrm{U}$ & 2 \\
\hline 3SF-B830-008 & $8 / 15 / 96$ & $<0.74 \mathrm{U}$ & $<0.74 \mathrm{U}$ & $<0.74 \mathrm{U}$ & $1.5^{\mathrm{F}}$ & $<0.74 \mathrm{U}$ & $<0.74 \mathrm{U}$ & $<0.74 \mathrm{U}$ & $<0.74 \mathrm{U}$ & $<0.74 \mathrm{U}$ & $<0.74 \mathrm{U}$ & $<0.74 \mathrm{U}$ & $<2.9 \mathrm{U}$ & 2 \\
\hline 3 SF-B830-008c & $8 / 15 / 96$ & $<0.70^{\mathrm{U}}$ & $<0.70^{\mathrm{U}}$ & $<0.70^{\mathrm{U}}$ & $1.8^{\mathrm{F}}$ & $<0.70^{\mathrm{U}}$ & $<0.70^{\mathrm{U}}$ & $<0.70 \mathrm{U}$ & $<0.70^{\mathrm{U}}$ & $<0.70^{\mathrm{U}}$ & $<0.70^{\mathrm{U}}$ & $<0.70^{\mathrm{U}}$ & $<2.8 \mathrm{U}$ & 2 \\
\hline 3SF-B830-008b & $8 / 15 / 96$ & $<0.82 \mathrm{U}$ & $<0.82 \mathrm{U}$ & $<0.82 \mathrm{U}$ & $1.5^{\mathrm{F}}$ & $<0.82 \mathrm{U}$ & $<0.82 \mathrm{U}$ & $<0.82 \mathrm{U}$ & $<0.82 \mathrm{U}$ & $<0.82 \mathrm{U}$ & $<0.82 \mathrm{U}$ & $<0.82 \mathrm{U}$ & $<3.3 \mathrm{U}$ & 2 \\
\hline 3SF-B830-009 & $8 / 14 / 96$ & $<0.73 \mathrm{U}$ & $<0.73 \mathrm{U}$ & $<0.73^{\mathrm{U}}$ & $5^{\mathrm{F}}$ & $<0.73 \mathrm{U}$ & $<0.73 \mathrm{U}$ & $<0.73^{U}$ & $<0.73^{\mathrm{U}}$ & $<0.73 \mathrm{U}$ & $<0.73 \mathrm{U}$ & $<0.73 \mathrm{U}$ & $<2.9 \mathrm{U}$ & 1 \\
\hline 3SF-B830-010 & $8 / 14 / 96$ & $<0.73^{U}$ & $<0.73^{\mathrm{U}}$ & $<0.73^{U}$ & $1.9^{\mathrm{F}}$ & $<0.73^{U}$ & $<0.73 \mathrm{U}$ & $<0.73 \mathrm{U}$ & $<0.73^{U}$ & $<0.73 \mathrm{U}$ & $<0.73 \mathrm{U}$ & $<0.73 \mathrm{U}$ & $<2.9 \mathrm{U}$ & 2 \\
\hline 3SF-B830-011 & $8 / 14 / 96$ & $<0.73 \mathrm{U}$ & $<0.73 \mathrm{U}$ & $<0.73 \mathrm{U}$ & $10^{\mathrm{F}}$ & $<0.73^{U}$ & $<0.73 \mathrm{U}$ & $<0.73 \mathrm{U}$ & $<0.73 \mathrm{U}$ & $<0.73 \mathrm{U}$ & $<0.73 \mathrm{U}$ & $<0.73 \mathrm{U}$ & $<2.9 \mathrm{U}$ & 1 \\
\hline 3SF-B830-012 & $8 / 14 / 96$ & $<0.72 \mathrm{U}$ & $<0.72 \mathrm{U}$ & $<0.72 \mathrm{U}$ & $1.4 \mathrm{~F}$ & $<0.72^{\mathrm{U}}$ & $<0.72 \mathrm{U}$ & $<0.72 \mathrm{U}$ & $<0.72 \mathrm{U}$ & $<0.72 \mathrm{U}$ & $<0.72 \mathrm{U}$ & $<0.72 \mathrm{U}$ & $<2.9 \mathrm{U}$ & 2 \\
\hline 3SF-B830-013 & $8 / 14 / 96$ & $<0.72 \mathrm{U}$ & $<0.72 \mathrm{U}$ & $<0.72 \mathrm{U}$ & $<0.72 \mathrm{U}$ & $<0.72 \mathrm{U}$ & $<0.72^{\mathrm{U}}$ & $<0.72 \mathrm{U}$ & 1.3 & $<0.72 \mathrm{U}$ & $<0.72 \mathrm{U}$ & $<0.72 \mathrm{U}$ & $<2.9 \mathrm{U}$ & 1 \\
\hline 3SF-B830-014 & $8 / 14 / 96$ & $<0.71 \mathrm{U}$ & $<0.71 \mathrm{U}$ & $<0.71 \mathrm{U}$ & $0.91 \mathrm{~F}$ & $<0.71 \mathrm{U}$ & $<0.71 \mathrm{U}$ & $<0.71 \mathrm{U}$ & $<0.71 \mathrm{U}$ & $<0.71 \mathrm{U}$ & $<0.71 \mathrm{U}$ & $<0.71^{\mathrm{U}}$ & $<2.8 \mathrm{U}$ & 2 \\
\hline 3 SF-B830-014c & $8 / 14 / 96$ & $<0.72 \mathrm{U}$ & $<0.72 \mathrm{U}$ & $<0.72 \mathrm{U}$ & ${ }_{1} \mathrm{~F}$ & $<0.72 \mathrm{U}$ & $<0.72 \mathrm{U}$ & $<0.72 \mathrm{U}$ & $<0.72 \mathrm{U}$ & $<0.72 \mathrm{U}$ & $<0.72 \mathrm{U}$ & $<0.72 \mathrm{U}$ & $<2.9^{\mathrm{U}}$ & 2 \\
\hline 3SF-B830-015 & $8 / 15 / 96$ & $<0.72 \mathrm{U}$ & $<0.72 \mathrm{U}$ & $<0.72 \mathrm{U}$ & $3.1^{\mathrm{F}}$ & $<0.72 \mathrm{U}$ & $<0.72 \mathrm{U}$ & $<0.72 \mathrm{U}$ & $<0.72 \mathrm{U}$ & $<0.72 \mathrm{U}$ & $<0.72 \mathrm{U}$ & $<0.72^{\mathrm{U}}$ & $<2.9 \mathrm{U}$ & 2 \\
\hline 3SF-B830-016 & $8 / 15 / 96$ & $<0.72^{\mathrm{U}}$ & $<0.72 \mathrm{U}$ & $<0.72 \mathrm{U}$ & $1.6^{\mathrm{F}}$ & $<0.72^{U}$ & $<0.72^{\mathrm{U}}$ & $<0.72 \mathrm{U}$ & $<0.72 \mathrm{U}$ & $<0.72 \mathrm{U}$ & $<0.72 \mathrm{U}$ & $<0.72 \mathrm{U}$ & $<2.9 \mathrm{U}$ & 3 \\
\hline 3SF-B830-017 & $8 / 15 / 96$ & $<0.72 \mathrm{U}$ & $<0.72 \mathrm{U}$ & $<0.72 \mathrm{U}$ & $1.2^{\mathrm{F}}$ & $<0.72 \mathrm{U}$ & $<0.72 \mathrm{U}$ & $<0.72 \mathrm{U}$ & $<0.72 \mathrm{U}$ & $<0.72 \mathrm{U}$ & $<0.72 \mathrm{U}$ & $<0.72 \mathrm{U}$ & $<2.9 \mathrm{U}$ & 3 \\
\hline 3SF-B830-018 & $8 / 15 / 96$ & $<0.73 \mathrm{U}$ & $<0.73 \mathrm{U}$ & $<0.73 \mathrm{U}$ & $1.2 \mathrm{~F}$ & $<0.73 \mathrm{U}$ & $<0.73 \mathrm{U}$ & $<0.73 \mathrm{U}$ & $<0.73 \mathrm{U}$ & $<0.73 \mathrm{U}$ & $<0.73 \mathrm{U}$ & $<0.73 \mathrm{U}$ & $<2.9 \mathrm{U}$ & 1 \\
\hline 3SF-B830-019 & $8 / 15 / 96$ & $<0.75 \mathrm{U}$ & $<0.75 \mathrm{U}$ & $<0.75^{\mathrm{U}}$ & $2.6 \mathrm{~F}$ & $<0.75^{\mathrm{U}}$ & $<0.75 \mathrm{U}$ & $<0.75 \mathrm{U}$ & $<0.75^{\mathrm{U}}$ & $<0.75^{\mathrm{U}}$ & $<0.75 \mathrm{U}$ & $<0.75^{\mathrm{U}}$ & $<3.0^{\mathrm{U}}$ & 1 \\
\hline 3 SF-B830-019a & $8 / 16 / 96$ & $<0.73 \mathrm{U}$ & $<0.73 \mathrm{U}$ & $<0.73^{U}$ & $2.1^{\mathrm{F}}$ & $<0.73^{U}$ & $<0.73^{U}$ & $<0.73 \mathrm{U}$ & $<0.73 \mathrm{U}$ & $<0.73 \mathrm{U}$ & $<0.73 \mathrm{U}$ & $<0.73^{\mathrm{U}}$ & $<2.9 \mathrm{U}$ & 2 \\
\hline 3SF-B830-020 & $8 / 15 / 96$ & $<0.72 \mathrm{U}$ & $<0.72 \mathrm{U}$ & $<0.72 \mathrm{U}$ & $0.72 \mathrm{~F}$ & $<0.72 \mathrm{U}$ & $<0.72 \mathrm{U}$ & $<0.72 \mathrm{U}$ & $<0.72^{U}$ & $<0.72 \mathrm{U}$ & $<0.72 \mathrm{U}$ & $<0.72 \mathrm{U}$ & $<2.9^{U}$ & 3 \\
\hline 3SF-B830-021 & $8 / 16 / 96$ & $<0.72 \mathrm{U}$ & $<0.72 \mathrm{U}$ & $<0.72 \mathrm{U}$ & $<0.72 \mathrm{U}$ & $<0.72 \mathrm{U}$ & $<0.72 \mathrm{U}$ & $<0.72 \mathrm{U}$ & $<0.72 \mathrm{U}$ & $<0.72 \mathrm{U}$ & $<0.72 \mathrm{U}$ & $<0.72 \mathrm{U}$ & $<2.9 \mathrm{U}$ & 1 \\
\hline 3 SF-B830-021c & $8 / 16 / 96$ & $<0.72 \mathrm{U}$ & $<0.72 \mathrm{U}$ & $<0.72 \mathrm{U}$ & $<0.72 \mathrm{U}$ & $<0.72 \mathrm{U}$ & $<0.72 \mathrm{U}$ & $<0.72 \mathrm{U}$ & $<0.72 \mathrm{U}$ & $<0.72 \mathrm{U}$ & $<0.72 \mathrm{U}$ & $<0.72^{\mathrm{U}}$ & $<2.9 \mathrm{U}$ & 1 \\
\hline 3SF-B830-022 & $8 / 16 / 96$ & $<0.72 \mathrm{U}$ & $<0.72 \mathrm{U}$ & $<0.72^{U}$ & $<0.72 \mathrm{U}$ & $<0.72 \mathrm{U}$ & $<0.72 \mathrm{U}$ & $<0.72 \mathrm{U}$ & $<0.72 \mathrm{U}$ & $<0.72 \mathrm{U}$ & $<0.72 \mathrm{U}$ & $<0.72 \mathrm{U}$ & $<2.9 \mathrm{U}$ & 3 \\
\hline 3SF-B830-023 & $8 / 16 / 96$ & $<0.72 \mathrm{U}$ & $<0.72 \mathrm{U}$ & $<0.72 \mathrm{U}$ & $0.97 \mathrm{~F}$ & $<0.72 \mathrm{U}$ & $<0.72 \mathrm{U}$ & $<0.72 \mathrm{U}$ & $<0.72^{\mathrm{U}}$ & $<0.72 \mathrm{U}$ & $<0.72 \mathrm{U}$ & $<0.72 \mathrm{U}$ & $<2.9 \mathrm{U}$ & 1 \\
\hline 3SF-B830-CB-01 & $8 / 14 / 96$ & $<0.75^{\mathrm{U}}$ & $<0.75^{\mathrm{U}}$ & $<0.75^{\mathrm{U}}$ & 3.9 & $<0.75^{\mathrm{U}}$ & $<0.75^{\mathrm{U}}$ & $<0.75^{\mathrm{U}}$ & $<0.75^{\mathrm{U}}$ & $<0.75^{\mathrm{U}}$ & $<0.75^{\mathrm{U}}$ & $<0.75 \mathrm{U}$ & $<3.0^{\mathrm{U}}$ & 1 \\
\hline 3SF-B830-CB-02d & $8 / 15 / 96$ & $<0.72 \mathrm{U}$ & $<0.72 \mathrm{U}$ & $<0.72 \mathrm{U}$ & 2.4 & $<0.72 \mathrm{U}$ & $<0.72 \mathrm{U}$ & $<0.72 \mathrm{U}$ & $<0.72 \mathrm{U}$ & $<0.72 \mathrm{U}$ & $<0.72 \mathrm{U}$ & $<0.72 \mathrm{U}$ & $<2.9 \mathrm{U}$ & 2 \\
\hline $3 \mathrm{~S} \Gamma-\mathrm{B} 830-\mathrm{CB}-03^{\mathrm{d}}$ & $8 / 14 / 96$ & $<0.72 \mathrm{U}$ & $<0.72 \mathrm{U}$ & $<0.72 \mathrm{U}$ & 2.9 & $<0.72 \mathrm{U}$ & $<0.72^{\mathrm{U}}$ & $<0.72 \mathrm{U}$ & $<0.72 \mathrm{U}$ & $<0.72 \mathrm{U}$ & $<0.72 \mathrm{U}$ & $<0.72 \mathrm{U}$ & $<2.9 \mathrm{U}$ & 3 \\
\hline 3 SF-B830-CB-01 d & $8 / 16 / 96$ & $<0.71^{U}$ & $<0.71 \mathrm{U}$ & $<0.71 \mathrm{U}$ & 1 & $<0.71 \mathrm{U}$ & $<0.71 \mathrm{U}$ & $<0.71 \mathrm{U}$ & $<0.71 \mathrm{U}$ & $<0.71 \mathrm{U}$ & $<0.71 \mathrm{U}$ & $<0.71 \mathrm{U}$ & $<2.8 \mathrm{U}$ & 1 \\
\hline 3SF-B830-CB-02d & $8 / 16 / 96$ & $<0.72 \mathrm{U}$ & $<0.72^{\mathrm{U}}$ & $<0.72 \mathrm{U}$ & 2 & $<0.72 \mathrm{U}$ & $<0.72 \mathrm{U}$ & $<0.72 \mathrm{U}$ & $<0.72 \mathrm{U}$ & $<0.72 \mathrm{U}$ & $<0.72 \mathrm{U}$ & $<0.72^{\mathrm{U}}$ & $<2.9^{\mathrm{U}}$ & 2 \\
\hline 3SF-B830-CB-03d & $8 / 16 / 96$ & $<0.72 \mathrm{U}$ & $<0.72 \mathrm{U}$ & $<0.72 \mathrm{U}$ & 2.1 & $<0.72 \mathrm{U}$ & $<0.72 \mathrm{U}$ & $<0.72 \mathrm{U}$ & $<0.72 \mathrm{U}$ & $<0.72 \mathrm{U}$ & $<0.72 \mathrm{U}$ & $<0.72^{\mathrm{U}}$ & $<2.9 \mathrm{U}$ & 3 \\
\hline 3SF-B830-CB-03bd & $8 / 16 / 96$ & $<0.72 \mathrm{U}$ & $<0.72 \mathrm{U}$ & $<0.72^{\mathrm{U}}$ & 2.1 & $<0.72 \mathrm{U}$ & $<0.72 \mathrm{U}$ & $<0.72 \mathrm{U}$ & $<0.72^{\mathrm{U}}$ & $<0.72 \mathrm{U}^{\mathrm{U}}$ & $<0.72 \mathrm{U}$ & $<0.72 \mathrm{U}$ & $<2.9 \mathrm{U}$ & 3 \\
\hline
\end{tabular}




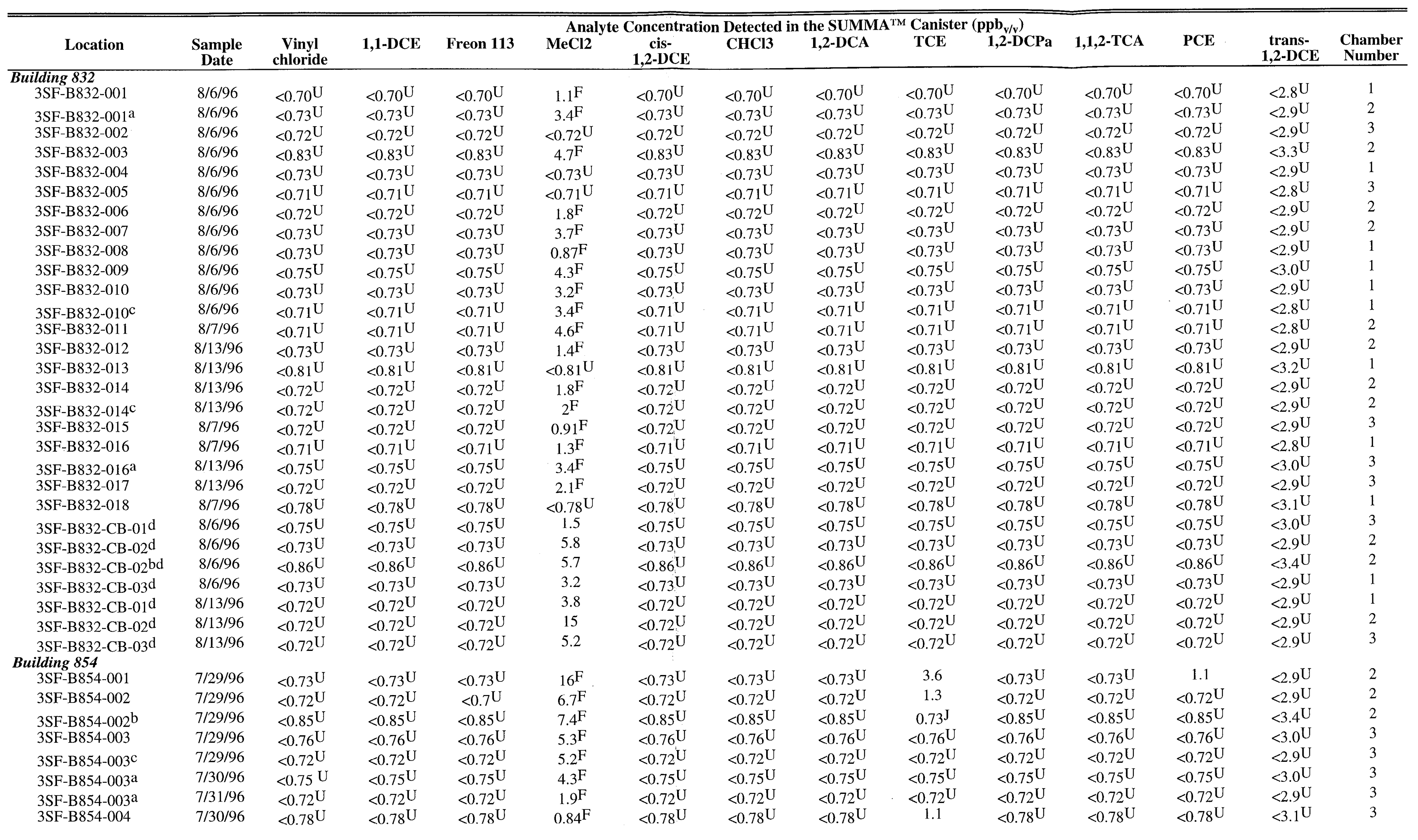




\begin{tabular}{|c|c|c|c|c|c|c|c|c|c|c|c|c|c|c|}
\hline \multirow[b]{2}{*}{ Location } & \multirow[b]{2}{*}{$\begin{array}{c}\text { Sample } \\
\text { Date }\end{array}$} & \multirow[b]{2}{*}{$\begin{array}{c}\text { Vinyl } \\
\text { chloride }\end{array}$} & \multirow[b]{2}{*}{ 1,1-DCE } & \multirow[b]{2}{*}{ Freon 113} & \multicolumn{6}{|c|}{ Analyte Concentration Detected in the SUMMA ${ }^{\mathrm{TM}}$ Canister $\left(\mathbf{p p b}_{\mathrm{v} / \mathrm{v}}\right)$} & \multirow[b]{2}{*}{ 1,1,2-TCA } & \multirow[b]{2}{*}{ PCE } & \multirow[b]{2}{*}{$\begin{array}{c}\text { trans- } \\
1,2-\mathrm{DCE} \\
\end{array}$} & \multirow[b]{2}{*}{$\begin{array}{c}\text { Chamber } \\
\text { Number }\end{array}$} \\
\hline & & & & & MeCl2 & $\begin{array}{c}\text { cis- } \\
\text { 1,2-DCE }\end{array}$ & $\mathrm{CHCl} 3$ & 1,2-DCA & TCE & 1,2-DCPa & & & & \\
\hline 3SF-B854-004c & $7 / 30 / 96$ & $<0.79 \mathrm{U}$ & $<0.79 \mathrm{U}$ & $<0.79 \mathrm{U}$ & $<0.7 \mathrm{U}$ & $<0.79 \overline{\mathrm{U}}$ & $<0.79^{\mathrm{U}}$ & $<0.79 \mathrm{U}$ & 1.7 & $<0.79 \mathrm{U}$ & $<0.79 \mathrm{U}$ & $<0.79 \mathrm{U}$ & $<3.2 \mathrm{U}$ & 3 \\
\hline 3SF-B854-005 & $7 / 30 / 96$ & $<0.75 \mathrm{U}$ & $<0.75 \mathrm{U}$ & $<0.75 \mathrm{U}$ & $0.9^{\mathrm{F}}$ & $<0.75 \mathrm{U}$ & $<0.75 \mathrm{U}$ & $<0.75 \mathrm{U}$ & $<0.75 \mathrm{U}$ & $<0.75 \mathrm{U}$ & $<0.75 \mathrm{U}$ & $<0.75 \mathrm{U}$ & $<3.0 \mathrm{U}$ & 3 \\
\hline 3SF-B854-006 & 7/30/96 & $<0.73 \mathrm{U}$ & $<0.73 \mathrm{U}$ & $<0.73 \mathrm{U}$ & $1.2^{\mathrm{F}}$ & $<0.73 \mathrm{U}$ & $<0.73 \mathrm{U}$ & $<0.73 \mathrm{U}$ & $<0.73 \mathrm{U}$ & $<0.73 \mathrm{U}$ & $<0.73 \mathrm{U}$ & $<0.73 \mathrm{U}$ & $<2.9 \mathrm{U}$ & 2 \\
\hline 3SF-B854-006 ${ }^{b}$ & $7 / 30 / 96$ & $<0.91 \mathrm{U}$ & $<0.91 \mathrm{U}$ & $<0.91 \mathrm{U}$ & $1.2^{\mathrm{F}}$ & $<0.91 \mathrm{U}$ & $<0.91 \mathrm{U}$ & $<0.91 \mathrm{U}$ & $<0.91 \mathrm{U}$ & $<0.91 \mathrm{U}$ & $<0.91 \mathrm{U}$ & $<0.91 \mathrm{U}$ & $<3.6 \mathrm{U}$ & 2 \\
\hline 3SF-B854-007 & $7 / 30 / 96$ & $<0.73 \mathrm{U}$ & $<0.73 \mathrm{U}$ & $<0.73 \mathrm{U}$ & ${ }_{1} \mathrm{~F}$ & $<0.73 \mathrm{U}$ & $<0.73 \mathrm{U}$ & $<0.73 \mathrm{U}$ & $<0.73 \mathrm{U}$ & $<0.73 \mathrm{U}$ & $<0.73 \mathrm{U}$ & $<0.73 \mathrm{U}$ & $<2.9 \mathrm{U}$ & 3 \\
\hline 3SF-B854-008 & 7/30/96 & $<0.75 \mathrm{U}$ & $<0.75^{\mathrm{U}}$ & $<0.75^{\mathrm{U}}$ & ${ }_{2} \mathrm{~F}$ & $<0.75 \mathrm{U}$ & $<0.75^{\mathrm{U}}$ & $<0.75^{\mathrm{U}}$ & $<0.75^{\mathrm{U}}$ & $<0.75 \mathrm{U}$ & $<0.75^{\mathrm{U}}$ & $<0.75^{\mathrm{U}}$ & $<3.0 \mathrm{U}$ & 2 \\
\hline 3SF-B854-009 & $7 / 30 / 96$ & $<0.78 \mathrm{U}$ & $<0.78 \mathrm{U}$ & $<0.78 \mathrm{U}$ & $0.93^{\mathrm{F}}$ & $<0.78 \mathrm{U}$ & $<0.78 \mathrm{U}$ & $<0.78^{\mathrm{U}}$ & $<0.78 \mathrm{U}$ & $<0.78 \mathrm{U}$ & $<0.78 \mathrm{U}$ & $<0.78 \mathrm{U}$ & $<3.1 \mathrm{U}$ & 3 \\
\hline 3SF-B854-009b & 7/30/96 & $<0.92 \mathrm{U}$ & $<0.92 \mathrm{U}$ & $<0.92 \mathrm{U}$ & $0.82^{\mathrm{FJ}}$ & $<0.92 \mathrm{U}$ & $<0.92 \mathrm{U}$ & $<0.92 \mathrm{U}$ & $<0.92 \mathrm{U}$ & $<0.92 \mathrm{U}$ & $<0.92 \mathrm{U}$ & $<0.92 \mathrm{U}$ & $<3.7 \mathrm{U}$ & 3 \\
\hline 3SF-B854-010 & 7/30/96 & $<0.75 \mathrm{U}$ & $<0.75 \mathrm{U}$ & $<0.75 \mathrm{U}$ & ${ }_{13} \mathrm{~F}$ & $<0.75 \mathrm{U}$ & $<0.75 \mathrm{U}$ & $<0.75 \mathrm{U}$ & $<0.75^{U}$ & $<0.75^{\mathrm{U}}$ & $<0.75^{\mathrm{U}}$ & $<0.75^{\mathrm{U}}$ & $<3.0 \mathrm{U}$ & 2 \\
\hline 3SF-B854-011 & 7/30/96 & $<0.78^{U}$ & $<0.78 \mathrm{U}$ & $<0.78 \mathrm{U}$ & $<0.78^{U}$ & $<0.78 \mathrm{U}$ & $<0.78^{\mathrm{U}}$ & $<0.78^{U}$ & $<0.78^{\mathrm{U}}$ & $<0.78^{\mathrm{U}}$ & $<0.78^{U}$ & $<0.78 \mathrm{U}$ & $<3.1 \mathrm{U}$ & 2 \\
\hline 3SF-B854-012 & 7/30/96 & $<0.73 \mathrm{U}$ & $<0.73 \mathrm{U}$ & $<0.73 \mathrm{U}$ & $1.2^{\mathrm{F}}$ & $<0.73 \mathrm{U}$ & $<0.73 \mathrm{U}$ & $<0.73 \mathrm{U}$ & $<0.73 \mathrm{U}$ & $<0.73 \mathrm{U}$ & $<0.73 \mathrm{U}$ & $<0.73 \mathrm{U}$ & $<2.9 \mathrm{U}$ & 2 \\
\hline 3SF-B854-013 & $7 / 31 / 96$ & $<0.73 \mathrm{U}$ & $<0.73 \mathrm{U}$ & $<0.73 \mathrm{U}$ & $2.3^{\mathrm{F}}$ & $<0.73 \mathrm{U}$ & $<0.73 \mathrm{U}$ & $<0.73 \mathrm{U}$ & $<0.73 \mathrm{U}$ & $<0.73 \mathrm{U}$ & $<0.73 \mathrm{U}$ & $<0.73 \mathrm{U}$ & $<2.9 \mathrm{U}$ & 2 \\
\hline 3SF-B854-014 & $7 / 31 / 96$ & $<0.75^{\mathrm{U}}$ & $<0.75^{\mathrm{U}}$ & $<0.75^{\mathrm{U}}$ & $9.4 \mathrm{~F}$ & $<0.75 \mathrm{U}$ & $<0.75 \mathrm{U}$ & $<0.75 \mathrm{U}$ & 0.95 & $<0.75^{\mathrm{U}}$ & $<0.75^{\mathrm{U}}$ & $<0.75 \mathrm{U}$ & $<3.0 \mathrm{U}$ & 1 \\
\hline 3SF-B854-015 & $7 / 31 / 96$ & $<0.75 \mathrm{U}$ & $<0.75^{U}$ & $<0.75 \mathrm{U}$ & $7.2^{\mathrm{F}}$ & $<0.75 \mathrm{U}$ & $<0.75^{\mathrm{U}}$ & $<0.75 \mathrm{U}$ & 7.9 & $<0.75^{U}$ & $<0.75^{\mathrm{U}}$ & $<0.75 \mathrm{U}$ & $<3.0 \mathrm{U}$ & 1 \\
\hline 3SF-B854-016 & 7/31/96 & $<0.76^{\mathrm{U}}$ & $<0.76^{\mathrm{U}}$ & $<0.76^{\mathrm{U}}$ & $2.4 \mathrm{~F}$ & $<0.76 \mathrm{U}$ & $<0.76^{\mathrm{U}}$ & $<0.76^{\mathrm{U}}$ & $<0.76^{\mathrm{U}}$ & $<0.76^{\mathrm{U}}$ & $<0.76^{\mathrm{U}}$ & $<0.76^{\mathrm{U}}$ & $<3.0 \mathrm{U}$ & 3 \\
\hline 3SF-B854-017 & $7 / 31 / 96$ & $<0.76^{\mathrm{U}}$ & $<0.76^{\mathrm{U}}$ & $<0.76^{\mathrm{U}}$ & $1.3^{\mathrm{F}}$ & $<0.76^{\mathrm{U}}$ & $<0.76^{\mathrm{U}}$ & $<0.76^{\mathrm{U}}$ & $<0.76 \mathrm{U}$ & $<0.76 \mathrm{U}$ & $<0.76 \mathrm{U}$ & $<0.76 \mathrm{U}$ & $<3.0 \mathrm{U}$ & 2 \\
\hline 3SF-B854-017c & $7 / 31 / 96$ & $<0.76^{\mathrm{U}}$ & $<0.76^{\mathrm{U}}$ & $<0.76^{\mathrm{U}}$ & $1.5^{\mathrm{F}}$ & $<0.76 \mathrm{U}$ & $<0.76^{\mathrm{U}}$ & $<0.76^{\mathrm{U}}$ & $<0.76^{\mathrm{U}}$ & $<0.76^{\mathrm{U}}$ & $<0.76^{\mathrm{U}}$ & $<0.76^{\mathrm{U}}$ & $<3.0^{\mathrm{U}}$ & 3 \\
\hline 3SF-B854-018 & $7 / 31 / 96$ & $<0.79 \mathrm{U}$ & $<0.79 \mathrm{U}$ & $<0.79 \mathrm{U}$ & $8.5^{\mathrm{F}}$ & $<0.79 \mathrm{U}$ & $<0.79 \mathrm{U}$ & $<0.79 \mathrm{U}$ & $<0.79 \mathrm{U}$ & $<0.79 \mathrm{U}$ & $<0.79 \mathrm{U}$ & $<0.79 \mathrm{U}$ & $<3.2 \mathrm{U}$ & 2 \\
\hline 3SF-B854-019 & $7 / 31 / 96$ & $<0.78^{U}$ & $<0.78^{\mathrm{U}}$ & $<0.78 \mathrm{U}$ & $1.3^{\mathrm{F}}$ & $<0.78^{\mathrm{U}}$ & $<0.78^{\mathrm{U}}$ & $<0.78^{\mathrm{U}}$ & $<0.78 \mathrm{U}$ & $<0.78^{\mathrm{U}}$ & $<0.78^{\mathrm{U}}$ & $<0.78 \mathrm{U}$ & $<3.1 \mathrm{U}$ & 3 \\
\hline 3SF-B854-019b & $7 / 31 / 96$ & $<0.92 \mathrm{U}$ & $<0.92 \mathrm{U}$ & $<0.92 \mathrm{U}$ & $1.6^{\mathrm{F}}$ & $<0.92 \mathrm{U}$ & $<0.92 \mathrm{U}$ & $<0.92 \mathrm{U}$ & $<0.92 \mathrm{U}$ & $<0.92 \mathrm{U}$ & $<0.92 \mathrm{U}$ & $<0.92 \mathrm{U}$ & $<3.7 \mathrm{U}$ & 3 \\
\hline 3SF-B854-020 & $7 / 31 / 96$ & $<0.79 \mathrm{U}$ & $<0.79^{\mathrm{U}}$ & $<0.79 \mathrm{U}$ & 2.6 & $<0.79 \mathrm{U}$ & $<0.79 \mathrm{U}$ & $<0.79 \mathrm{U}$ & $<0.79 \mathrm{U}$ & $<0.79 \mathrm{U}$ & $<0.79 \mathrm{U}$ & $<0.79 \mathrm{U}$ & $<3.2 \mathrm{U}$ & 2 \\
\hline 3SF-B854-021 & $8 / 1 / 96$ & $<0.73 \mathrm{U}$ & $<0.73 \mathrm{U}$ & $<0.73 \mathrm{U}$ & $2.2 \mathrm{~F}$ & $<0.73 \mathrm{U}$ & $<0.73 \mathrm{U}$ & $<0.73 \mathrm{U}$ & $<0.73 \mathrm{U}$ & $<0.73 \mathrm{U}$ & $<0.73 \mathrm{U}$ & $<0.73^{U}$ & $<2.9 \mathrm{U}$ & 3 \\
\hline 3SF-B854-021C & $8 / 1 / 96$ & $<0.75 \mathrm{U}$ & $<0.75^{\mathrm{U}}$ & $<0.75 \mathrm{U}$ & $2^{\mathrm{F}}$ & $<0.75^{\mathrm{U}}$ & $<0.75^{\mathrm{U}}$ & $<0.75^{\mathrm{U}}$ & $<0.75^{\mathrm{U}}$ & $<0.75^{\mathrm{U}}$ & $<0.75^{\mathrm{U}}$ & $<0.75^{\mathrm{U}}$ & $<3.0^{\mathrm{U}}$ & 3 \\
\hline 3SF-B854-021 & $8 / 1 / 96$ & $<0.75 \mathrm{U}$ & $<0.75^{\mathrm{U}}$ & $<0.75^{\mathrm{U}}$ & $2 \mathrm{~F}$ & $<0.75 \mathrm{U}$ & $<0.75^{\mathrm{U}}$ & $<0.75^{\mathrm{U}}$ & $<0.75 \mathrm{U}$ & $<0.75 \mathrm{U}$ & $<0.75^{\mathrm{U}}$ & $<0.75^{\mathrm{U}}$ & $<3.0 \mathrm{U}$ & 1 \\
\hline 3SF-B854-022 & $8 / 1 / 96$ & $<0.72 \mathrm{U}$ & $<0.72 \mathrm{U}$ & $<0.72 \mathrm{U}$ & ${ }_{4} \Gamma$ & $<0.72 \mathrm{U}$ & $<0.72 \mathrm{U}$ & $<0.72 \mathrm{U}$ & $<0.72 \mathrm{U}$ & $<0.72 \mathrm{U}$ & $<0.72 \mathrm{U}$ & $<0.72 \mathrm{U}$ & $<2.9 \mathrm{U}$ & 2 \\
\hline 3SF-B854-023 & $8 / 1 / 96$ & $<0.75^{U}$ & $<0.75^{\mathrm{U}}$ & $<0.75^{\mathrm{U}}$ & $<0.75^{\mathrm{U}}$ & $<0.75 \mathrm{U}$ & $<0.75 \mathrm{U}$ & $<0.75^{\mathrm{U}}$ & $<0.75^{U}$ & $<0.75^{\mathrm{U}}$ & $<0.75 \mathrm{U}$ & $<0.75 \mathrm{U}$ & $<3.0 \mathrm{U}$ & 2 \\
\hline 3SF-B854-024 & $8 / 1 / 96$ & $<0.75^{\mathrm{U}}$ & $<0.75 \mathrm{U}$ & $<0.75^{\mathrm{U}}$ & $2.3 \mathrm{~F}$ & $<0.75 \mathrm{U}$ & $<0.75 \mathrm{U}$ & $<0.75 \mathrm{U}$ & $<0.75 \mathrm{U}$ & $<0.75 \mathrm{U}$ & $<0.75 \mathrm{U}$ & $<0.75 \mathrm{U}$ & $<3.0 \mathrm{U}$ & 3 \\
\hline 3SF-B854-025 & $8 / 1 / 96$ & $<0.75^{\mathrm{U}}$ & $<0.75^{\mathrm{U}}$ & $<0.75^{\mathrm{U}}$ & $1.2^{\mathrm{F}}$ & $<0.75^{\mathrm{U}}$ & $<0.75^{\mathrm{U}}$ & $<0.75^{\mathrm{U}}$ & $<0.75^{\mathrm{U}}$ & $<0.75^{\mathrm{U}}$ & $<0.75^{\mathrm{U}}$ & $<0.75^{\mathrm{U}}$ & $<3.0^{\mathrm{U}}$ & 1 \\
\hline 3SF-B854-026 & $8 / 1 / 96$ & $<0.73 \mathrm{U}$ & $<0.73 \mathrm{U}$ & $<0.73 \mathrm{U}$ & $3^{F}$ & $<0.73 \mathrm{U}$ & $<0.73 \mathrm{U}$ & $<0.73 \mathrm{U}$ & $<0.73 \mathrm{U}$ & $<0.73 \mathrm{U}$ & $<0.73 \mathrm{U}$ & $<0.73 \mathrm{U}$ & $<2.9 \mathrm{U}$ & 1 \\
\hline 3SF-B854-CB-01d & 7/30/96 & $<0.73 \mathrm{U}$ & $<0.73 \mathrm{U}$ & $<0.73 \mathrm{U}$ & 5.8 & $<0.73 \mathrm{U}$ & $<0.73 \mathrm{U}$ & $<0.73 \mathrm{U}$ & $<0.73 \mathrm{U}$ & $<0.73 \mathrm{U}$ & $<0.73 \mathrm{U}$ & $<0.73 \mathrm{U}$ & $<2.9 \mathrm{U}$ & 2 \\
\hline 3SF-B854-CB-02d & 7/30/96 & $<0.73 \mathrm{U}$ & $<0.73 \mathrm{U}$ & $<0.73 \mathrm{U}$ & 3.2 & $<0.73 \mathrm{U}$ & $<0.73 \mathrm{U}$ & $<0.73 \mathrm{U}$ & $<0.73 \mathrm{U}$ & $<0.73 \mathrm{U}$ & $<0.73 \mathrm{U}$ & $<0.73 \mathrm{U}$ & $<2.9 \mathrm{U}$ & 3 \\
\hline 3SF-B854-CB-03 & 7/31/96 & $<0.7 \mathrm{U}$ & $<0.73 \mathrm{U}$ & $<0.73 \mathrm{U}$ & 1.9 & $<0.73 \mathrm{U}$ & $<0.73 \mathrm{U}$ & $<0.73 \mathrm{U}$ & $<0.73 \mathrm{U}$ & $<0.73 \mathrm{U}$ & $<0.73 \mathrm{U}$ & $<0.73 \mathrm{U}$ & $<2.9 \mathrm{U}$ & 3 \\
\hline 3SF-B854-CB-04d & $7 / 31 / 96$ & $<0.75 \mathrm{U}$ & $<0.75^{\mathrm{U}}$ & $<0.75^{\mathrm{U}}$ & 11 & $<0.75^{\mathrm{U}}$ & $<0.75^{\mathrm{U}}$ & $<0.75^{\mathrm{U}}$ & $<0.75^{\mathrm{U}}$ & $<0.75^{\mathrm{U}}$ & $<0.75^{\mathrm{U}}$ & $<0.75 \mathrm{U}$ & $<3.0^{\mathrm{U}}$ & 2 \\
\hline 3SF-B854-CB-05d & $7 / 31 / 96$ & $<0.75 \mathrm{U}$ & $<0.75^{\mathrm{U}}$ & $<0.75 \mathrm{U}$ & 12 & $<0.75^{\mathrm{U}}$ & $<0.75^{\mathrm{U}}$ & $<0.75 \mathrm{U}$ & $<0.75^{\mathrm{U}}$ & $<0.75^{\mathrm{U}}$ & $<0.75^{\mathrm{U}}$ & $<0.75 \mathrm{U}$ & $<3.0 \mathrm{U}$ & 1 \\
\hline 3SF-B854-CB-06 & $8 / 1 / 96$ & $<0.72 \mathrm{U}$ & $<0.72^{\mathrm{U}}$ & $<0.72 \mathrm{U}$ & 1 & $<0.72^{\mathrm{U}}$ & $<0.72 \mathrm{U}$ & $<0.72 \mathrm{U}$ & $<0.72^{\mathrm{U}}$ & $<0.72 \mathrm{U}$ & $<0.72^{\mathrm{U}}$ & $<0.72 \mathrm{U}$ & $<2.9^{\mathrm{U}}$ & 3 \\
\hline 3SF-B854-CB-07d & $8 / 1 / 96$ & $<0.72 \mathrm{U}$ & $<0.72 \mathrm{U}$ & $<0.72 \mathrm{U}$ & 1.6 & $<0.72 \mathrm{U}$ & $<0.72 \mathrm{U}$ & $<0.72 \mathrm{U}$ & $<0.72 \mathrm{U}$ & $<0.72 \mathrm{U}$ & $<0.72 \mathrm{U}$ & $<0.72 \mathrm{U}$ & $<2.9 \mathrm{U}$ & 2 \\
\hline 3SF-B854-CB-07db & $8 / 1 / 96$ & $<0.85 \mathrm{U}$ & $<0.85 \mathrm{U}$ & $<0.85 \mathrm{U}$ & 1.5 & $<0.85^{\mathrm{U}}$ & $<0.85 \mathrm{U}$ & $<0.85 \mathrm{U}$ & $<0.85^{\mathrm{U}}$ & $<0.85^{\mathrm{U}}$ & $<0.85^{\mathrm{U}}$ & $<0.85^{\mathrm{U}}$ & $<3.4 \mathrm{U}$ & 2 \\
\hline 3SF-B854-CB-08d & $8 / 1 / 96$ & $<0.75 \mathrm{U}$ & $<0.75 \mathrm{U}$ & $<0.75 \mathrm{U}$ & 1.5 & $<0.75 \mathrm{U}$ & $<0.75 \mathrm{U}$ & $<0.75 \mathrm{U}$ & $<0.75 \mathrm{U}$ & $<0.75 \mathrm{U}$ & $<0.75 \mathrm{U}$ & $<0.75 \mathrm{U}$ & $<3.0 \mathrm{U}$ & 1 \\
\hline
\end{tabular}


a Control point sample

b Laboratory duplicate.

c Collocated sample.

d Chamber blank.

$\mathrm{U}$ Compound was analyzed for, but not detected above the detection limit.

F Analyte found in field blank, trip blank, or equipment blank. Sample results were not blank subtracted.

J $\Lambda$ nalyte concentration estimated because it was detected below the detection limit. 
APPENDIX D

Measured Ambient Air Concentrations of VOCs in $\mathrm{ppb}_{\mathrm{v}} / \mathrm{v}$ at Buildings 830, 832 , and 854 


\begin{tabular}{|c|c|c|c|c|c|c|c|c|c|c|c|c|c|}
\hline Location & $\begin{array}{c}\text { Sample } \\
\text { Date }\end{array}$ & $\begin{array}{c}\text { Vinyl } \\
\text { chloride }\end{array}$ & 1,1-DCE & Freon 113 & $\begin{array}{l}\text { Ana } \\
\text { MeCl2 }\end{array}$ & $\begin{array}{l}\text { te Concentrati } \\
\text { cis-1,2-DCE }\end{array}$ & $\begin{array}{l}\text { Detected } \\
\text { CHCl3 }\end{array}$ & $\begin{array}{l}\text { he SUMM } \\
\text { 1,2-DCA }\end{array}$ & $\begin{array}{l}\text { Canister } \\
\text { TCE }\end{array}$ & $\begin{array}{l}\left.\mathbf{b}_{\mathbf{v} / \mathbf{v}}\right) \\
1,2-D^{\prime} \mathbf{a}\end{array}$ & 1,1,2-TCA & PCE & $\begin{array}{c}\text { trans-1,2- } \\
\text { DCE } \\
\end{array}$ \\
\hline \multicolumn{14}{|l|}{ Building 830 } \\
\hline 3AA-B830-001 & $8 / 13 / 96$ & 0.14 & $<0.043 \mathrm{U}$ & 0.15 & $0.5^{\mathrm{B}}$ & $<0.043 \mathrm{U}$ & $<0.043 \mathrm{U}$ & $<0.11 \mathrm{U}$ & 0.21 & $<0.11 \mathrm{U}$ & $<0.043 \mathrm{U}$ & $<0.043 \mathrm{U}$ & $<0.043 \mathrm{U}$ \\
\hline $3 \mathrm{AA}-\mathrm{B} 830-001^{\mathrm{a}}$ & $8 / 14 / 96$ & $<0.042 \mathrm{U}$ & $<0.042 \mathrm{U}$ & 0.1 & $0.48^{B}$ & $<0.042 \mathrm{U}$ & $<0.042 \mathrm{U}$ & $<0.11 \mathrm{U}$ & 0.043 & $<0.11 \mathrm{U}$ & $<0.042 \mathrm{U}$ & $<0.042 \mathrm{U}$ & $<0.042 \mathrm{U}$ \\
\hline 3AA-B830-002 & 8/13/96 & $<0.043^{\mathrm{U}}$ & $<0.043 \mathrm{U}$ & 0.11 & $0.59^{\mathrm{B}}$ & $<0.043 \mathrm{U}$ & $<0.043 \mathrm{U}$ & $<0.11 \mathrm{U}$ & 0.14 & $<0.11 \mathrm{U}$ & $<0.043 \mathrm{U}$ & $<0.043 \mathrm{U}$ & $<0.043 \mathrm{U}$ \\
\hline $3 \mathrm{AA}-\mathrm{B} 830-002^{\mathrm{b}}$ & 8/13/96 & $<0.051 \mathrm{U}$ & $<0.051 \mathrm{U}$ & 0.11 & $0.62^{\mathrm{B}}$ & $<0.051^{U}$ & $<0.051^{U}$ & $<0.13 \mathrm{U}$ & 0.14 & $<0.13 \mathrm{U}$ & $<0.051 \mathrm{U}$ & $<0.051 \mathrm{U}$ & $<0.051 \mathrm{U}$ \\
\hline 3AA-B830-002 & $8 / 14 / 96$ & $<0.042 \mathrm{U}$ & $<0.042 \mathrm{U}$ & 0.096 & $0.38^{B}$ & $<0.042 \mathrm{U}$ & $<0.042 \mathrm{U}$ & $<0.11 \mathrm{U}$ & 0.26 & $<0.11 \mathrm{U}$ & $<0.042 \mathrm{U}$ & $<0.042 \mathrm{U}$ & $<0.042 \mathrm{U}$ \\
\hline 3AA-B830-003 & $8 / 13 / 96$ & $<0.046^{\mathrm{U}}$ & $<0.046^{\mathrm{U}}$ & 0.11 & $0.35^{\mathrm{B}}$ & $<0.046 \mathrm{U}$ & $<0.046 \mathrm{U}$ & $<0.12 \mathrm{U}$ & $<0.046 \mathrm{U}$ & $<0.12 \mathrm{U}$ & $<0.046^{\mathrm{U}}$ & $<0.046^{\mathrm{U}}$ & $<0.046^{\mathrm{U}}$ \\
\hline 3AA-B830-003 & $8 / 14 / 96$ & $<0.043 \mathrm{U}$ & $<0.043 \mathrm{U}$ & 0.1 & $0.36^{\mathrm{B}}$ & $<0.043 \mathrm{U}$ & $<0.043^{U}$ & $<0.11 \mathrm{U}$ & $<0.043 \mathrm{U}$ & $<0.11 \mathrm{U}$ & $<0.043 \mathrm{U}$ & $<0.043 \mathrm{U}$ & $<0.043 \mathrm{U}$ \\
\hline 3AA-B830-004 & $8 / 13 / 96$ & 0.091 & $<0.045^{\mathrm{U}}$ & 0.1 & $0.42^{\mathrm{B}}$ & $<0.045^{\mathrm{U}}$ & 0.49 & 0.41 & 0.062 & $<0.11 \mathrm{U}$ & $<0.045^{\mathrm{U}}$ & 0.072 & $<0.045^{\mathrm{U}}$ \\
\hline 3AA-B830-004 & $8 / 14 / 96$ & $<0.035^{\mathrm{U}}$ & $<0.035 \mathrm{U}$ & 0.1 & $0.23 \mathrm{~B}$ & $<0.035 \mathrm{U}$ & $<0.035 \mathrm{U}$ & $<0.088 \mathrm{U}$ & 0.066 & $<0.088 \mathrm{U}$ & $<0.035^{\mathrm{U}}$ & $<0.035 \mathrm{U}$ & $<0.035 \mathrm{U}$ \\
\hline \multicolumn{14}{|l|}{ Building 832} \\
\hline $3 A A-B 832-001^{c}$ & $8 / 6 / 96$ & $<0.042 \mathrm{U}$ & $<0.042 \mathrm{U}$ & 0.13 & $0.29 \mathrm{~B}$ & $<0.042 \mathrm{U}$ & 0.042 & $<0.11 \mathrm{U}$ & $<0.042^{\mathrm{U}}$ & 0.37 & $<0.042 \mathrm{U}$ & $<0.042 \mathrm{U}$ & $<0.042^{U}$ \\
\hline 3AA-B832-001bc & $8 / 6 / 96$ & $<0.050^{\mathrm{U}}$ & $<0.050^{\mathrm{U}}$ & 0.14 & $0.32^{\mathrm{B}}$ & $<0.050 \mathrm{U}$ & $0.041^{\mathrm{J}}$ & $<0.12 \mathrm{U}$ & $<0.050 \mathrm{U}$ & 0.36 & $<0.050 \mathrm{U}$ & $<0.050 \mathrm{U}$ & $<0.050 \mathrm{U}$ \\
\hline 3AA-B832-001c & $8 / 7 / 96$ & $<0.032 \mathrm{U}$ & $<0.032 \mathrm{U}$ & 0.16 & $0.31^{B}$ & $<0.032 \mathrm{U}$ & 0.064 & $<0.081 \mathrm{U}$ & 0.048 & 0.43 & $<0.032 \mathrm{U}$ & 0.037 & $<0.032 \mathrm{U}$ \\
\hline 3AA-B832-002 & $8 / 6 / 96$ & $<0.041 \mathrm{U}$ & $<0.041 \mathrm{U}$ & 0.089 & $0.24 \mathrm{~B}$ & $<0.041 \mathrm{U}$ & $<0.041 \mathrm{U}$ & $<0.10^{\mathrm{U}}$ & $<0.041^{U}$ & $<0.10^{\mathrm{U}}$ & $<0.041^{U}$ & $<0.041 \mathrm{U}$ & $<0.041 \mathrm{U}$ \\
\hline 3AA-B832-002 & $8 / 7 / 96$ & $<0.042 \mathrm{U}$ & $<0.042 \mathrm{U}$ & 0.096 & $0.32^{\mathrm{B}}$ & $<0.042 \mathrm{U}$ & $<0.042 \mathrm{U}$ & $<0.11 \mathrm{U}$ & $<0.042 \mathrm{U}$ & $<0.11 \mathrm{U}$ & $<0.042 \mathrm{U}$ & $<0.042^{U}$ & $<0.042 \mathrm{U}$ \\
\hline 3AA-B832-003 & $8 / 6 / 96$ & $<0.043 \mathrm{U}$ & $<0.043 \mathrm{U}$ & 0.088 & $0.26^{\mathrm{B}}$ & $<0.043 \mathrm{U}$ & $<0.043 \mathrm{U}$ & $<0.11 \mathrm{U}$ & $<0.043 \mathrm{U}$ & $<0.11 \mathrm{U}$ & $<0.043 \mathrm{U}$ & $<0.043 \mathrm{U}$ & $<0.043 \mathrm{U}$ \\
\hline 3AA-B832-003 & $8 / 7 / 96$ & $<0.045^{\mathrm{U}}$ & $<0.045^{\mathrm{U}}$ & 0.098 & $0.33^{\mathrm{B}}$ & $<0.045^{\mathrm{U}}$ & $<0.045^{\mathrm{U}}$ & $<0.11 \mathrm{U}$ & $<0.045^{\mathrm{U}}$ & $<0.11 \mathrm{U}$ & $<0.045^{\mathrm{U}}$ & $<0.045^{\mathrm{U}}$ & $<0.045^{\mathrm{U}}$ \\
\hline 3AA-B832-004 & $8 / 6 / 96$ & $<0.035 \mathrm{U}$ & $<0.035 \mathrm{U}$ & 0.1 & $0.24 \mathrm{~B}$ & $<0.035 \mathrm{U}$ & $<0.035 \mathrm{U}$ & $<0.088 \mathrm{U}$ & $<0.035^{\mathrm{U}}$ & $<0.088 \mathrm{U}$ & $<0.035^{\mathrm{U}}$ & $<0.035 \mathrm{U}$ & $<0.035 \mathrm{U}$ \\
\hline 3AA-B832-004 & $8 / 7 / 96$ & $<0.045^{\mathrm{U}}$ & $<0.045^{\mathrm{U}}$ & 0.1 & $0.74 \mathrm{~B}$ & $<0.045 \mathrm{U}$ & $<0.045^{\mathrm{U}}$ & $<0.11 \mathrm{U}$ & $<0.045^{\mathrm{U}}$ & $<0.11 \mathrm{U}$ & $<0.045^{\mathrm{U}}$ & $<0.045^{\mathrm{U}}$ & $<0.045^{\mathrm{U}}$ \\
\hline \multicolumn{14}{|l|}{ Building 854} \\
\hline $3 \mathrm{AA}-\mathrm{B} 854-001^{\mathrm{d}}$ & $7 / 31 / 96$ & $<0.045 \mathrm{U}$ & $<0.045 \mathrm{U}$ & 0.15 & $0.24 \mathrm{~B}$ & $<0.045 \mathrm{U}$ & $<0.045 \mathrm{U}$ & $<0.11 \mathrm{U}$ & 0.45 & $<0.11 \mathrm{U}$ & $<0.045^{\mathrm{U}}$ & $<0.045 \mathrm{U}$ & $<0.045^{\mathrm{U}}$ \\
\hline $3 \mathrm{AA}-\mathrm{B} 854-001^{\mathrm{d}}$ & $8 / 1 / 96$ & $<0.033 \mathrm{U}$ & $<0.033 \mathrm{U}$ & 0.14 & $0.19^{\mathrm{B}}$ & $<0.033 \mathrm{U}$ & 0.51 & $<0.082 \mathrm{U}$ & 0.37 & $<0.082 \mathrm{U}$ & $<0.033 \mathrm{U}$ & 0.05 & $<0.033 \mathrm{U}$ \\
\hline 3AA-B854-002 & 7/31/96 & $<0.046^{\mathrm{U}}$ & $<0.046 \mathrm{U}$ & 0.12 & $0.32^{\mathrm{B}}$ & $<0.046^{\mathrm{U}}$ & 1 & $<0.12 \mathrm{U}$ & $<0.046 \mathrm{U}$ & $<0.12 \mathrm{U}$ & $<0.046^{\mathrm{U}}$ & 0.065 & $<0.046 \mathrm{U}$ \\
\hline 3AA-B854-002 & $8 / 1 / 96$ & $<0.043^{U}$ & $<0.043 \mathrm{U}$ & 0.11 & $0.23^{B}$ & $<0.043 \mathrm{U}$ & $<0.043 \mathrm{U}$ & $<0.11 \mathrm{U}$ & $<0.043 \mathrm{U}$ & $<0.11 \mathrm{U}$ & $<0.043 \mathrm{U}$ & 0.4 & $<0.043 \mathrm{U}$ \\
\hline 3AA-B854-003 & $7 / 31 / 96$ & $<0.046^{U}$ & $<0.046^{U}$ & 0.13 & $0.24 \mathrm{~B}$ & $<0.045 \mathrm{U}$ & 0.67 & $<0.12 \mathrm{U}$ & $<0.046^{U}$ & $<0.12 \mathrm{U}$ & $<0.046 \mathrm{U}$ & 0.055 & $<0.046^{\mathrm{U}}$ \\
\hline 3АA-B854-003 & $8 / 1 / 96$ & $<0.045^{\mathrm{U}}$ & $<0.045^{\mathrm{U}}$ & 0.12 & $0.23^{\mathrm{B}}$ & $<0.045^{\mathrm{U}}$ & $<0.045^{\mathrm{U}}$ & $<0.11^{\mathrm{U}}$ & $<0.045^{\mathrm{U}}$ & $<0.11^{\mathrm{U}}$ & $<0.045^{\mathrm{U}}$ & $<0.045^{\mathrm{U}}$ & $<0.045^{\mathrm{U}}$ \\
\hline 3AA-B854-004 & $7 / 31 / 96$ & $<0.047 \mathrm{U}$ & $<0.047 \mathrm{U}$ & 0.11 & $0.32^{\mathrm{B}}$ & $<0.047 \mathrm{U}$ & $<0.047 \mathrm{U}$ & $<0.12 \mathrm{U}$ & $<0.047 \mathrm{U}$ & $<0.12 \mathrm{U}$ & $<0.047 \mathrm{U}$ & $<0.047 \mathrm{U}$ & $<0.047 \mathrm{U}$ \\
\hline 3AA-B854-004 & $8 / 1 / 96$ & $<0.046^{\mathrm{U}}$ & $<0.046^{\mathrm{U}}$ & 0.12 & $0.25^{\mathrm{B}}$ & $<0.045^{\mathrm{U}}$ & $<0.046 \mathrm{U}$ & $<0.12 \mathrm{U}$ & $<0.046^{\mathrm{U}}$ & $<0.12^{\mathrm{U}}$ & $<0.046^{\mathrm{U}}$ & 0.23 & $<0.046^{\mathrm{U}}$ \\
\hline $3 \mathrm{AA}-\mathrm{B} 854-005^{\mathrm{e}}$ & $8 / 1 / 96$ & $<0.046^{\mathrm{U}}$ & $<0.046^{\mathrm{U}}$ & 2 & $7.6^{\mathrm{B}}$ & $<0.045^{\mathrm{U}}$ & $<0.046 \mathrm{U}$ & $<0.12 \mathrm{U}$ & $<0.046 \mathrm{U}$ & $<0.12 \mathrm{U}$ & $<0.046 \mathrm{U}$ & 0.046 & $<0.046 \mathrm{U}$ \\
\hline 3AA-B854-005 be & $8 / 1 / 96$ & $<0.055^{\mathrm{U}}$ & $<0.055^{\mathrm{U}}$ & 2 & $7.7^{\mathrm{B}}$ & $<0.055^{\mathrm{U}}$ & $<0.055 \mathrm{U}$ & $<0.14 \mathrm{U}$ & $<0.055^{\mathrm{U}}$ & $<0.14^{\mathrm{U}}$ & $<0.055^{\mathrm{U}}$ & $0.043^{\mathrm{J}}$ & $<0.055^{\mathrm{U}}$ \\
\hline 3AA-B854-006 & $8 / 1 / 96$ & $<0.050 \mathrm{U}$ & $<0.050 \mathrm{U}$ & 0.12 & $0.3^{\mathrm{B}}$ & $<0.05 \mathrm{j}^{\mathrm{U}}$ & $<0.050^{\mathrm{U}}$ & $<0.13 \mathrm{U}$ & $<0.050^{\mathrm{U}}$ & $<0.13 \mathrm{U}$ & $<0.050^{\mathrm{U}}$ & $<0.050 \mathrm{U}$ & $<0.050 \mathrm{U}$ \\
\hline 3AA-B854-007 & $8 / 1 / 96$ & $<0.050 \mathrm{U}$ & $<0.050 \mathrm{U}$ & 0.12 & $0.27^{\mathrm{B}}$ & $<0.050^{U} \mathrm{U}$ & $<0.050^{\mathrm{U}}$ & $<0.13 \mathrm{U}$ & $<0.050^{U}$ & $<0.13 \mathrm{U}$ & $<0.050^{\mathrm{U}}$ & $<0.050^{U}$ & $<0.050^{\mathrm{U}}$ \\
\hline 3AA-B854-008 & $8 / 1 / 96$ & $<0.049 \mathrm{U}$ & $<0.049 \mathrm{U}$ & 0.12 & $0.28^{B}$ & $<0.049 \mathrm{U}$ & $<0.049 \mathrm{U}$ & $<0.12 \mathrm{U}$ & $<0.049 \mathrm{U}$ & $<0.12 \mathrm{U}$ & $<0.049 \mathrm{U}$ & $<0.049 \mathrm{U}$ & $<0.049 \mathrm{U}$ \\
\hline Trip Blank & $7 / 31 / 96$ & $<0.02 \mathrm{U}$ & $<0.02 \mathrm{U}$ & $<0.02 \mathrm{U}$ & $0.16^{\mathrm{B}}$ & $<0.02 \mathrm{U}$ & $<0.02 \mathrm{U}$ & $<0.05^{\mathrm{U}}$ & $<0.02 \mathrm{U}$ & $<0.05^{\mathrm{U}}$ & $<0.02 \mathrm{U}$ & $<0.02 \mathrm{U}$ & $<0.02 \mathrm{U}$ \\
\hline Trip Blank & $8 / 1 / 96$ & $<0.02 \mathrm{U}$ & $<0.02 \mathrm{U}$ & $<0.02 \mathrm{U}$ & $0.16^{\mathrm{B}}$ & $<0.02 \mathrm{U}$ & $<0.02 \mathrm{U}$ & $<0.05^{\mathrm{U}}$ & $<0.02 \mathrm{U}$ & $<0.05^{\mathrm{U}}$ & $<0.02 \mathrm{U}$ & $<0.02 \mathrm{U}$ & $<0.02 \mathrm{U}$ \\
\hline
\end{tabular}

Indoor air sample collected in Building 830

b Laboratory duplicate.

c Indoor air sample collected in Building 832. 
d Indoor air sample collected in Building 854F.

e Indoor air sample collected in Building 854A.

U Compound was analyzed for, but not detected above the detection limit.

B Analyte found in method blank. Samples were not blank subtracted.

$\mathrm{J}$ The analyte was positively identified; the associated numerical value is the approximate concentration of the analyte in the sample. 


\title{
APPENDIX E
}

\author{
Active Soil Vapor Survey Results in $\mathrm{ppm}_{\mathrm{v}} / \mathrm{v}$ \\ Collected at Site 300 During the Summer of 1996
}

E-1 


\begin{tabular}{|c|c|c|c|c|c|c|c|c|c|c|c|}
\hline \multirow[b]{2}{*}{ Sample Name } & \multirow[b]{2}{*}{$\begin{array}{c}\text { Sample } \\
\text { Date }\end{array}$} & \multicolumn{10}{|c|}{ Analyte Concentration Detected in the Soil Gas $\left(\mathrm{ppm}_{\mathrm{v} / \mathrm{v}}\right)$} \\
\hline & & $1,1,2-\mathrm{TCA}$ & 1,1-DCE & 1,2-DCA & 1,2-DCPa & CHCl3 & $\mathrm{MeCl} 2$ & PCE & $\begin{array}{c}\text { trans-1,2- } \\
\text { DCE }\end{array}$ & TCE & $\begin{array}{c}\begin{array}{c}\text { Vinyl } \\
\text { chloride }\end{array} \\
\end{array}$ \\
\hline Building 830 & & & & & & & & & & & \\
\hline SVV-830-30-11.5F & $\begin{array}{l}09 / 17 / 96 \\
09 / 17 / 06\end{array}$ & $<0.2$ & $<0.2$ & $<0.3$ & $<0.2$ & $<0.2$ & $<0.4$ & $<0.2$ & $<0.3$ & $<0.2$ & $<0.8$ \\
\hline SVV-830-30-17.5F & 09/17/96 & $<0.2$ & $<0.2$ & $<0.3$ & $<0.2$ & $<0.2$ & $<0.4$ & $<0.2$ & $<0.3$ & $<0.2$ & $<0.8$ \\
\hline SVV-830-30-25.5F & 09/17/96 & $<0.2$ & $<0.2$ & $<0.3$ & $<0.2$ & $<0.2$ & $<0.4$ & $<0.2$ & $<0.3$ & $<0.2$ & $<0.8$ \\
\hline SVV-830-30-5.5F & 09/17/96 & $<0.2$ & $<0.2$ & $<0.3$ & $<0.2$ & $<0.2$ & $<0.4$ & $<0.2$ & $<0.3$ & 7.1 & $<0.8$ \\
\hline SVV-830-31-11.5F & 09/19/96 & $<0.2$ & $<0.2$ & $<0.3$ & $<0.2$ & $<0.2$ & $<0.4$ & $<0.2$ & $<0.3$ & 69 & $<0.8$ \\
\hline SVV-830-31-17.5F & 09/19/96 & $<0.2$ & $<0.2$ & $<0.3$ & $<0.2$ & $<0.2$ & $<0.4$ & $<0.2$ & $<0.3$ & 2.4 & $<0.8$ \\
\hline SVV-830-31-25.5F & 09/19/96 & $<0.2$ & $<0.2$ & $<0.3$ & $<0.2$ & $<0.2$ & $<0.4$ & $<0.2$ & $<0.3$ & 1.8 & $<0.8$ \\
\hline SVV-830-31-5.5F & $09 / 17 / 96$ & $<0.2$ & $<0.2$ & $<0.3$ & $<0.2$ & $<0.2$ & $<0.4$ & $<0.2$ & $<0.3$ & 6.9 & $<0.8$ \\
\hline SVV-830-32-11.5F & 09/18/96 & $<0.2$ & $<0.2$ & $<0.3$ & $<0.2$ & $<0.2$ & $<0.4$ & $<0.2$ & $<0.3$ & 1.5 & $<0.8$ \\
\hline SVV-830-32-17.5F & 09/18/96 & $<0.2$ & $<0.2$ & $<0.3$ & $<0.2$ & $<0.2$ & $<0.4$ & $<0.2$ & $<0.3$ & 3.4 & $<0.8$ \\
\hline SVV-830-32-25.5F & 09/18/96 & $<0.2$ & $<0.2$ & $<0.3$ & $<0.2$ & $<0.2$ & $<0.4$ & $<0.2$ & $<0.3$ & 6.5 & $<0.8$ \\
\hline SVV-830-32-35.5F & 09/18/96 & $<0.2$ & $<0.2$ & $<0.3$ & $<0.2$. & $<0.2$ & $<0.4$ & $<0.2$ & $<0.3$ & 42 & $<0.8$ \\
\hline SVV-830-32-5.5F & 09/18/96 & $<0.2$ & $<0.2$ & $<0.3$ & $<0.2$ & $<0.2$ & $<0.4$ & $<0.2$ & $<0.3$ & $<0.2$ & $<0.8$ \\
\hline SVV-830-33-11.5F & 09/19/96 & $<0.2$ & $<0.2$ & $<0.3$ & $<0.2$ & $<0.2$ & $<0.4$ & $<0.2$ & $<0.3$ & 14 & $<0.8$ \\
\hline SVV-830-33-17.5F & 09/19/96 & $<0.2$ & $<0.2$ & $<0.3$ & $<0.2$ & $<0.2$ & $<0.4$ & $<0.2$ & $<0.3$ & 0.98 & $<0.8$ \\
\hline SVV-830-33-25.5F & 09/19/96 & $<0.2$ & $<0.2$ & $<0.3$ & $<0.2$ & $<0.2$ & $<0.4$ & $<0.2$ & $<0.3$ & 0.27 & $<0.8$ \\
\hline SVV-830-33-5.5F & 09/18/96 & $<0.2$ & $<0.2$ & $<0.3$ & $<0.2$ & $<0.2$ & $<0.4$ & $<0.2$ & $<0.3$ & 17 & $<0.8$ \\
\hline SVV-830-34-11.5F & 09/19/96 & $<0.2$ & $<0.2$ & $<0.3$ & $<0.2$ & $<0.2$ & $<0.4$ & $<0.2$ & $<0.3$ & 1.5 & $<0.8$ \\
\hline SVV-830-34-17.5F & 09/20/96 & $<5$ & $<5$ & $<7.5$ & $<5$ & $<5$ & $<10$ & $<5$ & $<7.5$ & 400 & $<20$ \\
\hline SVV-830-34-25.5F & 09/20/96 & $<0.5$ & $<0.5$ & $<0.75$ & $<0.5$ & $<0.5$ & $<1$ & $<0.5$ & $<0.75$ & 6.1 & $<2$ \\
\hline SVV-830-34-5.5F & 09/19/96 & $<0.2$ & $<0.2$ & $<0.3$ & $<0.2$ & $<0.2$ & $<0.4$ & $<0.2$ & $<0.3$ & 1.1 & $<0.8$ \\
\hline SVV-830-35-11.5F & 09/20/96 & $<0.2$ & $<0.2$ & $<0.3$ & $<0.2$ & $<0.2$ & $<0.4$ & $<0.2$ & $<0.3$ & 0.82 & $<0.8$ \\
\hline SVV-830-35-17.5F & 09/20/96 & $<0.5$ & $<0.5$ & $<0.75$ & $<0.5$ & $<0.5$ & $<1$ & $<0.5$ & $<0.75$ & 160 & $<2$ \\
\hline SVV-830-35-25.5F & 09/20/96 & $<0.5$ & $<0.5$ & $<0.75$ & $<0.5$ & $<0.5$ & $<1$ & $<0.5$ & $<0.75$ & 2.8 & $<2$ \\
\hline SVV-830-35-5.5F & 09/20/96 & $<0.2$ & $<0.2$ & $<0.3$ & $<0.2$ & $<0.2$ & $<0.4$ & $<0.2$ & $<0.3$ & 0.61 & $<0.8$ \\
\hline SVV-830-36-11.5F & $09 / 24 / 96$ & $<0.2$ & $<0.2$ & $<0.3$ & $<0.2$ & $<0.2$ & $<0.4$ & $<0.2$ & $<0.3$ & 1.4 & $<0.8$ \\
\hline SVV-830-36-5.5F & $09 / 24 / 96$ & $<0.2$ & $<0.2$ & $<0.3$ & $<0.2$ & $<0.2$ & $<0.4$ & $<0.2$ & $<0.3$ & $<0.2$ & $<0.8$ \\
\hline SVV-830-37-5.5F & 09/24/96 & $<0.2$ & $<0.2$ & $<0.3$ & $<0.2$ & $<0.2$ & $<0.4$ & $<0.2$ & $<0.3$ & 1.6 & $<0.8$ \\
\hline SVV-830-38-5.5F & $09 / 24 / 96$ & $<0.2$ & $<0.2$ & $<0.3$ & $<0.2$ & $<0.2$ & $<0.4$ & $<0.2$ & $<0.3$ & 0.2 & $<0.8$ \\
\hline SVV-830-39-5.5F & $09 / 24 / 96$ & $<0.2$ & $<0.2$ & $<0.3$ & $<0.2$ & $<0.2$ & $<0.4$ & $<0.2$ & $<0.3$ & 0.21 & $<0.8$ \\
\hline SVV-830-41-5.5F & $09 / 25 / 96$ & $<0.2$ & $<0.2$ & $<0.3$ & $<0.2$ & $<0.2$ & $<0.4$ & $<0.2$ & $<0.3$ & $<0.2$ & $<0.8$ \\
\hline SVV-830-42-5.5F & $09 / 25 / 96$ & $<0.2$ & $<0.2$ & $<0.3$ & $<0.2$ & $<0.2$ & $<0.4$ & $<0.2$ & $<0.3$ & $<0.2$ & $<0.8$ \\
\hline SVV-830-43-5.5F & $09 / 25 / 96$ & $<0.2$ & $<0.2$ & $<0.3$ & $<0.2$ & $<0.2$ & $<0.4$ & $<0.2$ & $<0.3$ & $<0.2$ & $<0.8$ \\
\hline SVV-830-44-5.5F & $10 / 01 / 96$ & $<0.2$ & $<0.2$ & $<0.3$ & $<0.2$ & $<0.2$ & $<0.4$ & $<0.2$ & $<0.3$ & $<0.2$ & $<0.8$ \\
\hline SVV-830-45-5.5F & $10 / 01 / 96$ & $<0.2$ & $<0.2$ & $<0.3$ & $<0.2$ & $<0.2$ & $<0.4$ & $<0.2$ & $<0.3$ & $<0.2$ & $<0.8$ \\
\hline SVV-830-46-5.5F & $10 / 01 / 96$ & $<0.2$ & $<0.2$ & $<0.3$ & $<0.2$ & $<0.2$ & $<0.4$ & $<0.2$ & $<0.3$ & $<0.2$ & $<0.8$ \\
\hline SVV-830-47-5.5F & $10 / 01 / 96$ & $<0.2$ & $<0.2$ & $<0.3$ & $<0.2$ & $<0.2$ & $<0.4$ & $<0.2$ & $<0.3$ & $<0.2$ & $<0.8$ \\
\hline SVV-830-48-11.5F & $10 / 03 / 96$ & $<0.2$ & $<0.2$ & $<0.3$ & $<0.2$ & $<0.2$ & $<0.4$ & $<0.2$ & $<0.3$ & $<0.2$ & $<0.8$ \\
\hline SVV-830-48-17.5F & $10 / 03 / 96$ & $<0.2$ & $<0.2$ & $<0.3$ & $<0.2$ & $<0.2$ & $<0.4$ & $<0.2$ & $<0.3$ & $<0.2$ & $<0.8$ \\
\hline SVV-830-48-25.5F & $10 / 03 / 96$ & $<0.2$ & $<0.2$ & $<0.3$ & $<0.2$ & $<0.2$ & $<0.4$ & $<0.2$ & $<0.3$ & $<0.2$ & $<0.8$ \\
\hline SVV-830-48-34.5F & $10 / 03 / 96$ & $<0.2$ & $<0.2$ & $<0.3$ & $<0.2$ & $<0.2$ & $<0.4$ & $<0.2$ & $<0.3$ & $<0.2$ & $<0.8$ \\
\hline SVV-830-48-5.5F & $10 / 03 / 96$ & $<0.2$ & $<0.2$ & $<0.3$ & $<0.2$ & $<0.2$ & $<0.4$ & $<0.2$ & $<0.3$ & $<0.2$ & $<0.8$ \\
\hline SVV-830-49-5.5F & $10 / 04 / 96$ & $<0.2$ & $<0.2$ & $<0.3$ & $<0.2$ & $<0.2$ & $<0.4$ & $<0.2$ & $<0.3$ & $<0.2$ & $<0.8$ \\
\hline Building 832 & & & & & & & & & & & \\
\hline SVV-832-12-12F & $08 / 08 / 96$ & $<0.2$ & $<0.2$ & $<0.3$ & $<0.2$ & $<0.2$ & $<0.4$ & $<0.2$ & $<0.3$ & $<0.2$ & $<0.8$ \\
\hline SVV-832-12-17F & $08 / 08 / 96$ & $<0.2$ & $<0.2$ & $<0.3$ & $<0.2$ & $<0.2$ & $<0.4$ & $<0.2$ & $<0.3$ & $<0.2$ & $<0.8$ \\
\hline SVV-832-12-7F & $08 / 08 / 96$ & $<0.2$ & $<0.2$ & $<0.3$ & $<0.2$ & $<0.2$ & $<0.4$ & $<0.2$ & $<0.3$ & $<0.2$ & $<0.8$ \\
\hline
\end{tabular}




\begin{tabular}{|c|c|c|c|c|c|c|c|c|c|c|c|}
\hline \multirow[b]{2}{*}{ Sample Name } & \multirow[b]{2}{*}{$\begin{array}{c}\text { Sample } \\
\text { Date }\end{array}$} & \multicolumn{10}{|c|}{ Analyte Concentration Detected in the Soil Gas $\left(\mathrm{ppm}_{\mathrm{v} / \mathrm{v}}\right)$} \\
\hline & & $1,1,2-\mathrm{TCA}$ & $1,1-\mathrm{DCE}$ & $1,2-\mathrm{DCA}$ & 1,2-DCPa & CHCi3 & MeCl2 & PCE & $\underset{\text { DCE }}{\operatorname{trans}-1,2-}$ & TCE & $\begin{array}{c}\text { Vinyl } \\
\text { chloride }\end{array}$ \\
\hline SVV-832-13-10.5F & $08 / 09 / 96$ & $<0.2$ & $<0.2$ & $<0.3$ & $<0.2$ & $<0.2$ & $<0.4$ & $<0.2$ & $<0.3$ & $<0.2$ & $<0.8$ \\
\hline SVV-832-13-15.5F & 08/09/96 & $<5$ & $<5$ & $<7.5$ & $<5$ & $<5$ & $<10$ & $<5$ & $<7.5$ & 130 & $<20$ \\
\hline SVV-832-13-20.5F & $08 / 09 / 96$ & $<5$ & $<5$ & $<7.5$ & $<5$ & $<5$ & $<10$ & $<5$ & $<7.5$ & 80 & $<20$ \\
\hline SVV-832-13-5.5F & $08 / 09 / 96$ & $<0.2$ & $<0.2$ & $<0.3$ & $<0.2$ & $<0.2$ & $<0.4$ & $<0.2$ & $<0.3$ & $<0.2$ & $<0.8$ \\
\hline SVV-832-14-10.5F & $08 / 09 / 96$ & $<0.2$ & $<0.2$ & $<0.3$ & $<0.2$ & $<0.2$ & $<0.4$ & $<0.2$ & $<0.3$ & 1.3 & $<0.8$ \\
\hline SVV-832-14-15.5F & 08/09/96 & $<0.2$ & $<0.2$ & $<0.3$ & $<0.2$ & $<0.2$ & $<0.4$ & $<0.2$ & $<0.3$ & 17 & $<0.8$ \\
\hline SVV-832-14-20.5F & $08 / 09 / 96$ & $<0.2$ & $<0.2$ & $<0.3$ & $<0.2$ & $<0.2$ & $<0.4$ & $<0.2$ & $<0.3$ & 0.17 & $<0.8$ \\
\hline SVV-832-14-5.5F & $08 / 09 / 96$ & $<0.2$ & $<0.2$ & $<0.3$ & $<0.2$ & $<0.2$ & $<0.4$ & $<0.2$ & $<0.3$ & 0.85 & $<0.8$ \\
\hline SVV-832-15-10.5F & $08 / 12 / 96$ & $<0.2$ & $<0.2$ & $<0.3$ & $<0.2$ & $<0.2$ & $<0.4$ & $<0.2$ & $<0.3$ & $<0.2$ & $<0.8$ \\
\hline SVV-832-15-15.5F & $08 / 12 / 96$ & $<0.2$ & $<0.2$ & $<0.3$ & $<0.2$ & $<0.2$ & $<0.4$ & $<0.2$ & $<0.3$ & $<0.2$ & $<0.8$ \\
\hline SVV-832-15-20a & $08 / 12 / 96$ & $<0.2$ & $<0.2$ & $<0.3$ & $<0.2$ & $<0.2$ & $<0.4$ & $<0.2$ & $<0.3$ & $<0.2$ & $<0.8$ \\
\hline SVV-832-15-20.5F & $08 / 12 / 96$ & $<0.2$ & $<0.2$ & $<0.3$ & $<0.2$ & $<0.2$ & $<0.4$ & $<0.2$ & $<0.3$ & $<0.2$ & $<0.8$ \\
\hline SVV-832-15-5.5F & $08 / 12 / 96$ & $<0.2$ & $<0.2$ & $<0.3$ & $<0.2$ & $<0.2$ & $<0.4$ & $<0.2$ & $<0.3$ & $<0.2$ & $<0.8$ \\
\hline SVV-832-16-10.5F & $08 / 12 / 96$ & $<0.2$ & $<0.2$ & $<0.3$ & $<0.2$ & $<0.2$ & $<0.4$ & $<0.2$ & $<0.3$ & $<0.2$ & $<0.8$ \\
\hline SVV-832-16-15.5F & $08 / 12 / 96$ & $<0.2$ & $<0.2$ & $<0.3$ & $<0.2$ & $<0.2$ & $<0.4$ & $<0.2$ & $<0.3$ & $<0.2$ & $<0.8$ \\
\hline SVV-832-16-20.5F & $08 / 12 / 96$ & $<0.2$ & $<0.2$ & $<0.3$ & $<0.2$ & $<0.2$ & $<0.4$ & $<0.2$ & $<0.3$ & $<0.2$ & $<0.8$ \\
\hline SVV-832-16-5.5F & $08 / 12 / 96$ & $<0.2$ & $<0.2$ & $<0.3$ & $<0.2$ & $<0.2$ & $<0.4$ & $<0.2$ & $<0.3$ & $<0.2$ & $<0.8$ \\
\hline SVV-832-17-11.5F & $10 / 02 / 96$ & $<0.2$ & $<0.2$ & $<0.3$ & $<0.2$ & $<0.2$ & $<0.4$ & $<0.2$ & $<0.3$ & $<0.2$ & $<0.8$ \\
\hline SVV-832-17-5.5F & $10 / 02 / 96$ & $<0.2$ & $<0.2$ & $<0.3$ & $<0.2$ & $<0.2$ & $<0.4$ & $<0.2$ & $<0.3$ & $<0.2$ & $<0.8$ \\
\hline SVV-832-18-5.5F & $10 / 02 / 96$ & $<0.2$ & $<0.2$ & $<0.3$ & $<0.2$ & $<0.2$ & $<0.4$ & $<0.2$ & $<0.3$ & $<0.2$ & $<0.8$ \\
\hline SVV-832-19-5.5F & $10 / 02 / 96$ & $<0.2$ & $<0.2$ & $<0.3$ & $<0.2$ & $<0.2$ & $<0.4$ & $<0.2$ & $<0.3$ & $<0.2$ & $<0.8$ \\
\hline SVV-832-20-4.5F & $10 / 02 / 96$ & $<0.2$ & $<0.2$ & $<0.3$ & $<0.2$ & $<0.2$ & $<0.4$ & $<0.2$ & $<0.3$. & $<0.2$ & $<0.8$ \\
\hline SVV-832-21-11.5F & $10 / 03 / 96$ & $<0.2$ & $<0.2$ & $<0.3$ & $<0.2$ & $<0.2$ & $<0.4$ & $<0.2$ & $<0.3$ & $<0.2$ & $<0.8$ \\
\hline SVV-832-21-17.5F & $10 / 03 / 96$ & $<0.2$ & $<0.2$ & $<0.3$ & $<0.2$ & $<0.2$ & $<0.4$ & $<0.2$ & $<0.3$ & $<0.2$ & $<0.8$ \\
\hline SVV-832-21-5.5F & $10 / 03 / 96$ & $<0.2$ & $<0.2$ & $<0.3$ & $<0.2$ & $<0.2$ & $<0.4$ & $<0.2$ & $<0.3$ & $<0.2$ & $<0.8$ \\
\hline SVV-832-22-11.5F & $10 / 04 / 96$ & $<0.2$ & 7.8 & $<0.3$ & $<0.2$ & $<0.2$ & $<0.4$ & $<0.2$ & $<0.3$ & 30 & $<0.8$ \\
\hline SVV-832-22-17.5F & $10 / 04 / 96$ & $<0.2$ & $<0.2$ & $<0.3$ & $<0.2$ & $<0.2$ & $<0.4$ & $<0.2$ & $<0.3$ & 33 & $<0.8$ \\
\hline SVV-832-22-25.5F & $10 / 04 / 96$ & $<0.2$ & $<0.2$ & $<0.3$ & $<0.2$ & $<0.2$ & $<0.4$ & $<0.2$ & $<0.3$ & 23 & $<0.8$ \\
\hline SVV-832-22-5.5F & $10 / 04 / 96$ & $<0.2$ & 0.4 & $<0.3$ & $<0.2$ & $<0.2$ & $<0.4$ & $<0.2$ & $<0.3$ & 0.57 & $<0.8$ \\
\hline SVV-832-Probe Blank & $08 / 09 / 96$ & $<0.2$ & $<0.2$ & $<0.3$ & $<0.2$ & $<0.2$ & $<0.4$ & $<0.2$ & $<0.3$ & 0.29 & $<0.8$ \\
\hline SVV-Probe Blank & $08 / 26 / 96$ & $<0.2$ & $<0.2$ & $<0.3$ & $<0.2$ & $<0.2$ & $<0.4$ & $<0.2$ & $<0.3$ & $<0.2$ & $<0.8$ \\
\hline Building 854 & & & & & & & & & & & \\
\hline SVV-854-14-0.5F & 09/03/96 & $<0.2$ & $<0.2$ & $<0.3$ & $<0.2$ & $<0.2$ & $<0.4$ & $<0.2$ & $<0.3$ & $<0.2$ & $<0.8$ \\
\hline SVV-854-14-11.5F & $09 / 04 / 96$ & $<0.2$ & $<0.2$ & $<0.3$ & $<0.2$ & $<0.2$ & $<0.4$ & $<0.2$ & $<0.3$ & $<0.2$ & $<0.8$ \\
\hline SVV-854-14-17.5F & $09 / 04 / 96$ & $<0.2$ & $<0.2$ & $<0.3$ & $<0.2$ & $<0.2$ & $<0.4$ & $<0.2$ & $<0.3$ & $<0.2$ & $<0.8$ \\
\hline SVV-854-14-5.5F & 09/03/96 & $<0.2$ & $<0.2$ & $<0.3$ & $<0.2$ & $<0.2$ & $<0.4$ & $<0.2$ & $<0.3$ & $<0.2$ & $<0.8$ \\
\hline SVV-854-15-0.5F & $08 / 14 / 96$ & $<0.2$ & $<0.2$ & $<0.3$ & $<0.2$ & $<0.2$ & $<0.4$ & $<0.2$ & $<0.3$ & $<0.2$ & $<0.8$ \\
\hline SVV-854-15-11.5F & $08 / 14 / 96$ & $<0.2$ & $<0.2$ & $<0.3$ & $<0.2$ & $<0.2$ & $<0.4$ & $<0.2$ & $<0.3$ & $<0.2$ & $<0.8$ \\
\hline SVV-854-15-17.5F & $08 / 14 / 96$ & $<0.2$ & $<0.2$ & $<0.3$ & $<0.2$ & $<0.2$ & $<0.4$ & $<0.2$ & $<0.3$ & $<0.2$ & $<0.8$ \\
\hline SVV-854-15-5.5F & $08 / 14 / 96$ & $<0.2$ & $<0.2$ & $<0.3$ & $<0.2$ & $<0.2$ & $<0.4$ & $<0.2$ & $<0.3$ & $<0.2$ & $<0.8$ \\
\hline SVV-854-16-0.5F & $08 / 13 / 96$ & $<0.2$ & $<0.2$ & $<0.3$ & $<0.2$ & $<0.2$ & $<0.4$ & $<0.2$ & $<0.3$ & $<0.2$ & $<0.8$ \\
\hline SVV-854-16-11.5F & $08 / 13 / 96$ & $<0.2$ & $<0.2$ & $<0.3$ & $<0.2$ & $<0.2$ & $<0.4$ & $<0.2$ & $<0.3$ & $<0.2$ & $<0.8$ \\
\hline SVV-854-16-17.5F & 08/13/96 & $<0.2$ & $<0.2$ & $<0.3$ & $<0.2$ & $<0.2$ & $<0.4$ & $<0.2$ & $<0.3$ & $<0.2$ & $<0.8$ \\
\hline SVV-854-16-5.5F & 08/13/96 & $<0.2$ & $<0.2$ & $<0.3$ & $<0.2$ & $<0.2$ & $<0.4$ & $<0.2$ & $<0.3$ & $<0.2$ & $<0.8$ \\
\hline SVV-854-17-0.5F & $08 / 26 / 96$ & $<0.2$ & $<0.2$ & $<0.3$ & $<0.2$ & $<0.2$ & $<0.4$ & $<0.2$ & $<0.3$ & $<0.2$ & $<0.8$ \\
\hline SVV-854-17-11.5F & $08 / 26 / 96$ & $<0.2$ & $<0.2$ & $<0.3$ & $<0.2$ & $<0.2$ & $<0.4$ & $<0.2$ & $<0.3$ & $<0.2$ & $<0.8$ \\
\hline SVV-854-17-17.5F & $08 / 26 / 96$ & $<0.2$ & $<0.2$ & $<0.3$ & $<0.2$ & $<0.2$ & $<0.4$ & $<0.2$ & $<0.3$ & $<0.2$ & $<0.8$ \\
\hline SVV-854-17-29.5F & $08 / 26 / 96$ & $<0.2$ & $<0.2$ & $<0.3$ & $<0.2$ & $<0.2$ & $<0.4$ & $<0.2$ & $<0.3$ & 14. & $<0.8$ \\
\hline
\end{tabular}




\begin{tabular}{|c|c|c|c|c|c|c|c|c|c|c|c|}
\hline \multirow[b]{2}{*}{ Sample Name } & \multirow[b]{2}{*}{$\underset{\text { Date }}{\text { Sample }}$} & \multirow[b]{2}{*}{$1,1,2-\mathrm{TCA}$} & \multirow[b]{2}{*}{ 1,1-DCE } & \multicolumn{6}{|c|}{ Analyte Concentration Detected in the Soil Gas $\left(\mathrm{ppm}_{\mathrm{v} / \mathrm{v}}\right)$} & \multirow[b]{2}{*}{ TCE } & \multirow[b]{2}{*}{$\begin{array}{c}\text { Vinyl } \\
\text { chloride }\end{array}$} \\
\hline & & & & $1,2-\mathrm{DCA}$ & $1,2-\mathrm{DCPa}$ & $\mathrm{CHCl3}$ & MeCl2 & PCE & $\underset{D C E}{\operatorname{trans-1,2}}$ & & \\
\hline SVV-854-17-5.5F & $08 / 26 / 96$ & $<0.2$ & $<0.2$ & $<0.3$ & $<0.2$ & $<0.2$ & $<0.4$ & $<0.2$ & $<0.3$ & $<0.2$ & $<0.8$ \\
\hline SVV-854-18-0.5F & $08 / 28 / 96$ & $<0.2$ & $<0.2$ & $<0.3$ & $<0.2$ & $<0.2$ & $<0.4$ & $<0.2$ & $<0.3$ & $<0.2$ & $<0.8$ \\
\hline SVV-854-18-11.5F & $08 / 30 / 96$ & $<0.2$ & $<0.2$ & $<0.3$ & $<0.2$ & $<0.2$ & $<0.4$ & $<0.2$ & $<0.3$ & $<0.2$ & $<0.8$ \\
\hline SVV-854-18-23.5F & $08 / 30 / 96$ & $<0.2$ & $<0.2$ & $<0.3$ & $<0.2$ & $<0.2$ & $<0.4$ & $<0.2$ & $<0.3$ & $<0.2$ & $<0.8$ \\
\hline SVV-854-18-5.5F & $08 / 28 / 96$ & $<0.2$ & $<0.2$ & $<0.3$ & $<0.2$ & $<0.2$ & $<0.4$ & $<0.2$ & $<0.3$ & $<0.2$ & $<0.8$ \\
\hline SVV-854-19-0.5F & $08 / 15 / 96$ & $<0.2$ & $<0.2$ & $<0.3$ & $<0.2$ & $<0.2$ & $<0.4$ & $<0.2$ & $<0.3$ & $<0.2$ & $<0.8$ \\
\hline SVV-854-19-11.5F & $08 / 15 / 96$ & $<0.2$ & $<0.2$ & $<0.3$ & $<0.2$ & $<0.2$ & $<0.4$ & $<0.2$ & $<0.3$ & $<0.2$ & $<0.8$ \\
\hline SVV-854-19-17.5F & $08 / 15 / 96$ & $<0.2$ & $<0.2$ & $<0.3$ & $<0.2$ & $<0.2$ & $<0.4$ & $<0.2$ & $<0.3$ & $<0.2$ & $<0.8$ \\
\hline SVV-854-19-5.5F & $08 / 15 / 96$ & $<0.2$ & $<0.2$ & $<0.3$ & $<0.2$ & $<0.2$ & $<0.4$ & $<0.2$ & $<0.3$ & $<0.2$ & $<0.8$ \\
\hline SVV-854-20-0.5F & $08 / 14 / 96$ & $<0.2$ & $<0.2$ & $<0.3$ & $<0.2$ & $<0.2$ & $<0.4$ & $<0.2$ & $<0.3$ & $<0.2$ & $<0.8$ \\
\hline SVV-854-20-11.5F & $08 / 14 / 96$ & $<0.2$ & $<0.2$ & $<0.3$ & $<0.2$ & $<0.2$ & $<0.4$ & $<0.2$ & $<0.3$ & $<0.2$ & $<0.8$ \\
\hline SVV-854-20-15.5F & $08 / 15 / 96$ & $<0.2$ & $<0.2$ & $<0.3$ & $<0.2$ & $<0.2$ & $<0.4$ & $<0.2$ & $<0.3$ & $<0.2$ & $<0.8$ \\
\hline SVV-854-20-5.5F & $08 / 14 / 96$ & $<0.2$ & $<0.2$ & $<0.3$ & $<0.2$ & $<0.2$ & $<0.4$ & $<0.2$ & $<0.3$ & $<0.2$ & $<0.8$ \\
\hline SVV-854-21-0.5F & $09 / 03 / 96$ & $<0.2$ & $<0.2$ & $<0.3$ & $<0 . \overline{2}$ & $<0.2$ & $<0.4$ & $<0.2$ & $<0.3$ & $<0.2$ & $<0.8$ \\
\hline SVV-854-21-11.5F & $09 / 03 / 96$ & $<0.2$ & $<0.2$ & $<0.3$ & $<0.2$ & $<0.2$ & $<0.4$ & $<0.2$ & $<0.3$ & $<0.2$ & $<0.8$ \\
\hline SVV-854-21-17.5F & 09/03/96 & $<0.2$ & $<0.2$ & $<0.3$ & $<0.2$ & $<0.2$ & $<0.4$ & $<0.2$ & $<0.3$ & $<0.2$ & $<0.8$ \\
\hline SVV-854-21-5.5F & $09 / 03 / 96$ & $<0.2$ & $<0.2$ & $<0.3$ & $<0.2$ & $<0.2$ & $<0.4$ & $<0.2$ & $<0.3$ & 0.9 & $<0.8$ \\
\hline SVV-854-22-0.5F & $08 / 14 / 96$ & $<0.2$ & $<0.2$ & $<0.3$ & $<0.2$ & $<0.2$ & $<0.4$ & $<0.2$ & $<0.3$ & $<0.2$ & $<0.8$ \\
\hline SVV-854-22-11.5F & $08 / 14 / 96$ & $<0.2$ & $<0.2$ & $<0.3$ & $<0.2$ & $<0.2$ & $<0.4$ & $<0.2$ & $<0.3$ & $<0.2$ & $<0.8$ \\
\hline SVV-854-22-17.5F & $08 / 14 / 96$ & $<0.2$ & $<0.2$ & $<0.3$ & $<0.2$ & $<0.2$ & $<0.4$ & $<0.2$ & $<0.3$ & $<0.2$ & $<0.8$ \\
\hline SVV-854-22-5.5F & $08 / 14 / 96$ & $<0.2$ & $<0.2$ & $<0.3$ & $<0.2$ & $<0.2$ & $<0.4$ & $<0.2$ & $<0.3$ & $<0.2$ & $<0.8$ \\
\hline SVV-854-23-0.5F & $09 / 03 / 96$ & $<0.2$ & $<0.2$ & $<0.3$ & $<0.2$ & $<0.2$ & $<0.4$ & $<0.2$ & $<0.3$ & $<0.2$ & $<0.8$ \\
\hline SVV-854-23-11.5F & 09/03/96 & $<0.2$ & $<0.2$ & $<0.3$ & $<0.2$ & $<0.2$ & $<0.4$ & $<0.2$ & $<0.3$ & $<0.2$ & $<0.8$ \\
\hline SVV-854-23-17.5F & 09/03/96 & $<0.2$ & $<0.2$ & $<0.3$ & $<0.2$ & $<0.2$ & $<0.4$ & $<0.2$ & $<0.3$ & $<0.2$ & $<0.8$ \\
\hline SVV-854-23-5.5F & $09 / 03 / 96$ & $<0.2$ & $<0.2$ & $<0.3$ & $<0.2$ & $<0.2$ & $<0.4$ & $<0.2$ & $<0.3$ & $<0.2$ & $<0.8$ \\
\hline SVV-854-24-0.5F & $08 / 19 / 96$ & $<0.2$ & $<0.2$ & $<0.3$ & $<0.2$ & $<0.2$ & $<0.4$ & $<0.2$ & $<0.3$ & 0.21 & $<0.8$ \\
\hline SVV-854-24-11.5F & $08 / 19 / 96$ & $<0.2$ & $<0.2$ & $<0.3$ & $<0.2$ & $<0.2$ & $<0.4$ & $<0.2$ & $<0.3$ & 1.1 & $<0.8$ \\
\hline SVV-854-24-17.5F & $08 / 19 / 96$ & $<0.2$ & $<0.2$ & $<0.3$ & $<0.2$ & $<0.2$ & $<0.4$ & $<0.2$ & $<0.3$ & 1.2 & $<0.8$ \\
\hline SVV-854-24-5.5F & $08 / 19 / 96$ & $<0.2$ & $<0.2$ & $<0.3$ & $<0.2$ & $<0.2$ & $<0.4$ & $<0.2$ & $<0.3$ & 0.42 & $<0.8$ \\
\hline SVV-854-25-12F & $08 / 28 / 96$ & $<0.2$ & $<0.2$ & $<0.3$ & $<0.2$ & $<0.2$ & $<0.4$ & $<0.2$ & $<0.3$ & $<0.2$ & $<0.8$ \\
\hline SVV-854-25-18F & $08 / 28 / 96$ & $<0.2$ & $<0.2$ & $<0.3$ & $<0.2$ & $<0.2$ & $<0.4$ & $<0.2$ & $<0.3$ & $<0.2$ & $<0.8$ \\
\hline SVV-854-25-1F & $08 / 28 / 96$ & $<0.2$ & $<0.2$ & $<0.3$ & $<0.2$ & $<0.2$ & $<0.4$ & $<0.2$ & $<0.3$ & $<0.2$ & $<0.8$ \\
\hline SVV-854-25-24F & $08 / 28 / 96$ & $<0.2$ & $<0.2$ & $<0.3$ & $<0.2$ & $<0.2$ & $<0.4$ & $<0.2$ & $<0.3$ & $<0.2$ & $<0.8$ \\
\hline SVV-854-25-28F & $08 / 28 / 96$ & $<0.2$ & $<0.2$ & $<0.3$ & $<0.2$ & $<0.2$ & $<0.4$ & $<0.2$ & $<0.3$ & $<0.6$ & $<0.8$ \\
\hline SVV-854-25-6F & $08 / 28 / 96$ & $<0.2$ & $<0.2$ & $<0.3$ & $<0.2$ & $<0.2$ & $<0.4$ & $<0.2$ & $<0.3$ & $<0.2$ & $<0.8$ \\
\hline SVV-854-26-0.5F & $08 / 16 / 96$ & $<0.2$ & $<0.2$ & $<0.3$ & $<0.2$ & $<0.2$ & $<0.4$ & $<0.2$ & $<0.3$ & $<0.2$ & $<0.8$ \\
\hline SVV-854-26-11.5F & $08 / 16 / 96$ & $<0.2$ & $<0.2$ & $<0.3$ & $<0.2$ & $<0.2$ & $<0.4$ & $<0.2$ & $<0.3$ & $<0.2$ & $<0.8$ \\
\hline SVV-854-26-17.5F & $08 / 16 / 96$ & $<0.2$ & $<0.2$ & $<0.3$ & $<0.2$ & $<0.2$ & $<0.4$ & $<0.2$ & $<0.3$ & $<0.2$ & $<0.8$ \\
\hline SVV-854-26-5.5F & $08 / 16 / 96$ & $<0.2$ & $<0.2$ & $<0.3$ & $<0.2$ & $<0.2$ & $<0.4$ & $<0.2$ & $<0.3$ & $<0.2$ & $<0.8$ \\
\hline SVV-854-27-0.5F & $08 / 27 / 96$ & $<0.2$ & $<0.2$ & $<0.3$ & $<0.2$ & $<0.2$ & $<0.4$ & $<0.2$ & $<0.3$ & $<0.2$ & $<0.8$ \\
\hline SVV-854-27-11.5F & $08 / 27 / 96$ & $<0.2$ & $<0.2$ & $<0.3$ & $<0.2$ & $<0.2$ & $<0.4$ & $<0.2$ & $<0.3$ & $<0.2$ & $<0.8$ \\
\hline SVV-854-27-17.5F & $08 / 27 / 96$ & $<0.2$ & $<0.2$ & $<0.3$ & $<0.2$ & $<0.2$ & $<0.4$ & $<0.2$ & $<0.3$ & $<0.2$ & $<0.8$ \\
\hline SVV-854-27-5.5F & $08 / 27 / 96$ & $<0.2$ & $<0.2$ & $<0.3$ & $<0.2$ & $<0.2$ & $<0.4$ & $<0.2$ & $<0.3$ & $<0.2$ & $<0.8$ \\
\hline SVV-854-27A-0.5F & $08 / 27 / 96$ & $<0.2$ & $<0.2$ & $<0.3$ & $<0.2$ & $<0.2$ & $<0.4$ & $<0.2$ & $<0.3$ & $<0.2$ & $<0.8$ \\
\hline SVV-854-27A-11.5F & $08 / 28 / 96$ & $<0.2$ & $<0.2$ & $<0.3$ & $<0.2$ & $<0.2$ & $<0.4$ & $<0.2$ & $<0.3$ & $<0.2$ & $<0.8$ \\
\hline SVV-854-27A-17.5F & $08 / 28 / 96$ & $<0.2$ & $<0.2$ & $<0.3$ & $<0.2$ & $<0.2$ & $<0.4$ & $<0.2$ & $<0.3$ & $<0.2$ & $<0.8$ \\
\hline SVV-854-27A-5.5F & $08 / 27 / 96$ & $<0.2$ & $<0.2$ & $<0.3$ & $<0.2$ & $<0.2$ & $<0.4$ & $<0.2$ & $<0.3$ & $<0.2$ & $<0.8$ \\
\hline SVV-854-28-0.5F & $08 / 23 / 96$ & $<0.2$ & $<0.2$ & $<0.3$ & $<0.2$ & $<0.2$ & $<0.4$ & $<0.2$ & $<0.3$ & 0.4 & $<0.8$ \\
\hline
\end{tabular}




\begin{tabular}{|c|c|c|c|c|c|c|c|c|c|c|c|}
\hline \multirow[b]{2}{*}{ Sample Name } & \multirow[b]{2}{*}{$\begin{array}{c}\text { Sample } \\
\text { Date }\end{array}$} & \multirow[b]{2}{*}{$1,1,2-\mathrm{TCA}$} & \multirow[b]{2}{*}{$1,1-\mathrm{DCE}$} & \multicolumn{6}{|c|}{ Analyte Concentration Detected in the Soil Gas $\left(\mathrm{ppm}_{\mathrm{v} / \mathrm{v}}\right)$} & \multirow[b]{2}{*}{ TCE } & \multirow[b]{2}{*}{$\begin{array}{c}\begin{array}{c}\text { Vinyl } \\
\text { chloride }\end{array} \\
\end{array}$} \\
\hline & & & & 1,2-DCA & 1,2-DCPa & CHCl3 & $\mathrm{MeCl} 2$ & PCE & $\begin{array}{c}\text { trans-1,2- } \\
\text { DCE }\end{array}$ & & \\
\hline SVV-854-28-11.5F & & $<0.2$ & $<0.2$ & $<0.3$ & $<0.2$ & $<0.2$ & $<0.4$ & $<0.2$ & $<0.3$ & $<0.2$ & $<0.8$ \\
\hline SVV-854-28-17.5F & $08 / 21 / 96$ & $<0.2$ & $<0.2$ & $<0.3$ & $<0.2$ & $<0.2$ & $<0.4$ & $<0.2$ & $<0.3$ & $<0.2$ & $<0.8$ \\
\hline SVV-854-28-2.5F & $08 / 21 / 96$ & $<0.2$ & $<0.2$ & $<0.3$ & $<0.2$ & $<0.2$ & $<0.4$ & $<0.2$ & $<0.3$ & $<0.2$ & $<0.8$ \\
\hline SVV-854-28-23.5F & $08 / 21 / 96$ & $<0.2$ & $<0.2$ & $<0.3$ & $<0.2$ & $<0.2$ & $<0.4$ & $<0.2$ & $<0.3$ & $<0.2$ & $<0.8$ \\
\hline SVV-854-28-5.5F & $08 / 21 / 96$ & $<0.2$ & $<0.2$ & $<0.3$ & $<0.2$ & $<0.2$ & $<0.4$ & $<0.2$ & $<0.3$ & $<0.2$ & $<0.8$ \\
\hline SVV-854-29-0.5F & $08 / 22 / 96$ & $<0.2$ & $<0.2$ & $<0.3$ & $<0.2$ & $<0.2$ & $<0.4$ & $<0.2$ & $<0.3$ & 0.49 & $<0.8$ \\
\hline SVV-854-29-11.5F & $08 / 22 / 96$ & $<0.2$ & $<0.2$ & $<0.3$ & $<0.2$ & $<0.2$ & $<0.4$ & $<0.2$ & $<0.3$ & 3.3 & $<0.8$ \\
\hline SVV-854-29-17.5F & $08 / 22 / 96$ & $<0.2$ & $<0.2$ & $<0.3$ & $<0.2$ & $<0.2$ & $<0.4$ & $<0.2$ & $<0.3$ & 2.5 & $<0.8$ \\
\hline SVV-854-29-23.5F & $08 / 22 / 96$ & $<0.2$ & $<0.2$ & $<0.3$ & $<0.2$ & $<0.2$ & $<0.4$ & $<0.2$ & $<0.3$ & 7. & $<0.8$ \\
\hline SVV-854-29-35.5F & $08 / 26 / 96$ & $<0.2$ & $<0.2$ & $<0.3$ & $<0.2$ & $<0.2$ & $<0.4$ & $<0.2$ & $<0.3$ & 17. & $<0.8$ \\
\hline SVV-854-29-41.5F & $08 / 26 / 96$ & $<0.2$ & $<0.2$ & $<0.3$ & $<0.2$ & $<0.2$ & $<0.4$ & $<0.2$ & $<0.3$ & 18. & $<0.8$ \\
\hline SVV-854-29-5.5F & $08 / 22 / 96$ & $<0.2$ & $<0.2$ & $<0.3$ & $<0.2$ & $<0.2$ & $<0.4$ & $<0.2$ & $<0.3$ & 1.3 & $<0.8$ \\
\hline SVV-854-30-0.5F & $08 / 15 / 96$ & $<0.2$ & $<0.2$ & $<0.3$ & $<0.2$ & $<0.2$ & $<0.4$ & $<0.2$ & $<0.3$ & $<0.2$ & $<0.8$ \\
\hline SVV-854-30-11.5F & $08 / 15 / 96$ & $<0.2$ & $<0.2$ & $<0.3$ & $<0.2$ & $<0.2$ & $<0.4$ & $<0.2$ & $<0.3$ & $<0.2$ & $<0.8$ \\
\hline SVV-854-30-17.5F & 08/15/96 & $<0.2$ & $<0.2$ & $<0.3$ & $<0.2$ & $<0.2$ & $<0.4$ & $<0.2$ & $<0.3$ & $<0.2$ & $<0.8$ \\
\hline SVV-854-30-5.5F & $08 / 15 / 96$ & $<0.2$ & $<0.2$ & $<0.3$ & $<0.2$ & $<0.2$ & $<0.4$ & $<0.2$ & $<0.3$ & $<0.2$ & $<0.8$ \\
\hline SVV-854-31-0.5F & $08 / 30 / 96$ & $<0.2$ & $<0.2$ & $<0.3$ & $<0.2$ & $<0.2$ & $<0.4$ & $<0.2$ & $<0.3$ & $<0.2$ & $<0.8$ \\
\hline SVV-854-31-11.5F & 08/30/96 & $<0.2$ & $<0.2$ & $<0.3$ & $<0.2$ & $<0.2$ & $<0.4$ & $<0.2$ & $<0.3$ & $<0.2$ & $<0.8$ \\
\hline SVV-854-31-17.5F & $08 / 30 / 96$ & $<0.2$ & $<0.2$ & $<0.3$ & $<0.2$ & $<0.2$ & $<0.4$ & $<0.2$ & $<0.3$ & $<0.2$ & $<0.8$ \\
\hline SVV-854-31-5.5F & $08 / 30 / 96$ & $<0.2$ & $<0.2$ & $<0.3$ & $<0.2$ & $<0.2$ & $<0.4$ & $<0.2$ & $<0.3$ & $<0.2$ & $<0.8$ \\
\hline SVV-854-32-0.5F & $08 / 23 / 96$ & $<0.2$ & $<0.2$ & $<0.3$ & $<0.2$ & $<0.2$ & $<0.4$ & $<0.2$ & $<0.3$ & 1.5 & $<0.8$ \\
\hline SVV-854-32-11.5F & $08 / 20 / 96$ & $<0.2$ & $<0.2$ & $<0.3$ & $<0.2$ & $<0.2$ & $<0.4$ & $<0.2$ & $<0.3$ & & $<0.8$ \\
\hline SVV-854-32-17.5F & $08 / 21 / 96$ & $<0.2$ & $<0.2$ & $<0.3$ & $<0.2$ & $<0.2$ & $<0.4$ & $<0.2$ & $<0.3$ & 1.3 & $<0.8$ \\
\hline SVV-854-32-2.5F & $08 / 20 / 96$ & $<0.2$ & $<0.2$ & $<0.3$ & $<0.2$ & $<0.2$ & $<0.4$ & $<0.2$ & $<0.3$ & 2.4 & $<0.8$ \\
\hline SVV-854-32-23.5F & $08 / 21 / 96$ & $<0.2$ & $<0.2$ & $<0.3$ & $<0.2$ & $<0.2$ & $<0.4$ & $<0.2$ & $<0.3$ & 0.65 & $<0.8$ \\
\hline SVV-854-32-5.5F & $08 / 20 / 96$ & $<0.2$ & $<0.2$ & $<0.3$ & $<0.2$ & $<0.2$ & $<0.4$ & $<0.2$ & $<0.3$ & 0.44 & $<0.8$ \\
\hline SVV-854-33-12F & $08 / 28 / 96$ & $<0.2$ & $<0.2$ & $<0.3$ & $<0.2$ & $<0.2$ & $<0.4$ & $<0.2$ & $<0.3$ & 10 & $<0.8$ \\
\hline SVV-854-33-16F & $08 / 28 / 96$ & $<0.2$ & $<0.2$ & $<0.3$ & $<0.2$ & $<0.2$ & $<0.4$ & $<0.2$ & $<0.3$ & 9.5 & $<0.8$ \\
\hline SVV-854-33-6F & $08 / 28 / 96$ & $<0.2$ & $<0.2$ & $<0.3$ & $<0.2$ & $<0.2$ & $<0.4$ & $<0.2$ & $<0.3$ & 8.5 & $<0.8$ \\
\hline SVV-854-34-11.5F & $08 / 22 / 96$ & $<0.2$ & $<0.2$ & $<0.3$ & $<0.2$ & $<0.2$ & $<0.4$ & $<0.2$ & $<0.3$ & 0.48 & $<0.8$ \\
\hline SVV-854-34-17.5F & $08 / 22 / 96$ & $<0.2$ & $<0.2$ & $<0.3$ & $<0.2$ & $<0.2$ & $<0.4$ & $<0.2$ & $<0.3$ & 1. & $<0.8$ \\
\hline SVV-854-34-23.5F & $08 / 22 / 96$ & $<0.2$ & $<0.2$ & $<0.3$ & $<0.2$ & $<0.2$ & $<0.4$ & $<0.2$ & $<0.3$ & 2.1 & $<0.8$ \\
\hline SVV-854-34-5.5F & $08 / 22 / 96$ & $<0.2$ & $<0.2$ & $<0.3$ & $<0.2$ & $<0.2$ & $<0.4$ & $<0.2$ & $<0.3$ & 0.45 & $<0.8$ \\
\hline SVV-854-35-11.5F & $08 / 19 / 96$ & $<0.2$ & $<0.2$ & $<0.3$ & $<0.2$ & $<0.2$ & $<0.4$ & $<0.2$ & $<0.3$ & 1.7 & $<0.8$ \\
\hline SVV-854-35-17.5F & $08 / 19 / 96$ & $<0.2$ & $<0.2$ & $<0.3$ & $<0.2$ & $<0.2$ & $<0.4$ & $<0.2$ & $<0.3$ & 1.8 & $<0.8$ \\
\hline SVV-854-35-23.5F & $08 / 20 / 96$ & $<0.2$ & $<0.2$ & $<0.3$ & $<0.2$ & $<0.2$ & $<0.4$ & $<0.2$ & $<0.3$ & 2.3 & $<0.8$ \\
\hline SVV-854-35-5.5F & $08 / 19 / 96$ & $<0.2$ & $<0.2$ & $<0.3$ & $<0.2$ & $<0.2$ & $<0.4$ & $<0.2$ & $<0.3$ & 1.4 & $<0.8$ \\
\hline SVV-854-36-11.5F & $08 / 20 / 96$ & $<0.2$ & $<0.2$ & $<0.3$ & $<0.2$ & $<0.2$ & $<0.4$ & $<0.2$ & $<0.3$ & 0.6 & $<0.8$ \\
\hline SVV-854-36-17.5F & $08 / 20 / 96$ & $<0.2$ & $<0.2$ & $<0.3$ & $<0.2$ & $<0.2$ & $<0.4$ & $<0.2$ & $<0.3$ & 2.5 & $<0.8$ \\
\hline SVV-854-36-23.5F & $08 / 20 / 96$ & $<0.2$ & $<0.2$ & $<0.3$ & $<0.2$ & $<0.2$ & $<0.4$ & $<0.2$ & $<0.3$ & 2.5 & $<0.8$ \\
\hline SVV-854-36-5.5F & $08 / 20 / 96$ & $<0.2$ & $<0.2$ & $<0.3$ & $<0.2$ & $<0.2$ & $<0.4$ & $<0.2$ & $<0.3$ & 0.25 & $<0.8$ \\
\hline SVV-854-38-0.5F & $09 / 06 / 96$ & $<0.2$ & $<0.2$ & $<0.3$ & $<0.2$ & $<0.2$ & $<0.4$ & $<0.2$ & $<0.3$ & $<0.2$ & $<0.8$ \\
\hline SVV-854-38-11.5F & $09 / 06 / 96$ & $<0.2$ & $<0.2$ & $<0.3$ & $<0.2$ & $<0.2$ & $<0.4$ & $<0.2$ & $<0.3$ & $<0.2$ & $<0.8$ \\
\hline SVV-854-38-17.5F & $09 / 06 / 96$ & $<0.2$ & $<0.2$ & $<0.3$ & $<0.2$ & $<0.2$ & $<0.4$ & $<0.2$ & $<0.3$ & $<0.2$ & $<0.8$ \\
\hline SVV-854-38-5.5Г & $09 / 06 / 96$ & $<0.2$ & $<0.2$ & $<0.3$ & $<0.2$ & $<0.2$ & $<0.4$ & $<0.2$ & $<0.3$ & $<0.2$ & $<0.8$ \\
\hline SVV-854-40-0.5F & $09 / 04 / 96$ & $<0.2$ & $<0.2$ & $<0.3$ & $<0.2$ & $<0.2$ & $<0.4$ & $<0.2$ & $<0.3$ & $<0.2$ & $<0.8$ \\
\hline SVV-854-40-11.5F & $09 / 04 / 96$ & $<0.2$ & $<0.2$ & $<0.3$ & $<0.2$ & $<0.2$ & $<0.4$ & $<0.2$ & $<0.3$ & $<0.2$ & $<0.8$ \\
\hline SVV-854-40-17.5F & $09 / 04 / 96$ & $<0.2$ & $<0.2$ & $<0.3$ & $<0.2$ & $<0.2$ & $<0.4$ & $<0.2$ & $<0.3$ & $<0.2$ & $<0.8$ \\
\hline
\end{tabular}




\begin{tabular}{|c|c|c|c|c|c|c|c|c|c|c|c|}
\hline \multirow[b]{2}{*}{ Sample Name } & \multirow[b]{2}{*}{$\begin{array}{c}\text { Sample } \\
\text { Date }\end{array}$} & \multicolumn{10}{|c|}{ Analyte Concentration Detected in the Soil Gas $\left(\mathrm{ppm}_{\mathrm{v} / \mathrm{v}}\right)$} \\
\hline & & $1,1,2-$ TCA & 1,1-DCE & 1,2-DCA & 1,2-DCPa & CHCl3 & $\mathrm{MeCl} 2$ & PCE & $\underset{\text { DCE }}{\operatorname{trans-1,2-}}$ & TCE & $\begin{array}{c}\text { Vinyl } \\
\text { chloride }\end{array}$ \\
\hline SVV-854-40-5.5F & $09 / 04 / 96$ & $<0.2$ & $<0.2$ & $<0.3$ & $<0.2$ & $<0.2$ & $<0.4$ & $<0.2$ & $<0.3$ & $<0.2$ & $<0.8$ \\
\hline SVV-854-41-0.5F & $09 / 06 / 96$ & $<0.2$ & $<0.2$ & $<0.3$ & $<0.2$ & $<0.2$ & $<0.4$ & $<0.2$ & $<0.3$ & $<0.2$ & $<0.8$ \\
\hline SVV-854-41A-0.5F & $09 / 13 / 96$ & $<0.2$ & $<0.2$ & $<0.3$ & $<0.2$ & $<0.2$ & $<0.4$ & $<0.2$ & $<0.3$ & $<0.2$ & $<0.8$ \\
\hline SVV-854-41A-11.5F & $09 / 16 / 96$ & $<0.2$ & $<0.2$ & $<0.3$ & $<0.2$ & $<0.2$ & $<0.4$ & $<0.2$ & $<0.3$ & 0.54 & $<0.8$ \\
\hline SVV-854-41A-17.5F & 09/16/96 & $<0.2$ & $<0.2$ & $<0.3$ & $<0.2$ & $<0.2$ & $<0.4$ & $<0.2$ & $<0.3$ & 0.21 & $<0.8$ \\
\hline SVV-854-41A-23.5F & 09/16/96 & $<0.2$ & $<0.2$ & $<0.3$ & $<0.2$ & $<0.2$ & $<0.4$ & $<0.2$ & $<0.3$ & 0.28 & $<0.8$ \\
\hline SVV-854-41A-29.5F & $09 / 16 / 96$ & $<0.2$ & $<0.2$ & $<0.3$ & $<0.2$ & $<0.2$ & $<0.4$ & $<0.2$ & $<0.3$ & 0.39 & $<0.8$ \\
\hline SVV-854-41A-35.5F & $09 / 16 / 96$ & $<0.2$ & $<0.2$ & $<0.3$ & $<0.2$ & $<0.2$ & $<0.4$ & $<0.2$ & $<0.3$ & 0.35 & $<0.8$ \\
\hline SVV-854-41A-5.5F & $09 / 13 / 96$ & $<0.2$ & $<0.2$ & $<0.3$ & $<0.2$ & $<0.2$ & $<0.4$ & $<0.2$ & $<0.3$ & 0.48 & $<0.8$ \\
\hline SVV-854-42-0.5F & $09 / 12 / 96$ & $<0.2$ & $<0.2$ & $<0.3$ & $<0.2$ & $<0.2$ & $<0.4$ & $<0.2$ & $<0.3$ & $<0.2$ & $<0.8$ \\
\hline SVV-854-42-11.5F & 09/12/96 & $<0.2$ & $<0.2$ & $<0.3$ & $<0.2$ & $<0.2$ & $<0.4$ & $<0.2$ & $<0.3$ & 0.42 & $<0.8$ \\
\hline SVV-854-42-17.5F & $09 / 12 / 96$ & $<0.2$ & $<0.2$ & $<0.3$ & $<0.2$ & $<0.2$ & $<0.4$ & $<0.2$ & $<0.3$ & 0.56 & $<0.8$ \\
\hline SVV-854-42-23.5F & $09 / 12 / 96$ & $<0.2$ & $<0.2$ & $<0.3$ & $<0.2$ & $<0.2$ & $<0.4$ & $<0.2$ & $<0.3$ & 0.97 & $<0.8$ \\
\hline SVV-854-42-29.5F & $09 / 12 / 96$ & $<0.2$ & $<0.2$ & $<0.3$ & $<0.2$ & $<0.2$ & $<0.4$ & $<0.2$ & $<0.3$ & 0.28 & $<0.8$ \\
\hline SVV-854-42-5.5F & $09 / 12 / 96$ & $<0.2$ & $<0.2$ & $<0.3$ & $<0.2$ & $<0.2$ & $<0.4$ & $<0.2$ & $<0.3$ & 0.25 & $<0.8$ \\
\hline
\end{tabular}

Note: The sample name indicates the depth bclow ground surface by the final set of numbers following the last dash. 


\section{REFERENCES}

American Society for Testing and Materials (ASTM). 1994. Emergency standard guide for risked-based corrective action applied at petroleum release sites. ASTM. E-1739.

Batterman, S. A., McQuown, B. C., Murthy, P. N., and McFarland, A. R. 1992. Design and evaluation of a long-term soil gas flux chamber. Environmental Science \& Technology. 26:709-714.

Brown, R. H., and Purnell, C. J. 1979. Collection and analysis of trace organic vapour pollutants in ambient atmospheres. Journal of Chromatography. 178:7990.

Carlsen, T. M., Martins, S. A., and McNeel, P. J. 1996. Emission isolation flux chambers and risk assessments: applications for cost-effective risk assessment and risk management. Presented at the Eighth National Technology Information Exchange (TIE) Workshop in Santa Fe, New Mexico, April 16-18, 1996.

Ciccioli, P., Bertoni, G., Brancaleoni, E., Fratarcangeli, R, and Bruner, F. 1976. Evaluation of organic pollutants in the open air and atmospheres in industrial sites using graphitized carbon black traps and gas chromatographic mass spectrometric analysis with specific detectors. Journal of Chromatography. 126:757-770.

Dibley, V., and Depue, R. 1995. Livermore Site and Site 300 Environmental Restoration Division standard operating procedures (SOPs). Lawrence Livermore National Laboratory, Livermore, California 94550. UCRL-MA-109115 Rev. 2.

Eklund, B. 1992. Practical guidance for flux chamber measurements of fugitive volatile organic emission rates. Air Waste Management Association. 42:15831591. 
Gallegos, G. M., P. J. Tate, B.K.Balke, E. Christofferson, R. J. Harrach, W. G. Hoppes, R. A. Failor, S. Wander, B. C. Fields, L. M.Garcia, and A. R. Grayson. 1994. Lawrence Livermore National Laboratory environmental report for 1993. Lawrence Livermore National Laboratory, Livermore, California 94550. UCRL50027-93.

Gholsen, A. R., Albritton, J. R., and Jayanty, R. K. M. 1991. Evaluation of an enclosure method for measuring emissions of volatile organic compounds from quiescent liquid surfaces. Environmental Science \& Technology. 25:519-524.

Harsch, D. E. 1980. Evaluation of a versatile gas sampling container design. Atmospheric Environment. 14:1105-1107.

Hutte, R. S., Williams, E. J., Staehelin, J., Hawthorne, S. B., Barkley, R. M., and Sievers, R. E. 1984. Chromatographic analysis of organic compounds in the atmosphere. Journal of Chromatography. 302;173-179.

Hwang, S. T., Falco, J. W., and Nauman, C. H. 1986. Development of advisory levels for polychlorinated biphenyls $(P C B s)$ cleanup. Office of Health and Environmental Assessment, Exposure Assessment Group. U.S. Environmental Protection Agency, Washington, D.C. PB86-232774.

Krost, K. J., Pellizzari, E. D., Walburn, S. G., and Hubbard, S. A. 1982. Collection and analysis of hazardous organic emissions. Anal. Chem. 54:810-817.

Leedy, P. D. 1989. Practical research planning and design. 5th ed. New York: Macmillian Publishing Co.

Lentzner, H. L., R. J. Harrach, R. A. Failor, G. M. Gallegos, P. J. Tate, E. Christofferson, E. R. Brandstetter, J. M. Larson, A. H. Biermann, R. A. Brown, B. C. Fields, L. M. Garcia, and A. R. Grayson. 1996. Lawrence Livermore National Laboratory environmental report for 1995. Lawrence Livermore National Laboratory, Livermore, Calif. UCRL-50027-95. 
Little, J. C., Daisey, J. M., and Nazaroff, W. W. 1992. Transport of subsurface contaminants into buildings: an exposure pathway for volatile organics. Environmental Science \& Technology. 26:2058-2066.

Millison, D., Marcotte, B., Rudolph, C., and Randles, K. 1991. Applications and comparison of soil gas, flux chamber and ambient air sampling results to support risk assessment at a hazardous waste site. HMC. July/August:51-59.

Marrin, D. L., and Kerfoot, H. B. 1988. Soil-gas surveying techniques. Environmental Science \& Technology. 22:740-745.

Martins, S. 1993. Ground surface vapor flux sampling protocols for volatile organic compounds. Vadose Zone Standard Operations Manual, Section 2.4. Lawrence Livermore National Laboratory, Livermore, Calif.

Oliver, K. D., and Pleil, J. D. 1986. Sample integrity of trace level volatile organic compounds in ambient air stored in SUMMA polished canisters. Atmospheric Environment. 20(7):1403-1411.

Pellizzari, E. D., Bunch, J. E., Carpenter, B. H., and Sawicki, E. 1975. Collection and analysis of trace organic vapor pollutants in ambient atmospheres. Environmental Science \& Technology. 9(6):552-555.

Reinhart, D. R., Cooper, D. C., and Walker, B. L. 1992. Flux chamber design and operation for the measurement of municipal solid waste landfill gas emission rates. Air Waste Management Association. 42:1067-1070.

Ritts, D., and Wolbach, D. 1991. Combining flux chambers and summa canisters to estimate very low chemical emissions from soil surfaces. Presented at the 84th Annual and Exhibition of the Air \& Waste Management Association in Vancouver, British Columbia, June 16-21, 1991. 
Rothweiler, H., Wager, P.A., and Schlatter, C. 1991. Comparison of Tenax TA and Carbotrap for sampling and analysis of volatile organic compounds in air. Atmospheric Environment. 25B:231-235.

Rueth, L., Berry, T., Brogna, E., Carlsen, T., Caviness, G., Devany, R., GreenHorner, L., Hall, L., Landgraf, R., Maley, M., McDowell, B., McNeel, P., Scott, D. 1995. Final feasibility sudy for the General Services Area operable unit Lawrence Livermore National Laboratory Site 300. Lawrence Livermore National Laboratory, Livermore, CA. UCRL-AR-113860.

Sanders, P. F., McChesney, M. M., and Seiber, J. N. 1985. Measuring pesticide volatilization from small surface areas in the field. Bulletin of Environmental Contamination and Toxicology. 35:569-575

Sanders, P. F., and Stern, A. H. 1994. Calculation of soil cleanup criteria for carcinogenic volatile organic compounds as controlled by the soil-to-indoor air exposure pathway. Environmental Toxicology and Chemistry. 13:1367-1373.

Shen, T. T. 1981. Estmating hazardous air emissions from disposal sites. Pollution Engineering. Aug. 1981.

Sittig, M. 1991. Handbook of toxic and hazardous chemical and carcinogens. 3rd ed. Vol. 1. Park Ridge: Noyes Publications.

Smucker, S. J. 1995. Memo regarding Region IX Preliminary Remediation Goals (PRGs) Second Half 1994.

Turner, D. B. 1982. Workbook of atmospheric dispersion estimates. Office of Air Programs. U.S. Enviromental Protection Agency. Research Triangle Park, N.C. TD-18/Office of Air Programs Publication No. AP-26 (revised 1970).

USDOE. 1995. Hazard Identifiaction/Basic Concepts. In U.S. Department of Energy Risk Assessment Workshop. Pleasanton California. 
USEPA. 1982. Sampling air for gaseous organic chemicals using solid adsorbents application to Tenex. Environmental Monitoring Division. Research Triangle Park, North Carolina. PB82-262189.

USEPA. 1984. Evaluation of sampling methods for gaseous atmospheric samples. Environmental Sciences Research Laboratory. Research Triangle Park, North Carolina. PB84-190735

USEPA. 1986. Measurement of gaseous emission rates from land surfaces using an emission isolation flux chamber user's guide. Office of Research and Development. Las Vegas, Nevada 89114. EPA/600/8-86/008.

USEPA. 1988a. Compendium of methods for the determination of toxic organic compounds in ambient air, method TO14. Office of Research and Development. Research Triangle Park, North Carolina 27711. EPA/600/4-89/017.

USEPA. 1988b. Superfund exposure assessment manual. Office of Remedial Response. Washington, DC 20460. EPA/540/1-88/001.

USEPA. 1989a. Evaluation of the flux chamber method for measuring volatile organic emissions from surface impoundments. Environmental Monitoring Division. Research Triangle Park, North Carolina. PB89-148589.

USEPA. 1989b. Risk assessment guidance for superfund, volume I : human health evaluation manual (part A). Office of Emergency and Remedial Response. Washington, DC 20450. EPA/540/1-89/002.

USEPA. 1990. Estimation of baseline air emissions at superfund sites (revised), volume II. Office of Air Quality Planning and Standards. Research Triangle Park, North Carolina 27711. EPA-450/1-89-002a.

USEPA. 1991. Standard default exposure factors; supplemental guidance to human health evaluation manual. Office of Solid Waste and Emergency Response. Washington, DC 20460. OSWER-9285.6-03. 
USEPA. 1992a. Guideline for predictive baseline emissions estimation procedures for superfund sites. Office of Air Quality Planning and Standards. Research Triangle Park, North Carolina. PB92-171909.

USEPA. 1992b. Supplemental guidance to RAGS: calculating the concentration term. Office of Solid Waste and Emergency Response. Washington, DC 20460. PB92963373.

Walling, J. F. 1984. The utility of distributed air volume sets when sampling ambient air using solid adsorbants. Atmospheric Environment. 18(4):855-859.

Walling, J. F., Bumgarner, J. E., Driscoll, D. J., Morris, C. M., Riley , A. E., and Wright, L. H. 1986. Apparent reaction products desorbed from Tenax used to sample ambient air. Atmospheric Environment. 20:51-57.

Webster-Scholten, C.P., Berg, L. L., Bryn, S. M., Carlsen, T. M., Carpenter, D. W., Caviness, G. A., Chamberlain, C. S., Copland, J. R., Crow, N. B., Daniels, J. I., Ferry, R. A., Gardner, J. K., Goodrich, R. L., Green-Horner, L. K., Gregory, S. D., Hall, L. C., Hilbelink, K., Hill, E. M., Johnson, V. M., Kiszka, V. R., Kitay, R. E., Kulshrestha, A., Landgraf, R. K., Lima, M. R., MacQueen, D. H., Madrid, V. M., Maley, M. P., McClish, T. J., Oberdorfer, J. A., Ottesen, P.L., Pavletich, J. P., Ridley, M. N., Rueth, L. S., Shin, M. M., Taffet, M. J., Toney, K. C., Vonder Haar, S. P., Wade, W. M. 1994. Final site-wide remedial investigation report lawrence livermore national Laboratory Site 300. Lawrence Livermore National Laboratory, Livermore, CA. UCRL-AR-108131.

Woodrow, J. E., and Seiber, J. N. 1991. Two chamber methods for the determination of pesticide flux from contaminated soil and water. Chemosphere. 23:291-304. 
Zlatkis, A., Lichtenstein, H.A., and Tishbee, A. 1973. Concentration and analysis of trace organics in gases and biological fluids with a new solid adsorbent.

Chromatographia. 6(2):67-70. 


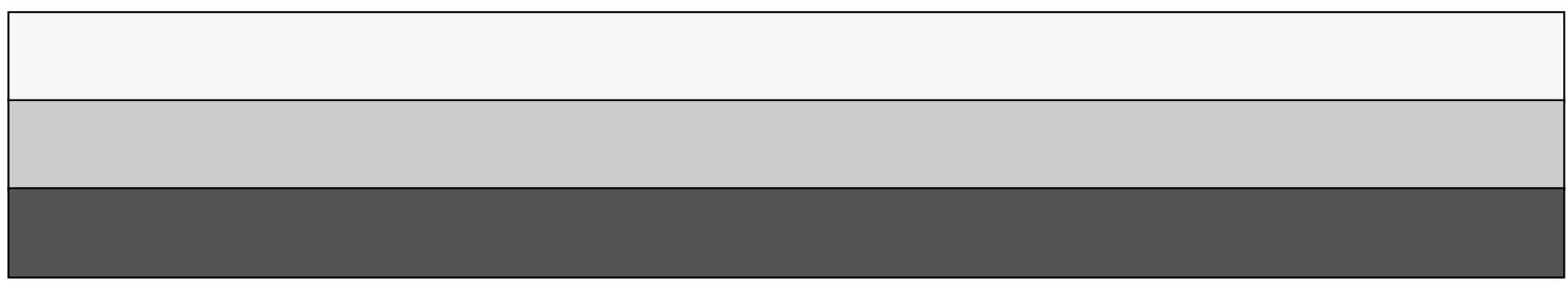

